\title{
Report to The American Physical Society of the study group on radionuclide release from severe accidents at nuclear power plants
}

APS Study Group Participants

Richard Wilson, Chairman

Harvard University, Cambridge, Massachusetts 02138

Kamal J. Araj, Executive Assistant

Brookhaven National Laboratory, Upton, New York 11973

Augustine O. Allen

Shoreham, New York 11786

Peter Auer

Cornell University, Ithaca, New York 14850

David G. Boulware

University of Washington, Seattle, Washington 98195

Fred Finlayson

Aerospace Corporation, Los Angeles, California 90009

Simon Goren

University of California, Berkeley, California 94720

Clark Ice

Aiken, South Carolina 29801

Leon Lidofsky

Columbia University, New York, New York 10027

Allen Lee Sessoms

U.S. Department of State, Washington, D.C. 20520

Mary L. Shoaf

Princeton University, Princeton, New Jersey 08544

Irving Spiewak

Institute for Energy Analysis, Oak Ridge, Tennessee 37830

Thomas Tombrello

California Institute of Technology, Pasadena, California 91125 


\section{APS Council Review Committee}

\section{Herbert S. Gutowsky, Chairman}

University of Illinois, Urbana, Illinois 61801

\section{Andreas Acrivos}

Stanford University, Stanford, California 94305

\section{Herman Feshbach}

Massachusetts Institute of Technology, Cambridge, Massachusetts 02139

William A. Fowler

California Institute of Technology, Pasadena, California 91125 


\section{RADIONUCLIDE RELEASE FROM SEVERE ACCIDENTS AT NUCLEAR POWER PLANTS}

\section{EXECUTIVE SUMMARY}

Report prepared by a study group of The American Physical Society under contract with the U.S. Nuclear Regulatory Commission

In 1983, The American Physical Society formed a study group on radionuclide release from severe accidents at nuclear power plants to "review the adequacy of the technical base upon which the phenomenological models for radionuclide release from postulated severe reactor accidents are constructed, the adequacy of the models themselves, and the correct use of the complex computer codes that incorporate these models in the analyses of accident sequences."

The impetus to the existing research came from the observation that much less radioactive iodine was released during the Three Mile Island accident than had been expected in an accident of that magnitude. It is of obvious interest to inquire how general that observation is.

Although this executive summary describes, explains, and paraphrases some of the conclusions of this report, any reference should be to the specific conclusion as written in Chapter VIII rather than to the executive summary.

This report is concerned with the release of radionuclides from a hypothetical severe nuclear reactor accident-more severe than any that has yet taken place. It discusses both the predictions and the scientific basis for making them. Although we have not calculated probabilities of individual accident sequences, we have chosen for detailed discussion those sequences deemed by others to be "risk dominant" or to involve a wide range of physical and chemical phenomena.

The study group finds considerable progress in developing both a scientific basis and computational ability for predicting the consequences of hypothetical nuclear reactor accidents since the Reactor Safety Study of 1975 (WASH-1400) which is the current basis for regulation concerned with severe accidents. In several cases, the new calculations indicate that significantly smaller quantities of radionuclides reach the environment than calculated in the Reactor Safety Study. In other cases, the calculated quantities have not changed dramatically.

A reactor accident can lead to severe consequences only if several barriers between the radioactivity and the environment are breached. One postulated scenario by which this could occur is the failure of the core heat-removal systems. This would cause the core to overheat, lose coolant, melt, fall to the bottom of the reactor pressure vessel, melt through the vessel, and be quenched in the water of the reactor cavity. This would release steam and noncondensible gases to the reactor containment building, and thereby increase the pressure, which would stress the containment. The Reactor Safety Study assigned a high probability-one in ten-that the containment would fail at this time. This is now considered to be very unlikely.

Once the water in the reactor cavity is evaporated, the core would remelt from the heat generated by the decay of the fission products and would attack the concrete floor. This interaction would be very complex, releasing gases and radioactive aerosols. Calculations indicate that this would cause the containment building to fail from overpressure many hours later-although it is possible (and claimed by some investigators) that the containment would hold for many days. If the containment does not fail, the molten core might eventually penetrate the basemat, but this possibility would have only modest immediate consequences for public safety.

Where new calculations indicate that radionuclide emissions would be less than those reported in the Reactor Safety Study, the reduction can be attributed to three principal factors:

(i) the recognition that the containment buildings, which are designed to contain the radionuclides in the event of an accident, are stronger than was assumed in the Reactor Safety Study and therefore would fail, if at all, at later times;

(ii) the inclusion in the modeling of various physical and chemical phenomena, previously neglected, that will lead to retention of fission products; this retention is particularly effective if more time elapses before containment failure; and

(iii) the inclusion in the calculation of a number of sites which can retain fission products-such as suppression pools and ice beds, and in some cases auxiliary buildings-that had not previously been considered in detail.

The Reactor Safety Study pessimistically assumed that iodine would be released to the environment as gaseous molecular iodine. There is good evidence that the iodine reacts with cesium to form cesium iodide, a salt of low volatility, which would either dissolve in water or condense to form an aerosol. Some of the aerosols would deposit on surfaces in the primary reactor system or, if a sufficiently long time were available, on surfaces in the containment building; in either case, the release to the environment would be reduced.

Some reactors are equipped with suppression pools and ice condensers that are designed to condense steam. These can reduce the release by scavenging the fission products. However, experimental studies to evaluate their effectiveness are only now in progress (suppression pools) or have not been planned (ice beds). Moreover the effectiveness of these devices has not been subjected to detailed peer review. Reactors that contain these scavenging sites-the Boiling Water Reactors with suppression pools and those few Pressurized Water Reactors with ice condenser containments-have been studied far less than Pressurized Water Reactors with large dry containments, and little confirmatory work has been carried out. The study group recommends more study of hypothetical severe accidents involving these reactors.

The study group looked for phenomena which might increase the radionuclide releases above those calculated 
in the Reactor Safety Study. One such effect is the release of nonvolatile radionuclides during the coreconcrete interaction. Some nonvolatile fission products, such as lanthanides, and some transuranics, such as plutonium, are biologically quite dangerous. The phenomena in the core-concrete interaction are complex and are not fully understood; releases depend critically upon the temperature achieved in the core-concrete interaction, and other parameters which are not understood. Moreover, the calculations are only in a preliminary stage. Some recent calculations indicate that releases of nonvolatile species may be greater than predicted in the Reactor Safety Study for some postulated accident sequences. More experiments and analytical work are needed to improve the knowledge of the chemistry and physics in this crucial area.

Phenomena that could generate aerosols or volatile iodine late in an accident sequence as the result of decay heating or chemical reactions may also be underestimated. The aerosols or iodine might have very slow deposition rates, and even be emitted to the environment following a late containment failure. These phenomena are not included in the present NRC computer models.

The study group examined results produced by the computer codes used by participants in the severe accident research program. These codes have not, in general, been publicly released. Although these computer codes go a long way toward describing the complex phenomena involved, and represent a major advance in the art of accident description, the normal scientific procedure for establishing the reliability of the results is not complete. The study group recommends that the theoretical and experimental studies be published in archival, peer-reviewed journals, and that the computer codes together with a clear and complete technical description of the models and the assumptions be made available to interested parties.

Reliable estimation of possible radionuclide release during severe accidents at nuclear power plants requires direct calculations, complex computer codes, small scale experiments, and large scale experiments. This research has been underway in several countries, some of the research being of an international cooperative nature. Because of the complexities of the phenomena being modeled, it is essential to compare the computer codes against well controlled, small scale experiments and against realistic, adequately instrumented, large scale integral experiments to ensure that all important phenomena are modeled with sufficient accuracy. Such comparison is not yet completed. Because of this, the study group concluded that it cannot endorse at this time specific quantitative estimates for the amounts of radionuclides released. However, the general trends shown by the calculations are consistent with our understanding of the chemical and physical phenomena involved. Fortunately, some of the key parameters are largely determined by overall energy considerations (as for example the maximum pressure reached in the containment) and these can be estimated with a reasonable degree of confidence.

The quantity of radionuclides released is called the source term. It consists of contributions from groups of radionuclides, broadly classified as gaseous, volatile, and nonvolatile. The contributions from the first two of these have been widely considered to have the most significant potential impacts on public health. These are better understood now than they were previously.

The environmental impacts and mechanisms for releases of noble gases are the best understood. Their releases are not thought to differ importantly from those calculated in the Reactor Safety Study, except insofar as radioactive decay could reduce their radioactivity when containment failure is late. Some current calculations of the release of the volatile radionuclides to the environment predict substantially smaller values than those reported in the Reactor Safety Study because of the later times to containment failure. The magnitude of the contribution from the nonvolatile radionuclides is still open to question, primarily because of the uncertainty of the core-concrete interaction.

For the reasons described in the previous six paragraphs, the study group believes that it is not yet possible to derive factors by which the source terms for all radionuclides and all reactors can be changed from the values reported in the Reactor Safety Study. Research that is currently in progress will improve this situation and may enable such factors to be determined for all important radionuclides and reactor sequences. 
I. Preamble

II. General Introduction

II.A. History

II.A.1. Pre-1957

II.A.2. The Windscale accident

II.A.3. The SL-1 accident

II.A.4. Maximum credible accidents (design basis accidents)

II.A.5. Early site selection criteria

II.A.6. The reactor safety study (RSS) - WASH1400

II.A.7. The Three Mile Island-2 reactor accident

II.B. Release consequences

II.B.1. Doses

II.B.1.a. Radiation sources

II.B.1.b. Effluent dispersion

II.B.1.c. Estimates of dose for particular releases

II.B.2. Biological effects

II.B.2.a. Biological effects of radiation

II.B.2.b. Lethal and near-lethal doses of radiation

II.B.2.c. Whole body exposure to sub-lethal doses of radiation

II.B.3. Contributions of radionuclides to health effects

III. Reactor Accidents: General Features and Important Sequences

III.A. General features of reactors and reactor accidents

III.A.1. Energy production in nuclear reactors

III.A.2. Reactor control

III.A.2.a. Moderator

III.A.2.b. Delayed neutrons

III.A.2.c. Control rods

III.A.3. Fission product heating

III.A.4. Light water reactor design

III.A.4.a. The fuel

III.A.4.b. The coolant system

III.A.4.c. Barriers against radionuclide release

III.A.4.d. The emergency core cooling system

III.A.5. Sources and sinks of heat

III.A.5.a. Sources

III.A.5.b. Sinks

III.A.5.c. Rate of heat transfer

III.A.6. General features of severe nuclear reactor accidents

III.B. Sequence selection

III.B.1. The risk analysis procedures of the RSS

III.B.2. Risk significance of RSS accident sequences

III.B.3. Basis for selection of scenarios for source term studies

III.C. Specific sequences

III.C.1. Detailed description of the TMLB' sequence

III.C.2. Containment bypass sequences

III.C.3. Failure to isolate containment

III.C.4. BWR sequences

III.C.5. Accidents caused by earthquakes, fire, and sabotage

IV. Chemical and Physical Phenomena

IV.A. Thermal hydraulics: Fluid flow, heat transfer, and in-vessel phenomena

IV.A.1. Introduction

IV.A.2. Blowdown

IV.A.3. Boiloff (until the core is uncovered)

IV.A.4. Heatup
IV.A.5. Natural convection

IV.A.6. Core melt

IV.A.7. Melt-through

IV.A.8. Core-concrete interaction

IV.B. Chemical forms and interactions

IV.B.1. Introduction

IV.B.2. Chemical state of the fuel pins during normal operation

IV.B.3. Release of radionuclides from fuel

IV.B.4. Chemical transformation after release from the core

IV.B.5. Chemical interactions in the containment building

IV.B.6. Chemical phenomena in the core-concrete interaction

IV.B.7. Conclusions

IV.C. Aerosol theory and experiments

IV.C.1. Introduction

IV.C.2. Evolution equation for the particle size density function

IV.C.3. Averaged equations for the particle size density function

IV.C.4. Aerosol deposition mechanisms and deposition velocities

IV.C.4.a. General comments

IV.C.4.b. Deposition by sedimentation

IV.C.4.c. Deposition by thermophoresis

IV.C.4.d. Deposition by Stefan flow and diffusiophoresis

IV.C.4.e. Deposition by impaction

IV.C.4.f. Deposition resulting from turbulent motion

IV.C.4.g. Deposition by diffusion

IV.C.4.h. Intercomparison of various deposition velocities

IV.C.5. Aerosol growth by condensation or shrinkage by evaporation

IV.C.6. Aerosol growth by coagulation

IV.C.7. Aerosol removal by engineered safety

features

IV.C.7.a. Suppression pools

IV.C.7.b. Ice bed condensors

IV.C.7.c. Water sprays and filters

IV.C.8. Numerical solution approaches

IV.C.9. Experimental validation of aerosol modeling

IV.C.9.a. Nuclear Safety Pilot Plant (NSPP)

IV.C.9.b. Demonstration of the Behavior of Nuclear Aerosols (DEMONA)

IV.C.9.c. LWR Aerosol Containment Experiments (LACE)

IV.C.9.d. MARVIKEN

IV.C.9.e. Smaller scale experiments

IV.C.10. Conclusions

IV.D. Containment integrity

IV.D.1. Introduction

IV.D.2. Why containment phenomena are important

IV.D.3. Description of various types of containment

IV.D.3.a. Large dry

IV.D.3.b. Ice condenser

IV.D.3.c. BWR Mark I

IV.D.3.d. BWR Mark II

IV.D.3.e. BWR Mark III

IV.D.4. Containment failure modes

IV.D.5. Containment leaks 
IV.D.6. The impact of hole size on the source term IV.D.7. Summary

IV.E. Containment loads

IV.E.1. Categorization

IV.E.2. Hydrogen burning

IV.E.3. Steam explosions (rapid phase transitions; superheat explosions)

IV.E.4. Late containment failures

IV.E.5. Earthquakes

IV.E.6. Summary

V. Computer Codes and Their Validation

V.A. The uses of computer codes

V.B. A sample suite of accident model codes

V.B.1. The inventory of radionuclides in the fuel (ORIGEN)

V.B.2. The thermal hydraulics code (MARCH)

V.B.3. Details of MARCH

V.B.4. MERGE

V.B.5. Modeling of fission product releases (CORSOR)

V.B.6. Transport and deposition of fission products (TRAP-MELT)

V.B.7. The core-concrete interaction (INTER/CORCON)

V.B.8. Production of $\mathrm{H}_{2}$ and CO (VANESA)

V.B.9. Aerosol deposition code (NAUA)

V.B.10. Removal by ice condensers (ICEDF)

V.B.11. Water suppression pool removal (SPARC)

V.C. Calibration and validation of codes by experiment

V.D. Summary

V.E. Conclusions

VI. Sensitivity Studies of Key Parameters Affecting the Source Term

VI.A. Introduction

VI.B. Stylized model illustrating the times of significance influencing the "source term"

VI.C. The key factors influencing the "source term" for actual reactors

VI.C.1. Size of containment opening

VI.C.2. Primary system retention

VI.C.3. Timing of containment breach

VI.D. Summary

VII. The Severe Accident Research Program

VII.A. The Nuclear Regulatory Commission program

VII.B. Program of other U.S. organizations

VII.B.1. American Nuclear Society (ANS)

VII.B.2. Industry Degraded Core Rulemaking Program (IDCOR)

VII.B.3. The Electric Power Research Institute (EPRI)

VII.B.4. The Stone and Webster Engineering Company (SWEC)

VII.B.5. The New York Power Authority (NYPA)

VII.C. Work outside the USA

VII.C.1. Nuclear Energy Agency (NEA)

VII.C.2. Commission of European Communities

VII.C.3. Federal Republic of Germany (FRG)

VII.C.4. France

VII.C.5. Sweden

VII.C.6. Belgium

VII.C.7. Canada

VII.C.8. Denmark

VII.C.9. Finland

VII.C.10. Japan

VII.C.11. Netherlands

VII.C.12. Switzerland

VII.C.13. Italy
VII.C.14. U.K.

VII.C.15. USSR

VII.D. The organizational structure of the Office of Nuclear Regulatory Research (NRR)

VII.E. Coordination

VII.F. Recommendations for future research

VII.F.1. Vaporization of low volatility fission products

VII.F.2. Thermal hydraulics of the core-concrete interaction

VII.F.3. Release of refractory materials in the core-concrete interaction

VII.F.4. Transport of radionuclides through the reactor

VII.F.5. Tellurium behavior

VII.F.6. Release of volatile forms of iodine

VII.F.7. Damage progression in the core

VII.F.8. Fragmentation of the corium at RPV melt-through

VII.F.9. Research on containment breach

VII.F.10. Containment-failure modes

VII.F.11. Generation mechanisms for aerosols

VII.F.12. The effectiveness of suppression pools and ice beds

VII.F.13. Growth and deposition of aerosols

VII.F.14. Change of sequence by fission product heating

VII.F.15. Intercomparison of aerosol codes

VII.F.16. Aerosol deposition on pipes

VII.F.17. Natural circulation research

VII.F.18. Integrated severe-accident code

VIII. Conclusions and Recommendations

VIII.A. Conclusions

VIII.B. Detail of conclusion VIII.A.1

VIII.C. Detail of conclusion VIII.A.2

VIII.D. Possible implications

VIII.E. Major recommendations

Appendix I: Transport of Radionuclides

I.A. General theory of effluent dispersion

I.B. Consequence analysis

I.C. General features of dose distributions

Appendix II: Health Effects

Appendix III: Experimental Data Base on Steam Explosions

References

\section{PREAMBLE}

After the degraded-core accident at Three Mile Island in March, 1979 the U.S. Nuclear Regulatory Commission (NRC), the nuclear industry, the nuclear technical community, and the utilities all established separate groups to reassess the technical basis for evaluating the consequences of severe accidents at nuclear power reactors. The American Physical Society was asked by the NRC to carry out a broad scientific review of these studies, which were scheduled to appear in 1984. The APS formed this study group in 1983 to review the adequacy of the technical base upon which the phenomenological models for radionuclide release from postulated severe reactor accidents are constructed, the adequacy of the models themselves, and the correct use of the complex computer codes that incorporate these models in the analyses of accident sequences. 
Just over a decade ago The American Physical Society adopted a policy of analyzing important and timely issues with significant scientific and technical content as a public service. One of the first of these reports, prepared by the Study Group on Light-Water Reactor Safety in 1975, had as its goal "the assessment of the technical aspects of the safety of large light-water nuclear power reactors typical of present commercial practice in the United States..." (Lewis et al., 1975). In its transmittal letter, the peer review committee for the Lewis study group noted, among other things, the inadequacy of the scope of the experimental research programs and the absence of established scaling relations between experiment and actual reactor operations. The Lewis Study Group called for revised and expanded research and for remedial programs that might require a decade to resolve the problems completely.

The Reactor Safety Study [WASH-1400 (NRC, 1975a)] has served as the basis for the analysis of the risk from severe accidents included in the environmental impact statement for each reactor constructed during the last decade. Since its publication there has been continuing discussion of its methodology, the results of the calculations for fission product release from severe accident sequences, and the consequences for the general public of such postulated releases.

The dozen members of this study group have, on a part-time basis, spent the last eighteen months organizing and analyzing information gathered from many of those working on the severe accident consequences problem. The charge to the study group is scientific, and its members have carefully limited their work to the scientific problems encompassed in that charge. During its meetings the study group learned of an extensive body of work on such phenomena as aerosol formation and deposition that were ignored or only partially described in earlier analyses. We have therefore included expanded summaries of the scientific and technical data bases for such phenomena.

The layout of this report is as follows: Chapter I shows how this study came into being. Chapter II begins with an historical discussion of the attempts to understand radionuclide release, and the impetus to the present research from the observation that little iodine was released during the Three Mile Island accident. Section II.B gives a brief summary of how the atmospheric dispersion is calculated, and of the relative biological importance of the various radionuclides.

Chapter III discusses the general features of severe nuclear reactor accidents, including the safety features that must fail if a particular accident is to have severe consequences. Then we outline the method of choosing accident sequences, using an event tree analysis. Although we have not calculated probabilities of individual accident sequences, we discuss those sequences deemed by others to be "risk dominant" or those that involve a wide range of physical and chemical phenomena. In Section III.C, we describe in some detail a particular accident sequence, TMLB, to highlight the physical phenomena involved, and the method of calculation of the source term for this particular sequence.

Chapter IV deals with the physical and chemical phenomena themselves. Section IV.A details the thermal hydraulic phenomena of blowdown, core-melt, and interaction of a molten core with a concrete basemat. Section IV.B discusses the chemistry of the radioactivity released from the fuel and, to a limited extent, the chemistry of the core-concrete interaction. Section IV.C discusses the formation and deposition of aerosols, including a brief review of the large scale experimental tests used to verify and study the relevant processes. Section IV.D discusses the various kinds of containment vessels which have been built to entrap radionuclides in the event of an accident, and describes their ability to do so. Section IV.E discusses various challenges to containment-a pressure rise from heating, hydrogen burning, and metal-water interactions.

In Chapter $\mathbf{V}$ we discuss the suites of computer programs that have been written to describe these phenomena. We present their strengths and weaknesses and suggest tests of their reliability and sensitivity.

A simple pedagogical model to illuminate and describe some of the numerical results of the computer codes is the subject of Chapter VI. Here we have tried to put the results into a scientific perspective. Chapter VII discusses the research program that has developed worldwide to study the source term issues. We have also noted what may be expected from work still in progress.

Although we include some conclusions at the end of each chapter, the most important conclusions and recommendations are presented in Chapter VIII.

The group appreciates the help that it has received from, and acknowledges the contribution of, R. J. Budnitz, who served as special consultant, and of Kenneth Whitby, deceased, who was a member during the early stages of its work. The group also wishes to recognize the work of H.S. Gutowsky, A. Acrivos, H. Feshbach, and W. Fowler, who served as the APS Council Peer Review Committee.

Staff and members of the Nuclear Regulatory Commission, its Accident Source Term Program Office, the Electric Power Research Institute, the American Nuclear Society Special Committee on Source Term, the Industry Degraded Core Rulemaking Program, the Stone and Webster Engineering Corporation, Battelle Columbus Laboratories, Sandia National Laboratories, Oak Ridge National Laboratory, the New York Power Authority, the Idaho National Engineering Program, and various foreign scientists have all been most generous in explaining their work to the group and have graciously provided additional information on request.

The members of the study group brought to their task experience in diverse technical backgrounds. A few had worked directly on nuclear reactor safety problems; most had not. Some members have served as members of panels or commissions on technical policy issues; others have not. The group also realizes that there are as many published policy positions on nuclear power issues as 
there are parties with vested or "pro bono" interests in the role of nuclear power in the national energy supply; the study group has not addressed any of these ancillary issues.

This report is an exception to most articles in the $R e$ views of Modern Physics, which presents accounts of published work. We found ourselves in the position of reviewing work in progress. We were given the results of analyses done with computer programs still under development, and we received preliminary results from experiments still being evaluated. As a consequence, some of our conclusions must also be tentative. In spite of this, we chose to complete our review now because of the pressing need for a technical reassessment of the source term research.

\section{GENERAL INTRODUCTION}

\section{II.A. History}

\section{II.A.1. Pre-1957}

Since the earliest days of reactor power plant development, attempts have been made to calculate the probabilities of source terms and consequences associated with hypothetical nuclear reactor accidents. One of the important intermediate parameters in these calculations is the amount of radionuclides released to the environment from a given reactor accident sequence; this has been colloquially dubbed the "source term" because it is the source in any calculation of dispersion of radionuclides.

The first U.S. Reactor Safeguards Committee, whose name was changed in 1953 to the Advisory Committee on Reactor Safeguards (ACRS), was designated a statutory committee in 1957. It defined in WASH-3 (AEC, 1950) a zone around a nuclear reactor within which the general public is excluded. The defined radius of this circular area equaled (in miles) $1 / 100 \times \sqrt{P}$ where $P$ is the normal thermal power level in kilowatts. For a $3000 \mathrm{MW}_{t}$ reactor, which is typical of modern nuclear electric generating stations, this crude formulation establishes an exclusion radius of 17 miles.

In 1957, to provide a framework for indemnification for insurance purposes (the Price-Anderson Act), Brookhaven National Laboratory prepared the report WASH-740, "Theoretical Possibilities and Consequences of Major Accidents in Large Nuclear Plants" (AEC, 1957). This report presented three reactor accident scenarios in which large releases of fission products to the environment were postulated. At that time nuclear reac-

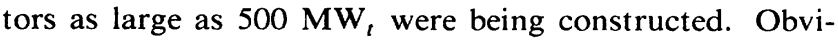
ously, the report was strongly influenced by a reactor accident that occurred that year at Windscale in the United Kingdom.

\section{II.A.2. The Windscale accident}

On October 9, 1957 an air-cooled, graphite-moderated plutonium production reactor at Windscale (Cumberland,
England), caught fire. The graphite moderator was being annealed by slowly raising its temperature to release energy that had been stored in the graphite as fast neutrons knocked carbon atoms out of the lattice (Wigner effect). The fire started in one fuel channel but quickly spread to 150 other channels and burned for about four days before it was finally extinguished by flooding the reactor with water. The reactor was not enclosed by a containment building and the cooling air was directly released to the atmosphere. Radioactive materials carried by the air were subsequently dispersed and deposited over England, Wales, and parts of northern Europe. The major radionuclide found in ground deposits was I-131 that was preferentially released because of its volatility. The physical conditions during the accident provided an environment that facilitated the formation of elemental iodine.

Estimates of the amounts of fission products released during the accident have been made by Loutit et al. (1960) based mainly on measurements of the contamination in environmental materials around Windscale immediately after the accident, and by Clarke (1974) who used a computer code to model the fission product inventory of the reactor. Some of these estimates are presented in Table II.A.1.

The stack filter removed that part of the iodine attached to particulate matter [estimated to be between 20000 and 50000 curies $(\mathrm{Ci})$ ] and retained between 800 to $1000 \mathrm{Ci}$ of cesium. Hence $25-43 \%$ of the iodine and $17-18 \%$ of the cesium must have escaped from the core.

Iodine is a particularly dangerous element because it concentrates as it proceeds through the biological chain and is finally stored in the body. It was estimated that the maximum individual thyroid dose to a child as the result of this accident was $160 \mathrm{mSv}(16 \mathrm{rem}$ ) (Crick et al., 1982).

\section{II.A.3. The SL-1 accident}

Another accident that strongly influenced subsequent thinking on consequences to the public occurred in Idaho in 1961. The stationary low-power plant No. 1 (SL-1) was a natural recirculation, highly enriched (93\% U-235), boiling water reactor with a $3 \mathrm{MW}$ capacity designed for use at remote military installations. The core consisted of elements of a uranium-aluminum alloy, encased in aluminum-nickel cladding.

The accident occurred on January 3, 1961 during recoupling of the shut-down and control rods to their drive shafts after maintenance. The most plausible cause was postulated by General Electric to be the manual withdrawal of the central control rod. It led to a severe power excursion and steam explosion that resulted in some metal vaporization and damage to $\sim 20 \%$ of the core. Two of the operators were killed immediately (one impaled on a control rod) and a third died within one hour.

Approximately $20 \%$ of the core plates, containing $\sim 40 \%$ of the fission products, were destroyed. About one-fourth of the damaged material $(5 \%$ of the total) 
TABLE II.A.1. Estimated radionuclide releases from the Windscale accident. Note: Very recent reports of the Windscale accident reveal that immediately before the annealing, the reactor was being used to produce Po-210 (an intense $\alpha$-emitter with a 140 day half-life) and tritium by irradiation of bismuth and lithium, respectively. The total polonium release was estimated at 180-290 Ci (Nuclear News, 1983).

\begin{tabular}{|c|c|c|c|}
\hline Isotope & $\begin{array}{l}\text { Inventory } \\
\text { (Ci) }\end{array}$ & $\begin{array}{l}\text { Released to } \\
\text { atmosphere } \\
\text { (Ci) }\end{array}$ & $\begin{array}{l}\text { Percent } \\
\text { released }^{\text {a }}\end{array}$ \\
\hline $\mathrm{Kr}-85$ & 1593 & 1593 & $\sim 100$ \\
\hline $\mathrm{Xe}-133$ & $3.24 \times 10^{5}$ & $3.24 \times 10^{5}$ & $\sim 100$ \\
\hline I-131 & 162000 & $16200 / 19980$ & $10.0 / 12.3$ \\
\hline $\mathrm{Te}-132$ & 161000 & $16200 / 11880$ & $10.1 / 7.4$ \\
\hline Ba-140 & & 173 & \\
\hline Sr-89 & 275000 & $138 / 81$ & $0.05 / 0.03$ \\
\hline Sr-90 & 11500 & $5.9 / 2$ & $0.05 / 0.02$ \\
\hline Cs-134 & & 32 & \\
\hline Cs-136 & & 40 & \\
\hline Cs-137 & 12300 & $1242 / 594$ & $10.1 / 4.8$ \\
\hline Ru-106 & 32000 & $159 / 81$ & $0.5 / 0.3$ \\
\hline $\mathrm{Ru}-103$ & & 1080 & \\
\hline Mo-99 & & 972 & \\
\hline Zr-95 & & 203 & \\
\hline$Y-91$ & & 173 & \\
\hline Ce- 144 & 218000 & $108 / 81$ & $0.05 / 0.04$ \\
\hline La- 140 & & 173 & \\
\hline $\mathrm{Ce}-141$ & & 192 & \\
\hline
\end{tabular}

${ }^{a}$ The first figure is from Clarke (1974); the second from Loutit et al. (1960).

resolidified onto the intact portion of the plates. The missing $15 \%$ of the fuel should have contained about $30 \%$ of the total fission product inventory and $1790 \mathrm{~g}$ of $\mathrm{U}-235$. Of this $1104 \mathrm{~g}$ of $\mathrm{U}-235$ were recovered from the bottom of the reactor vessel (Thompson et al., 1964).

It appears that between $5 \%$ and $15 \%$ of the total fission product inventory escaped from the reactor vessel, but less than $0.5 \%$ of the I-131 and $0.01 \%$ of the nonvolatile inventory were found outside the reactor building in the surrounding desert (GE, 1962).

The reactor building was not designed specifically to contain radionuclides. It should be pointed out, however, that almost all the energy released in the accident was released during the short nuclear transient. The system was not pressurized and the fission product decay heat was not sufficiently high to cause the core to remain molten after the accident or to cause further core melting when the coolant was lost. There was, therefore, little driving force for the radionuclide release.

\section{II.A.4. Maximum credible accidents} (design basis accidents)

The ACRS proposed the use of "maximum credible accidents." A procedure was developed in which a number of severe accidents were postulated that might happen to the reactor although they were deemed very unlikely. Plant designers then developed various approaches to avoid the effects of these postulated severe accidents. Such approaches included the development of engineered systems intended to prevent an accident from proceeding to core melt, and the provision of a containment vessel to retain the radioactive products if they were released. This concept of considering the "maximum credible accident" is extremely useful in limiting or preventing the occurrence of severe accidents. It was always realized that the engineered safety devices developed to cope with these postulated accidents might not work exactly in accordance with their designs, and that failures of such devices might cause an accident that would normally have minor consequences to become an accident with serious consequences. For this reason the word credible was added to imply that, while more severe scenarios could be envisaged, they were considered so unlikely as to be deemed incredible by reactor designers and the AEC.

A substantial number of maximum credible accidents-or as they have been alternatively designated, Design Basis Accidents (DBA's) - has been defined by the AEC (and retained for continuing use by the NRC) to establish the licensing basis for design requirements for the nuclear safety systems in the plants. The most severe of the DBA's is the sudden, double-ended, guillotine break of the largest reactor coolant pipe in the primary system of the reactor-the so-called DBA Loss of Coolant Accident (DBA-LOCA). The blowdown of the highpressure reactor primary coolant system from this event, and the consequent increase in containment pressure from the conversion of the thermal energy of the fluid in the primary system into steam in the containment, are used to establish the design pressure of the containment structure. 
In accordance with NRC regulations, the DBA-LOCA was used to establish the requirements upon which the emergency core cooling system (ECCS) and other engineered safety features (such as containment sprays and cooling fans) of the plant were designed. Consequently, the double-ended pipe break LOCA became an incident that by definition would not result in melting of the reactor core.

This practice of defining the maximum credible accident is accepted in emergency planning. For example, in water resources management, the "100 year flood" has long been used as a guide to the extent to which society should reasonably protect itself from disaster.

\section{II.A.5. Early site selection criteria}

The AEC defined a source term for the DBA-LOCA to help establish criteria for the licensing of plant sites that considered the kinds and magnitudes of public health hazards for the population distribution about those sites. Thus, the source terms for Design Basis Accidents were intentionally defined to be arbitrarily (and unrealistically) large. Although the DBA-LOCA would not result in a core melt (because, by definition, it was assumed that the engineered safeguards would stop the accident), the source terms were defined in terms of quasi-core melt conditions. Thus, in the source term defined for the DBA-LOCA (which also became known as the TID-14844 source term, in a reference to the published report in which it was first derived), $15 \%$ of the fission product activity was considered to be released to the containment vessel. This consisted of $100 \%$ of the noble gases, $50 \%$ of the iodine in gaseous form (based on the results of the Windscale accident), and $1 \%$ of the "solids" in the fission product inventory. Subsequently, one-half of the released iodine in the containment structure and all of the "solid" fission products were assumed to fall out, to be adsorbed onto the internal structures of the building, or to adhere to internal reactor components and, therefore, to be unavailable for release to the external environment. In addition, designers were permitted to consider reductions in the airborne iodine of the source term in accordance with the projected effectiveness of the design of the containment spray systems as time passed following accidental releases during the hypothetical accident sequence. Release of this hypothetical fission product mixture from the containment structure to the atmosphere was then assumed to occur at a constant rate of 0.1 volume percent per day, as a result of inabilities to design and fabricate a perfectly leak-tight containment structure. No substantive failure of the containment system was assumed to be associated with this design basis leak path (AEC, 1962, pp. 14-16).

In the late 1960s, the TID-14844 source term was incorporated into AEC Safety Guides 3 and 4 (renamed Regulatory Guides 1.3 and 1.4) which specify the assumptions to be used in estimating the off-site consequences of the maximum credible accident.
II.A.6. The reactor safety study (RSS)-WASH-1400

By 1974, nuclear technology had advanced to a point at which it was possible to try to make a realistic estimate of the probabilities and consequences of nuclear power plant accidents that might proceed beyond DBA limits to core melt. This was attempted by Rasmussen and his collaborators in the Reactor Safety Study (RSS) (NRC, 1975). The RSS study team outlined logical sequences of accidental steps that could lead to release of radioactive material-usually as a direct result of a core melt. They then attempted to assign probabilities to each step of the sequence. When available, historical data were used as bases for the projected probabilities. If historical data were not available, engineering judgments took their place.

Before the RSS, it was widely assumed that only the Design Basis Accidents could lead to core melt and release of appreciable radioactivity. Emphasis was placed upon the double ended guillotine break of a large coolant pipe. One of the surprises of the RSS was that many more such sequences exist; in total, the probabilities of their occurrence exceeded that of the DBA. These sequences include small pipe breaks and various transientinitiated events. Models of the physical processes associated with the sequences were developed to assess the magnitude and timing of the release, transport, and deposition of the radioactive materials from the core through the primary system and the containment to the environment. Consequence models were also developed to calculate the dispersal of radioactivity into the atmosphere so as to estimate the risks, thus coupling the probability and health effect consequences of various accidents.

The Reactor Safety Study was released just after the Atomic Energy Commission became ERDA and its regulatory functions were taken over by the Nuclear Regulatory Commission (NRC).

The RSS was a trend-setter in nuclear power plant safety analysis. As a result, it has been criticized and extended. In a review conducted by the NRC at the request of Congress, a committee chaired by $\mathrm{H}$. Lewis (1977) provided a number of findings with respect to the adequacy of the RSS, including (in part) the following:

"[The RSS ] was a substantial advance over previous attempts to estimate the risks of the nuclear option. The methodology has set a framework that can be used more broadly to assess choices involving both technical consequences and impacts on humans.

"[The RSS] was largely successful in at least three ways: in making the study of reactor safety more rational, in establishing the topology of many accident sequences, and in delineating procedures through which quantitative estimates of the risk can be derived for those sequences for which a data base exists. ...

"Despite its shortcomings, [the RSS] provides at this time the most complete single picture of accident probabilities associated with nuclear reactors. The fault- 
tree/event-tree approach coupled with an adequate data base is the best available tool with which to quantify these probabilities....

"It is conceptually impossible to be complete in a mathematical sense in the construction of event-trees and fault-trees; what matters is the approach to completeness and the ability to demonstrate with reasonable assurance that only small contributions are omitted. This inherent limitation means that any calculation using this methodology is always subject to revision and to doubt as to its completeness. ..." (Lewis et al., 1977)

The Lewis Committee also stated in its findings:

\begin{abstract}
"We are unable to determine whether the absolute probabilities of accident sequences in the RSS are high or low, but we believe that the error bounds on those estimates are, in general, greatly understated. This is true in part because there is in many cases an inadequate data base, in part because of an inability to quantify common cause failures, and in part because of some questionable methodological and statistical procedures." (Lewis et al., 1977)
\end{abstract}

Because of the many criticisms of RSS and the uncertainties inherent in Probabilistic Risk Assessment, the methodology was not used before 1979 for reactor design, reactor operator training, or for regulation.

\section{A.7. The Three Mile Island-2 reactor accident}

On March 28, 1979, a loss of feedwater transient occurred at the Three Mile Island-2 (TMI-2) PWR nuclear power plant (Fig. II.A.1) that led to a series of events culminating in a partially mitigated loss-of-coolant accident (LOCA) with significant core damage. The sequence of events that led to core damage was a combination of equipment malfunctions, design deficiencies, and human errors.

It is generally believed that in this accident most of the noble gases escaped from the core into the primary coolant system, and that $50 \%$ of the iodine and cesium and lesser amounts of other isotopes also escaped from the fuel. These fission products were presumably carried by the water, either in solution or as bubbles. Some were transported by means of a "let-down line" to the auxiliary building atmosphere from which a fraction leaked to the environment. Because the let-down line was not isolated, a limited amount of the primary coolant water was transported out of the containment building.

The first reaction of many observers to the accident was that the Reactor Safety Study methodology was completely wrong because it had not predicted that type of accident would soon occur. The particular sequence, TMLQ (cf. Section III.B for a description of the acronyms used in the RSS), was calculated for the Surry facility (a Westinghouse reactor upon which the RSS results were modeled) to have a frequency of once in $10^{5}$ years. Yet, even as early as the afternoon of March 28, several analysts realized with surprise that, if the RSS procedures had been applied to a Babcock and Wilcox reactor like TMI-2, the methodology would have predicted a frequency of occurrence of once in 300 years. Babcock and Wilcox reactors had an operating history of about 30 reactor years. The differences stemmed from: (a) the pressure relief valve settings that caused the valve to be released be-

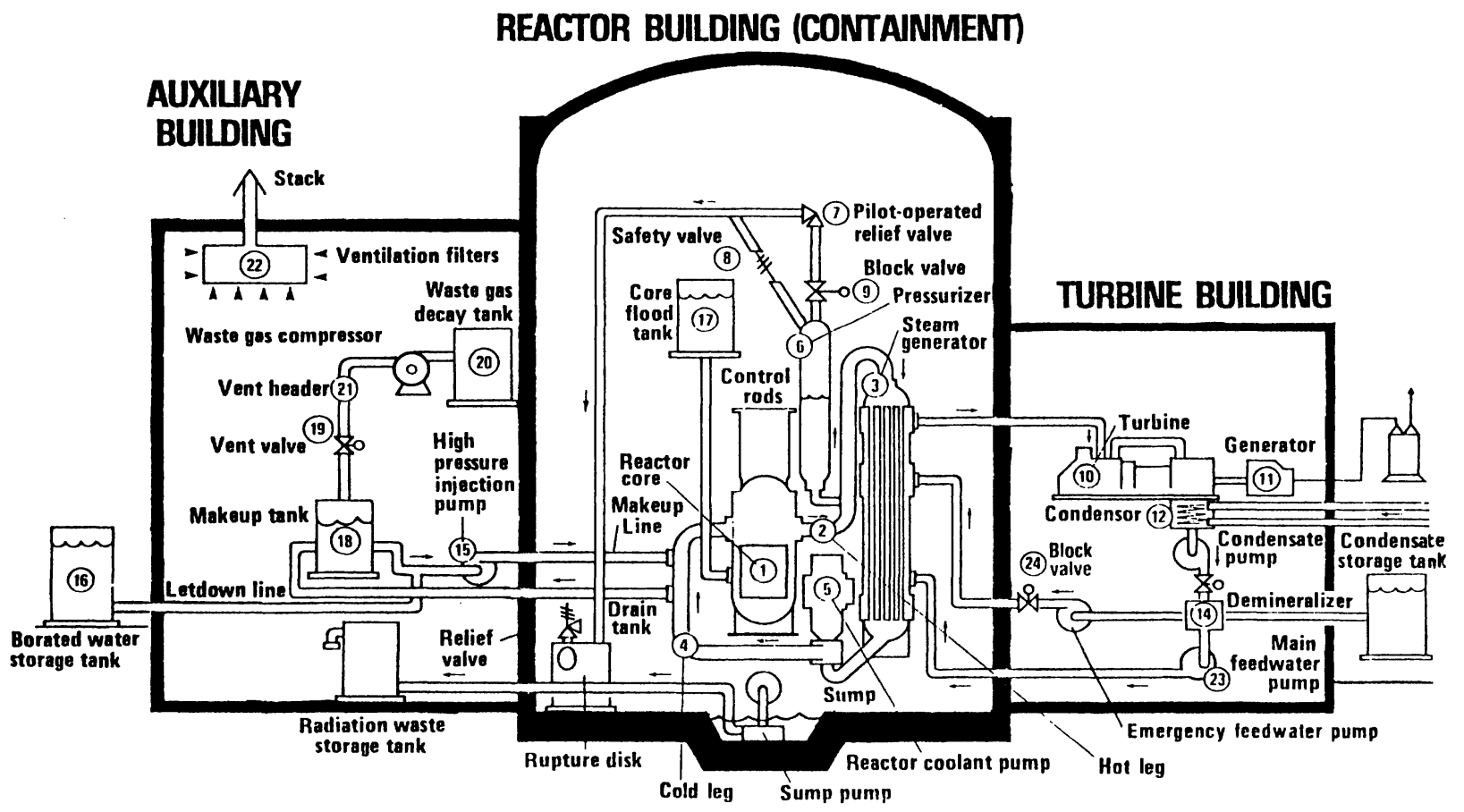

FIG. II.A.1. TMI-2 nuclear plant layout. 
fore reactor scram and (b) the fact that the steam generator had a small heat capacity and dried out in ten minutes, compared with a time of about an hour calculated for the Westinghouse reactors such as Surry. The actual values of the probabilities and frequencies calculated in the reactor safety study may not be correct in view of the uncertainties associated with their prediction; yet, if the methodology had been applied to the reactor at Three Mile Island, the plant specific scenario differences might have been noted, modifications might have been made, and the accident perhaps avoided.

This realization led to a general acceptance of the methodology of Probabalistic Risk Assessment (PRA) as an important part of design and of accident prevention.

From measurement of off-site radiation doses around TMI, it can be estimated that between 2.4 million and 13 million curies $(\mathrm{Ci})$ of the noble gas xenon-133 escaped to the environment. Since the calculated inventory of xenon- 133 in the core was 154 million $\mathrm{Ci}$, this is a release fraction of between 1.6 and $8.4 \%$. On the other hand, only $17 \mathrm{Ci}$ of iodine- 131 was released to the environment. The total inventory was 64 million $\mathrm{Ci}$. Approximately $16.6 \%$ of the iodine was retained in the containment building water, about $0.06 \%$ in the containment atmosphere, and about $6.3 \%$ in the auxiliary building tanks (outside the containment). The release fraction is $2.7 \times 10^{-7}$. No cesium or other metallic fission products are known to have escaped to the environment (Kemeny et al., 1979).

Radioactive xenon was the source responsible for almost all of the offsite doses to people in the vicinity of the reactor. An ad hoc Dose Assessment group of six federal agencies (Battist et al., 1979) estimated that the maximum dose to any individual was $37 \mathrm{mrem}$. It is generally agreed that this is small; even if the dose were multiplied tenfold (by a postulated $84 \%$ release of noble gases), it would still not be large. The differences between the release fractions of noble gases and of iodine can be attributed to the following:

- Noble gases by their physical and chemical nature are inert (i.e., they do not react chemically with other materials even at high temperatures), very volatile, and are not strongly retained in water.

- The majority of the iodine was chemically absorbed by the primary coolant water in the core. In the containment, the deliberate injection of sodium hydroxide enhanced iodine absorption by increasing the alkalinity of the water.

- The general reducing environment (a hydrogen-rich mixture of steam, water, and hydrogen in which little or no free oxygen was present) promoted the formation of metallic iodides.

- About $90 \%$ of the iodine released from the auxiliary building was trapped by the filters.
It is important to note that, although the containment building was not completely isolated, there was no structural failure of the reactor containment building at TMI-2, and that the release of radioactivity occurred through leaks in the secondary systems of the auxiliary building. If the containment had failed at the start of the accident, the iodine release to the environment could have been as large as $0.06 \%$ to $0.2 \%$. These numbers can be compared with the 1962 regulatory assumptions for potential releases of noble gases and iodine to the environment for a DBA-LOCA at TMI of $0.003 \%$ (noble gases) and $0.00001 \%$ iodine for a small LOCA (NRC, 1976a). For a large LOCA (NRC, 1976b), the corresponding numbers are $3 \%$ and $0.04 \%$.

Table II.A.2 from Stratton (1984) summarizes the data from other nuclear accidents.

The TMI-2 event naturally led to a complete reexamination of the regulatory assumptions. In its aftermath, some reactor safety professionals came to believe that the source terms defined by the Design Basis Accident procedure (AEC, 1962) or calculated by the RSS (NRC, 1975) procedures were unduly conservative (i.e., excessively large). It should be noted that the TMI accident sequence was not specifically described in the Environmental Impact Statement for the facility. It was neither a small LOCA without substantial fuel failure nor a large (rapid-depressurization) LOCA. Although the TMI accident was a slow, small break leak, and was therefore not representative of the DBA-LOCA, it did demonstrate that, in the presence of a reducing (hydrogen rich) atmosphere and with a substantial amount of water remaining in the reactor primary system, iodine was evidently not released from the reactor pressure vessel as an elemental vapor. On the contrary, the majority of the iodine released in the partial core melt of TMI was found to have been converted to cesium iodide, a highly water soluble and relatively nonvolatile compound. Thus, the cesium iodide formed at TMI was largely retained in the water that leaked from the primary system to the containment structure and/or the water that remained within the primary system of the reactor.

In any case, the realism of both the DBA-LOCA source term defined for the licensing accident and the RSS source terms have been challenged as a result of TMI, whether or not the scenario of TMI term can be appropriately associated with the maximum credible accident. In reviewing the basis of the DBA-LOCA licensing source term, the NRC has maintained that its definition was never based upon a perceived requirement for realism (Pasadeg et al., 1981). That source term was intended to provide a conservative prescription for a hypothetical accident that exceeded DBA limits and went to partial meltdown. Though the driving pressures behind the release of the source term fission products were correlated with DBA-LOCA conditions in the containment structure, the fission products designated as being released were not intended to be a realistic representation of releases from this particular DBA or any other particular accident. The NRC has acknowledged that a reassess- 
TABLE II.A.2. Summary of fission products release at various accidents (involving fuel damage) in test, research, experimental, and power production reactors (adapted from Stratton, 1984).

\begin{tabular}{|c|c|c|c|c|c|c|}
\hline \multicolumn{7}{|c|}{ Escape of fission products $(\mathrm{Ci})$} \\
\hline Facility & Coolant & Iodine & Noble gas & Metal & $\begin{array}{c}\text { MW } \\
\text { thermal }\end{array}$ & Date \\
\hline NRX & Water & not measured & $10^{4}$ in $10^{6}$ gallons water & not measured & 30 & $12 / 12 / 52$ \\
\hline BORAX & Water & & no measurement made & & transient & $7 / 22 / 54$ \\
\hline Windscale & Air & $2 \times 10^{4}(12 \%)$ & $3.4 \times 10^{5}$ (est.) & 12800 (est.) & & $10 / 9 / 57$ \\
\hline HTRE-3 & Air & $34(2 \%)$ & not measured & $0.1(\mathrm{Sr}-90)$ & transient & $11 / 18 / 58$ \\
\hline WTR & Water & 0.0 & 260 & 0.0 & 60 & $4 / 3 / 60$ \\
\hline SL-1 & Water & $\begin{array}{l}10 \text { in } 16 \mathrm{~h} \\
70 \text { in } 30 \text { days }\end{array}$ & $10^{4}$ (est.) & 0.6 & 3 & $1 / 3 / 61$ \\
\hline ETR & Water & 0 & 6 (est.) & & 170 & $12 / 12 / 61$ \\
\hline SPERT & Water & none detected & $7 \%$ & 0 & transient & $11 / 5 / 62$ \\
\hline MTR & Water & 0 & not measured & & 40 & $11 / 13 / 62$ \\
\hline ORR & Water & 0.15 & 500 (est.) & & 24 & $7 / 1 / 63$ \\
\hline Snaptran-3 & $\mathrm{NaK}$ & none detected & $3 \%$ & 0 & transient & 1964 \\
\hline PRTR & Water & & "no appreciable release" & & & $9 / 29 / 65$ \\
\hline Lucens & $\mathrm{CO}_{2}$ & 0.0 & 1.5 & & 30 & $1 / 21 / 69$ \\
\hline St. Laurent & $\mathrm{CO}_{2}$ & & no measurement reported & & 1350 & $10 / 17 / 69$ \\
\hline Three Mile Island-2 & Water & $13-18$ & $2.5 \times 10^{6}-13 \times 10^{6}$ & 0 & 2700 & $3 / 28 / 79$ \\
\hline
\end{tabular}

ment of the concept of using the DBA-LOCA source terms for site evaluation may be in order, but it has concluded that the rulemaking processes associated with emergency planning, siting, minimum engineered safety features, and degraded cores should be used as the vehicle for such a reassessment (Pasadeg et al., 1981, p. 5).

As a result of the observations of radionuclides released at TMI, the NRC and the technical community have felt that a more realistic evaluation of severe reactor accident source terms is necessary. The NRC, the nuclear industry here and abroad, and regulatory commissions abroad have responded by supporting greatly expanding programs of experimental research and theoretical analysis of the physical and chemical phenomena involved in radionuclide release. Other physical processes that might affect the release and distribution of radioactivity from the core have also been reexamined.

The major organizations in the U.S. involved in this "source term research" are Battelle Columbus Laboratories (theoretical analysis for the NRC), Oak Ridge National Laboratory (experiments), Sandia National Laboratory (experiments), the Electric Power Research Institute (EPRI), Stone and Webster Engineering Corporation (SWEC), New York Power Authority, the American Nuclear Society, and an ad hoc nuclear industry group called IDCOR (for Industry Degraded Core Rulemaking Program). Internationally, there is active experimental work in France, Germany, and Sweden, and theoretical analysis in France, Germany, Japan, and England.

\section{II.B. Release consequences}

II.B.1. Doses

Of the various environmental impacts that could result from a postulated nuclear reactor accident, biological ef- fects to a population as a consequence of the radiation dose are of the highest concern. The number of people exposed and the distribution of dose over that population serve as measures of the impact. The dose at a position as a result of the release of a particular radionuclide depends on the amount released, its radiological characteristics, the weather conditions, the duration of exposure, and the geometric relationship between the receptor and the source. The dose from each nuclide is proportional to the mass of radionuclide released. How the wind distributes released materials determines the magnitudes of doses within given geographical regions. The information in this chapter is background information. It is a summary of other work which can help the reader to understand the selection of particular radionuclides for study.

\section{II.B.1.a. Radiation sources}

Some radionuclides which comprise the source material are released in gaseous forms and some as aerosols. Whatever their form, it is useful to distinguish four ways in which they can contribute to the total radiation dose $\left(D_{T}\right)$.

(1) Cloud dose $\left(D_{c}\right)$-an external dose caused by exposure to radiation emitted by radionuclides in the effluent cloud. If the radionuclide release is of short duration compared with the longitudinal dispersion divided by the wind speed, so is the cloud dose.

(2) Inhalation dose $\left(D_{i}\right)$-a dose caused by inhalation of radionuclide constituents of the cloud. This includes a prompt dose and the dose from radionuclides retained in the body. Because of this retention, this dose can spread over an appreciable time interval.

(3) Ground dose $\left(D_{g}\right)$-an external dose caused by radionuclides that have formed a surface deposit by gravita- 
tional settling on the ground and other surfaces. The ground dose depends upon the time the individual remains in the contaminated area which, in principle, could be many years.

(4) Food pathway dose $\left(D_{f}\right)$-dose from ingestion of food and drink contaminated by deposited radionuclides. In what follows, the study group assumes that procedures have been adopted to limit the intake of such contaminated material so that doses received are insignificant compared with the other three doses above.

The cloud dose $\left(D_{c}\right)$ that an individual at ground level receives as a result of the radionuclides in the effluent cloud is the sum of the contributions of direct radiation from all sources distributed in the air around that individual. For a passing cloud, the dose rate would begin when the cloud approaches, reach a maximum when the cloud is overhead, and fall off as the cloud recedes. The dose is estimated as a time integral of the contributions of the radionuclides in each volume element as the cloud passes through (or above) the position concerned.

The magnitude of the inhalation dose $\left(D_{i}\right)$ depends upon the quantity of radionuclides inhaled. It is estimated as the integral of exposure to the cloud for those volume elements at the position of the individual (at ground level). The duration of exposure depends on the effective radiological and biological half-lives of the particular radionuclide in the body.

The ground dose $\left(D_{g}\right)$ is determined both by the quantity and distribution of source material deposited at ground level and by the subsequent time interval during which the individual remains in the contaminated region. Since the ground-level deposit results from the fallout of aerosols, the surface source strength also depends on the radionuclide concentration in the cloud at ground level integrated over time.

\section{II.B.1.b. Effluent dispersion}

When released into the atmosphere, radioactive gases and aerosols will follow prevailing winds and be dispersed about that path because of wind direction fluctuations and local atmospheric turbulence. Experiments show that the distributions transverse to the average path are nearly Gaussian. A simple but sufficient model-the "Gaussian plume" model-treats the distribution of the radioactivity in the cloud as the result of turbulent diffusion superposed on the mean velocity of the entire medium. This model is used widely, for analyzing the dispersion of atmospheric pollutants and is well described in the procedures guide for risk analysis (NRC, 1983b) and a pamphlet (EPA, 1975). A particular version is given here. For any distance $x$ from the release point, the maximum ground level concentration of radioactivity occurs beneath the center line of the cloud directly downwind. This maximum value is useful as an estimate for the time integrated concentration at off-centerline positions and may be estimated as

$$
\chi_{0}(x)=\frac{Q}{\pi u_{x} \sigma_{y} \sigma_{z}} \exp \left[-h^{2} /\left(2 \sigma_{z}^{2}\right)\right],
$$

where $\chi_{0}(x)$ gives the time integrated concentration in $\mathrm{Cis} / \mathrm{m}^{3}$ at ground level resulting from a time integrated release of $Q$ units of radionuclides (in $\mathrm{Cis}$ ) from a height $h$ (in $\mathrm{m}$ ), at time $t=0$, and into a wind of velocity $u_{x}$ (in $\mathrm{m} / \mathrm{s}$ ) blowing in the $x$ direction. The standard deviations for the distribution in the $y$ and $z$ directions, $\sigma_{y}$ and $\sigma_{z}$, are increasing functions of $x$. The values of $\sigma_{y}$ and $\sigma_{z}$ (in $\mathrm{m})$ depend upon the ambient weather conditions. Sets of values for these have been obtained from observational data (Pasquill, 1962; Slade, 1968). In particular, $\sigma_{z}$ (see Table AI.2 in Appendix I) increases very rapidly with distance for unstable atmospheres but much less rapidly for stable atmospheres. When $\sigma_{z}$ becomes large compared with $h$, the exponential factor is close to unity and the ground level concentration becomes appreciable. It is usually assumed, for a nuclear power accident, that the height of release is small enough so that this is true for all values of $x$ of interest.

Except for noble gases (and molecular iodine if it remains), all other constituents of the release are transported as aerosols. Fallout leads to an exponential depletion of effluent plume concentration and to the buildup of a ground deposit. This is usually modeled by assigning a deposition velocity, $V_{d}$ (which is assumed to be constant), to the settling of the aerosols. Then the aerosol effluent concentration decays exponentially with increasing distance with an attenuation length $L_{d}=u_{x} \bar{z} / V_{d}$ where $\bar{z}$ is the mean height of the cloud. Radioactive decay also leads to a further reduction in effluent activity with distance. Its characteristic relaxation length, $L_{r}$ is $u_{x} / \lambda=\left(u_{x} t_{1 / 2}\right) / \ln 2$, where $\lambda$ is the usual radioactive decay constant and $t_{1 / 2}$ is the usual half-life. Combining all of these, the expression for center-line ground level, the time-integrated concentration $\chi_{0}(x)$ becomes

$$
\begin{aligned}
\chi_{0}(x)= & \frac{Q}{\pi u_{x} \sigma_{y} \sigma_{z}} \exp \left[-h^{2} /\left(2 \sigma_{z}^{2}\right)\right] \exp \left(-x / L_{r}\right) \\
& \times \exp \left(-x / L_{d}\right) .
\end{aligned}
$$

$\chi_{0}(x) / Q$ is often called the dilution factor $F$. (See Appen$\operatorname{dix}$ I.)

The "source term" is often given as a fraction of the radionuclide inventory $I$ (given in $\mathrm{Ci}$ ) in the core, whence $Q=I f$, where $f$ is the release fraction. In general values of $f$ are different for different radionuclides. Once the local concentrations are known then, using the biological dose conversion factors (given, for example, in Table II.B.3), radioactive dose estimates for individuals exposed at distances ( $x$ 's) from the reactor can be calculated. These equations must be summed over all the radionuclides released.

\section{II.B.1.C. Estimates of dose for particular releases}

The dose at ground level from any isotope may be written as the sum of the three components mentioned previously (omitting the ingestion dose, as stated above): 


$$
D_{T}=D_{c}+D_{i}+D_{g}
$$

These may be estimated by first representing both the cloud of radionuclides and the ground deposit of radionuclides as uniform and infinite in extent and then correcting for the limited actual cloud extent and ground deposit distributions. In this way the explicit dependence of the dose at any distance from the release point on both source characteristics and atmospheric conditions is considered.

In order to represent the consequences of a hypothetical nuclear accident for a given site and specified population distribution, numerical methods are customarily employed in order to evaluate the effect of time dependent meteorological conditions. It is usual to make many repeated calculations of the distribution of short and long term dose over the population area surrounding a site. Each calculation in a set provides a single deterministic projection of the local concentration associated with the atmospheric dispersion that would have resulted from a statistically selected hourly description of weather conditions from the past history at the site. The set of results is then analyzed statistically for the potential consequences considering the year's weather conditions. The results may be used to infer probability distributions for the dose at various distances and directions from the site for a given type of accident. This set of calculations is usually done using a computer code, of which the most commonly used is the CRAC2 code (Calculation of Reactor Accident Consequences-Version 2) developed by the NRC.

It is traditional to categorize various radionuclides into groups according to their physical and chemical similarities. The radionuclide groups are related, in part, to the vapor pressure of the radionuclides at the temperature of the damaged core of the reactor. The groups commonly used are the noble gases, the halogens, the cesium and rubidium group, the tellurium group, the barium and strontium group, the volatile oxides or ruthenium group, and the nonvolatile oxides or lanthanides. For noble gases the release fraction $(f)$ can be close to unity, but is much less for other radionuclides depending on the details of the accident. The relative contributions of each of the three major elements to doses, $D_{c}, D_{i}$, and $D_{g}$, vary considerably depending upon the nature of the accident and the meteorological conditions. However, the development of the illustrative model in Appendix I indicates that the spatial dependence of dose distributions for different radionuclides should be very similar assuming that deposition velocities $\left(V_{d}\right)$ for the relevant radionuclides are similar. This suggests that the consequences derived from an analysis of the noble gas group could be useful for making first order estimates of consequences for other radionuclide groups for a given site based upon projected release fractions for the other groups.

Karahalios (1984) has noted that the shape of the spatial distribution curves of dose appears to be relatively independent of local weather histories, particularly for the high dose, low probability tail of the distribution of dose. This somewhat counterintuitive result can be understood more readily when the contributing factors of the high dose distribution are understood. One cause of an unusu- ally large dose is rain that falls just as the cloud of radionuclides passes over the receptor; this greatly increases the local concentration and the surface deposit. At nearly all receptor locations around nearly all reactor sites enough rain falls during the averaging period of a year to yield an appreciable probability of an event with an unusually large dose at each location. Meteorological differences make some substantial differences in statistical dose distribution from one site to another, but they are small enough in the high dose, low probability, end of the distribution to make Karahalios's statement approximately correct.

\section{II.B.2. Biological effects}

\section{II.B.2.a. Biological effects of radiation}

This section is a very brief summary of this subject; a more detailed description is given in Appendix II.

Exposure of individuals or populations to high levels of radiation may result in the incidence of severe health effects, which vary with dose and with time elapsed after irradiation. The most definitive human data are for the very high exposures experienced by survivors of A-bombs and by medical patients treated with massive doses of radiation. Observed deleterious effects range from death soon after exposure to various fatal and nonfatal neoplasms that may appear many years following exposure. The evaluation of response to lower exposures is uncertain in that the incidence of effects resulting from radiation exposure is masked by a much larger incidence of similar effects from other, uncontrolled sources. Models have been developed for the relationship between exposure and effect, and, while there is substantial uncertainty in the predictions for very low doses, there is reasonable agreement on the expected consequences for doses above 10 rad.

\section{II.B.2.b. Lethal and near-lethal doses of radiation}

The consequences of whole body irradiation depend both on the dose and on the time elapsed after exposure. A typical characterization is that an external gamma source producing an air dose of about $350 \mathrm{rad}$ delivered in a short time will kill $50 \%$ of exposed but untreated people in 60 days (LD-50/60) (Cronkite, 1958). It is believed that $100 \%$ mortality would be reached at about $500 \mathrm{rad}$ unless alleviated by extensive medical treatment. The availability of such treatment would depend, at least in part, on the number of casualties relative to the treatment capacities of nearby hospitals (Cronkite, 1981). Prompt fatalities are not ordinarily seen at doses below 150 rad. It is interesting to note that the dose limit allowable for astronauts-who are heavily exposed to cosmic rays-is set at $75 \mathrm{rad}$, safely below prompt fatality levels but substantially above the protective action guidelines for the general public set by the EPA at 1 to $5 \mathrm{rad}$. 
II.B.2.c. Whole body exposure to sub-lethal doses of radiation

Early clinical effects of whole body radiation exposure are not statistically significant for doses less than about $150 \mathrm{rad}$ (Conrad, 1980). For exposures near that value, the sources of supply of mature functional cells are reduced so that individual organs and the host individual have impaired function (this depletion can be detected at doses as low as $40 \mathrm{rad}$ in some organs). If the individual survives the early period (30-60 days) following exposure, the damaged organ is likely to regenerate its normal complement of cells and the individual will recover. For those who do survive, the most serious long term somatic effect is the increase in probability of delayed cancer incidence. Periods of delay between exposure and incidence of cancer are seldom less than five years, and incidence may not occur for periods of 30 years or more after exposure. Estimates of an individual's probability of dying from radiation induced cancer from low doses (of the order of $10 \cdot \mathrm{rad}$ ) vary substantially among protagonists of various biological consequence models. The estimates of probability of death range from the order of $10^{-3}$ to about $10^{-4}$-with correspondingly lower values (approaching negligibility at the lower limit) as doses decrease in magnitude (NAS, 1980, Table V-25).

\section{II.B.3. Contributions of radionuclides to health effects}

The question of which radionuclides are most significant to health effects depends strongly upon the nature of the accident being evaluated and the resultant size of the accidental release. In addition to the prompt doses associated with exposure directly from the cloud, from material deposited on the ground, and from inhalation of the cloud, longer term exposure may also result from ingestion of radioactive material through the food chain or inhalation of resuspended material deposited upon the ground. Local emergency procedures may reduce the effects of these last two mechanisms. The current investigations indicate that substantial changes may be in order for the source terms used from the RSS as a basis for specification of current emergency planning procedures for public health protection about nuclear power plants. If this proves to be correct, revisions would be necessary in the projections for the dominant radioisotopic contributors to public health effects from the upgraded source terms. Under these circumstances, it would also be desirable to investigate the potential for improvements in the effectiveness of some emergency procedures (such as evacuation, sheltering, and temporary relocation concepts) in light of potential changes in the radiation characteristics of the revised mix of radioisotopes projected for the revised source terms.

Various estimates have been made of the relative importance of the three relatively short term dose induction mechanisms (here we again omit the ingestion dose) (e.g., NRC, 1975, Appendix VI; Lewis et al., 1975, Appendix II). Even if only the noble gases $\mathrm{Kr}$ and $\mathrm{Xe}$ were released, the inhaled dose exceeds the cloud dose. Although these gases deposit neither in the lung to give a persistent inhalation dose, nor on the ground, yet because they are $\beta$ emitters the increased solid angle of inhaled radionuclides leads to a larger dose. For other radionuclides the cloud dose contribution is generally substantially smaller than the contributions to dose from either of the other two sources.

For aerosols, there can be appreciable deposition in the lung and on the ground. For a gas such as molecular iodine, there can be deposition in the lung by absorption

TABLE II.B.1. Contribution of different exposure pathways to latent-cancer fatalities for the PWR-2 release category. ${ }^{\text {a.b }}$ Reproduced from NRC (1983b; Table 9-7).

\begin{tabular}{|c|c|c|c|c|c|c|c|c|}
\hline Pathway & Leukemia & Lung & Breast & $\begin{array}{l}\text { Bontage } \\
\text { Bone }\end{array}$ & $\begin{array}{l}\text { tribution } \\
\text { GI } \\
\text { tract }^{c}\end{array}$ & $\begin{array}{c}\text { All } \\
\text { others }^{d}\end{array}$ & Total & $\begin{array}{l}\text { Whole } \\
\text { body }^{\mathrm{e}}\end{array}$ \\
\hline $\begin{array}{l}\text { External irradiation from } \\
\text { cloud }\left(D_{c}\right)\end{array}$ & 0.2 & 0.1 & 0.5 & 0.1 & 0.1 & 0.1 & 1 & 1 \\
\hline $\begin{array}{l}\text { Inhalation from cloud }\left(D_{i}\right) \\
\text { External ground }\left(D_{g}\right)\end{array}$ & 0.5 & 4 & 0.7 & 0.2 & 0.4 & 0.2 & 6 & 3 \\
\hline$<7$ days & 3 & 2 & 7 & 0.7 & 0.9 & 3 & 16 & 16 \\
\hline$>7$ days & 12 & 8 & 28 & 3 & 4 & 11 & 66 & 68 \\
\hline $\begin{array}{l}\text { Inhalation of resuspended } \\
\text { contamination } \\
\text { Ingestion of contaminated }\end{array}$ & 0.2 & 1 & 0.2 & 0.4 & 0.2 & 0.1 & 3 & 2 \\
\hline food $\left(D_{f}\right)$ & 2 & 1 & 3 & 1 & 1 & 1 & 9 & 10 \\
\hline Total & 18 & 16 & 39 & 5 & 6 & 16 & 100 & 100 \\
\hline
\end{tabular}

${ }^{\mathrm{a} D a t a}$ from Wall et al. (1977).

${ }^{\mathrm{b}}$ This table does not include latent fatalities from thyroid cancer, which are calculated separately, as discussed in Appendix VI of the Reactor Safety Study (USNRC, 1975).

"The gastrointestinal tract includes the stomach and the rest of the alimentary canal.

d“"All others" denotes all cancers except those specified in the table.

'Whole-body values are proportional to the 50-year whole-body population dose commitment (man-rem). 
on the lung surfaces. These processes are-similar to the depositional processes that take place in a reactor environment (Section IV.C). The radionuclides that are particularly dangerous are those which deposit on the ground or lung, but for some reason do not deposit in the reactor.

If local emergency procedures are relatively effective and ground exposures are limited to one day or less, then the inhalation dose may be substantially larger than the ground dose. For example, in the previous APS study (Lewis et al., 1975) of consequences of very severe reactor accidents for PWR-2 source terms (shown in Table II.B.1), it was found that the cloud dose contributed about 4 percent of the overall whole-body dose (an estimated 4.4 million person-rem); the inhalation dose contributed 71 percent; and the one-day ground dose contributed 25 percent. In Table II.B.1, the RSS estimates are shown for contributions to dose from various exposure pathways (NRC, 1983b). Assuming that ground doses are approximately proportional to exposure duration, the whole-body dose results for one-day ground exposure would have approximately the same proportional contribution as in those APS results. In Table II.B.2, the significant radionuclides for the RSS results are shown (NRC, 1983b). Approximate agreement exists between the determination of significant radionuclides in the APS study and RSS.

Table II.B.3 lists the most important radionuclides present in the reactor at the time the accident is assumed to occur. Column 3 shows the radionuclide inventory (in $\mathrm{Ci}$ ) in the reactor at the shutdown of the fission process.
Columns 4, 5, and 6 show the whole-body dose conversion factors for the cloud dose, inhalation dose, and ground dose, respectively. The cloud dose conversion factor in column 4 converts local values of the integrated ground level cloud radioisotope concentration (which is derived in $\mathrm{Ci} \mathrm{s} / \mathrm{m}^{3}$ ) directly to whole-body dose for a human receptor. In order to determine inhalation dose, the individual's exposure to the local concentration of the cloud, integrated over time, and his/her breathing rate must be used to determine the integrated quantities of radionuclides inhaled (activity measured in $\mathrm{Ci}$ ) during the exposure period. From this quantity, the conversion factor in column 5 permits direct determination of the inhalation dose. The ground dose to an individual may be determined by applying the conversion factor in column 6 to the projected local surface radiation deposition, $S$ (derived in $\mathrm{Ci} / \mathrm{m}^{2}$ ). It should be noted that the conversion factor for ground dose is listed here for a 7-day exposure, but with evacuation or relocation much of this factor could be reduced. The conversion factor for the inhalation dose, given for 0-50 years, includes the dose commitment of the inhaled material. Many of the potentially significant radioisotopic contributors to the inhalation dose have exceptionally long biological and radiological halflives and hence may contribute to the dose over substantial portions of the 50 year commitment period.

The current studies of the source term have tended to concentrate their attention on iodine, cesium, and to a modest extent, tellurium. These fission products are rela-

TABLE II.B.2. Radionuclides considered in the Reactor Safety Study consequence analysis. ${ }^{a}$ Reproduced from NRC (1983b; Table 9-11).

\begin{tabular}{|c|c|c|c|}
\hline Element & Radionuclide & Element & Radionuclide \\
\hline Cobalt & $\mathrm{Co}-58,{ }^{*} \mathrm{Co}-60^{*}$ & Iodine & $\mathrm{I}-131,^{\mathrm{c}, \mathrm{g}, \mathrm{h}, \mathrm{i}} \mathrm{I}-132^{\mathrm{b}, \mathrm{g}, \mathrm{h}} \mathrm{I}-133^{\mathrm{b}, \mathrm{g}, \mathrm{i}}$ \\
\hline Krypton & $\mathrm{Kr}-85,^{*} \mathrm{Kr}-85 m,{ }^{*} \mathrm{Kr}-87,{ }^{*} \mathrm{Kr}-88^{\mathrm{b}}$ & & $\mathrm{I}-134, \mathrm{I}-135^{\mathrm{b}, \mathrm{g}, \mathrm{h}}$ \\
\hline Rubidium & $\mathrm{Rb}-86^{*}$ & Xenon & $\mathrm{Xe}-133, \mathrm{Xe}-135$ \\
\hline Strontium & Sr- $89,{ }^{c}$ Sr- $-90,{ }^{\text {d,e }}$ Sr -91 & Cesium & Cs- $134,{ }^{\mathrm{c}}$ Cs- $136, \mathrm{Cs}-137^{\mathrm{j}}$ \\
\hline Yttrium & $Y-90, * \quad Y-91$ & Barium & $\mathrm{Ba}-140^{\mathrm{c}}$ \\
\hline Zirconium & $\mathrm{Zr}-95, \mathrm{Zr}-97$ & Lanthanum & La-140 \\
\hline Niobium & $\mathrm{Nb}-95^{*}$ & Cerium & $\mathrm{Ce}-141, \mathrm{Ce}-143,{ }^{*} \mathrm{Ce}-144^{\mathrm{f}}$ \\
\hline Molybdenum & Mo-99 & Praseodymium & Pr-143* \\
\hline Technetium & Tc-99 $m^{*}$ & Neodymium & Nd-147* \\
\hline Ruthenium & $\mathrm{Ru}-103, \mathrm{Ru}-105,^{*} \mathrm{Ru}-106^{\mathrm{f}}$ & Neptunium & Np-239 \\
\hline Rhodium & Rh- $105^{*}$ & Plutonium & $\mathrm{Pu}-238,{ }^{\mathrm{e}} \mathrm{Pu}-239, \mathrm{Pu}-240, \mathrm{Pu}-241^{\mathrm{e}}$ \\
\hline Tellurium & $\begin{array}{l}\text { Te-127, }{ }^{*} \text { Te- } 127 m, \text { Te-129, }{ }^{*} \text { Te-131m, } \\
\text { Te-132 }\end{array}$ & $\begin{array}{l}\text { Americium } \\
\text { Curium }\end{array}$ & $\begin{array}{l}\mathrm{Am}-241^{*} \\
\mathrm{Cm}-242, \mathrm{Cm}-244\end{array}$ \\
\hline Antimony & $\mathrm{Sb}-127, \mathrm{Sb}-129$ & & \\
\hline
\end{tabular}

aApplicable to releases from LWR's only. The radionuclides marked with an asterisk are negligible contributors to health effects. The most significant contributors are signaled with superscript letters for the modes or effects listed below.

${ }^{\mathrm{b}}$ Cloudshine.

${ }^{\mathrm{c}}$ Inhalation (early effects).

${ }^{\mathrm{d}}$ Leukemia (inhalation dose).

'Bone cancer (inhalation dose).

${ }^{\mathrm{f}}$ Lung cancer (inhalation dose).

${ }^{g}$ Groundshine (early effects).

${ }^{\mathrm{h}}$ Thyroid dose.

${ }^{i}$ Milk-ingestion pathway.

${ }^{j}$ Long-term groundshine. 
TABLE II.B.3. Radioactive inventories and whole-body dose conversion factors ( $3200 \mathrm{MW}_{t}-\mathrm{PWR}$ ).

\begin{tabular}{|c|c|c|c|c|c|}
\hline Radionuclides & $\begin{array}{c}\text { Half-life } \\
t_{1 / 2} \text { (days) }\end{array}$ & $\begin{array}{c}\text { Shutdown } \\
\text { inventory } \\
\left(10^{6} \mathrm{Ci}\right)\end{array}$ & $\begin{array}{c}\text { Cloud } \\
D_{c} / \chi_{0} \\
\left(\mathrm{rem} \mathrm{m} \mathrm{m}^{3} / \mathrm{Cis}\right)\end{array}$ & $\begin{array}{c}\text { Inhalation, } \kappa_{i} \\
(\mathrm{rem} / \mathrm{Ci} \text { inhaled }) \\
(0-50 \mathrm{yr})\end{array}$ & $\begin{array}{c}\text { Ground } \\
D_{\mathrm{g}} / S \\
\text { (rem m } \mathrm{m}^{2} / \mathrm{Ci} \text { ) }\end{array}$ \\
\hline \multicolumn{6}{|l|}{ Noble gases } \\
\hline $\mathrm{Kr}-85$ & 3950.0 & 0.56 & $0.475 E-03$ & $0.310 E+00$ & \\
\hline $\mathrm{Kr}-85 \mathrm{~m}$ & 0.183 & 24.0 & $0.364 E-01$ & $0.260 E+00$ & \\
\hline Kr-87 & 0.0528 & 47.0 & $0.181 E+00$ & $0.100 E+01$ & \\
\hline $\mathrm{Kr}-88$ & 0.117 & 68.0 & $0.467 E+00$ & $0.230 E+01$ & \\
\hline $\mathrm{Xe}-133$ & 5.28 & 170.0 & $0.906 E-02$ & $0.700 E+00$ & \\
\hline $\mathrm{Xe}-135$ & 0.384 & 34.0 & $0.567 E-01$ & $0.120 E+01$ & \\
\hline \multicolumn{6}{|l|}{ Iodines } \\
\hline I-131 & 8.05 & 85.0 & $0.872 E-01$ & $0.600 E+03$ & $0.708 E+03$ \\
\hline I-132 & 0.0958 & 120.0 & $0.511 E+00$ & $0.700 E+02$ & $0.107 E+03$ \\
\hline I-133 & 0.875 & 170.0 & $0.154 E+00$ & $0.200 E+03$ & $0.311 E+03$ \\
\hline I-134 & 0.0366 & 190.0 & $0.533 E+00$ & $0.300 E+02$ & $0.414 E+02$ \\
\hline I- 135 & 0.280 & 150.0 & $0.419 E+00$ & $0.150 E+03$ & $0.285 E+03$ \\
\hline \multicolumn{6}{|c|}{ Cesiums and rubidiums } \\
\hline Cs-134 & 750.0 & 7.5 & $0.350 E+00$ & $0.470 E+05$ & $0.369 E+04$ \\
\hline Cs-136 & 13.0 & 3.0 & $0.478 E+00$ & $0.590 E+04$ & $0.410 E+04$ \\
\hline Cs-137 & 11000.0 & 4.7 & $0.122 E+00$ & $0.360 E+05$ & $0.131 E+04$ \\
\hline $\mathrm{Rb}-86$ & 18.7 & 0.026 & $0.207 E-01$ & $0.660 E+04$ & $0.185 E+03$ \\
\hline \multicolumn{6}{|c|}{ Telluriums and antimony } \\
\hline Te- 127 & 0.391 & 5.9 & $0.936 E-03$ & $0.340 E+02$ & $0.813 E+00$ \\
\hline $\mathrm{Te}-127 \mathrm{~m}$ & 109.0 & 1.1 & $0.110 E-02$ & $0.240 E+04$ & $0.584 E+02$ \\
\hline Te-129 & 0.048 & 31.0 & $0.147 E-01$ & $0.980 E+01$ & $0.198 E+01$ \\
\hline Te- $129 m$ & 0.340 & 5.3 & $0.783 E-02$ & $0.300 E+04$ & $0.246 E+03$ \\
\hline $\mathrm{Te}-131 \mathrm{~m}$ & 1.25 & 13.0 & $0.314 E+00$ & $0.550 E+03$ & $0.960 E+03$ \\
\hline $\mathrm{Te}-132$ & 3.25 & 120.0 & $0.475 E-01$ & $0.150 E+04$ & $0.308 E+04$ \\
\hline Sb-127 & 3.88 & 6.1 & $0.151 E+00$ & $0.790 E+03$ & $0.920 E+03$ \\
\hline Sb-129 & 0.179 & 33.0 & $0.268 E+00$ & $0.110 E+03$ & $0.104 E+03$ \\
\hline
\end{tabular}

tively volatile, and their release fractions were believed to be higher than the release fractions for other radionuclides. From an inspection of Table II.B.3, it is apparent that, if released in sufficiently large quantities, some of the relatively low volatility or nonvolatile fission products and actinides might also contribute to consequences. An examination of the inhalation dose conversion factors shows that some of these less volatile (more refractory) radionuclides, especially the actinides plutonium, americium, and curium, might be associated with very large dose-conversion factors. Because the dose-conversion factors for these radionuclides are so large, it is clear that a small fractional release of the refractory core materials could have a large impact on consequences. Similar arguments could be given for the need for special consideration of the radionuclides with significant ground dose conversion factors. The magnitudes of these factors suggest that several of the less volatile radionuclides could be significant contributors to consequences and hence could be important elements of the source term.

In Appendix I, a set of calculations are reviewed that compare the biologically significant doses contributed by combined exposure to the cloud, inhalation, and a one-day ground dose as a function of distance for various nuclide groups. From these calculations, Table II.B.4 shows the release fraction for each group that could produce a whole body dose at 5 miles equivalent to that contributed by exposure to $100 \%$ of the noble gases for parametric conditions of 2-hour and 24-hour delays between reactor shutdown and containment failure. The differences between the results for the two parametric conditions reflect the presence in the cloud of significant short-lived radioactive isotope components in the noble gas group (cf. Table II.B.3). If (see Table II.B.4) a smaller reference value is projected for the 24-hour release condition than for the 2-hour release condition for one of the gaseous, volatile, or nonvolatile fission product groups, it indicates that a smaller release fraction of such groups could be required to achieve dose equivalence with the corresponding noble gas 24-hour release conditions. Since the noble gases would almost certainly be released (eventually) for the severe nuclear accident conditions considered in our investigations, the noble gases have been considered to be benchmark conditions. While the projected doses for 
TABLE II.B.3. (Continued).

\begin{tabular}{|c|c|c|c|c|c|}
\hline Radionuclides & $\begin{array}{c}\text { Half-life } \\
t_{1 / 2} \text { (days) }\end{array}$ & $\begin{array}{l}\text { Shutdown } \\
\text { inventory } \\
\left(10^{6} \mathrm{Ci}\right)\end{array}$ & $\begin{array}{c}\text { Cloud } \\
D_{c} / \chi_{0} \\
\left(\mathrm{rem} \mathrm{m} \mathrm{m}^{3} / \mathrm{Cis}\right)\end{array}$ & $\begin{array}{c}\text { Inhalation, } \kappa_{i} \\
\text { (rem/Ci inhaled) } \\
(0-50 \mathrm{yr})\end{array}$ & $\begin{array}{c}\text { Ground } \\
D_{g} / S \\
\left.\text { (rem m }{ }^{2} / \mathrm{Ci}\right)\end{array}$ \\
\hline \multicolumn{6}{|l|}{ Alkaline earths } \\
\hline Sr-89 & 52.1 & 94.0 & & $0.410 E+04$ & \\
\hline Sr-90 & 11030.0 & 3.70 & & $0.240 E+06$ & \\
\hline Sr-91 & 0.403 & 110.0 & $0.169 E+00$ & $0.310 E+03$ & $0.205 E+03$ \\
\hline $\mathrm{Ba}-140$ & 12.8 & 160.0 & $0.444 E-01$ & $0.190 E+04$ & $0.365 E+04$ \\
\hline \multicolumn{6}{|l|}{ Volatile oxides $(\mathbf{R u})$} \\
\hline Co- 58 & 71.0 & 0.78 & $0.216 E+00$ & $0.420 E+04$ & $0.244 E+04$ \\
\hline Co- 60 & 1920.0 & 0.29 & $0.600 E+00$ & $0.820 E+05$ & $0.588 E+04$ \\
\hline Mo-99 & 2.8 & 160.0 & $0.364 E-01$ & $0.420 E+03$ & $0.325 E+03$ \\
\hline Tc- $99 m$ & 0.25 & 140.0 & $0.306 E-01$ & $0.980 E+01$ & $0.162 E+02$ \\
\hline Ru-103 & 39.5 & 110.0 & $0.111 E+00$ & $0.190 E+04$ & $0.116 E+04$ \\
\hline Ru-105 & 0.185 & 72.0 & $0.179 E+00$ & $0.660 E+02$ & $0.794 E+02$ \\
\hline $\mathrm{Ru}-106$ & 366.0 & 25.0 & $0.431 E-01$ & $0.620 E+05$ & $0.456 E+03$ \\
\hline Rh-105 & 1.50 & 49.0 & $0.182 E-01$ & $0.960 E+02$ & $0.567 E+02$ \\
\hline \multicolumn{6}{|c|}{ Nonvolatile oxides (La) } \\
\hline $\mathrm{Y}-90$ & 2.67 & 3.9 & & $0.780 E+03$ & \\
\hline $\mathrm{Y}-91$ & 59.0 & 120.0 & $0.625 E-03$ & $0.560 E+04$ & $0.591 E+01$ \\
\hline Zr-95 & 65.2 & 150.0 & $0.162 E+00$ & $0.560 E+04$ & $0.177 E+04$ \\
\hline $\mathrm{Zr}-97$ & 0.71 & 150.0 & $0.422 E-01$ & $0.520 E+03$ & $0.538 E+03$ \\
\hline $\mathrm{Nb}-95$ & 35.0 & 150.0 & $0.166 E+00$ & $0.190 E+04$ & $0.164 E+04$ \\
\hline La- 140 & 1.67 & 160.0 & $0.567 E+00$ & $0.920 E+03$ & $0.180 E+04$ \\
\hline $\mathrm{Ce}-141$ & 32.3 & 150.0 & $0.183 E-01$ & $0.110 E+04$ & $0.182 E+03$ \\
\hline $\mathrm{Ce}-143$ & 1.38 & 130.0 & $0.681 E-01$ & $0.340 E+03$ & $0.224 E+03$ \\
\hline $\mathrm{Ce}-144$ & 284.0 & 85.0 & $0.431 E-02$ & $0.320 E+05$ & $0.120 E+03$ \\
\hline Pr-143 & 13.7 & 130.0 & & $0.820 E+03$ & \\
\hline Nd-147 & 11.1 & 60.0 & $0.314 E-01$ & $0.790 E+03$ & $0.305 E+03$ \\
\hline Np-239 & 2.35 & 1640.0 & $0.308 E-01$ & $0.250 E+03$ & $0.202 E+03$ \\
\hline $\mathrm{Pu}-238$ & 32500.0 & 0.057 & $0.525 E-04$ & $0.730 E+08$ & $0.620 E+01$ \\
\hline $\mathrm{Pu}-239$ & $8.9 E+06$ & 0.021 & $0.230 E-04$ & $0.820 E+08$ & $0.263 E+01$ \\
\hline $\mathrm{Pu}-240$ & $2.4 E+06$ & 0.021 & $0.464 E-04$ & $0.830 E+08$ & $0.547 E+01$ \\
\hline $\mathrm{Pu}-241$ & 5350.0 & 3.4 & $0.417 E-09$ & $0.150 E+07$ & $0.221 E-02$ \\
\hline Am-241 & $1.5 E+05$ & 0.0017 & $0.465 E-02$ & $0.860 E+08$ & $0.143 E+03$ \\
\hline $\mathrm{Cm}-242$ & 163.0 & 0.50 & $0.500 E-04$ & $0.190 E+07$ & $0.546 E+01$ \\
\hline $\mathrm{Cm}-244$ & 6630.0 & 0.023 & $0.142 E-02$ & $0.430 E+08$ & $0.346 E+02$ \\
\hline
\end{tabular}

Table II.B.4 were determined for a distance of 5 miles, there is a similarity in the spatial dependence of dose for all groups (cf. Figure II.B.1). This suggests that although doses from the noble gases would decrease with distance, the magnitudes of the single fission product release group equivalent values would provide an appropriate approximation for doses at all distances. Thus, for a 2-hour delay prior to release, if the release fraction $(f)$ for iodine is $4 \%$ of the reactor shutdown inventory, the iodine could (by itself) double the effective noble gas dose. On the other hand, if only $0.1 \%$ of the shutdown inventory of lanthanum were released, it (by itself) could also effectively double the noble gas dose.

Relatively nonvolatile radionuclide contributors to the source term have been neglected in many of the analyses by NRC and others. In view of the contributions from biological dose conversion factors cited in Table II.B.3 and the "equivalent release factors" computed above, the relatively nonvolatile elements of the source term should be evaluated as carefully as the contributions of the more volatile radionuclides. This is particularly true when the release fraction of the volatile radionuclides is calculated to be small.

In Figure II.B.1 are shown some upper 95th percentiles of the dose probability distribution from several sets of CRAC2 calculations (Karahalios, 1984). Several observations are pertinent. Firstly, dose-distance results are shown for the cases where only the noble gases were released at parametric times of 2 hours and 24 hours after reactor shutdown, as a function of distance from the reactor. Secondly, the ratios of doses from other radionuclides to the dose from the noble gases were normalized to unity at 5 miles. The near constancy of the ratios suggests a potential for broad application of the insights ob- 
TABLE II.B.4. Table of doses due to release of $100 \%$ of core inventory of noble gases and equivalent releases of other groups.

\begin{tabular}{lcc}
\hline \hline & $\begin{array}{c}2 \text { hour decay } \\
\text { prior to release }\end{array}$ & $\begin{array}{c}24 \text { hour decay } \\
\text { prior to release }\end{array}$ \\
\hline & 95 th percentile & noble gas dose \\
& 40 rem & 7.5 rem \\
& & \\
& Fractional release of single groups whose \\
Gases & 95 th percentile dose is the same \\
Iodine & as that from 100\% noble gas release \\
Volatiles & & \\
Cs-Rb & 0.04 & 0.016 \\
Te-Sb & & \\
Ba-Sr & 0.065 & 0.01 \\
Ru & 0.05 & 0.01 \\
& 0.022 & 0.005 \\
Nonvolatiles & 0.025 & 0.005 \\
La & & \\
\hline
\end{tabular}

Release conditions

3412 MWt PWR end of life core inventory

2 hour release duration

Deposition velocity $0.01 \mathrm{~m} / \mathrm{s}$

Miami typical meteorological year data

Distance $(x) 5$ miles downwind from reactor

Equivalent whole body dose

24 hour exposure to ground contamination

Lifetime (50 year) commitment for inhalation dose

tained from Table II.B.4 and Figure II.B.1. Suppose, for example, that it is desired to consider an accident in which almost all the noble gases are released after 2 hours. Then (from Figure II.B.1) 95\% of the time, the dose at a point 2 miles from the reactor will be less than about $100 \mathrm{rem}$. If no other radionuclides were released, there would be no prompt radiation fatalities projected for this dose level. However, if an additional $4 \%$ of the iodine were released, the 95 th percentile dose would be increased by about $150 \%$ (to nearly 250 rem) and a few prompt radiation fatalities might be expected if individuals were exposed at this location.

If the type of accident leading to such releases were estimated to have a frequency of $10^{-5}$ per year, the probability of an individual being exposed to the doses in the example at a distance of 2 miles from the reactor falls to $0.05 \times 10^{-5}$ or $5 \times 10^{-7}$. The projected doses would be reduced if the containment retained its integrity for 24 hours or if the emergency planning zone distance of 10 miles were used to evaluate the projected doses and resulting health impacts for potential individual exposures.

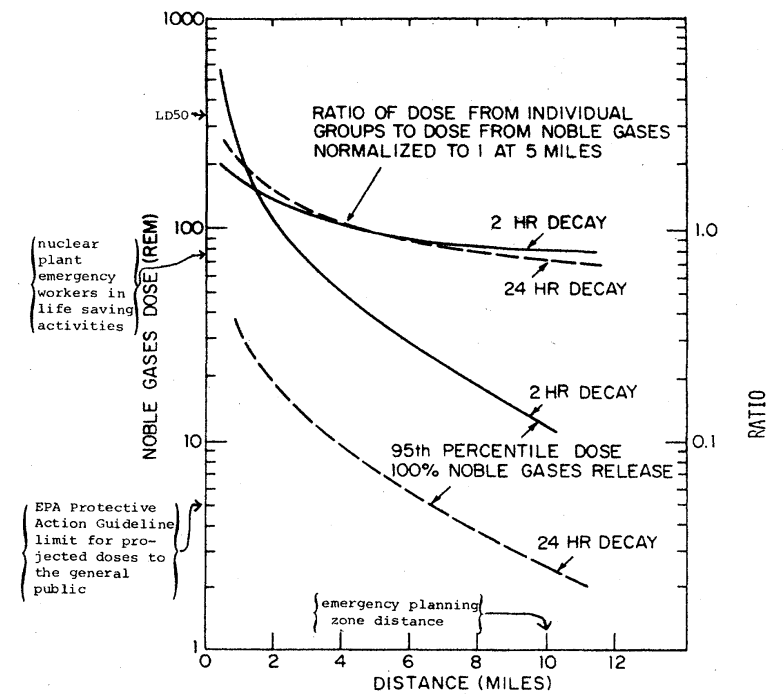

FIG. II.B.1. The spatial dependence of the ratio of dose from individual groups to dose from noble gases (normalized to 1 at 5 miles) (CRAC2 calculations).

\section{REACTOR ACCIDENTS: GENERAL FEATURES AND IMPORTANT SEQUENCES}

\section{III.A. General features of reactors and reactor accidents}

In this section we present a synopsis of the important features of light water reactors (LWR) that determine the course of reactor accidents, and the general safety features that are incorporated to prevent accidents. The reader is also referred to the "primer on LWR and related safety issues" in Lewis (1975).

\section{III.A.1. Energy production in nuclear reactors}

The energy in nuclear fission reactors comes from the fission of uranium or plutonium nuclei. The total rest mass of the products is less than the rest mass of the fissioning nucleus with the difference appearing as energy. On the average, the fissioning of a single ${ }^{235} \mathrm{U}$ nucleus releases 2 to 3 neutrons and about $212 \mathrm{MeV}$ distributed as shown in Table III.A.1. Since the neutrino energy cannot be recovered, the fission of a single ${ }^{235} \mathrm{U}$ nucleus effectively releases $200 \mathrm{MeV}$ of recoverable energy. In more common units, the complete fissioning of $1 \mathrm{~kg}$ of ${ }^{235} \mathrm{U}$ produces about $1000 \mathrm{MW}_{t}$-day of energy. The kinetic energies of the fission fragments and neutrons, as well as the energy of the prompt and capture gamma rays, are released coincident with the fission events, while that por- 
TABLE III.A.1. The contributions to the energy of fission of ${ }^{235} \mathrm{U}$.

\begin{tabular}{lr}
\hline \hline End product & Energy $(\mathrm{MeV})$ \\
\hline Kinetic energy of fission products & 168 \\
Kinetic energy of fission neutron radiation & 5 \\
Prompt $\gamma$ radiation & 7 \\
Fission product decay & \\
$\beta$ radiation & 8 \\
$\gamma$ radiation & 7 \\
neutrinos (not recovered) & 12 \\
Neutron capture $\gamma$ rays & \\
(depends on structures) & 5 \\
& \\
\hline
\end{tabular}

tion associated with fission product decay (about $15 \mathrm{MeV}$ or 7.5 percent) is released subsequently. In particular, fission product heat continues to be released after the fission process has ceased.

\section{III.A.2. Reactor control}

\section{III.A.2.a. Moderator}

The spectrum of neutrons emitted in fission has an average energy of $2 \mathrm{MeV}$ and a median energy of $1 \mathrm{MeV}$. While the fission cross section for the isotopes of uranium at $\mathrm{MeV}$ energies is relatively small, the cross section for fission of ${ }^{235} \mathrm{U}$ increases rapidly with decreasing energy. It is necessary to incorporate a light moderating material (usually water) to slow down neutrons and increase the probability that they initiate another fission rather than escape. Reactors used in the United States use ordinary (light) water as a moderator. Natural uranium has $0.72 \%$ of isotope ${ }^{235} \mathrm{U}$, the remainder being the ${ }^{238} \mathrm{U}$ isotope. It is necessary to enrich that fuel slightly in ${ }^{235} \mathrm{U}$ to overcome losses from parasitic neutron capture in water. Further, because ${ }^{238} \mathrm{U}$ has a high (nonfission) resonant capture cross section for neutrons in the energy range between the $\mathrm{MeV}$ and thermal regions, it is necessary to arrange the fuel in rods separated by moderator. The water filled space, at the density corresponding to operating temperatures and pressures, is designed to allow most fission neutrons to slow down to thermal energies before reentering neighboring fuel rods. If the fission energy exceeds the capacity of the heat sink, the moderator and fuel temperatures rise. The corresponding decrease in moderator density causes neutrons to reenter the fuel at slightly higher energy than thermal, thus increasing the relative probability that neutrons will be lost through parasitic capture in ${ }^{238} \mathrm{U}$. The effective Doppler broadening of the ${ }^{238} \mathrm{U}$ resonances through the rise in fuel temperature also increases parasitic capture. Together these effects limit the extent of power transients. Finally, if the water were to be removed completely, the fission reaction could not continue.

\section{III.A.2.b. Delayed neutrons}

At steady state, the chain reaction is in equilibrium. The occurrence of each fission leads, on the average, to exactly 1 subsequent fission. The remaining neutrons are absorbed by reactor fuel, structures or moderator, or by neutron absorbing rods designed to control fission rate. The time that elapses between successive neutron fissions (hundreds of microseconds) would seem too short to allow steady state to be attained and maintained by purely mechanical means. Control is possible because a small fraction (less than 1 percent) of the average number of neutrons emitted per fission is produced following the radioactive decay of precursor fission products. As a result, the rate of change of neutron population has a component with a time constant of several seconds; this provides time for mechanical controls to act.

\section{III.A.2.c. Control rods}

The reactor is controlled by inserting or withdrawing control rods of material that absorbs neutrons. They are arranged on a ratchet so that they can enter quickly (to shut down the reactor) but can only be withdrawn slowly. The design is such that the removal of a single control rod cannot change the reactivity of the reactor by more than the number of delayed neutrons, so that accidental withdrawal cannot lead to an uncontrollable rapid excursion.

It is generally agreed that in most accident conditions for a light water reactor, the chain reaction will cease and not cause further heat that might disperse the fuel with its dangerous radioactivity.

\section{III.A.3. Fission product heating}

The energy from the decay of the fission products remaining after the nuclear chain reaction is shut down is the principal driving force for potential accidental dispersion of the fuel and its radioactivity. After long term operation, the fission product decay power level approaches $7.5 \%$ of the reactor's operating power at shutdown, or 250 Megawatts thermal for an 1100 Megawatt (electrical) $\left(\mathrm{MW}_{e}\right)$ [or equivalently, a 3300 Megawatt (thermal) $\left(\mathrm{MW}_{t}\right)$ ] reactor. If the removal of heat from the reactor were interrupted for a long enough time, this fission product decay heat would be sufficient to melt the core and liberate the radioactivity.

After reactor shutdown, the decay power diminishes with time-very rapidly at first and then more slowly as the various radionuclides decay. Figure III.A. 1 shows the fission and total decay power for a power reactor at the end of the second year of operation calculated using the 1979 ANSI standard (1979) and some experimental results. One third of the fuel is normally replaced in a reactor at each yearly refuelling shutdown, so that one third of the fuel will have been irradiated for 1 year, one third for 2 years, and one third for 3 years. The inventory of 


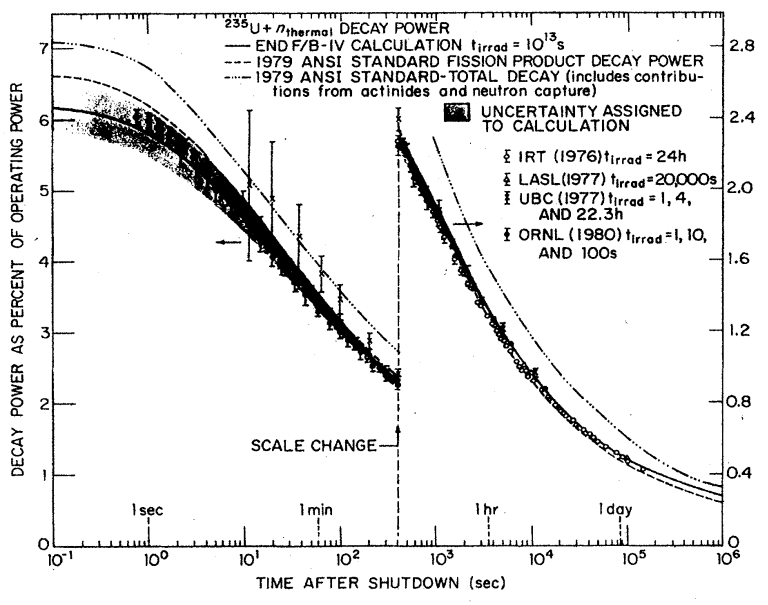

FIG. III.A.1. Decay power of fission products and actinides as calculated from the 1979 ANSI standard compared to various experimental results.

long lived isotopes and of transuranic elements is highest at the end of a life cycle.

\section{III.A.4. Light water reactor design}

\section{III.A.4.a. The fuel}

The hydrogen in the water of a light water reactor (LWR) not only interacts, as desired, with fast neutrons to slow them down, but also absorbs slow neutrons (cross section 0.33 barn). It turns out that a chain reaction is not possible with uranium fuel of natural isotopic composition $\left(99.28 \%{ }^{238} \mathrm{U}\right.$ and $\left.0.72 \%{ }^{235} \mathrm{U}\right)$ since ${ }^{238} \mathrm{U}$ is not fissile with slow neutrons. The fuel is enriched in ${ }^{235} \mathrm{U}$, which is fissile with slow neutrons, to about $3 \%$. As the fission process proceeds, the ${ }^{235} U$ is consumed, and some of the ${ }^{238} \mathrm{U}$ is converted by neutron capture and subsequent radioactive decay to ${ }^{239} \mathrm{Pu}$ which is also fissile with slow neutrons. At the end of the fuel life about $30 \%$ of all fissions come from ${ }^{239} \mathrm{Pu}$.

The fuel is arranged in sintered uranium dioxide $\left(\mathrm{UO}_{2}\right)$ pellets, inserted in a long (12 ft) tube usually fabricated of zirconium alloy (zircalloy), so chosen because of its low neutron capture. A typical reactor contains about 51000 (PWR) [47000 (BWR)] such fuel rods, arranged in 193 (PWR) [764 (BWR)] square assemblies of 264 (PWR) [62 (BWR)] fuel rods each, as shown in Figures III.A.2 and III.A.3.

\section{III.A.4.b. The coolant system}

In light water reactors the water moderator is also used to transfer heat from the hot reactor core to the electricity generating system where water, as steam, drives a steam turbine. Since the system operates at high temperatureabout $600 \mathrm{~K}$-to maintain a reasonable thermodynamic efficiency, the water must be pressurized.
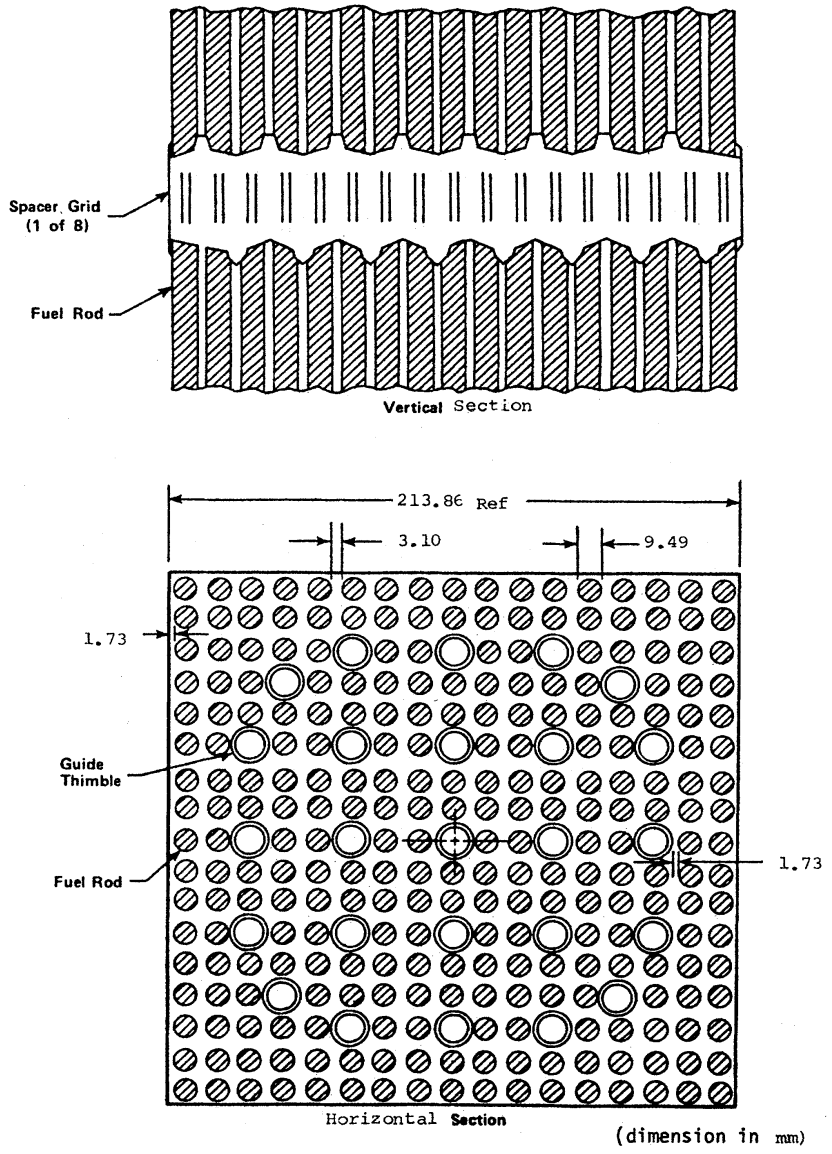

FIG. III.A.2. PWR $17 \times 17$ fuel bundle.

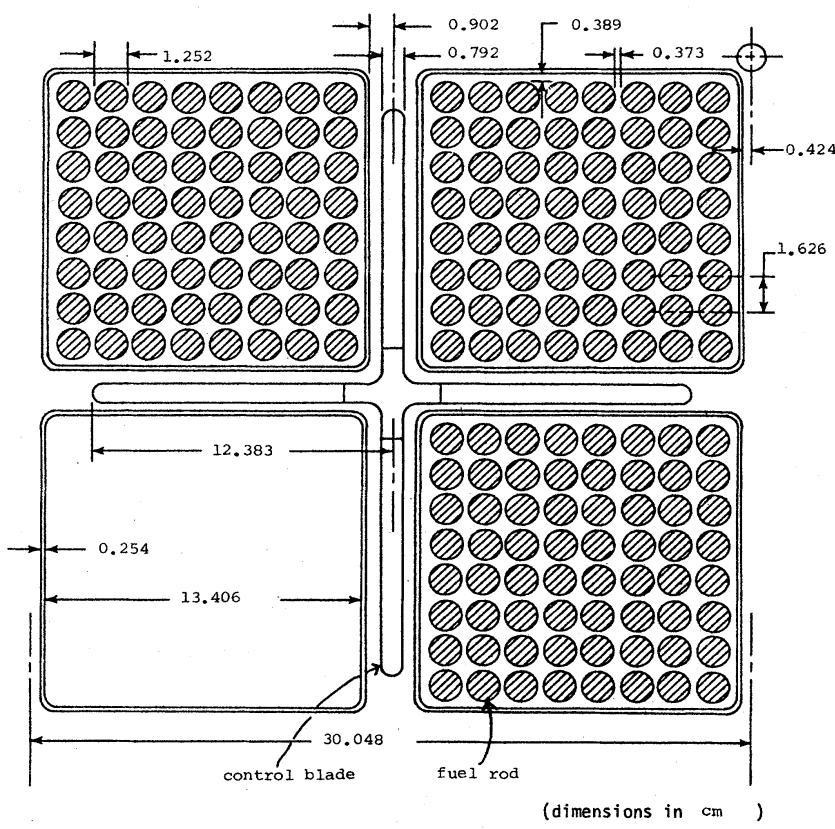

FIG. III.A.3. Four BWR fuel bundles with control blade (horizontal section). 


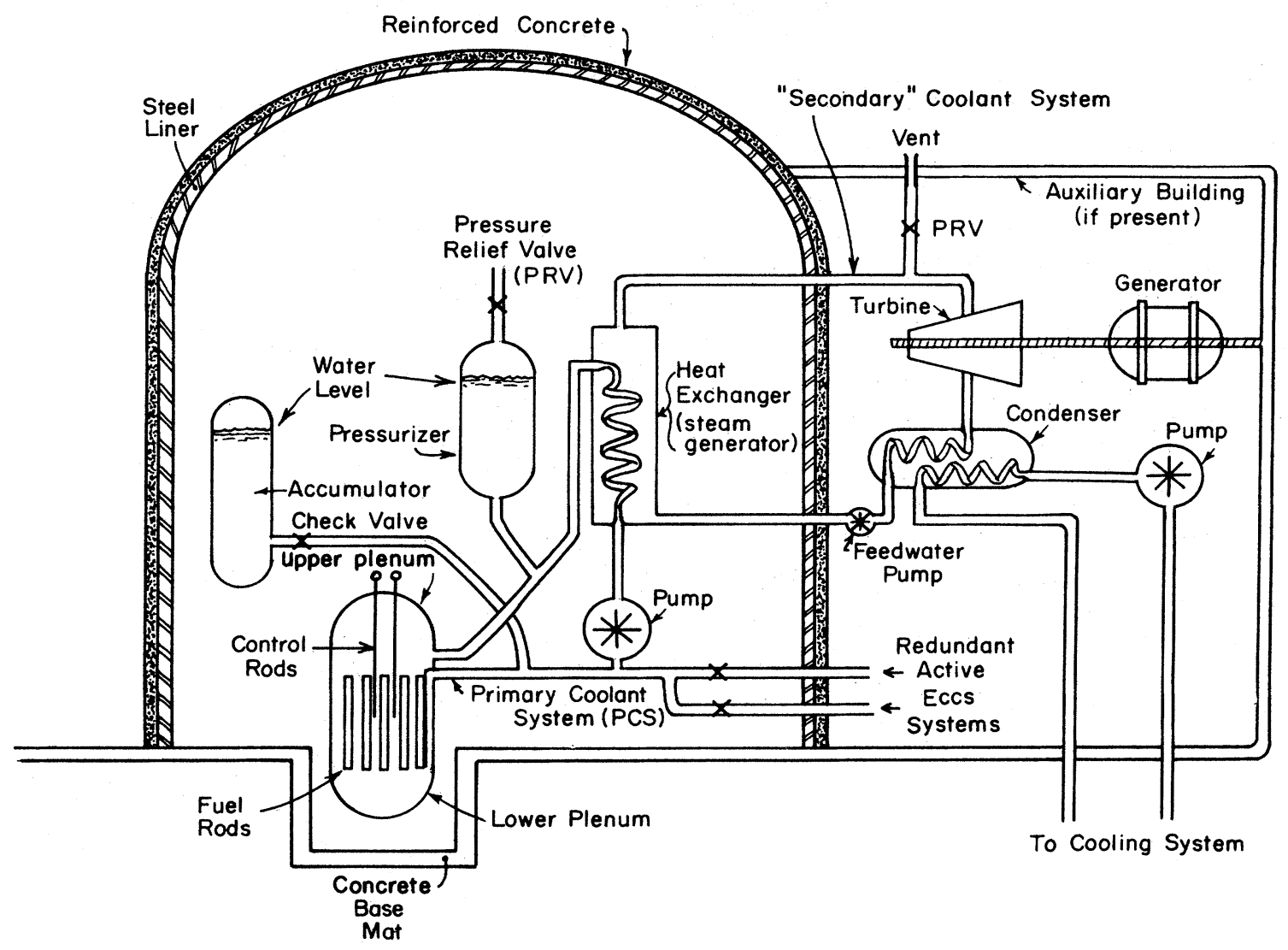

FIG. III.A.4. Schematic of a typical (large dry) PWR.

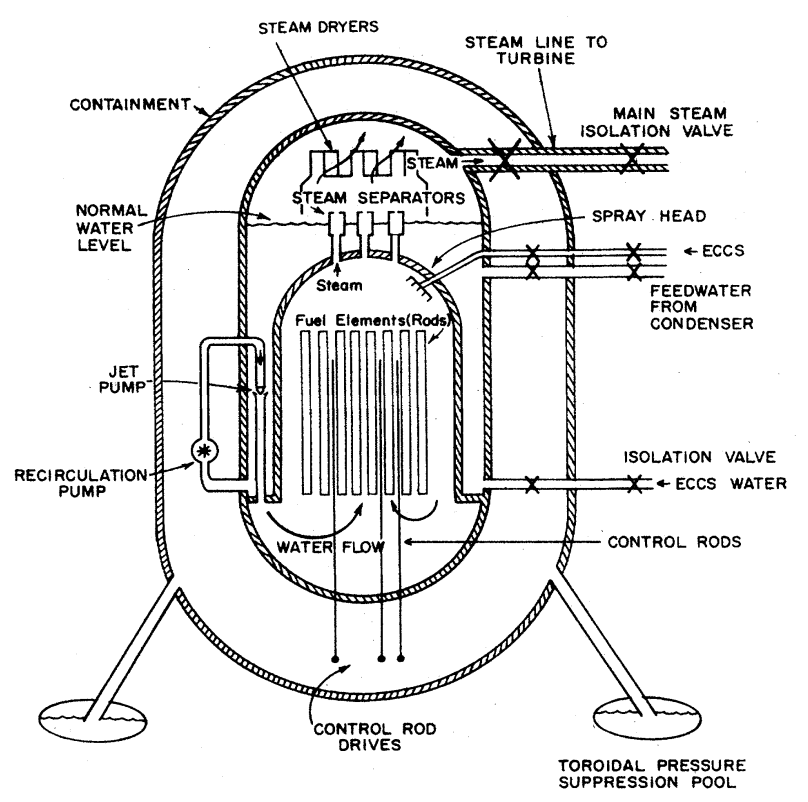

FIG. III.A.5: Schematic of a typical BWR.
In the primary side of a pressurized water reactor (PWR) the water is heated in the core, passed through a heat exchanger, and pumped back to the core at a pressure high enough to prevent the water from flashing to steam (15.7 MPa, or $2300 \mathrm{psia})$. The secondary side of this heat exchanger is a steam generator, which generates steam to drive the turbine. Its pressure is lower than that of the primary side (about 5.5 MPa or 800 psia). This is shown in the idealized schematic of Figure III.A.4, which portrays just one primary "loop"-steam generator, pump, emergency core cooling system (ECCS) accumulator. Most PWR's contain 3 or 4 separate steam generators and pumps, each on a separate "loop."

In the boiling water reactor (BWR), steam for operating the turbine is generated directly in the core, at a pressure of about $7 \mathrm{MPa}$ or $1000 \mathrm{psia}$, without utilizing the isolation provided by the heat exchanger (steam generator) associated with a PWR. This is shown in the idealized schematic of Figure III.A.5. The turbine itself, not shown here, is similar to that for the PWR. The steam passing through the turbine is condensed and returned as feedwater to the core. In addition, water is recirculated through the core by a number of jet pumps driven by a water recirculation pump. One of these pumps is shown in the schematic. 
TABLE III.A.2. Operational parameters for Surry (PWR) and Peach Bottom (BWR) light water reactors.

\begin{tabular}{|c|c|c|}
\hline Parameters & Surry & Peach Bottom 2 \\
\hline Thermal power rating $\left(\mathrm{MW}_{t}\right)$ & 2441 & 3293 \\
\hline Electrical output $\left(\mathrm{MW}_{e}\right)$ & 823 & 1065 \\
\hline \multicolumn{3}{|l|}{ Thermal hydraulic data } \\
\hline System pressure $(\mathrm{MPa})$ & 15.8 & 7.0 \\
\hline Inlet temperature $(\mathrm{K})$ & 557 & 464 \\
\hline Outlet temperature & 592 & 559 \\
\hline Coolant flow rate $\left(10^{6} \mathrm{~kg} / \mathrm{h}\right)$ & 45.7 & 46.5 \\
\hline \multicolumn{3}{|l|}{ Core data } \\
\hline Active height $(\mathrm{cm})$ & 366 & 381 \\
\hline Equivalent active diameter $(\mathrm{cm})$ & 304 & 475 \\
\hline Core weight (kg) & 102820 & 232012 \\
\hline $\mathrm{UO}_{2}(\mathrm{~kg})$ & 79820 & 159410 \\
\hline Zircalloy (kg) & 16500 & 65490 \\
\hline Misl. (kg) & 6500 & 7112 \\
\hline Flow area $\left(\mathrm{m}^{2}\right)$ & 4.05 & 13.4 \\
\hline Assemblies/core & 157 & 764 \\
\hline Rods/assembly & $204^{\mathrm{a}}$ & $62^{\mathrm{b}}$ \\
\hline Annual discharge & $1 / 3$ & $1 / 3$ \\
\hline Avg. burnup at equil. ( $\left.\mathrm{MW}_{d} / \mathrm{MTU}\right)$ & 22100 & 20000 \\
\hline \multicolumn{3}{|l|}{ Fuel element data } \\
\hline Pitch $(\mathrm{cm})$ & 1.43 & 1.63 \\
\hline O. D. $(\mathrm{cm})$ & 1.072 & 1.23 \\
\hline Clad thickness $(\mathrm{cm})$ & 0.0617 & 0.0813 \\
\hline Diametral gap (cm) & 0.019 & 0.0229 \\
\hline Number of rods & $32028^{\mathrm{a}}$ & $47368^{b}$ \\
\hline Initial fuel enrichment & 3.6 & 2.99 \\
\hline \multicolumn{3}{|l|}{ Heat transfer at rated power } \\
\hline Active surface area $\left(\mathrm{m}^{2}\right)$ & 3945 & 6140 \\
\hline Average heat flux $\left(\mathrm{W} / \mathrm{m}^{2}\right)$ & 602695 & 514791 \\
\hline Max. heat flux $\left(\mathrm{W} / \mathrm{m}^{2}\right)$ & 1684402 & 1349784 \\
\hline
\end{tabular}

The characteristics of a typical PWR and a typical BWR are shown in Table III.A.2.

\section{III.A.4.C. Barriers against radionuclide release}

Protection of the public from radionuclide release in nuclear reactor accidents is provided by a series of barriers:

(i) the radionuclides reside mostly in the solid fuel matrix;

(ii) the zircalloy tube (fuel clad) surrounding the fuel is normally leak tight;

(iii) the reactor pressure vessel and primary water circuit constitute a further barrier against release;

(iv) a containment building surrounds the primary system to contain radionuclides (see Section IV.D for details); these might be released should all three of the preceding barriers fail.

In all accidents that have occurred in commercial nuclear power reactors, one or more of these barriers has remained sufficiently intact to contain most of the radionuclides.

However, severe accidents have been postulated where these barriers could be broken simultaneously by melting. of the fuel and a buildup of internal pressure. If the moderator water is lost by evaporation, and is not replaced, then the meltdown will follow; the resulting pressure in the containment will rise and might crack the containment, resulting in a large release of radionuclides.

\section{III.A.4.d. The emergency core cooling system}

A break in the reactor pressure vessel or primary coolant circuit piping would cause a loss of water or steam. To keep the reactor cooled, and the fuel and fuel cladding barriers intact, an emergency core cooling system (ECCS) is incorporated to replace the water as soon as possible. These systems are shown schematically in Figure III.A.6 (for a PWR) and Figure III.A.7 (for a BWR).

The emergency core cooling system has several subsys- 
TABLE III.A.2. (Continued).

\begin{tabular}{|c|c|c|}
\hline Parameters & Surry & Peach Bottom 2 \\
\hline \multicolumn{3}{|l|}{ Reactor vessel data } \\
\hline I.D. of shell $(\mathrm{cm})$ & 399 & 638 \\
\hline Overall height $(\mathrm{cm})$ & 1232 & 2210 \\
\hline \multicolumn{3}{|l|}{ Primary coolant system } \\
\hline Total water mass $(\mathrm{kg})$ & 192000 & 290620 \\
\hline Reactor vessel volume $\left(\mathrm{m}^{3}\right)$ & 105.3 & 585.2 \\
\hline subcooled liquid & & 222.2 \\
\hline sat. liquid & & 113.4 \\
\hline steam & & 249.6 \\
\hline Piping (including pumps) $\left(\mathrm{m}^{3}\right)$ & 40.6 & 146.4 \\
\hline Steam generator & 91.5 & \\
\hline Pressurizer (60\% liquid) & 36.8 & \\
\hline Accumulators $(67 \%$ liquid $)$ & 123.2 & \\
\hline \multicolumn{3}{|l|}{ Containment } \\
\hline Free volume $\left(\mathrm{m}^{3}\right)$ & $5.1 \times 10^{4}$ & $7.9 \times 10^{3}$ \\
\hline Drywell $\left(\mathrm{m}^{3}\right)$ & & $4.5 \times 10^{3}$ \\
\hline Wetwell $\left(\mathrm{m}^{3}\right)$ & & $3.4 \times 10^{3}$ \\
\hline Initial temperature $(\mathbf{K})$ & 311 & 311 \\
\hline Initial pressure $(\mathrm{MPa})$ & 0.0689 & 0.101 \\
\hline \multicolumn{3}{|l|}{ Pressure suppression chamber } \\
\hline Free volume $\left(\mathrm{m}^{3}\right)$ & & 3370 \\
\hline Water volume $\left(\mathrm{m}^{3}\right)$ & & 3851 \\
\hline
\end{tabular}

aPWR's now use the $17 \times 17$ fuel lattice shown in Figure III.A.2. However, these calculations were done with an older $15 \times 15$ fuel lattice.

${ }^{b}$ BWR's have used an $8 \times 8$ fuel lattice since 1975 , as shown in Figure III.A.3. However, in Gieseke et al. (1984, Vol. 2), the analyses for Peach Bottom used a mixed core of $8 \times 8$ and $7 \times 7$ lattice having $[62,63]$ and 49 fuel rods per assembly, respectively. This was motivated by the availability of oRIGEN runs for these assemblies. The total number of fuel elements in Gieseke et al. was 44749 .

tems that operate at different times and different pressures. However, it is possible to group these subsystems for subsequent discussion into a passive subsystem and an active subsystem.

Each PWR has several pressurized accumulator tanks filled with water (borated to absorb neutrons) at about 4.8 $\mathrm{MPa}$, or $680 \mathrm{psia}$, pressure. As soon as the reactor pressure falls below 4.8 $\mathrm{MPa}$, a check valve opens and the core is reflooded. This is a passive subsystem.

Both PWR's and BWR's have a number of active ECCS subsystems. These emergency coolant injection systems are driven by pumps, some of which operate at high pressure (and low throughput) and some at low pressure (and high throughput) to maintain water in the core. These are active systems. For their operation the control circuits must operate. In some reactor designs these pumps depend on electric power, while in other designs some of these pumps are driven by steam from the primary circuit. Considerable redundancy is employed to ensure that the likelihood of operation of the ECCS, when called upon, is high.

If the emergency core coolant systems operate properly, the accident will normally be terminated without fuel damage or breach of any of the barriers between the radioactivity and the public. The (hypothetical) severe nuclear accidents with which this report is concerned are those in which elements of the emergency core coolant system are assumed either not to operate or to fail because of other failures that affect them. It should be emphasized that such an accident has never occurred, and is considered very improbable. At TMI, the ECCS was turned on and off manually by the operators on several crucial occasions. Had the systems been left to operate in their normal automatic mode it is unlikely that the fuel would have been degraded.

\section{III.A.5. Sources and sinks of heat}

The driving forces behind fission product releases are derived from the heat generated in the reactor. It is therefore important to understand the sources and sinks (reservoirs for absorption) of heat that may be applicable to a given situation. These are briefly summarized here.

\section{III.A.5.a. Sources}

(i) If the reactor protection system (control rods, borated water) has failed to scram, fission chain reaction heating will continue until criticality is ultimately stopped by 


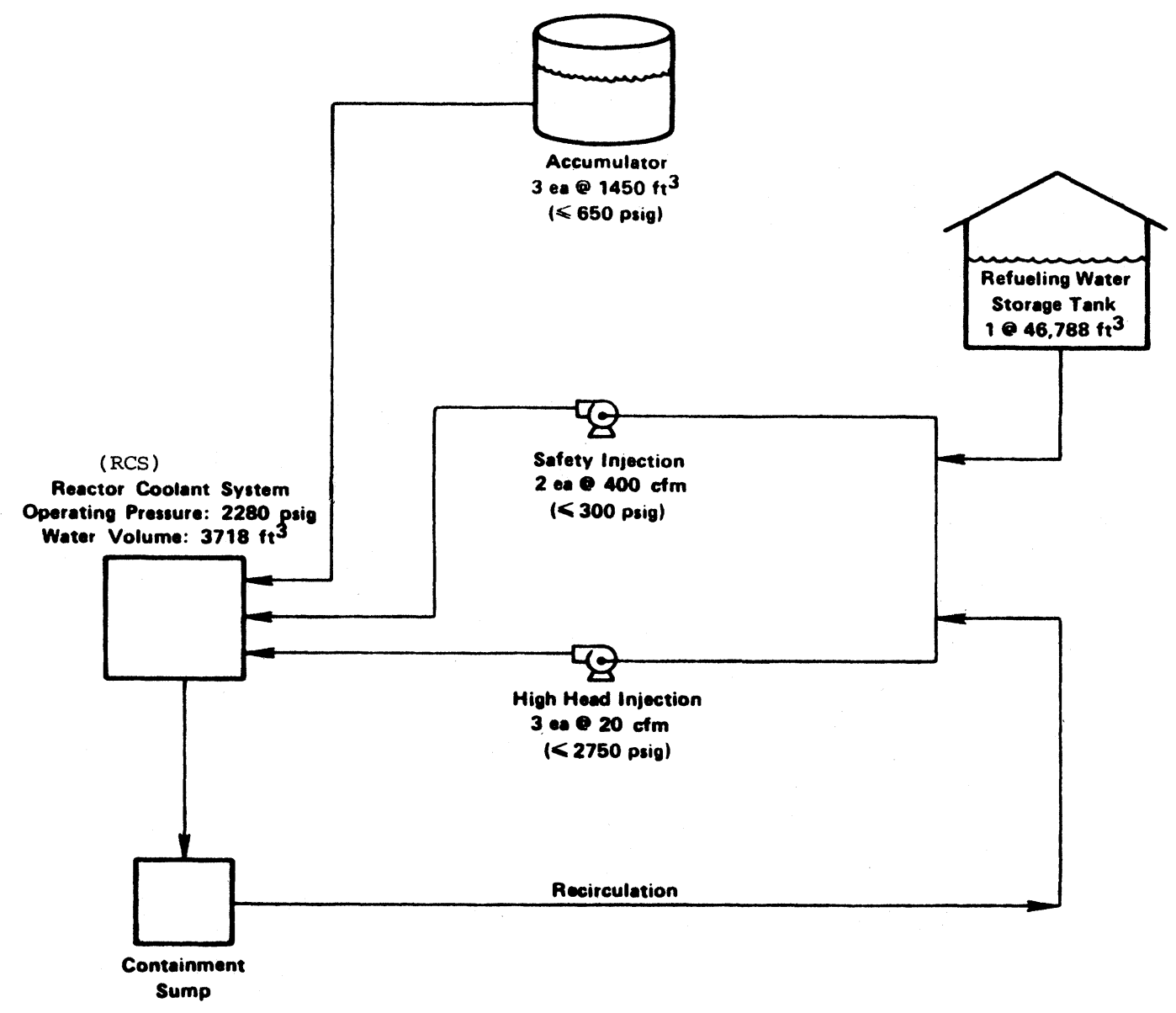

FIG. III.A.6. PWR emergency core cooling system parameters (Surry).

the use of redundant control systems or loss of the water moderator.

(ii) Under normal operating conditions, the fuel pins run at a higher average temperature than the coolant (i.e, the center of the fuel pin operates at temperatures near its melting point, while the outer surface is close to the coolant temperature). Consequently there is sensible heat stored in the fuel pins which is released after the fission process ceases.

(iii) The radioactive fission products continue to produce decay heat long after the fission reaction ceases (see Section III.A.3).

(iv) As the temperature rises above $1300 \mathrm{~K}$ the zirconium fuel cladding begins to interact with water or steam, oxidizing in a strongly exothermic reaction:

$$
\mathrm{Zr}+2 \mathrm{H}_{2} \mathrm{O} \rightarrow \mathrm{ZrO}_{2}+2 \mathrm{H}_{2}
$$

with an energy release $\Delta H$ (Lemmon, 1957)

$$
\Delta H=6.774 \times 10^{6}-244.9 T,
$$

where $\Delta H$ is expressed in joules per kilogram of $\mathrm{Zr}$ reacted and $T$ is in degrees Kelvin.
The rate of heat generated from the metal-water reaction equals the heat of reaction multiplied by the rate of reaction, the latter given, if sufficient steam is available, by a solid state diffusion law,

$$
\dot{X}=A e^{(-B / T)} / X_{0},
$$

where $\dot{X}$ is the metal reaction rate, $A$ and $B$ are kinetic constants and $X_{0}$ is the thickness of the oxide layer on the outside surface of the cladding.

Iron also oxidizes exothermically in a steam environment by the reaction:

$$
3 \mathrm{Fe}+4 \mathrm{H}_{2} \mathrm{O}=\mathrm{Fe}_{3} \mathrm{O}_{4}+4 \mathrm{H}_{2}
$$

with an energy release of $1.063 \times 10^{6} \mathrm{~J}$ per kilogram of iron (ANL, 1966).

(v) As the temperature rises further, other reactor vessel internals, fuel supports or even the vessel itself can oxidize exothermically. However these reactions are not as important as the zirconium reaction discussed in (iv). above.

(vi) At very high temperatures, and when very finely divided, the uranium dioxide $\left(\mathrm{UO}_{2}\right)$ can oxidize further to 


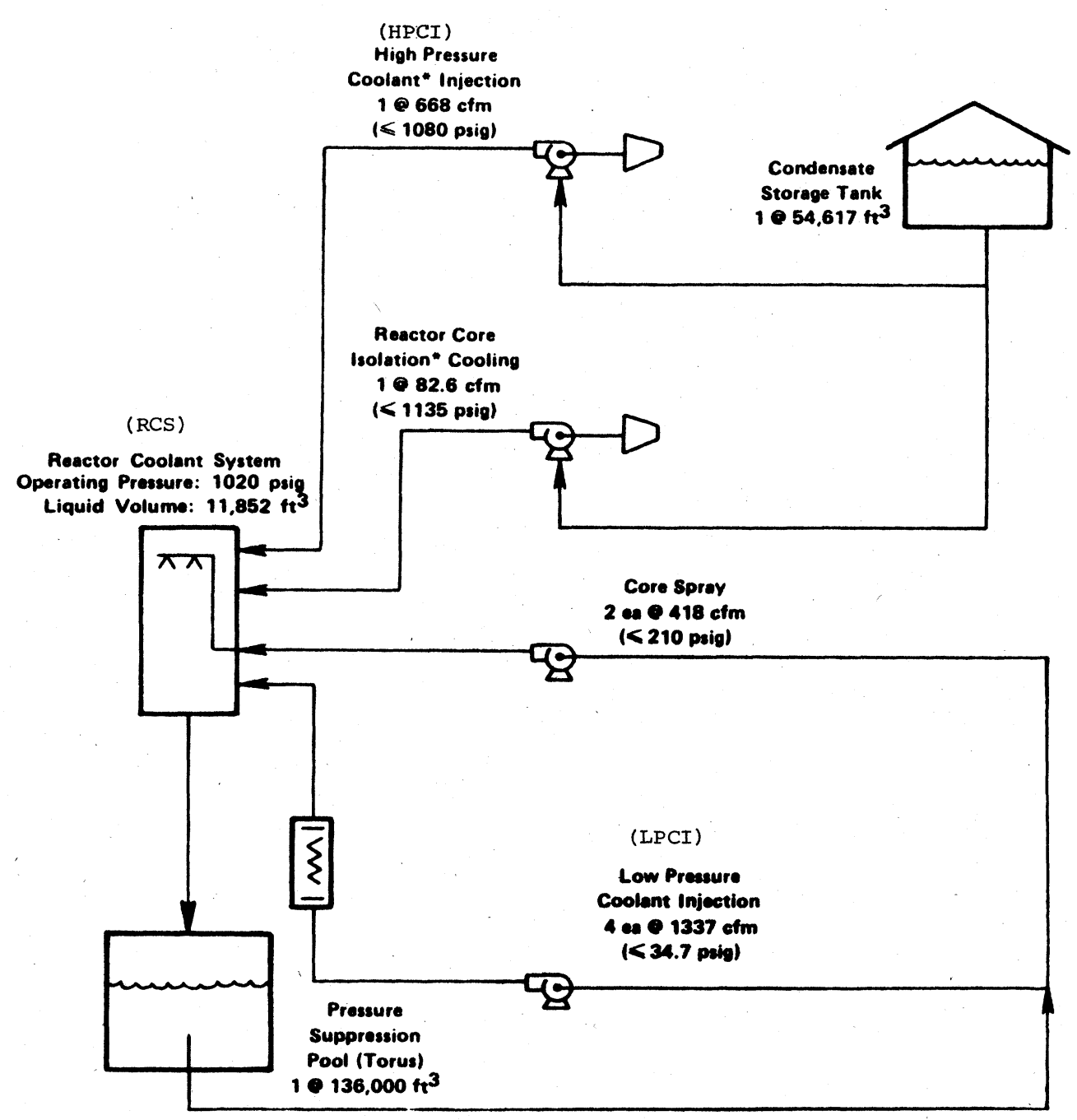

- Pumps are turbine-driven by steam generated by decay heat.

FIG. III.A.7. BWR emergency core cooling system parameters (Peach Bottom).

$\mathrm{U}_{3} \mathrm{O}_{8}$ exothermically if exposed to air. This reaction is considered unlikely in most accident sequences thought to be important.

\section{III.A.5.b. Sinks}

(i) The secondary water flowing through the steam generator, before isolation of the secondary system, can remove heat for times varying from 30 seconds to many hours.

(ii) Flow of water and steam in the primary system can remove heat from the fuel rods and distribute it within the primary system, during a time period depending upon the accident sequence.

(iii) After loss of water, energy can radiate from rod to rod and to the reactor vessel, resulting in heat exchange between the fuel rods and the vessel-but the view factor from the inner rods to the reactor vessel is sufficiently small that their temperatures are not strongly affected by this process.

(iv) When steam or the molten core is released to the containment, heat is transferred to the containment atmosphere, and thereafter slowly to surfaces of equipment in the containment or containment walls. 
(v) Finally, the whole external world outside the containment is an enormous potential heat sink.

\section{III.A.5.c. Rate of heat transfer}

The amount of heat in a source and the capacity to store heat in a sink are well determined. However it is often the rate of heat transfer from one to the other that determines the course of accidents, and this is less well determined.

The fission product decay heat rate (or power) is very well determined, as shown in Figure III.A.1. The rate of the other major source of heat-the zirconium oxidation-is dependent on many factors. Figure III.A.8 shows the parabolic rate constant of this oxidation rate, for various correlations, as a function of temperature. The Urbanic-Heidrick (1978) correlation is currently used in Gieseke et al. (1984) source term computations. The discontinuity at $1850 \mathrm{~K}$ is due to phase change in the oxide layer at that temperature. The Urbanic-Heidrick correlation exhibits better agreement with the experimental data (not shown in the figure) than the other correlations. The high temperature data $(>1850 \mathrm{~K})$ of various experiments generally show scatter on the order of a factor of two.

In a core heatup transient, it is generally found that, for temperatures above $1470 \mathrm{~K}$, the zirconium-water reaction

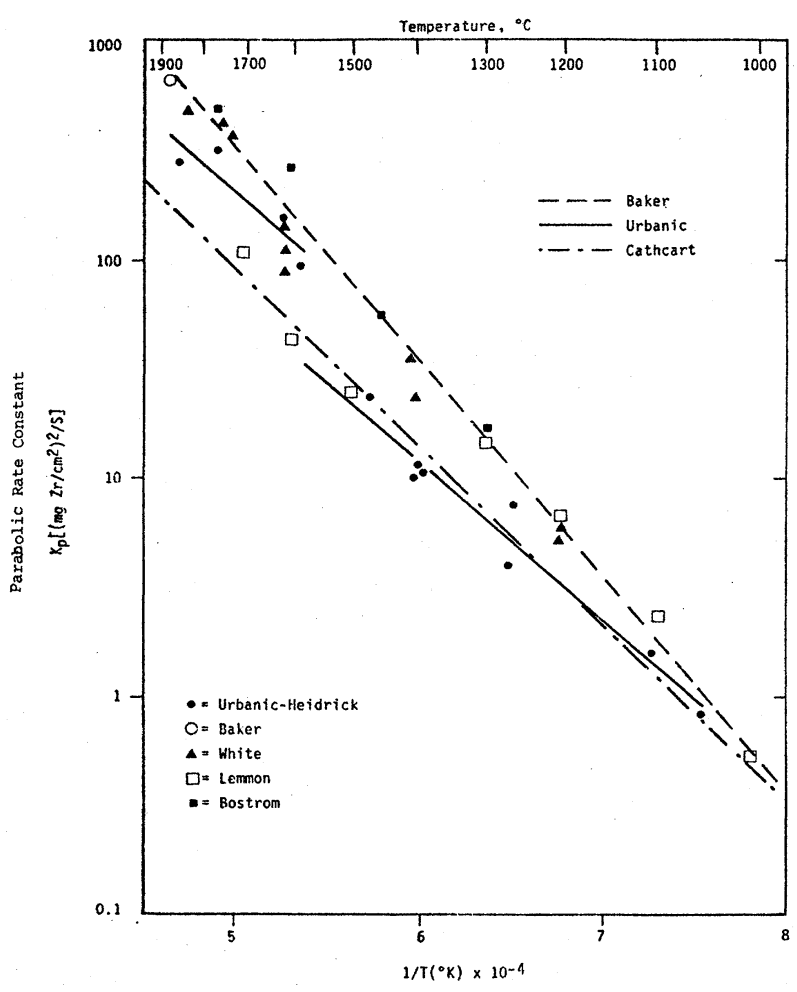

FIG. III.A.8. Reaction rate of zirconium/zircalloy in steam; experimental data and predictions of various solid-state rate law correlations. can be steam-limited and Figure III.A.8 cannot be used. Instead, from the stoichiometry of the reaction, a steamsupply limited rate is used,

$$
\dot{X}=91.22 W_{s} /(36 \rho A) \mathrm{cm} / \mathrm{s},
$$

where $W_{s}=$ steam flow rate, $\mathrm{gm} / \mathrm{s} ; \rho=$ zirconium density, $\mathrm{gm} / \mathrm{cm}^{3}$; and $A=$ cladding surface area, $\mathrm{cm}^{2}$.

MARCH calculations of core meltdown show little sensitivity to the choice of the correlations in Figure III.A.8. However, the calculations are more sensitive to core meltdown models that affect the steam flow rate and hence the cladding oxidation. The uncertainty in the fraction of cladding reacted owing to the steam flow rate is estimated, based on MARCH calculations, to be on the order of a factor of two.

For some accident analyses (as in the ECCS), overestimation of the reaction rate is considered conservative (pessimistic). However, as shown later in Table IV.B.2, a slower rate leaves some zirconium unreacted at the time of reactor vessel meltthrough, and this can be nonconservative.

The fission product decay heat, although produced at a slow steady rate, is stored in the fuel in the reactor pressure vessel, together with that part of the zirconium water reaction that occurs therein. This stored heat is released into the containment atmosphere suddenly if and when the reactor pressure vessel melts through. Although ultimately this heat is expected to be transferred to the numerous surfaces in the containment vessel, the heat may be transferred to the containment gas more rapidly than it can be transferred to the solid surfaces. This is important, for it may lead to a sudden pressure rise that becomes a major stress on the containment.

\section{III.A.6. General features of severe nuclear reactor accidents}

The severe accident sequences that may result in large source terms must proceed not only through core melt, but also through containment failure. Although there are many accident scenarios that could lead to core melt, and many causes of containment failure, all basic accident processes are associated with sequences of events similar to those shown in Figure III.A.9 and Table III.A.3.

As noted above, the accidents that are expected to lead to the possibility of an appreciable source term (i.e., those in which a substantial amount and wide variety of types of radioactive material are released to the environment) are all postulated to involve a system failure that results in loss of water from the primary system. An initiating event is assumed to have occurred that may have been induced by either equipment failure, and/or operator error, or external event (earthquake, fire, etc.).

If a break in the Reactor Coolant System (RCS) has been assumed to occur as a result of a pipe or valve opening, the high pressure in the reactor pressure vessel (RPV) will drive water and steam out of the break. The sudden depressurization is called a blowdown. The accident is a 


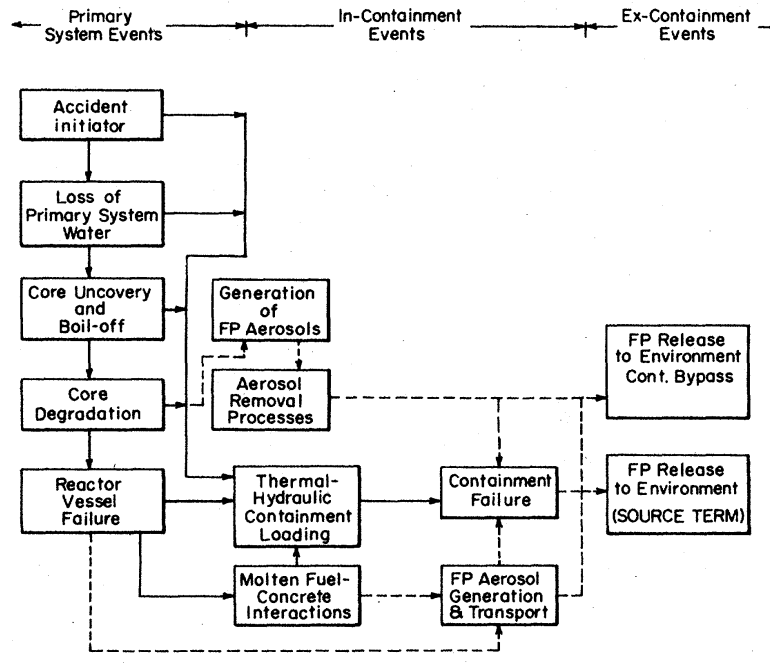

FIG. III.A.9. Core-melt accident sequence. Thermal-hydraulic processes are indicated by solid lines, fission-product-aerosol processes by dotted lines.
Loss of Coolant Accident, or LOCA. Alternatively, a transient in the power level may initiate a turbine trip with an interruption in the heat removal. If heat is not removed by another heat sink, the core temperature will rise, eventually raising the internal pressure beyond the pressure relief valve (PRV) setting so that coolant may be lost out the valve. In most such instances, the emergency core cooling system (ECCS) will replace the losses of coolant. However, in the hypothetical case that the emergency systems are inoperable, fail to operate, or are disabled, the core would eventually become uncovered. This phase of the accident is called boiloff.

Although the nuclear chain reaction will have stopped, either by the reactor protection (SCRAM) system of control rod or boron poison insertion, or by removal of the water moderator when there is no more water to cover the core, there will be enough fission product decay heat to heat up and ultimately to melt the core.

In the heatup phase, the core will be heated well above the boiling point of water until it approaches tempera-

TABLE III.A.3. Core-melt accident phases.

\begin{tabular}{|c|c|}
\hline Accident phase & Remarks \\
\hline \multicolumn{2}{|l|}{ In Vessel } \\
\hline Blow-down & $\begin{array}{l}\text { Loss of coolant through break or relief valve. May be rapid or slow. } \\
\text { May occur at high pressure or with loss of pressure. }\end{array}$ \\
\hline Boil-off & $\begin{array}{l}\text { Liquid level gradually drops as decay heat vaporizes water and loss of } \\
\text { coolant occurs through break or relief valve. }\end{array}$ \\
\hline Heat-up & $\begin{array}{l}\text { Core becomes uncovered. Zircalloy steam reaction produces hydrogen } \\
\text { and heat. Cladding fails, releasing volatile fission products which mi- } \\
\text { grate and deposit in primary system circuit and/or escape to the con- } \\
\text { tainment with steam. }\end{array}$ \\
\hline Core melt/slump & $\begin{array}{l}\text { Bulk of core is uncovered; core melt drips/fragments and begins to } \\
\text { fall into water pool in vessel bottom. Fission product migration } \\
\text { through primary, and to containment can be significant for more vola- } \\
\text { tile fission products. Small scale steam explosions in vessel are prob- } \\
\text { able, and large ones unlikely but possible. }\end{array}$ \\
\hline Melt-through & $\begin{array}{l}\text { Pressure vessel fails as molten core melts through the bottom head } \\
\text { and drops into reactor cavity. }\end{array}$ \\
\hline \multicolumn{2}{|l|}{ Ex Vessel } \\
\hline Core quench & $\begin{array}{l}\text { The molten debris falls to the reactor cavity. It boils off whatever } \\
\text { water is there. If sufficient water is present, the core would be } \\
\text { cooled and solidify, and would subsequently remelt. }\end{array}$ \\
\hline Core dispersion & $\begin{array}{l}\text { Steam explosions may also occur at this time as the molten fuel falls } \\
\text { onto water in the reactor cavity. This can disperse fuel, create ra- } \\
\text { dioactive aerosols, and increase the rate of heat transfer to the con- } \\
\text { tainment atmosphere. }\end{array}$ \\
\hline Core-concrete interaction & $\begin{array}{l}\text { The molten corium attacks the concrete basemat, which it proceeds to } \\
\text { penetrate, and creates a cauldron that releases aerosols and gases. }\end{array}$ \\
\hline Containment fails & $\begin{array}{l}\text { Containment pressure rises and the containment fails, or the core } \\
\text { melts through the basemat. }\end{array}$ \\
\hline
\end{tabular}


tures at which melting of the cladding and fuel mixture occurs.

As the core heats to temperatures above $1300 \mathrm{~K}$, the steam will begin to react chemically with the zirconium cladding of the uncovered fuel elements, to produce a new source of heat. At temperatures of $1500 \mathrm{~K}$ and above the reactions could produce enough heat to be comparable with that of the decaying fission products, if sufficient steam were available for the reaction. In this zirconium oxidation process, hydrogen is liberated from the steam and would mix with the remaining steam that had not participated in the reaction. In addition, at elevated temperatures the $\mathrm{Zr}$ could combine with the $\mathrm{UO}_{2}$ fuel to form phases with a significantly lower melting point than that of $\mathrm{UO}_{2}$.

The hot water and steam leaked to the containment building during this period would increase the pressure and temperature in the building. In addition, the flow of high temperature gases and vapors within the reactor coolant system could lead to localized changes in the temperature and pressure throughout the entire system and (in particular) within the reactor pressure vessel (RPV).

At temperatures of the order of $1000 \mathrm{~K}$ and above (depending upon initial pressures built up by release of fission product gases within the fuel rods), the $\mathrm{Zr}$ cladding could begin to weaken, balloon, and rupture. Evidence of this effect is seen in Figure III.A.10 which shows photographs of damaged fuel rods used in the Power Burst Facility (PBF) experiments. Upon rupture of the cladding, a few percent of the most volatile fission products would be released. The noble gases $\mathrm{Xe}$ and $\mathrm{Kr}$, and the volatile materials Cs, I, and Te would diffuse out of the hot fuel and would be released as vapors. While the chemically inert xenon and krypton would exist as inert gases, the other elements would begin to undergo chemical interactions among themselves, and to form aerosols that could move throughout the system. The eventual melting of the fuel elements would complete the release of most of the volatile radioactive products.

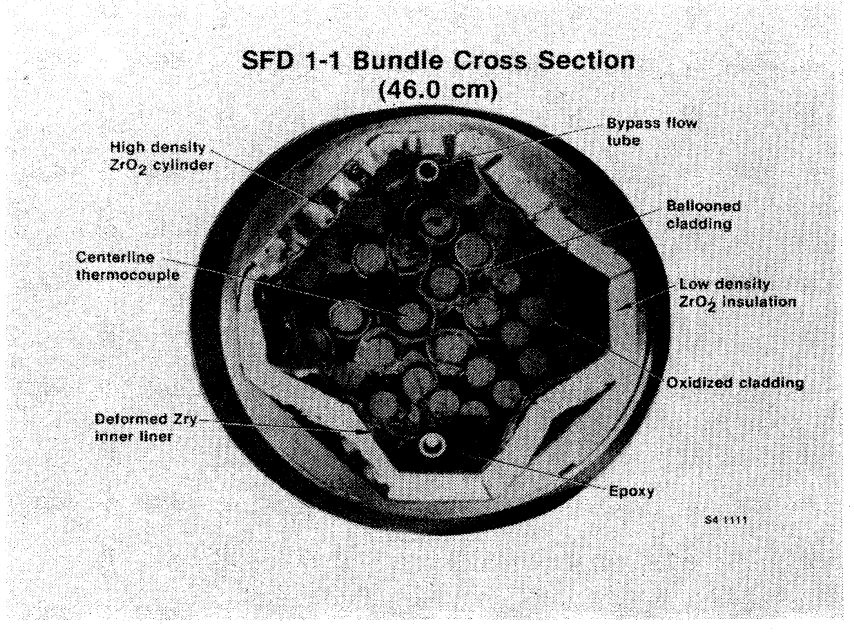

FIG. III.A.10. Photograph of a cross section at $46 \mathrm{~cm}$ of damaged fuel bundle in PBF Test-SFD 1-1. (Courtesy of EG\&G.)
If there were breaks in the reactor coolant system (RCS) boundary, some of the transported radioactive material would be immediately released as gas and aerosol into the reactor containment building, along with the steam, hydrogen, and reactor coolant. Whether in containment or inside the RCS, the aerosols, though rather stable, would tend to increase in size by agglomeration processes. As time passes, the larger aerosols would be slowly removed by settling, and transported to surfaces by diffusion, temperature differences, and other processes. The total suspended mass of aerosols at any time would depend upon their generation rate as well as their removal rate.

As the heatup continues, the fuel would continue to distort and melt. The melting fuel elements would eventually destroy the reactor's core support structure and would fall in molten form into the lower head of the reactor. The coolant passages between the fuel elements might become blocked by the melting material. As the hot material fell into any remaining water in the lower head, the steam generation process would be accelerated. The continued evolution of decay heat from the molten core would evaporate the remaining water in the RPV, and the combined molten fuel and structural materials would then attack the lower head of the RPV.

This point represents a logical division in the progression of the accident. When the core is calculated to melt through the bottom of the pressure vessel, the molten material (including part of the support structure and pressure vessel) and all the remaining radioactive materials would then be deposited in the containment volume. Whether this would occur slowly or rapidly as materials are injected into the containment in a jet would depend on the previous history of the core melt scenario and, in particular, on the pressure in the RPV at the time of failure.

The failure of the RPV would be followed by a substantial increase in the containment pressure as the internal energy of the steam and gases retained within the RCS is released to the containment along with the molten corium (a molten mixture of core fuel and vessel internal and core structural supports). This represents a crucial time in the accident progression. If this pressure rise were large enough to cause the containment to fail, the failure would occur at a time when many of the radioactive aerosols had just been generated and released to the containment, and before they had a chance to agglomerate and settle or be removed by other processes.

At this time steam explosions can occur as the molten core falls on the water in the reactor cavity.

If the containment were to remain intact at this time, the pressure would fall as steam condensed on various containment structures. If there were no water in the cavity below the reactor vessel, or after the water is vaporized, the molten core and vessel material would attack the concrete basemat, which would liberate copious amounts of $\mathrm{CO}_{2}$, steam, and the flammable gases $\mathrm{H}_{2}$ and $\mathrm{CO}$. These processes would all contribute to an increase in the containment pressure (whether or not the flammable gases burned or exploded) that might lead to its failure at the 
same time that the concrete would be going through rapid dissolution. As this occurred, aerosols would be sparged from the molten mass into the atmosphere of the containment volume. A small proportion of these aerosols would be radioactive. If the containment failed from these pressure sources, any newly generated and suspended aerosols would then be immediately dispersed into the environment.

If the containment were to survive the pressurization associated with the above processes, the remainder of the molten core would continue to erode the concrete floor, until it could ultimately penetrate the basemat and release radioactive material into the soil beneath the reactor. If this were to occur, it is probable that the molten core would quickly reach equilibrium with its surroundings as it penetrated the soil, and would not descend to any substantial depth into the ground. (Calculations suggest maximum depths of penetration of about $3 \mathrm{~m}$.)

There are additional engineered safety features (ESF) designed into the reactor system. These include spray systems to spray water into the containment building to condense steam and deposit aerosols. However, in any severe accident the electrical power is often assumed to be unavailable. In some reactors, the partial or complete removal of fission products may be accomplished without active intervention, by the action of passive suppression pools through which the steam, vapors, and aerosols must flow in boiling water reactors (BWR), and by ice condensing systems in some pressurized water reactors (PWR's). On the other hand, if a sufficient time passes before containment failure, electrical power may be restored and active intervention by fans and spray systems in the containment volume for PWR's or BWR's could then also reduce the fission product aerosol densities. As long as these active or passive safety systems function in accordance with their designs, they would also serve to reduce containment temperature and pressure loadings, in addition to accelerating fission product removal processes. These fans and spray systems are so effective that, if operative, they would usually prevent containment failure. Thus, in the evaluation of risk dominant accident scenarios, the sequences of principal concern are those in which the engineered safety features are assumed to fail or to be inoperative.

\section{III.B. Sequence selection}

It is always difficult to foresee the future. It is, however, easy to postulate the occurrence of catastrophic accidents associated with natural and man-induced events. The scientific community has been trying to estimate the probability and consequences of postulated severe accidents in nuclear power plants on the basis of historical experience with lesser accidents in similar plants. The procedures for making such risk projections have been developed over the last 35 years (beginning with efforts conducted in the aerospace industry) and have gained increasing credibility within the scientific community with the passage of time. During the last decade, risk analysis techniques have been applied within the nuclear industry. In the course of such applications, the state-of-the-art of risk analysis has been advanced and the concepts have gained increasing acceptance. This study group has not addressed probabilistic risk analyses directly. Nevertheless, the probability of severe accident scenarios has been utilized as an important criterion in selecting them for review, as discussed in more detail below.

\section{III.B.1. The risk analysis procedures} of the RSS

The inaccuracies of the probability estimation of the RSS (NRC, 1975), discussed earlier in Section II.A, have not been a focus for this report, although we note that subsequent probabilistic risk analyses have improved upon that study. However we note that the procedure of attempting to project all of the logically consistent scenarios by which accidents might occur is generally accepted, even though it is still subject to the inherent limitations on completeness cited by the Lewis Committee (1978) (see II.A above). Nevertheless, we have considered the results of probabilistic risk analyses in our reviews of accident scenarios in order to ascertain potentially risk dominant scenarios and to evaluate the relative likelihood of certain categories of events. Beyond that application, accident scenario probabilities have not played a particularly significant role in our deliberations; hence we have not attempted to verify their reliability.

The statistical reliability of the RSS depends in part upon the observation that the gross course of an accident may be represented by a series of dichotomous events [e.g., does the emergency core cooling system (ECCS) function or not when called upon? Does a valve close or not?]. Under these circumstances, the accident sequences or scenarios involve a number of steps that are usually independent-or can be designed to be nearly independent. Consider an example of an accident scenario with four such steps. If the projected frequency of the first step in the accident occurring is $F_{1}$, and the probability of failure of successive safety devices 2,3 , and 4 are, respectively, $P_{2}, P_{3}$, and $P_{4}$ per call, the overall frequency of an adverse consequence $F=F_{1} \times P_{2} \times P_{3} \times P_{4}$. The frequency $F_{1}$ of the initiating event can be determined with reasonable accuracy if it is of the order of $1 / 100$ years or greater. Similarly, the probabilities of failure of safety devices can be measured with reasonable reliabililty if they are of the order of one percent or greater. Thus if we can believe in the independence of events with as many as three safety system failures with probabilities of these magnitudes, it appears that we might discuss frequencies as small as $10^{-8}$ per year with some degree of confidence. Often the results are expressed as probability per year instead of frequency.

This method, as simply applied, depends upon the independence of the steps $1,2,3,4$ and their dichotomous nature. Much calculational and engineering design effort is expended in an endeavor to ensure this independence. 
However, in the actual performance of probabilistic risk analyses, analysts can, and do, evaluate cases in which dependent relationships exist among individual steps. Though the evaluation of interstep dependencies may be difficult, independence is not a prerequisite for such probabilistic analyses.

The risk to the public is a combination of the frequency of the occurrence of adverse events (e.g., as calculated in the RSS) and the magnitude of the consequences of the event. The magnitude of the consequences in turn, depends upon the amount of radionuclides released (the "source term" studied here), the transport to the public, and the specific biological hazard induced by the radioactive exposures to the population. RSS was the first study to make a significant attempt to use realistic scenarios to define the probability and consequences of the accidents investigated. However, because of uncertainties in physical models of the processes involved in the scenarios, it was often necessary for the RSS analysts to use conservative parameters in their accident evaluations; hence the realism of the RSS results has been questioned by some members of the scientific community.

\section{III.B.2. Risk significance of RSS accident sequences}

The results of the investigations of source terms and accident sequences by the Reactor Safety Study are presented in Tables III.B.1, 2, and 3 (NRC, 1975, Main Report, pp. 78-82). Table. III.B.1 presents the RSS source terms in the columns labeled "Fraction of core inventory released" as a function of the PWR and BWR release categories listed in the first column. In Table III.B.2, the nine representative PWR release categories are related to the principal accident sequences associated with them. Each of the alphabetized sequences represents a particular accident scenario whose composite elements are described in the backup key to the accident sequence symbols on the following page. The greek symbols at the end of the alphabetical sequences indicate containment failure mechanisms associated with the sequences. For example, TMLB $^{\prime}-\delta$ symbolizes an accident initiated by a transient event $(T)$ for which there is a failure of the secondary system relief valve and the power conversion system (M), plus failure of the auxiliary feedwater system (L), and failure to recover electric power within one to three hours of the initiating event $\left(\mathbf{B}^{\prime}\right)$, and with containment failure stemming from overpressure $(\delta)$. The principal BWR sequences are defined in Table III.B.3 and the key to their alphabetical descriptions presented following that table.

Estimates of the probabilities that individual sequences will occur during any given reactor-year are presented below each of the contributing sequences in Tables III.B.2 and III.B.3. The probabilistic results are summed for the major types of initiating events considered in the sequences: large and small loss-of-coolant-accidents (LOCA's); reactor vessel ruptures; interfacing system LOCA's; and transient events. Overall summations of RSS estimates of accident sequence probabilities for the various release categories are presented at the bottom of Tables III.B.2 and III.B.3.

From a scan of the accident sequences and associated release categories shown in Tables III.B.2 and III.B.3, it can be seen that a few sequences dominate the tabulated probabilities. The probabilities of contributing PWR sequences are dominated (for all release categories) by about eight sequences. The probabilities of the sequences in the PWR 2 release category are dominated by the $V$ $\left(4 \times 10^{-6}\right)$ and TMLB' $-\delta\left(2 \times 10^{-6}\right)$ sequences. These two sequences represent $75 \%$ of the total median probability for the PWR 2 release category. The PWR 3 release category is dominated by the single accident sequence, $\mathrm{S}_{2} \mathrm{C}-\delta\left(2 \times 10^{-6}\right)$. The probability of this single sequence represents one-half of the total probability of the PWR 3 release category $\left(4 \times 10^{-6}\right)$. In release category PWR 7, the probabilities are dominated by the $S_{1} D$-epsilon (or $\mathrm{S}_{1} \mathrm{H}$-epsilon) $\left(3 \times 10^{-6}\right.$ each) and the similar $\mathrm{S}_{2} \mathrm{D}$-epsilon (or $\mathrm{S}_{2} \mathrm{H}$-epsilon) $\left(\sim 1 \times 10^{-5}\right.$ each) sequences, as well as the transient sequences such as TML-epsilon $\left(6 \times 10^{-6}\right)$. Taken together, these five sequences from the PWR 7 release category represent about 80 percent of the total median probability of the release category $\left(4 \times 10^{-5}\right)$. Considering all eight of these sequences from the PWR 2, 3 , and 7 release categories, their collective probabilities represent two-thirds of the overall median probability of core melt accidents shown in Table III.B.2.

If we assume that the source terms shown in Table III.B. 1 are correct, it is clear that the fission product release fractions associated with the PWR 1, 2, and 3 categories far exceed the source terms of other PWR release categories. From Table III.B.2, it can be seen that the release categories PWR 1,2, and 3 are dominated by gross containment failure mechanisms such as bypass of the containment structure by an interfacing system LOCA (the V sequence), or through containment building ruptures resulting from steam explosions, or overpressurization from hydrogen burning, or simply failures because of excessive steam pressures. The $\mathrm{V}$ sequence for containment bypass represents the failures of the check valves between the low-pressure injection system (LPIS) of the emergency core cooling system and the primary side of the reactor coolant system. The LPIS is located outside of the containment structure, and connected to the primary system by a pipe running through the containment wall. If the check valves fail to function, the lowpressure injection system (designed for 600 psi pressures) may suddenly be subjected to the 2500 psi operating pressures of the primary system. Immediate failure of the LPIS piping outside the containment structure is assumed to occur if the check valves fail. Release Category PWR 7 , on the other hand, is associated exclusively with the containment basemat melthrough mechanism (the socalled "China-syndrome" scenario). It should be noted that the source terms associated with such failure mechanisms are very small compared with those of the PWR 1, 2 , and 3 categories with their above ground containment failure mechanisms. The source terms for basemat melt through failure mechanisms are small because the ground 


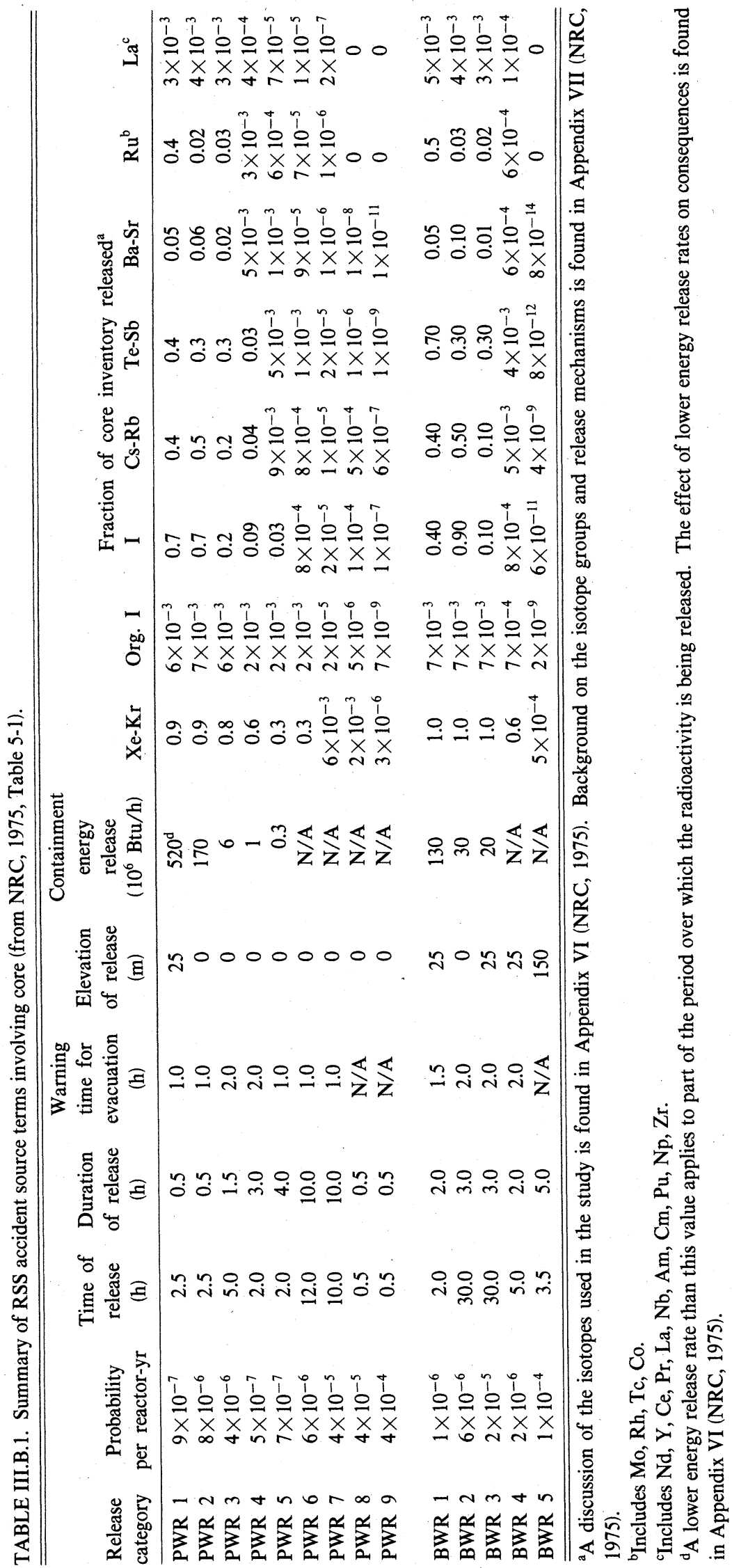


TABLE III.B.2. PWR dominant accident sequences vs release categories (from NRC, 1975). Note: The probabilities for each release category for each event tree and the $\sum$ for all accident sequences are the median values of the dominant accident sequences summed by Monto Carlo simulation plus a $10 \%$ contribution from the adjacent release category probability.

\begin{tabular}{|c|c|c|c|c|c|c|c|c|c|}
\hline & \multicolumn{9}{|c|}{ Release categories } \\
\hline & \multicolumn{7}{|c|}{ Core melt } & \multicolumn{2}{|c|}{ No core melt } \\
\hline & 1 & 2 & 3 & 4 & 5 & 6 & 7 & 8 & 9 \\
\hline \multirow[t]{4}{*}{ Large LOCA (A) } & $\begin{array}{l}\mathrm{AB}-\alpha \\
1 \times 10^{-11}\end{array}$ & $\begin{array}{l}\text { AB- } \gamma \\
1 \times 10^{-10}\end{array}$ & $\begin{array}{l}\text { AD- } \alpha \\
2 \times 10^{-8}\end{array}$ & $\begin{array}{l}\text { ACD- } \beta \\
1 \times 10^{11}\end{array}$ & $\begin{array}{l}\text { AD- } \beta \\
4 \times 10^{-9}\end{array}$ & $\begin{array}{l}\text { AB- } \varepsilon \\
1 \times 10^{-9}\end{array}$ & $\begin{array}{l}\text { AD- } \\
2 \times 10^{-6}\end{array}$ & $\begin{array}{c}\text { A- } \beta \\
2 \times 10^{-7}\end{array}$ & $\underset{1 \times 10^{-4}}{\text { A }}$ \\
\hline & $\begin{array}{l}\text { AF- } \alpha \\
1 \times 10^{-10}\end{array}$ & $\begin{array}{l}\text { AB- } \delta \\
4 \times 10^{-11}\end{array}$ & $\begin{array}{l}\text { AH- } \alpha \\
1 \times 10^{-8}\end{array}$ & & $\begin{array}{l}\text { AH- } \beta \\
3 \times 10^{-9}\end{array}$ & $\begin{array}{l}\text { AHF- } \varepsilon \\
1 \times 10^{-10}\end{array}$ & $\begin{array}{l}\text { AH- } \varepsilon \\
1 \times 10^{-6}\end{array}$ & & \\
\hline & $\begin{array}{l}\mathrm{ACD}-\alpha \\
5 \times 10^{-11}\end{array}$ & $\begin{array}{l}\text { AHF- } \gamma \\
2 \times 10^{-11}\end{array}$ & $\begin{array}{c}\text { AF- } \delta \\
1 \times 10^{-8}\end{array}$ & & & $\begin{array}{c}\text { ADF- } \varepsilon \\
2 \times 10^{-10}\end{array}$ & & & \\
\hline & $\begin{array}{l}\text { AG- } \alpha \\
9 \times 10^{-11}\end{array}$ & & $\begin{array}{c}\text { AG- } \delta \\
9 \times 10^{-9}\end{array}$ & & & & & & \\
\hline A probabilities & $2 \times 10^{-9}$ & $1 \times 10^{-8}$ & $1 \times 10^{-7}$ & $1 \times 10^{-8}$ & $4 \times 10^{-8}$ & $3 \times 10^{-7}$ & $3 \times 10^{-6}$ & $1 \times 10^{-5}$ & $1 \times 10^{-4}$ \\
\hline \multirow[t]{4}{*}{ Small LOCA $S_{1}$} & $\begin{array}{l}S_{1} B-\alpha \\
3 \times 10^{-11}\end{array}$ & $\begin{array}{l}\mathbf{S}_{1} \mathrm{~B}-\gamma \\
4 \times 10^{-10}\end{array}$ & $\begin{array}{l}\mathrm{S}_{1} \mathrm{D}-\alpha \\
3 \times 10^{-8}\end{array}$ & $\begin{array}{l}\mathrm{S}_{1} \mathrm{CD}-\beta \\
1 \times 10^{-11}\end{array}$ & $\begin{array}{l}\mathrm{S}_{1} \mathrm{H}-\beta \\
5 \times 10^{-9}\end{array}$ & $\begin{array}{l}S_{1} \mathrm{DF}-\varepsilon \\
3 \times 10^{-10}\end{array}$ & $\begin{array}{l}S_{1} D-\varepsilon \\
3 \times 10^{-6}\end{array}$ & $\begin{array}{l}S_{1}-\beta \\
6 \times 10^{-7}\end{array}$ & $\begin{array}{c}S_{1} \\
3 \times 10^{-4}\end{array}$ \\
\hline & $\begin{array}{l}\mathrm{S}_{1} \mathrm{CD}-\alpha \\
7 \times 10^{-11}\end{array}$ & $\begin{array}{l}\mathbf{S}_{1} \mathbf{B}-\delta \\
1 \times 10^{-8}\end{array}$ & $\begin{array}{l}S_{1} H-\alpha \\
3 \times 10^{-8}\end{array}$ & & $\begin{array}{l}S_{1} D-\beta \\
6 \times 10^{-9}\end{array}$ & $\begin{array}{l}S_{1} B-\varepsilon \\
2 \times 10^{-9}\end{array}$ & $\begin{array}{l}\mathbf{S}_{1} \mathbf{H}-\varepsilon \\
3 \times 10^{-6}\end{array}$ & & \\
\hline & $\begin{array}{l}S_{1} F-\alpha \\
3 \times 10^{-10}\end{array}$ & $\begin{array}{l}\mathrm{S}_{1} \mathrm{HF}-\gamma \\
6 \times 10^{-11}\end{array}$ & $\begin{array}{l}S_{1} F-\delta \\
8 \times 10^{-8}\end{array}$ & & & $\begin{array}{c}S_{1} H F-\varepsilon \\
4 \times 10^{-10}\end{array}$ & & & \\
\hline & $\begin{array}{l}\mathrm{S}_{1} \mathrm{G}-\alpha \\
3 \times 10^{-10}\end{array}$ & & $\begin{array}{l}S_{1} G-\delta \\
3 \times 10^{-8}\end{array}$ & & & & & & \\
\hline $\mathrm{S}_{1}$ probabilities & $3 \times 10^{-9}$ & $2 \times 10^{-8}$ & $2 \times 10^{-7}$ & $3 \times 10^{-8}$ & $8 \times 10^{-8}$ & $6 \times 10^{-7}$ & $6 \times 10^{-6}$ & $3 \times 10^{-5}$ & $3 \times 10^{-4}$ \\
\hline \multirow[t]{5}{*}{ Small LOCA $S_{2}$} & $\begin{array}{l}\mathrm{S}_{2} \mathrm{~B}-\alpha \\
1 \times 10^{-10}\end{array}$ & $\begin{array}{l}\mathbf{S}_{2} \mathbf{B}-\gamma \\
1 \times 10^{-9}\end{array}$ & $\begin{array}{l}S_{2} D-\alpha \\
9 \times 10^{-8}\end{array}$ & $\begin{array}{l}\mathrm{S}_{2} \mathrm{DG}-\beta \\
1 \times 10^{-12}\end{array}$ & $\begin{array}{l}S_{2} D-\beta \\
2 \times 10^{-8}\end{array}$ & $\begin{array}{l}\mathbf{S}_{2} \mathbf{B}-\varepsilon \\
8 \times 10^{-9}\end{array}$ & $\begin{array}{l}S_{2} D-\varepsilon \\
9 \times 10^{-6}\end{array}$ & & \\
\hline & $\begin{array}{c}\mathrm{S}_{2} \mathrm{~F}-\alpha \\
1 \times 10^{-9}\end{array}$ & $\begin{array}{l}\mathrm{S}_{2} \mathrm{HF}-\gamma \\
2 \times 10^{-10}\end{array}$ & $\begin{array}{c}\mathrm{S}_{2} \mathrm{H}-\alpha \\
6 \times 10^{-8}\end{array}$ & & $\begin{array}{c}\mathrm{S}_{2} \mathrm{H}-\beta \\
1 \times 10^{-8}\end{array}$ & $\begin{array}{c}S_{2} \text { CD- } \varepsilon \\
2 \times 10^{-8}\end{array}$ & $\begin{array}{c}\mathrm{S}_{2} \mathrm{H}-\varepsilon \\
6 \times 10^{-6}\end{array}$ & & \\
\hline & $\begin{array}{l}\mathrm{S}_{2} \mathrm{CD}-\alpha \\
2 \times 10^{-10}\end{array}$ & $\begin{array}{l}S_{2} B-\delta \\
4 \times 10^{-10}\end{array}$ & $\begin{array}{l}\mathbf{S}_{2} \mathbf{F}-\delta \\
1 \times 10^{-7}\end{array}$ & & & $\begin{array}{l}\mathrm{S}_{2} \mathrm{HF}-\varepsilon \\
1 \times 10^{-9}\end{array}$ & & & \\
\hline & $\begin{array}{l}S_{2} G-\alpha \\
9 \times 10^{-10}\end{array}$ & & $\begin{array}{l}\mathrm{S}_{2} \mathrm{C}-\delta \\
2 \times 10^{-6}\end{array}$ & & & & & & \\
\hline & $\begin{array}{l}\mathrm{S}_{2} \mathrm{C}-\alpha \\
2 \times 10^{-8}\end{array}$ & & $\begin{array}{l}S_{2} G-\delta \\
9 \times 10^{-8}\end{array}$ & & & & & & \\
\hline $\mathbf{S}_{2}$ probabilities & $1 \times 10^{-7}$ & $3 \times 10^{-7}$ & $3 \times 10^{-6}$ & $3 \times 10^{-7}$ & $3 \times 10^{-7}$ & $2 \times 10^{-6}$ & $2 \times 10^{-5}$ & & \\
\hline $\begin{array}{l}\text { Reactor vessel } \\
\text { rupture } \mathbf{R}\end{array}$ & $\begin{array}{c}\mathrm{RC}-\alpha \\
2 \times 10^{-12}\end{array}$ & $\begin{array}{l}\mathrm{RC}-\gamma \\
3 \times 10^{-11}\end{array}$ & $\begin{array}{l}\mathrm{R}-\alpha \\
1 \times 10^{-9}\end{array}$ & & & & $\begin{array}{l}\mathbf{R}-\varepsilon \\
1 \times 10^{-7}\end{array}$ & & \\
\hline & & $\begin{array}{c}\mathbf{R F}-\delta \\
1 \times 10^{-11}\end{array}$ & & & & & & & \\
\hline & & $\begin{array}{l}\mathrm{RC}-\delta \\
1 \times 10^{-12}\end{array}$ & & & & & & & \\
\hline $\mathrm{R}$ probabilities & $2 \times 10^{-11}$ & $1 \times 10^{-10}$ & $1 \times 10^{-9}$ & $2 \times 10^{-10}$ & $1 \times 10^{-9}$ & $1 \times 10^{-8}$ & $1 \times 10^{-7}$ & & \\
\hline
\end{tabular}


TABLE III.B.2. ( Continued).

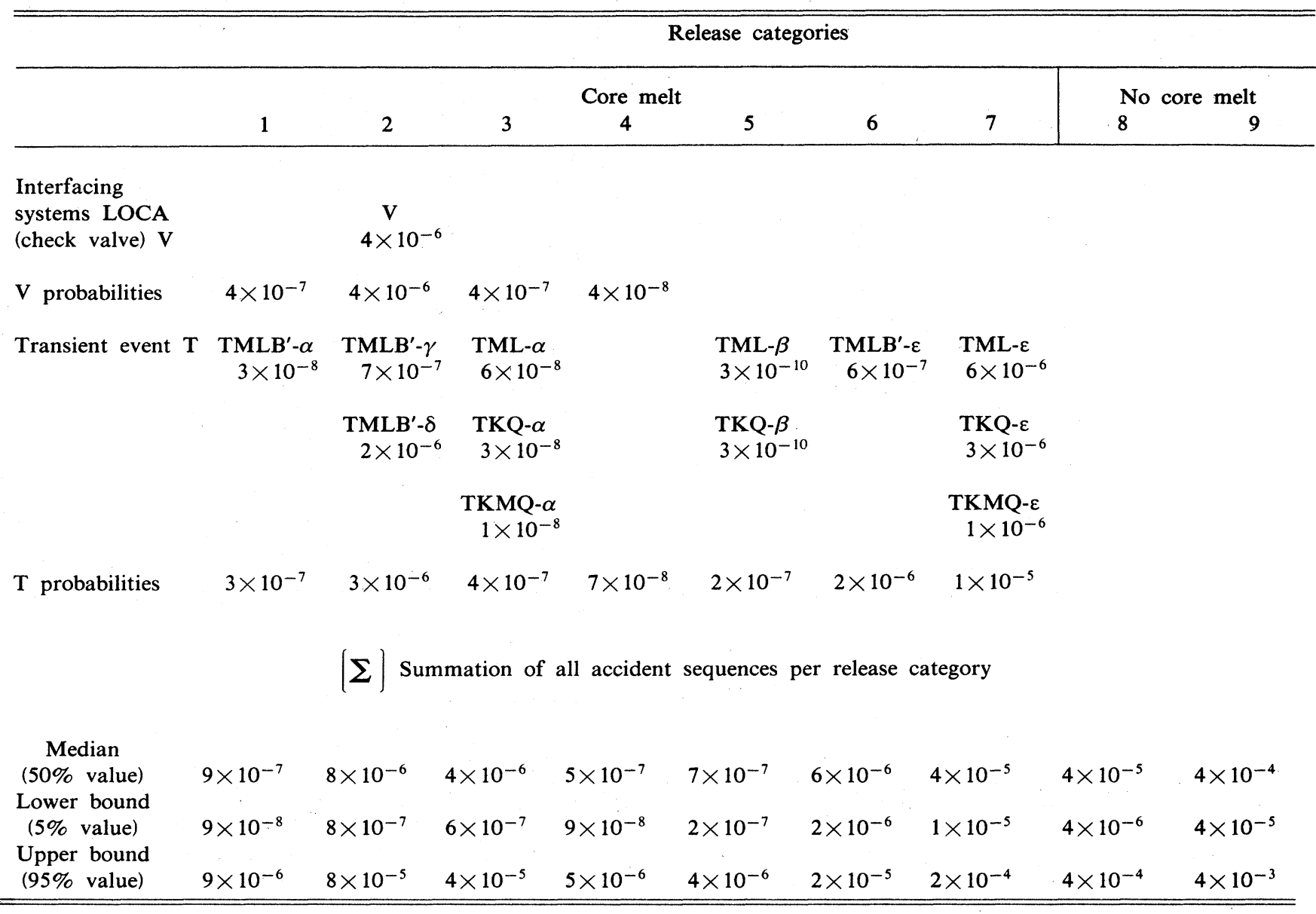

Key to PWR accident sequence symbols.

A Intermediate to large LOCA.

B Failure of electric power to ESF's.

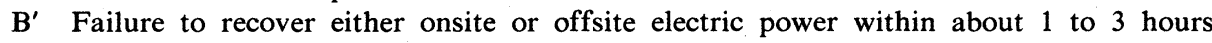
following an initiating transient which is a loss of offsite ac power.

C Failure of the containment spray injection system.

D Failure of the emergency core cooling injection system.

F Failure of the containment spray recirculation system.

$G$ Failure of the containment heat removal system.

$\mathrm{H}$ Failure of the emergency core cooling recirculation system.

$\mathrm{K}$ Failure of the reactor protection system.

L Failure of the secondary system steam relief valves and the auxiliary feedwater system.

$M$ Failure of the secondary system steam relief valves and the power conversion system.

$Q$ Failure of the primary system safety relief valves to reclose after opening.

$\mathrm{R}$ Massive rupture of the reactor vessel.

$S_{1}$ A small LOCA with an equivalent diameter of about 2-6 inches.

$\mathrm{S}_{2}$ A small LOCA with an equivalent diameter of about $\frac{1}{2}-2$ inches.

$T$ Transient event.

U Chemical and volume control system.

V LPIS check valve failure.

$\alpha$ Containment rupture due to a reactor vessel steam explosion.

$\beta$ Containment failure resulting from inadequate isolation of containment openings and penetrations.

$\gamma$ Containment failure due to hydrogen burning.

$\delta$ Containment failure due to overpressure.

$\varepsilon \quad$ Containment vessel melt-through. 
TABLE III.B.3. BWR dominant accident sequences of each event tree vs release category (from NRC, 1975). Note: The probabilities for each release category for each event tree and the $\sum$ for all accident sequences are the median values of the dominant accident sequences summed by Monte Carlo simulation plus a $10 \%$ contribution from the adjacent release category probability.

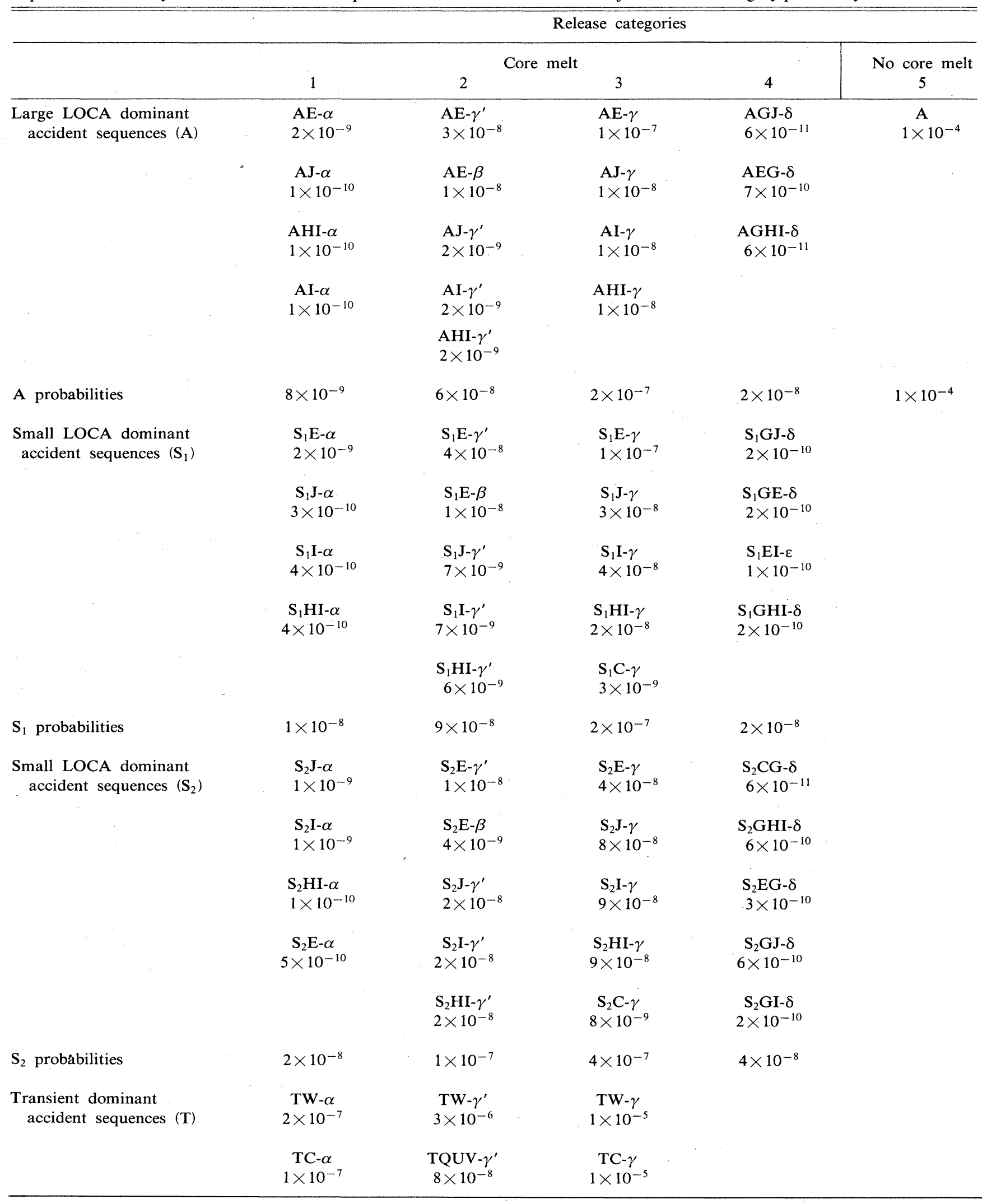


TABLE III.B.3. ( Continued).

\begin{tabular}{|c|c|c|c|c|c|}
\hline & \multicolumn{5}{|c|}{ Release categories } \\
\hline & 1 & 2 & 3 & 4 & $\begin{array}{c}\text { No core melt } \\
5\end{array}$ \\
\hline & $\begin{array}{l}\text { TQUV- } \alpha \\
5 \times 10^{-9}\end{array}$ & & $\begin{array}{l}\text { TQUV- } \gamma \\
4 \times 10^{-7}\end{array}$ & & \\
\hline $\mathrm{T}$ probabilities & $1 \times 10^{-6}$ & $6 \times 10^{-6}$ & $2 \times 10^{-5}$ & $2 \times 10^{-6}$ & \\
\hline $\begin{array}{l}\text { Pressure vessel } \\
\quad \text { rupture accidents }(\mathbf{R})\end{array}$ & & $\begin{array}{c}\text { P.V. RUPT. } \\
1 \times 10^{-8} \\
\text { oxidizing } \\
\text { atmosphere }\end{array}$ & $\begin{array}{l}\text { P.V. RUPT. } \\
1 \times 10^{-7} \\
\text { nonoxidizing } \\
\text { atmosphere }\end{array}$ & & \\
\hline $\mathrm{R}$ probabilities & $2 \times 10^{-9}$ & $2 \times 10^{-8}$ & $1 \times 10^{-7}$ & $1 \times 10^{-8}$ & \\
\hline $\begin{array}{l}\text { Median ( } 50 \% \text { value) } \\
\text { Lower bound ( } 5 \% \text { value) } \\
\text { Upper bound ( } 95 \% \text { value) }\end{array}$ & $\begin{array}{l}\text { Summation } \\
3.13 \times 10^{-7} \\
1 \times 10^{-6} \\
1 \times 10^{-7} \\
8 \times 10^{-6}\end{array}$ & $\begin{array}{l}\text { accident sequ } \\
\qquad \begin{array}{l}6 \times 10^{-6} \\
1 \times 10^{-6} \\
3 \times 10^{-5}\end{array}\end{array}$ & $\begin{array}{l}2 \times 10^{-5} \\
5 \times 10^{-6} \\
8 \times 10^{-5}\end{array}$ & $\begin{array}{l}3.3 \times 10^{-9} \\
2 \times 10^{-6} \\
5 \times 10^{-7} \\
1 \times 10^{-5}\end{array}$ & $\begin{array}{l}1 \times 10^{-4} \\
1 \times 10^{-5} \\
1 \times 10^{-3}\end{array}$ \\
\hline
\end{tabular}

Key to BWR accident sequence symbols.

A Rupture of reactor coolant boundary with an equivalent diameter of greater than six inches.

B Failure of electric power to ESF's.

C Failure of the reactor protection system.

D Failure of vapor suppression.

E Failure of emergency core cooling injection.

F Failure of emergency core cooling functionability.

G Failure of containment isolation to limit leakage to less than 100 volume per cent per day.

H Failure of core spray recirculation system.

I Failure of low pressure recirculation system.

J Failure of high pressure service water system.

M Failure of safety/relief valves to open.

P Failure of safety/relief valves to reclose after opening.

Q Failure of normal feedwater system to provide core make-up water.

$S_{1} \quad$ Small pipe break with an equivalent diameter of about 2-6 inches.

$\mathrm{S}_{2} \quad$ Small pipe break with an equivalent diameter of about $\frac{1}{2}-2$ inches.

T Transient event.

U Failure of HPCI or RCIC to provide core make-up water.

$\mathrm{V}$ Failure of low pressure ECCS to provide core make-up water.

W Failure to remove residual core heat.

$\alpha$ Containment failure due to steam explosion in vessel.

$\beta \quad$ Containment failure due to steam explosion in containment.

$\gamma \quad$ Containment failure due to overpressure-release through reactor building.

$\gamma^{\prime} \quad$ Containment failure due to overpressure-release direct to atmosphere.

$\delta \quad$ Containment isolation failure in drywell.

$\varepsilon \quad$ Containment isolation failure in wetwell.

$\zeta$ Containment leakage greater than 2400 volume per cent per day.

$\eta \quad$ Reactor building isolation failure.

$\theta \quad$ Standby gas treatment system failure.

into which the fission products are released is a very effective filter. Release Categories PWR 4 and 5 are exclusively associated with above ground releases resulting from electrical and mechanical penetration failures. These forms of containment failure mechanisms have been associated with source terms of intermediate (but rel- atively small) magnitude in the RSS results as the penetrations were assumed to present a tortuous path for released fission products that provided some filtering effects.

It can be shown that for the RSS, the calculated public health risks from PWR accidents would be dominated by 
Release Categories PWR 1, 2, and 3-assuming that the magnitudes and probabilities of these releases were valid. In spite of the relatively low probabilities of accidents occurring within these three release categories, the public health consequences associated with their source terms have been calculated to be so much larger than those of other categories that the accident sequences in these release categories dominate the PWR risks in the RSS. Thus the most significant accident sequences contributing to PWR risks 'according to RSS are the V, TMLB', and $\mathrm{S}_{2} \mathrm{C}$ sequences.

A similar assessment may be made of the dominant BWR accident sequences for the RSS shown in Table III.B. 3 as a function of associated release categories. The probabilities of sequences for release categories BWR 1, 2, and 3 are dominated by the transient TW and TC sequences. A review of the results presented in Table II.E.1 indicates that the source terms associated with release categories BWR 1, 2, and 3 are roughly comparable in magnitude to those of the PWR 1,2, and 3 categories. Hence the TC and TW accident sequences would tend to dominate the BWR risks defined by the RSS.

Since the publication of RSS, many new insights have evolved that affect reactor accident sequence likelihoods. These insights were derived from the findings of PRA's, conclusions from other studies, special studies, operational experience and changes resulting from Three Mile Island "fixes." The Accident Sequence Evaluation Program (ASEP) (Kolaczkowski, 1983) is attempting to formulate updated LWR accident probabilities. Some of the important rebaselined sequences (including new sequences) are shown in Table III.B.4 for Surry (PWR) and in Table III.B.5 for Peach Bottom (BWR). We note that the probability for the TMLB' has increased, primarily through the inclusion of the long-term blackout effects; the probability of the $\mathrm{V}$ sequence is now reduced as a result of changes introduced [testing and monitoring of Low Pressure Injection System (LPIS) check valve-a better probability value would require a plant-specific reanalysis]. Two new sequences were added for Surry; TKMU and $S_{3} D$. The latter represents a small LOCA caused by a Reactor Coolant Pump (RCP) seal leak.

However if, as noted later in the report, a TMLB' sequence will not lead to containment failure for several hours, instead of the 90 minutes postulated in RSS, then the probability that on site power cannot be recovered in time to prevent containment failure (and release to the en-

TABLE III.B.4. Important Surry re-baselined (revised) results (after Kolaczkowski, 1983; Appendix D, Table D.1).

\begin{tabular}{lcc}
\hline \hline Sequence & RSS frequency & Re-baseline frequency \\
\hline TMLB & $3.3 \times 10^{-6}$ & $2 . \times 10^{-5}$ \\
TML & $6 . \times 10^{-6}$ & $4 . \times 10^{-6}$ \\
V & $4 . \times 10^{-6}$ & $<1 . \times 10^{-6}$ \\
TKMU & (new sequence) & $1 . \times 10^{-5}$ \\
$\mathrm{~S}_{3} \mathrm{D}$ & (new sequence) & $9 . \times 10^{-5}$ \\
\hline \hline
\end{tabular}

TABLE III.B.5. Important Peach-Bottom re-baselined results (after Kolaczkowski, 1983; Appendix H, Table H.2).

\begin{tabular}{lcc}
\hline \hline Sequence & RSS frequency & Re-baseline frequency \\
\hline TW & $1.5 \times 10^{-5}$ & $3 . \times 10^{-6}$ \\
TQUV & $4.9 \times 10^{-7}$ & $2 . \times 10^{-7}$ \\
TB & (new sequence) & $8 . \times 10^{-6}$ \\
\hline \hline
\end{tabular}

vironment) will be much reduced.

The probability of TQUV sequence for Peach Bottom has been reduced principally because of revised estimates of the success criteria for Passive Heat Removal (PHR) by Low Pressure Coolant Injection. The reduction in TW sequence probability reflects reduction in the nonrecovery factors and a decrease in the offsite power nonrecovery. The new sequence $T B$ is a variation of the TQUV sequence with the addition of station blackout.

\section{III.B.3. Basis for selection of scenarios for source term studies}

An NRC study (Gieseke et al., 1984) has been conducted to upgrade source term definitions using the advanced codes and models of the physical processes occurring during core melt accidents that have been developed since the Reactor Safety Study was completed. The NRC's investigators have selected accident sequences and specific plants for analysis which involve a considerable range in physical conditions. In the selection process for the sequences, analysts have included potentially high-risk, large-consequence accident sequences for the plants (in an apparent attempt to bound the probable range of interest for physical processes and design characteristics of nuclear plants).

The specific plants and sequences that have been chosen for the current NRC study are as follows.

o Surry (a Westinghouse PWR-822 $\mathrm{MW}_{e}$ - with a large, dry subatmospheric containment): AB, TMLB', $\mathrm{S}_{2} \mathrm{D}, \mathrm{V}$ (Gieseke et al., 1984, Vol. 5)

o Peach Bottom [a GE-BWR-1065 $\mathrm{MW}_{e}$-with a Mark I containment (light bulb and torus design)]: AE, TC, TW (Gieseke et al., 1984, Vol. 2)

o Grand Gulf [a GE-BWR-1250 $\mathrm{MW}_{e}$ - with a Mark III containment (utilizing a moat \& weir type suppression pool)]: TC, TQUV, TPI, $\mathrm{S}_{2} \mathrm{E}$ (Gieseke et al., 1984, Vol. 3)

o Sequoyah [a Westinghouse PWR-1148 $\mathrm{MW}_{e}$-with a steel shell, ice condenser containment (reinforced concrete, secondary containment/shield building)] $\mathrm{S}_{2} \mathrm{HF}$, TML, TMLB' (Gieseke et al., 1984, Vol. 4)

o Zion (a Westinghouse PWR-1040 $\mathrm{MW}_{e}$-large, dry, reinforced concrete containment): TMLB' $^{\prime}, \mathrm{S}_{2} \mathrm{D}$ (Gieseke et al., 1984, Vol. 6)

The details of some of these sequences are discussed in Section III.C. Here we consider the criteria for their selection.

It should be noted that the Surry and Peach Bottom units were the specific plants used in the RSS (NRC, 1975) to model "typical" U.S. nuclear power plants. As 
noted above, the current NRC selection embraces a larger, more representative variety of plants and facilities than was included in RSS. Although the RSS analyzed a much larger set of accident scenarios than is being evaluated in the current study, the accident scenarios shown above do represent many of the more risk significant, plant specific events upon which the analysis of fission product releases and source terms might be conducted.

In the selection process, it appears that the Surry and Peach Bottom plants were selected for reanalyses so that the RSS could be used as a basis for comparison of early and updated projections of source terms. For Surry (and PWR's in general), the TMLB' and V sequences were evidently selected for reassessment because they were shown by the RSS to be relatively high probability-very high risk events. The $S_{2} D$ event was probably selected because in the RSS calculations it was shown to be one of the highest probability sequences-not because it was found to be a significant contributor to the public health risks derived in the RSS. The AB sequence (though found to be relatively low in probability in the RSS) may logically have been selected because it is representative of an event in which all the reactor cooling water is lost rapidly and early in the sequence. As a result, core melt is calculated to occur relatively rapidly in the $A B$ scenario. In the TMLB' sequence, on the other hand, a very long time is projected to be required before core uncovery. In this sequence, the decay heat removal systems are assumed to be inoperative, leading to excessive temperatures and pressures in the reactor coolant system. As a result, the reactor coolant is calculated to be lost slowly as high pressure triggers the relief valve resulting in the equivalent of a small leak through the valve (somewhat similar to the TMI event). Thus the AB and TMLB' sequences represent potentially high risk scenarios that bracket the short and long term time scales for the chronological sequences leading to core-melt.

The selection of the accident sequences for the Peach Bottom facility may have been justified on a similar basis. The TC \& TW scenarios were found to be relatively high probability, high risk contributing sequences in the RSS. The AE scenario, on the other hand, was shown to be a relatively low probability event but it was also projected to be a potentially high consequence contributing sequence. Again, the basis for selection of the large LOCA (AE) sequence may have been that such events appear to represent cases of rapidly progressing core melt scenarios for evaluation-when compared with the relatively slow characteristic core melting times of transient induced sequences such as the TC \& TW scenarios (although the TC sequence progresses relatively rapidly when compared with the TW transient).

The Grand Gulf (BWR) sequences were apparently selected to perform a comparative evaluation of the fission product filtering effectiveness of the more modern Mark III containment, with its new and ostensibly improved suppression pool design, and the older Mark I BWR containments. In the Mark III containment design, fission products released during core melt processes would have to pass through the suppression pool under most conceivable circumstances-even if the external containment structure itself were projected to fail. Thus analysts have anticipated that source terms for Grand Gulf would probably be smaller than those of equivalent sequences for the Peach Bottom (Mark I containment) design, where suppression pool bypass sequences have been projected to exist. The principal issues to be examined in the Grand Gulf design would be the effectiveness of the suppression pool as a filter for fission products if the fluid in the pool was in either nonboiling or boiling condition as a result of the sequential events of the several accident scenarios being evaluated.

Consideration of the newer aspects of BWR designs embodied in the Grand Gulf facility required analyses of several additional accident sequences (TPI, TQUV, and $\mathrm{S}_{2} \mathrm{E}$ ). The TPI sequence is a slowly progressing scenario similar in time scale to the TW sequence for Peach Bottom. Initially, the TQUV sequence progresses rapidly (much like the TC sequences) but analysts have evaluated the sequence under the assumption that a suppression pool cooling system is functional throughout the accident. (In the TC \& TW sequences, the RSS analysts assumed that the suppression pool was boiling at the time of core meltdown, thereby reducing its filtering effectiveness. This assumption is also part of the current scenario analysis.) In the $S_{2} E$ sequence, events are calculated to progress rapidly, and an early drywell containment failure is assumed to occur so that some fission products may bypass the suppression pool. Otherwise, the $S_{2} E$ sequence is not dramatically different from the TQUV sequence in the timing of the core melt related events.

Each of the Grand Gulf sequences (TC, TQUV, TPI, and $S_{2} E$ ) was determined to have a significant individual contribution to the overall accident probabilities in a PRA conducted for the plant. In a subsequent rebaselining of the frequencies of risk contributing sequences (Kolaczkowski, 1983), these Grand Gulf events retained their significance, with rebaselined probabilities comparable to the original Peach Bottom (NRC, 1975) TC and TW sequences probabilities shown in Table III.B.3.

In addition to the Surry plant, other PWR containment designs were also considered by the NRC in their current study. The Sequoyah plant was analyzed in order to study the modeled fission product filtering effectiveness of a facility that uses ice (stored permanently in the containment building) to condense the steam from a DBALOCA. Distributed about the perimeter of the Sequoyah's steel shell containment structure are 2.45 million pounds of ice held in a tubular, cylindrical structure, nearly $60-\mathrm{ft}$ high and about 14-ft wide, supporting a collection of ice baskets. Theoretically, the ice in the Sequoyah containment would perform a function similar to that of a suppression pool for a BWR, condensing and filtering the steam that passed through it following a LOCA. However, the effectiveness of the ice beds for filtering fission products released in a severe reactor accident is somewhat uncertain, since there has been no study of the extent to 
which channeling of the steam flow in the ice beds (and hence preferred, unfiltered pathways) would occur during the blowdown period of the accidents.

The TMLB' sequences for Sequoyah and Surry are very similar in the timing of their characteristic accident stages. Moreover, the TML sequence is very similar in timing to the TMLB' sequence. However, in the TML sequence, the containment safety features (i.e., recirculation fans, containment sprays, and hydrogen igniters) are all assumed to be operable-whereas in the TMLB' sequence, the station blackout assumption $\left(B^{\prime}\right)$ results in the unavailability of all these safety features throughout the duration of the accident. In Sequoyah, the $S_{2} H F$ sequence is initiated by a small break in the reactor coolant system. The emergency core cooling and containment spray systems are assumed to function in the injection mode for this sequence, but fail during the recirculation mode due to a common mode failure. The consequences of the Sequoyah $\mathrm{S}_{2} \mathrm{HF}$ sequence are potentially more severe than the $S_{2} D$ sequence in the Surry plant. A Sequoyah-specific PRA suggested that an $\mathrm{S}_{2} \mathrm{HF}$ sequence might result in a Category 3 or 4 release whereas the $S_{2} D$ sequence in Surry is associated with a Category 7 release (cf. Table III.B.1). The revised estimate of the probability of the $S_{2} H F$ sequence's occurring was determined from the Sequoyah PRA to be about $3 \times 10^{-5}$, which made it one of the most probable sequences analyzed (Kolaczkowski, 1983).

As a study group we believe that the process of selection of accident sequences for assessment will have a very significant impact on resulting projections of source terms. We acknowledge that choosing sequences for analysis from among the more probable scenarios leading to core melt is an appropriate selection criterion. We recognize that it is important to have a realistic understanding of the effectiveness of the engineered safety features in reducing released fission products. Hence, we acknowledge that attention should be given to sequences where the engineered safety features are operational. However, we believe that when a limited number of scenarios is being evaluated, attention should be focused upon sequences that are potentially risk dominant (i.e., those that could potentially lead to large source terms). The focus should be maintained on risk dominant sequences even if the chosen sequences appear to be somewhat lower in probability than some sequences that may appear to be potentially less threatening. In this regard, we have seen no justification for the neglect of the $\mathrm{S}_{2} \mathrm{C}$ sequence for Surry [which had a relatively high probability $-2 \times 10^{-6}$ - but was projected by RSS (NRC, 1975) to lead to much larger releases-Category 3-than the $S_{2} D$ sequence-a Category 7 event that is currently under review].

We find no other particular problems with the NRC's selection of the accident sequences that have been made available to us for review. However, we recognize that the number of sequences evaluated is relatively small when compared with the sequences considered in the RSS. The number of sequences that has been analyzed is not sufficient to reestablish the existence of source term release categories-such as those utilized in RSS. With the relatively small number of sequences examined, it is difficult to be sure that those that have been selected are representative of sequences that might still belong to the original, risk dominant RSS release categories for comparative purposes or to be sure that the risk relevant sequences have been bounded. Thus it is difficult to be sure that we have examined the risk dominant sequences to see how our improved understanding of the physical phenomena and processes associated with core melt accidents has influenced the projections of the magnitudes of their contributions to reactor accident source terms. Further, to the extent that sequences originally believed to be risk dominant are now shown to result in smaller releases, other sequences must be examined to ensure that they are not in fact risk dominant.

Nevertheless, we believe that the physical concepts, analytical methods, and numerical procedures or codes associated with the more significant core melt physical phenomena have been exercised in most of their critical modes in the sequences that we have examined. The study group's evaluation of the effectiveness of these concepts, methods, and procedures as they are utilized in analyzing core melt and fission product release phenomena will be discussed in Sections IV.A.6 and IV.B.3, respectively.

\section{III.C. Specific sequences}

\section{III.C.1. Detailed description}

of the TMLB' sequence

In Table III.C.1, a description is presented of the time sequence of events for a specific accident scenarioTMLB' - calculated for a specific reactor (Surry) (Gieseke et al., 1983, Vol. V). The parameters and events of this important sequence are further illustrated in Figures III.C. 1 to III.C.7 that have been reproduced (with some editorial comments of the study group added) from the referenced document. This set of figures will be used later in this report to emphasize additional features associated with source term calculations.

Figure III.C. 1 shows a containment pressure-time trace of the TMLB' scenario. In Table III.C.1, a corresponding list is presented of the physical phenomena and their characteristics as they are associated with the features shown in the pressure-time trace. At $t=0$, a transient is assumed to occur that initiates the accident at the plant. As implied by the alphabetical sequence descriptors for the event, failure of the secondary steam relief valves, the power conversion system, the auxiliary feedwater system, and a continuing station blackout (without recovery of onsite or offsite power) is postulated in this scenario. As a result of the failure of the auxiliary feedwater system, and the continuing release of decay heat of the fuel, the secondary system water begins to boil away almost immediately after the accident is initiated. At 67.5 minutes the steam. generators dry out. 
TABLE III.C.1. Thermal hydraulic scenario for the TMLB' event.

\begin{tabular}{lc}
\hline \multicolumn{1}{c}{ Event } & Time (mins.) \\
\hline Transient occurs & 0 \\
Steam generator dry & 67.5 \\
Pressure surge line uncovers & \\
$\quad$ (steam enters containment and slowly & $\sim 85$ \\
$\quad$ condenses) & 95.5 \\
Core uncovers & 118.3 \\
Core melt starts & \\
Core starts to slump & 146.3 \\
$\quad$ (surge of steam to containment) & 147.3 \\
Core collapse & 152.7 \\
Pressure vessel dry out & 157.3 \\
Bottom head fails & \\
$\quad$ (Molten corium enters containment \\
$\quad$ temperature rises, pressure rises, then \\
$\quad$ steam slowly condenses-although steam \\
$\quad$ generation continues for more than \\
$\quad$ an hour) \\
Corium quenches \\
Cavity dry (steam generation stops) \\
Core remelts and attacks concrete \\
Basemat melt-through ${ }^{\mathrm{a}}$
\end{tabular}

aIf basemat melt-through does not occur, the pressure will continue to rise until the containment fails.

The heat transfer from the fuel rods to the primary coolant water is governed by "pool boiling;" this mode of heat transfer is understood well enough that the steam generation rates, first in the secondary system and then in the primary system, can be calculated reliably from the decay heat in the core. Only a small amount of the heat goes into increasing the temperature of the primary system piping. Since the pipes are well insulated to prevent losses to the surrounding containment volume in ordinary operation, heat losses in this accident are also small.

The time $\left(t_{1}\right)$ at which the secondary system dries out is given approximately by

$$
\int_{0}^{t_{1}} Q_{d} d t=\rho h_{f g} V_{s c}+\text { insulation losses },
$$

where $Q_{d}=$ decay power, $V_{s c}=$ volume of liquid in the secondary side of the steam generators, $\rho=$ density of water, and $h_{f g}=$ latent heat of evaporation at the steam generator relief valve set point of about $7.6 \mathrm{MPa}$ (1100 psia).

For this purpose we shall use the simplified equation for $Q_{d}$ that was used in Appendix VII of the Reactor Safety Study (NRC, 1975),

$$
\begin{aligned}
Q_{d} & =1.20\left(Q_{0} \times 0.0766 t^{-0.181}\right), \quad 10<t<150 \mathrm{~s} \\
& =1.20\left(Q_{0} \times 0.130 t^{-0.283}\right), \quad 150<t<4 \times 10^{6} \mathrm{~s} .
\end{aligned}
$$

A multiplication factor of 1.20 is included here to account roughly for the decay heat from the actinides.

The mass of water in the steam generator is $1.4 \times 10^{5}$ $\mathrm{kg}$ and is at a pressure of $6.89 \mathrm{MPa}$; the heat of vaporization, $h_{f g}$, is $1512 \mathrm{~kJ} / \mathrm{kg}$. The energy required to vaporize this water is, thus, $2.13 \times 10^{5} \mathrm{MJ}$,

$$
\begin{aligned}
\int_{0}^{t_{1}} Q_{d} d t & =-1.88 Q_{0}+0.217 Q_{0} t_{1}^{0.717} \\
& =2.13 \times 10^{5} \mathrm{MJ} .
\end{aligned}
$$

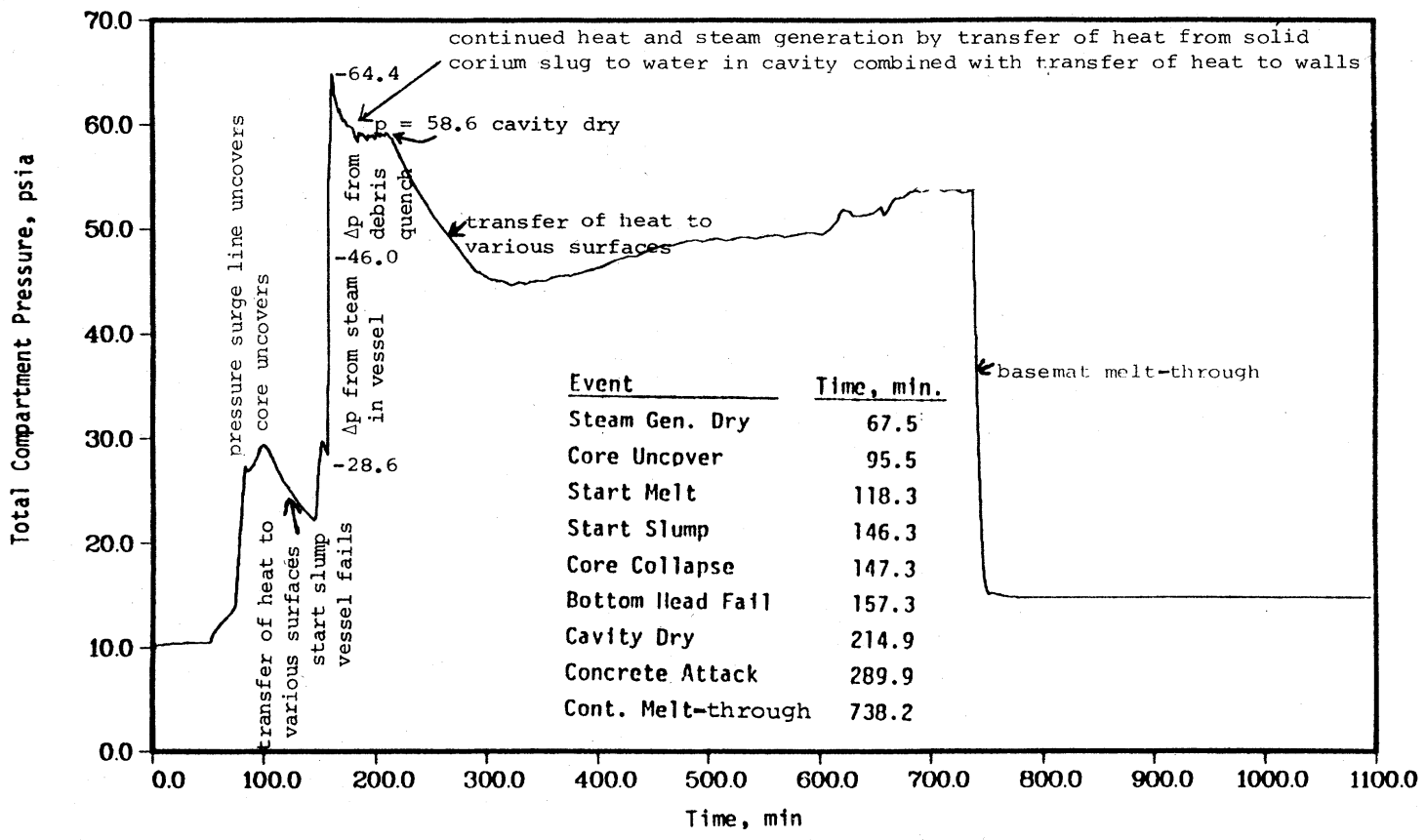

FIG. III.C.1. Containment pressure response for Surry $T_{M L B}^{\prime}-\varepsilon$ sequence. 


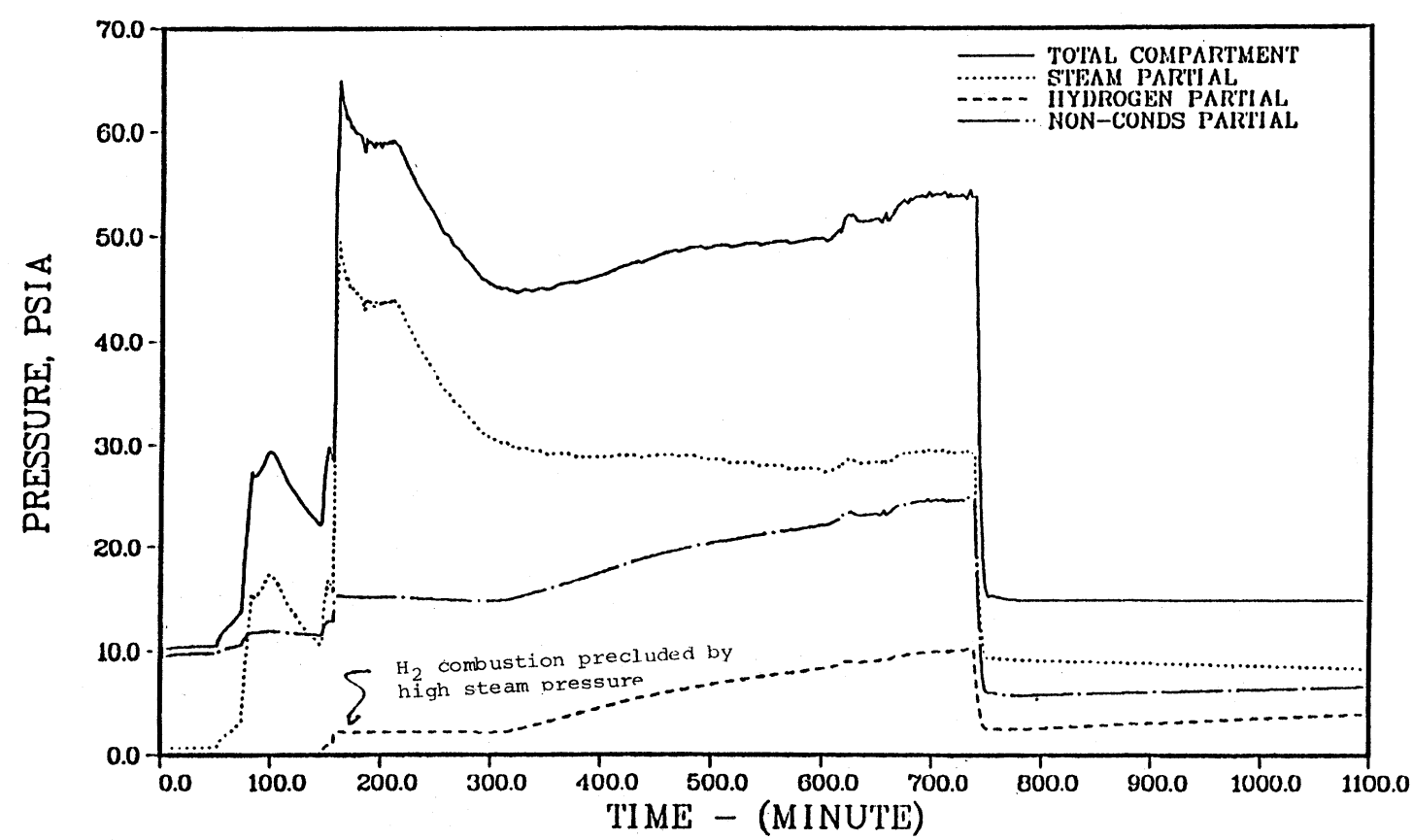

FIG. III.C.2. Partial pressures for TMLB' $-\varepsilon$.

For $Q_{0}=2441 \mathrm{MW}$ we find $t_{1}=69 \mathrm{~min}$. As a consequence of the drying out of the steam generators, no heat sink is subsequently available for the removal of the heat which continues to evolve within the primary system. The containment temperature (Figure III.C.3) and pressure (Figures III.C.1 and III.C.2) begin to rise slowly at the on- set of the accident. After the secondary system dries out, the pressure in the primary system rises until it exceeds the pressure relief valve set point. Then the steam enters the containment through the pressurizer quench tank. The containment is then heated by the release of the primary system steam.

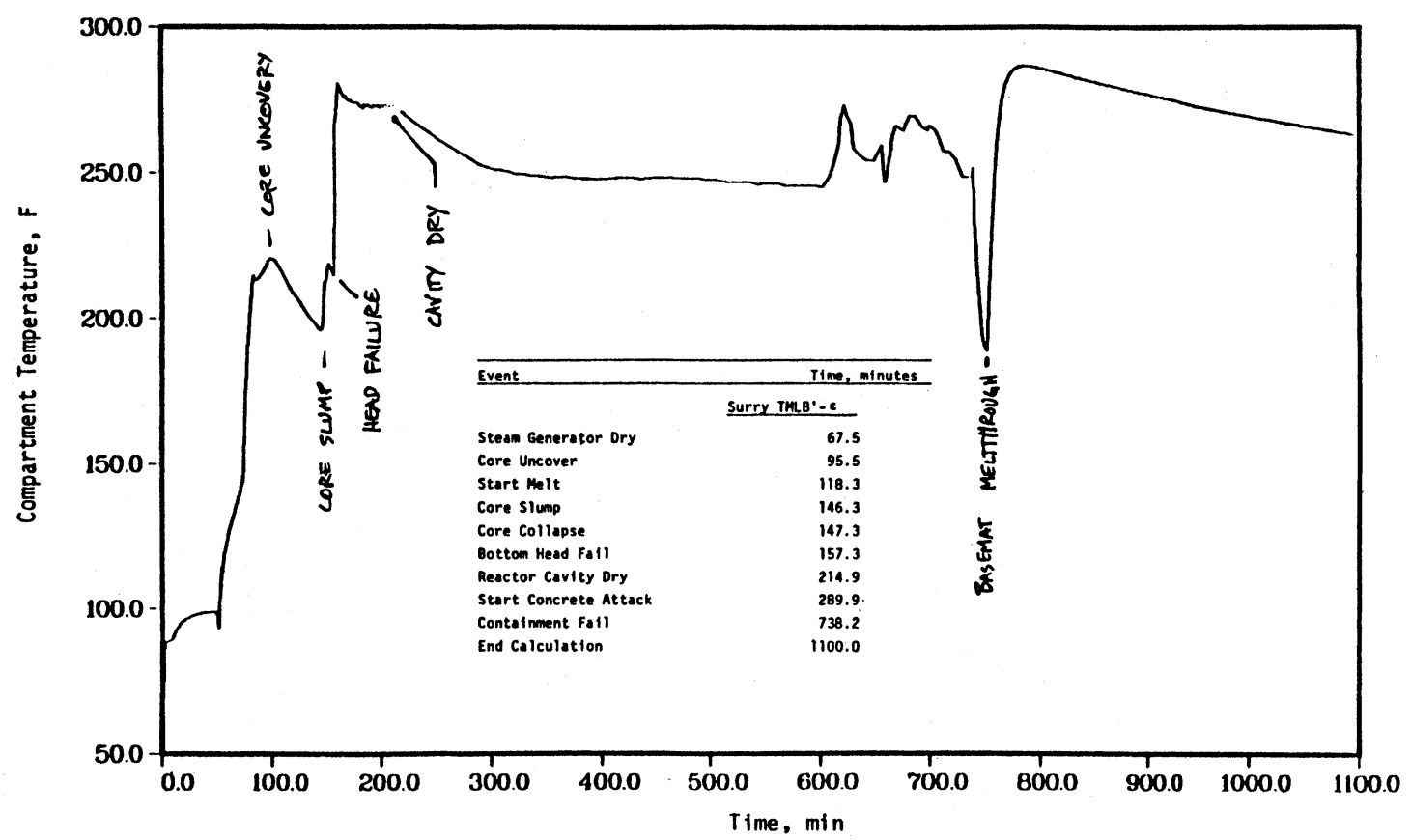

FIG. III.C.3. Containment temperature response for Surry $\mathrm{TMLB}^{\prime}-\varepsilon$ sequence. 


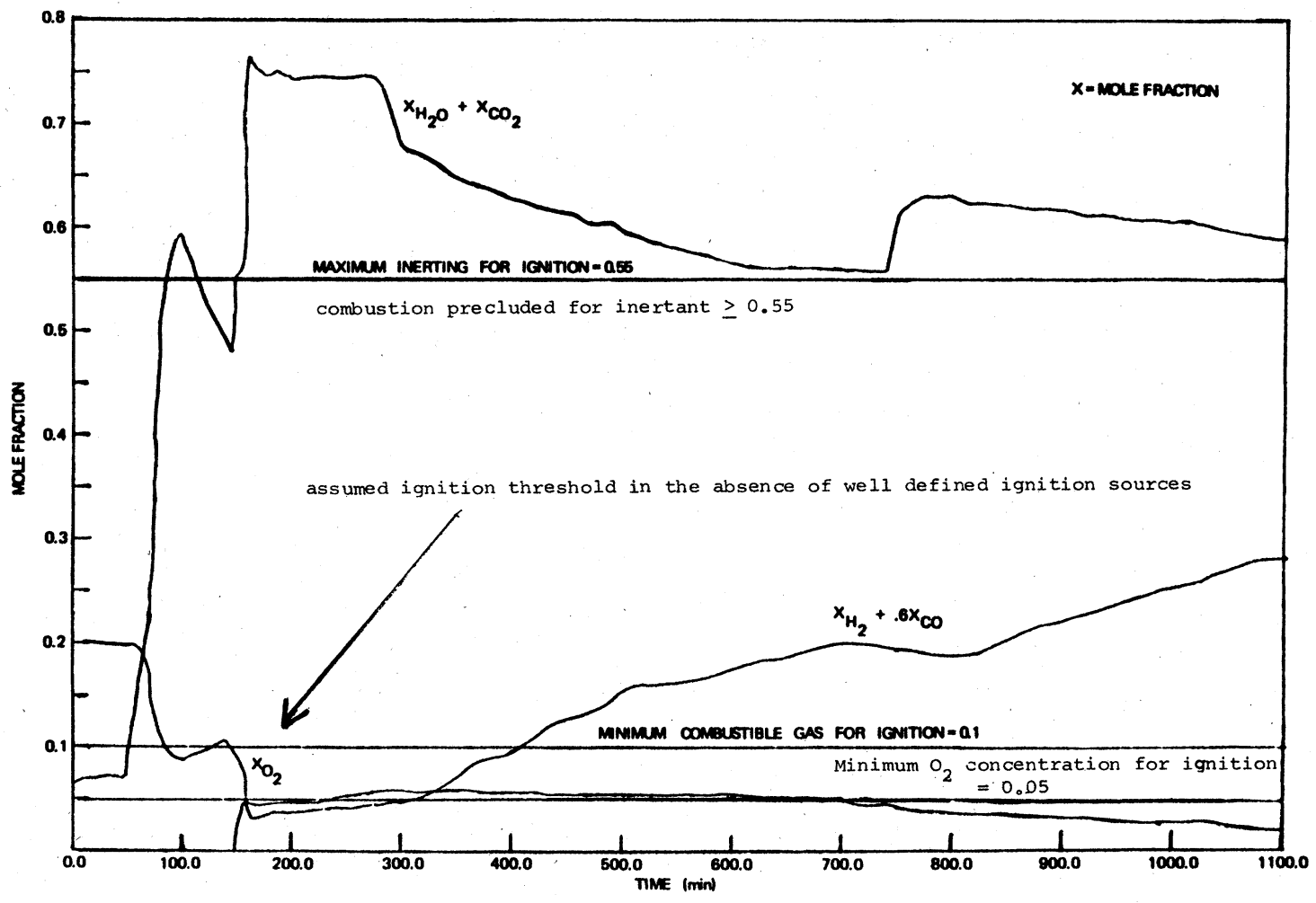

FIG. III.C.4. Surry $\mathrm{TMLB}^{\prime}-\varepsilon$ time dependent ignition requirements.

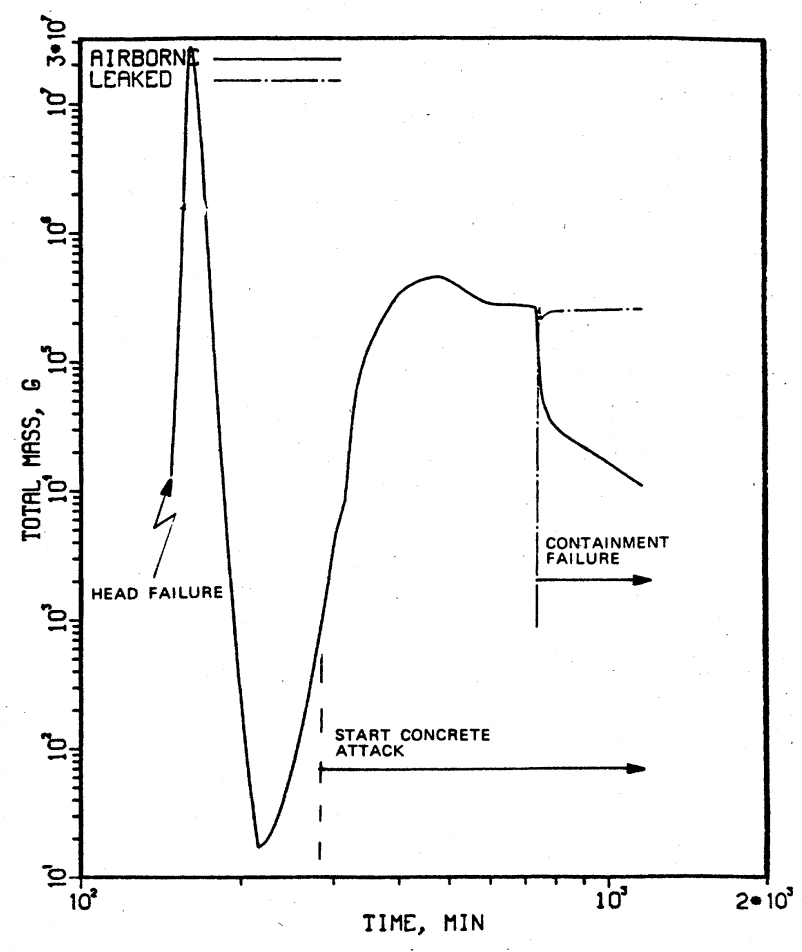

FIG. III.C.5. Airborne and leaked masses, TMLB'- $-\varepsilon$ (including condensed steam).

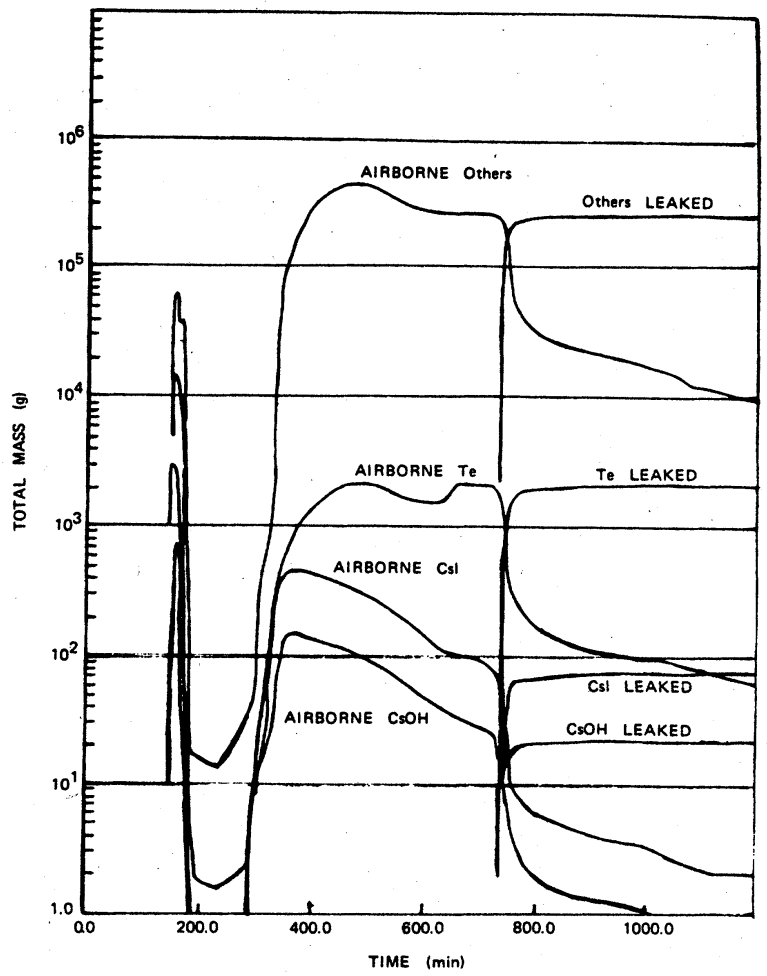

FIG. III.C.6. Surry TMLB'$^{\prime}-\varepsilon$ total containment airborne and leaked radionuclide masses as a function of time. 


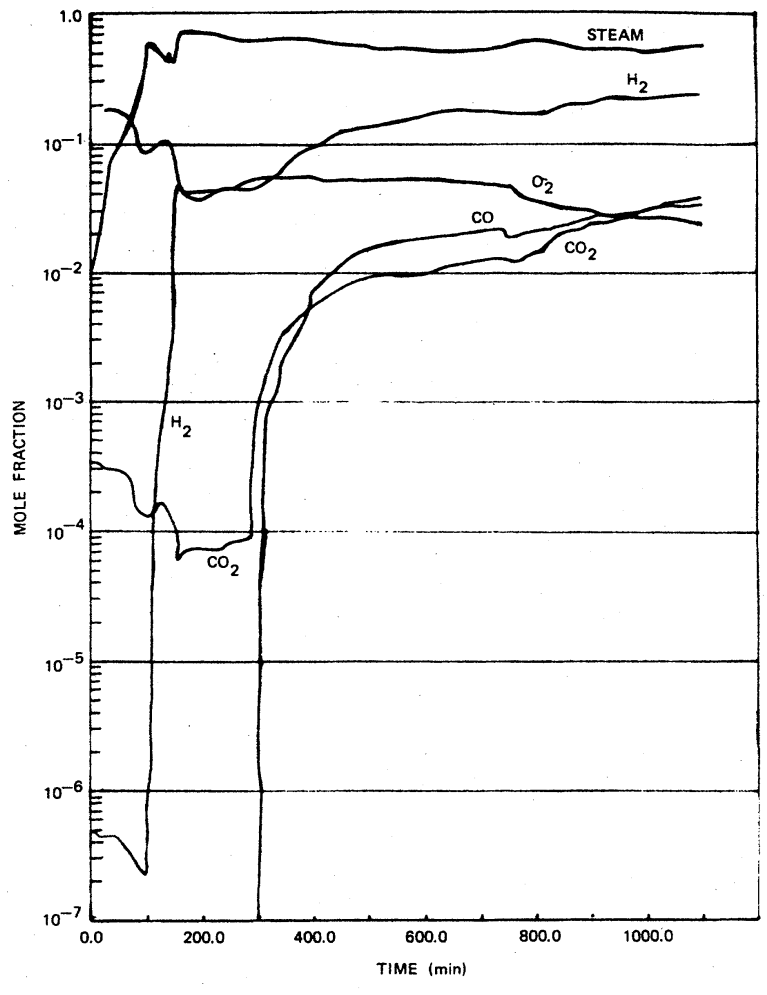

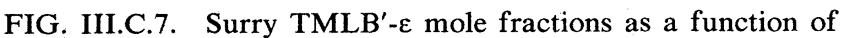
time for steam, hydrogen, oxygen, carbon dioxide, and carbon monoxide.

The time $\left(t_{2}\right)$ at which the core uncovers is given by

$$
\int_{t_{1}}^{t_{2}} Q_{d} d t=\rho h_{f g} V p_{u}+C_{v} \Delta T+\text { insulation losses , }
$$

where $V p_{u}=$ the volume of the primary above top of the core, $C_{v}=$ heat capacity, $\Delta T=$ the temperature difference between operating temperature and boiling temperature at the relief valve setting.

The insulation heat losses will elevate containment temperatures a small amount and increase $t_{1}$ and $t_{2}$ slightly.

The mass of water in the primary system is $1.94 \times 10^{5}$ $\mathrm{kg}$. Of this, $1.29 \times 10^{5} \mathrm{~kg}$ must be lost to uncover the core. Because of the PWR system geometry about $1.04 \times 10^{5} \mathrm{~kg}$ of liquid water is forced through the relief valve before steam leakage begins. The amount of liquid water converted to steam is the amount forced through the relief valve as steam plus the amount of steam required to fill the volume vacated by the liquid water forced through the relief valve; this amount is $4.82 \times 10^{4}$ $\mathrm{kg}$. The energy required to vaporize the water (with $h_{f g}=830 \mathrm{~kJ} / \mathrm{kg}$ ) is $4.35 \times 10^{4} \mathrm{MJ}$. Ignoring the sensible heat of the water (the second term in the above equation),

$$
\begin{aligned}
\int_{t_{1}}^{t_{2}} Q_{d} d t & =-84.7 Q_{0}+0.217 Q_{0} t_{2}^{0.717} \\
& =4.35 \times 10^{4} \mathrm{MJ} \\
& \Longrightarrow t_{2}=90 \mathrm{~min}
\end{aligned}
$$

These approximate results of $69 \mathrm{~min}$ for $t_{1}$ and $90 \mathrm{~min}$ for $t_{2}$ compare favorably with the computer prediction (see Table III.C.1) of 67.5 and $95.5 \mathrm{~min}$. Therefore this approximate calculation seems to provide an adequate physical representation of this sequence during the boiloff stage, and the full calculation with all the corrections, seems reasonable.

For a small pipe break, in which the blowdown and boiloff are occurring simultaneously, the phenomena are more complex. The time to core uncovery is then determined by the properties of two-phase flow which it is then important to describe accurately. Such accidents are analyzed in, e.g., the $S_{2} D$ sequence in Vol. V of BMI2104.

The precise amounts of heat and gas in the containment are sensitive to the details of the thermal hydraulics, core melt, fission product deposition within the primary system, the core concrete interaction, etc. In the following paragraphs, we present a "scoping" calculation which roughly gives the values of the temperature and pressure in the containment without knowing these details. Data are taken from Table III.C.2 and steam tables (Keenan et al., 1978). The results of the calculations are presented in Figure III.C. 8 as an overlay on a graph of the computer calculations given in Gieseke (1984).

As indicated above, $1.04 \times 10^{5} \mathrm{~kg}$ of water goes into the containment with the specific enthalpy of saturated water at the pressure relief valve set point, $1666 \mathrm{~kJ} / \mathrm{kg}$. Since this is not enough for all the water to flash into steam, the amount of water ending up as steam can only be found by trial and error using the specific heats and steam tables. The result is that $57 \%\left(5.93 \times 10^{4} \mathrm{~kg}\right)$ of the water is in the form of steam and the pressure is

$$
p_{\text {st }}=0.205 \mathrm{MPa}(29.7 \mathrm{psia}) \text {. }
$$

The pressure surge line uncovers at approximately 85 minutes after the accident is initiated, the pressure in the reactor pressure vessel reaches the relief valve actuation level and steam is rapidly released to the containment as the primary system pressure relief valve is actuated. The remaining $2.51 \times 10^{4} \mathrm{~kg}$ of water emerges as steam through the pressure surge line as a result of the repeated activation of the relief valve until at 95.5 minutes the core uncovers. The specific enthalpy of saturated steam at the pressure release valve set point is $2.57 \times 10^{3} \mathrm{~kJ} / \mathrm{kg}$. If the steam were released quickly, so that there was no time for conduction to the walls, this would result in $8.44 \times 10^{4} \mathrm{~kg}$ of steam filling the containment with an internal energy of

$$
\begin{aligned}
U & =0.57 \times 1.04 \times 10^{5} \times 2500+2.51 \times 10^{4} \times 2570 \\
& =2.15 \times 10^{8} \mathrm{~kJ}
\end{aligned}
$$

or a specific internal energy of $1.78 \times 10^{3} \mathrm{~kJ} / \mathrm{kg}$ and a specific volume of

$$
v_{\mathrm{st}}=51000 \mathrm{~m}^{3} / 8.44 \times 10^{4} \mathrm{~kg}=0.604 \mathrm{~m}^{3} / \mathrm{kg} .
$$

Again, this is not enough energy to maintain the water as steam and some must condense; this time, $63 \%$ of the 
TABLE III.C.2. Table of data for Surry TMLB'.

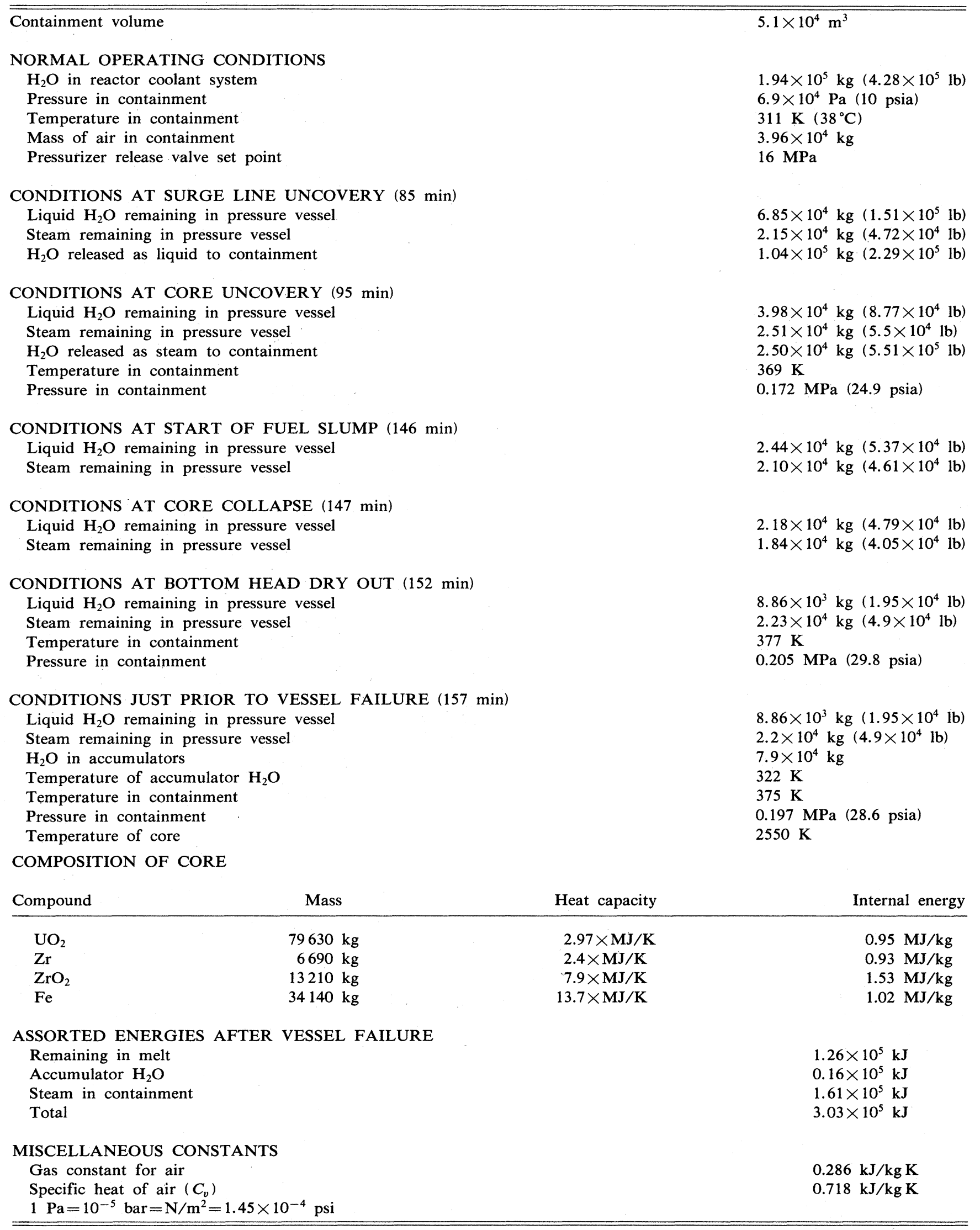




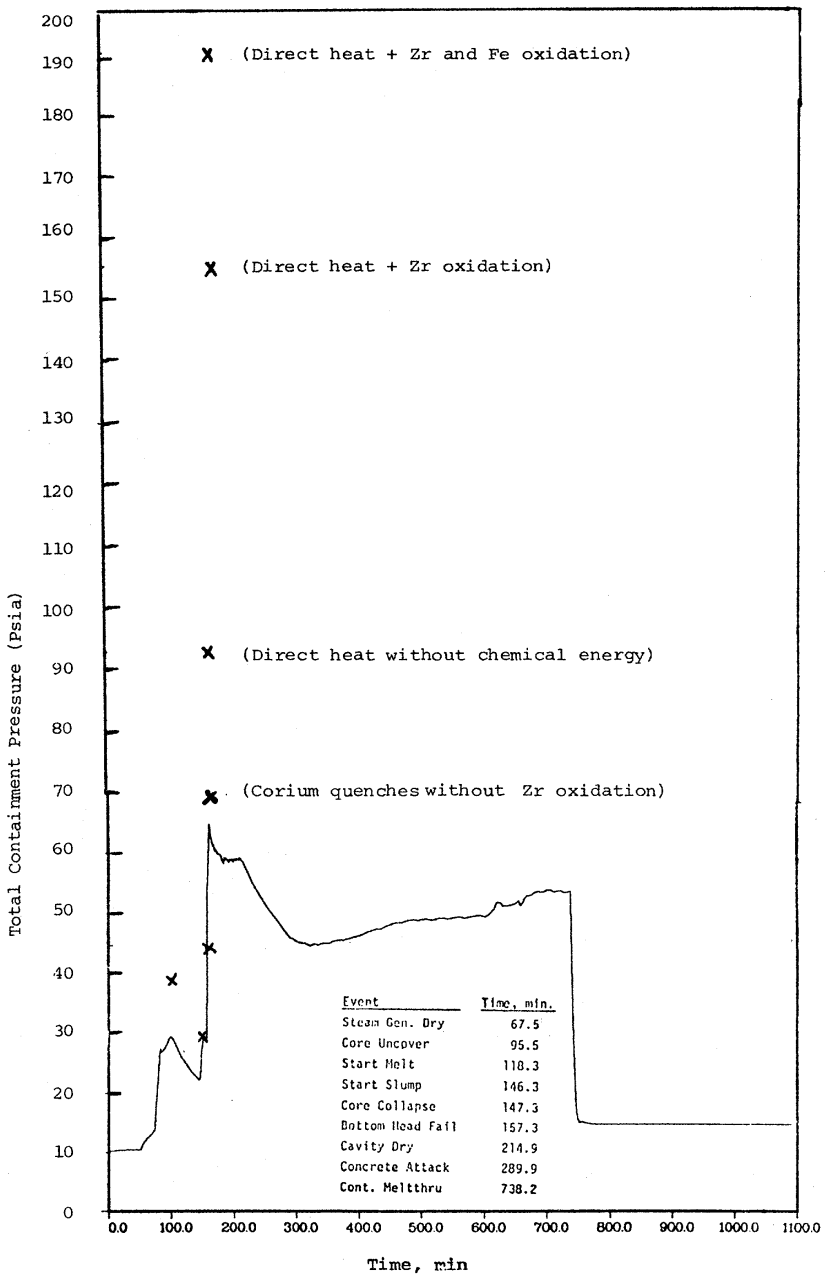

FIG. III.C.8. Comparison of containment pressure, for Surry $T_{M L B}-\varepsilon$ sequence, as calculated approximately by this study $(\times)$ with the computer predictions (solid line) of Gieseke et al. (1984).

$\mathrm{H}_{2} \mathrm{O}$ remains as steam and the resultant pressure and temperature are

$$
\begin{aligned}
& p_{\text {st }}=0.185 \mathrm{MPa}(26.8 \mathrm{psia}), \\
& p_{\text {air }}=0.087 \mathrm{MPa}(12.6 \mathrm{psia}), \\
& p_{\text {tot }}=0.272 \mathrm{MPa}(39.4 \mathrm{psia}), \\
& T=391 \mathrm{~K} .
\end{aligned}
$$

The water and steam are actually emitted over a period of approximately half an hour and there is time for heat transfer to the walls. As a result the pressure is predicted (Figure III.C.1) to decline gradually after peaking at about $0.2 \mathrm{MPa}$ (29 psia).

Subsequent to core uncovery, the remaining water in the pressure vessel boils at a lower rate (and the core heats up rapidly). The steam already in the containment condenses upon various surfaces leading to the fall in containment pressure shown in Figure III.C. 1 at times be- tween about 100 and about 150 minutes. This can also be seen clearly in the plot of the partial pressures of gases and vapors contributing to the overall containment pressure as shown in Figure III.C.2. During this time, the fission product decay heat is augmented by heat from the zirconium-water reaction. At 118.3 minutes the core begins to melt-an event barely reflected in the containment thermal hydraulic parameters shown. Of course, a plot of fission product content within the reactor pressure vessel would be expected to show the effects of the onset of core melting more significantly. At 146.3 minutes, the core begins to slump to the bottom of the reactor vessel (causing rapid boiling of the remaining water there and sending a surge of steam to the containment vessel). Approximately one minute later, the remainder of the core is predicted by the computer calculations to collapse into the bottom head.

About ten minutes after the core collapses, the reactor pressure vessel fails, and the molten core, together with the melted remains of the vessel internals and core support structure (a mixture called "corium" in the jargon of the trade) fall to the concrete floor of the reactor cavity. What happens then is uncertain, but in this particular calculation, it is assumed that water is released by the passive elements of the emergency core cooling system as the reactor pressure vessel fails and the pressure in the primary system is rapidly reduced. This relatively large quantity of water (about $7.9 \times 10^{4} \mathrm{~kg}$ ) is discharged into the reactor cavity onto the melt, where it boils away rapidly until the corium is quenched (solidified). This rapid steam evolution process leads to a significant pressure rise in the containment which may be separated into two components: the first $[\Delta P=0.12 \mathrm{MPa}(17.4 \mathrm{psia})]$ from the steam released from the vessel at reactor pressure vessel failure, and the second [ $\Delta P=0.13 \mathrm{MPa}$ (18.4 psia)] from the steam produced by debris quench. The two components together contribute to a peak total containment pressure of $0.44 \mathrm{MPa}$ (64.4 psia).

Since the time scale is shorter, these pressures can be roughly understood by simple calculations as follows.

At the time of core collapse, the temperature of the containment is predicted by the computer codes to be 369 $\mathrm{K}$ (Table III.C.2). The pressure of the air at that temperature is

$$
P_{\text {air }}=0.069(369 / 311)=0.08 \mathrm{MPa}(11.6 \mathrm{psia})
$$

and saturated steam has a specific volume of $1.91 \mathrm{~m}^{3} / \mathrm{kg}$ and a pressure of $0.088 \mathrm{MPa}$ for a total pressure of

$$
P_{\text {st }}+P_{\text {air }} \sim 0.168 \mathrm{MPa}(24.4 \text { psia })
$$

compared with the computer prediction of $0.172 \mathrm{MPa}$. There are $51000 / 1.91=2.67 \times 10^{4} \mathrm{~kg}$ of water remaining in the containment as steam.

Between core collapse and vessel dry out, $0.9 \times 10^{4} \mathrm{~kg}$ of saturated steam are released to the containment at the pressure relief valve set point.

This results in a total of $3.58 \times 10^{4} \mathrm{~kg}$ of steam with an internal energy of $6.68 \times 10^{7} \mathrm{~kJ}$ from the steam originally 
present and an additional $2.34 \times 10^{7} \mathrm{~kJ}$ carried by the steam from the vessel for a total of $9.01 \times 10^{7} \mathrm{~kJ}$. This amount of energy is sufficient to superheat the steam slightly. The specific volume is $1.4 \mathrm{~m}^{3} / \mathrm{kg}$ and the temperature and pressure are given by

$$
T=383 \mathrm{~K}
$$

and

$$
p_{\text {tot }}=p_{\text {st }}+p_{\text {air }}=0.208 \mathrm{MPa}(30.1 \mathrm{psia}) \text {. }
$$

At the time of vessel failure, $0.886 \times 10^{4} \mathrm{~kg}$ of liquid $\mathrm{H}_{2} \mathrm{O}$ and $2.23 \times 10^{4} \mathrm{~kg}$ of steam remain in the vessel. When the vessel fails the calculated temperature in the containment is $375 \mathrm{~K}$. At this temperature the containment can hold $3.26 \times 10^{4} \mathrm{~kg}$ of saturated steam, the remaining steam having condensed. The total amount of water is then

$$
M_{\text {water }}=(3.26+3.12) \times 10^{4}=6.38 \times 10^{4} \mathrm{~kg}
$$

with a total internal energy of

$$
U_{\text {tot }}=1.54 \times 10^{8} \mathrm{~kJ}
$$

or $2.41 \times 10^{3} \mathrm{~kJ} / \mathrm{kg}$ is the specific internal energy.

At this specific volume, $51000 / 63800=0.799 \mathrm{~m}^{3} / \mathrm{kg}$, saturated steam has a temperature of $396 \mathrm{~K}$, a partial pressure of $0.22 \mathrm{MPa}$, and a specific internal energy of $2.53 \times 10^{3} \mathrm{~kJ} / \mathrm{kg}$. The air pressure is $0.088 \mathrm{MPa}$ for a total pressure of

$$
p_{\text {tot }}=0.308 \mathrm{MPa}(44.6 \mathrm{psia}) \text {. }
$$

An additional $120 \mathrm{~kJ} / \mathrm{kg}$ or $0.75 \times 10^{7} \mathrm{~kJ}$ is required to keep the steam from partially condensing. We assume that this heat is supplied by the molten core which is at a temperature of $2550 \mathrm{~K}$ with an internal energy of

$$
M_{\text {int }}=1.37 \times 10^{5} \mathrm{MJ}
$$

and the required heat is about $5 \%$ of that available.

This estimated pressure is somewhat less than the 64.4 psia of Figure III.C.1. This, however, is not the end. Possible scenarios include:

(a) The accumulators will dump their water when the vessel depressurizes. If that water drops on the molten core, it will boil, cooling the core but adding steam and pressure to the containment.

(b) Alternatively, the molten core may be sprayed into the containment under pressure forming a fine aerosol which directly heats the air-steam mixture in the containment. This results in a higher pressure (the accumulator water then dumps onto the containment floor and does not immediately cool the containment).

The actual pressure in the containment depends upon the amount of $\mathrm{Zr}$ oxidation-whether the process proceeds through $\mathrm{Zr}+\mathrm{O}_{2}$ or $\mathrm{Zr}+\mathrm{H}_{2} \mathrm{O}$ - the rate at which heat is removed from the containment, and the rate at which the melt is quenched. These all depend critically on assumptions regarding how the melt is ejected from the pressure vessel and fragmented and, at later stages, upon its behavior during the core-concrete interaction. Both the code calculations and these estimates can only give a range of possible values.

In the first case, there is not enough energy in the melt to boil all the accumulator water. However, the water can interact with the $\mathrm{Zr}$ in the melt to produce additional heat. If all the $\mathrm{Zr}$ reacts, the heat is more than adequate to boil all the water. However, the amount that actually interacts depends upon the extent to which the water has access to the $\mathrm{Zr}$; this is modeled in terms of the fragment size and the codes predict that a few percent of the $\mathrm{Zr}$ is in fact oxidized at this stage. In these calculations, the remaining water is boiled away slowly by the decay heat. The pressure in the containment derives from the heating of the air and steam already present, the additional steam boiled by the melt, and the $\mathrm{H}_{2}$ generated by the reaction,

$$
\mathrm{Zr}+2 \mathrm{H}_{2} \mathrm{O} \rightarrow \mathrm{ZrO}_{2}+2 \mathrm{H}_{2}+616 \mathrm{MJ} / \mathrm{kg} \text { mole. }
$$

In the absence of the $\mathrm{Zr}$ reaction, the amount of water boiled can only be found by trial and error using the heat capacity of the core and steam tables. The result is that about $4.47 \times 10^{4} \mathrm{~kg}$ of accumulator water can be boiled by the heat in the melt. The various energies available are shown in Table III.C.2.

The $1.09 \times 10^{5} \mathrm{~kg}$ of saturated steam in $5.1 \times 10^{4} \mathrm{~m}^{3}$ have a specific vol. of $0.470 \mathrm{~m}^{3} / \mathrm{kg}$, at a pressure of 0.393 $\mathrm{MPa}(56.9 \mathrm{psia})$, a temperature of $416 \mathrm{~K}$. At this temperature, the air pressure is

$$
p_{\text {air }}=0.069(416 / 311)=0.092 \mathrm{MPa}(13.3 \mathrm{psia})
$$

and the total pressure is

$$
p_{\text {tot }}=P_{\text {st }}+P_{\text {air }}=0.485 \mathrm{MPa}(70.3 \text { psia }) \text {. }
$$

In this scenario, we expect that the zirconium oxidation and the decay heat of the melt will continue to heat the saturated steam atmosphere of the containment; however, they should not do so rapidly on the time scale of removal of heat to the walls. Indeed, this estimate of the containment pressure is already in excess of the computer code prediction, presumably because of the losses.

The alternative scenario in which the melt is sprayed as an aerosol into the containment results in the direct heating of the original air and steam. The energy available is now $2.91 \times 10^{8} \mathrm{~kJ}$ (Table III.C.2) since the accumulator water does not participate. From Table III.C.2 the heat capacity of the melt is $2.7 \times 10^{4} \mathrm{~kJ} / \mathrm{K}$, hence the internal energy of the melt may be written as

$$
\begin{aligned}
U_{\text {melt }} & =1.37 \times 10^{5}+2.7 \times 10^{4}(T-2550) \mathrm{kJ} \\
& =6.82 \times 10^{7}+2.7 \times 10^{4} T \mathrm{~kJ}
\end{aligned}
$$

and, using the steam tables, one finds that the temperature is

$$
T=793 \mathrm{~K}
$$

and

$$
\begin{aligned}
& p_{\text {st }}=0.46 \mathrm{MPa}(66.6 \mathrm{psia}), \\
& p_{\text {air }}=0.69(859 / 311)=0.176 \mathrm{MPa}(25.5 \mathrm{psia}),
\end{aligned}
$$


or

$$
p_{\text {tot }}=0.64 \mathrm{MPa}(92.7 \mathrm{psia}) \text {. }
$$

The $\mathrm{Zr}$ is now in the form of an aerosol in the containment and may be oxidized directly,

$$
\mathrm{Zr}+\mathrm{O}_{2} \rightarrow \mathrm{ZrO}_{2}+1100 \mathrm{MJ} / \mathrm{kg} \text { mole }
$$

releasing $807 \times 10^{7} \mathrm{~kJ}$. The temperature is then given by the steam tables to be

$$
T=1,34 \times 10^{3} \mathrm{~K}
$$

and

$$
\begin{aligned}
& p_{\text {st }}=0.773 \mathrm{MPa}(112 \mathrm{psia}), \\
& p_{\text {air }}=0.297 \mathrm{MPa}(43 \mathrm{psia}), \\
& p_{\text {tot }}=1.07 \mathrm{MPa}(155 \mathrm{psia})
\end{aligned}
$$

This should be compared with the design pressure of the containment, about $0.41 \mathrm{MPa}(59 \mathrm{psia})$ and the expected failure pressure, about $0.925 \mathrm{MPa}$ (130 psia) (Table III.F.1).

In addition, the iron can also oxidize (Handbook of Chemistry and Physics)

$$
0.947 \mathrm{Fe}+1 / 2 \mathrm{O}_{2} \rightarrow \mathrm{Fe}_{0.947} \mathrm{O}+279 \mathrm{MJ} / \mathrm{kg} \text { mole }
$$

and the $34140 \mathrm{~kg}$ of $\mathrm{Fe}$ can oxidize to generate $4.93 \times 10^{7}$ $\mathrm{kJ}$ (there is only enough $\mathrm{O}_{2}$ to oxidize about $27 \%$ of the $\mathrm{Fe})$. An interpolation of the steam tables yields the result that the pressure in the containment could reach, if it did not fail first, $1.32 \mathrm{MPa}$ (191 psia). Of course this most pessimistic number assumes that all the core fragmented into an aerosol so that heat transfer and zirconium oxidation are complete. This is generally considered to be highly unlikely.

The details of the computer programs also tell us how much heat is transferred to the walls during the period of melt through and core ejection. This transfer occurs on a time scale of about an hour; hence it may be neglected during processes which complete within a small fraction of an hour but not over longer times.

The core debris lying on the floor of the containment will reheat as a consequence of the radioactive decay, melt and begin to attack the concrete floor. As a result, gases are given off which, if the containment is still intact, will further load the containment and may eventually cause it to fail. The process depends on the rates of attack, which in turn depend on how the debris is distributed. The effect on the containment is a balance among the rate at which heating takes place, gases are evolved, and heat is dissipated throughout the containment. We have not attempted to estimate the resultant pressures.

We now return to the computer calculation for the remainder of the discussion.

Given the detailed scenario used in the computer codes, about $3.3 \times 10^{4} \mathrm{~kg}$ of water remain on the cavity floor that was not evaporated in the corium quenching process. This water continues to boil in the reactor cavity owing to the continued generation of decay heat until 214.9 minutes, when the cavity is finally dry. During this time the steam condenses on the walls and materials inside the containment slightly faster than it is produced. This leads to a relatively small drop in pressure to a value of 0.4 $\mathrm{MPa}$ (58.6 psia) in the containment. Thereafter, for a little over an hour after the reactor cavity dries out, the steam condenses rather rapidly and the containment pressure drops to about $0.31 \mathrm{MPa}$ (45 psia).

After the cavity is dry, the corium heats up again, remelts, at 289.9 minutes, and begins to attack the concrete base mat. The noncondensible gases generated in the course of the dissociation of the concrete cause the pressure to rise slowly in the containment. In the particular TMLB'- $\varepsilon$ scenario shown, the corium penetrates through the base mat at 738 minutes, relieving the containment pressure and releasing a portion of the radionuclides that are suspended within the containment to permeate into the soil beneath the containment structure (which acts as a very efficient filter against subsequent releases of fission products to the air outside the containment).

If the reactor base mat were substantially thicker than that of the Surry plant used in the example, the pressure could increase within the containment until it failed (either as a result of leakage through a relatively small opening which might stablize the pressure, or until the containment cracked with a large hole and depressurized rapidly). Alternatively, given sufficient time, site power might be restored (either from external sources or by eventually starting-or replacing-one or more emergency diesel generators) and the pressure might then be brought within acceptable limits by the action of containment sprays and fans.

After reactor pressure vessel meltthrough occurs at 157 minutes, the metal-water reactions occurring during the corium quench generate hydrogen which enters the containment. Still more hydrogen and other noncondensible gases (such as carbon monoxide and carbon dioxide) are subsequently generated by the core-concrete interaction. Figure III.C.4 shows that for this particular calculated sequence and in this large, dry containment structure, the hydrogen ignition point would not be reached-primarily because sufficient steam is generated to prevent the flammability limits from being reached in the hydrogen-airsteam mixture.

Figure III.C. 5 shows the total airborne aerosol mass at various times after failure of the reactor pressure vessel head. Just after reactor pressure vessel failure, a large quantity of core debris is suspended as an aerosol. These aerosols, and associated fission products, are calculated to settle out within a few hours, substantially reducing the airborne density. However, more aerosols are added after about 200 minutes as the core remelts and then begins to attack the concrete. Figure III.C.6 shows a partial isotopic subdivision of this total mass of aerosols. Figure III.C.7 shows the quantities of nonradioactive gases present in the containment.

By comparing Figures III.C.1 and III.C.5, we see that if the containment failed at or close to the time at which it was subject to its highest pressure (at about 158 
minutes) it would do so close to the time of the highest airborne mass. Therefore, failure at this time would have the highest potential for significant release of radionuclides; such a sequence is considered in the analysis of TMLB' $^{\prime} \delta$ in BMI-2104 Vol. V. As shown in Figure III.C.6, if the containment did not fail until several hours later, the airborne densities of Cs and I would have been substantially reduced from their peak values. Under these circumstances, the principal isotopes available for release from the containment would be aerosols liberated in the concrete attack (Te along with "other" radioactive and nonradioactive materials).

The extension of the above TMLB' scenario description to other large dry PWR's is straightforward. The calculated magnitudes and timing of the events would be expected to vary slightly with different power levels and containment sizes, but the general features of the scenario would presumably be the same. See for example, the treatment of TMLB' $^{\prime}$ in the Zion plant as described in Vol. VI of Gieseke et al. (1984).

In some large, dry PWR's the reactor cavity might be more completely filled with water. Such an accident scenario would be expected to proceed along lines similar to the events shown in Figure III.C.1, but the reactor cavity would not be expected to dry out at 215 minutes. Steam would continue to be generated and the pressure would also be expected to rise slowly beyond the values shown in Figure III.C.1. The core concrete interaction would then be expected to occur at a later time. Under such circumstances, it is possible to develop scenarios in which fewer radionuclide aerosols would appear in the containment building. However, the total quantity of aerosols generated over the time period of the accident scenario is not as critical a variable for evaluating source term magnitudes as is the quantity of aerosols that remains in suspension at the time of containment failure.

For a PWR with an ice condenser containment, the TMLB' accident related processes occurring inside the reactor pressure vessel will be almost identical to those occurring in a reactor in a large, dry containment. However, in an ice condenser facility, the steam emitted at 85 minutes would almost immediately be condensed. Thus, the initial pressure spike inside the containment (as shown in Figure III.C.1) would barely exist. The pressure increase that did occur would be caused primarily by transfer of the thermal energy of the accident to the noncondensible gases within the containment prior to the accident. Thus, the large pressure spike shown in Figure III.C. 1 at reactor pressure vessel failure (157 minutes) would start from a lower level, and would undoubtedly be much smaller in magnitude. On the other hand, the containment vessel has a smaller volume, which would act to increase the peak pressure ratios for the two containment structures in inverse proportion to their volume ratios (assuming all other variables remained constant). More importantly, the noncondensible gases released up to this time in the sequence would be mostly hydrogen. Thus, as a result of the large quantities of steam condensed by the melting ice, the mixture of gases and vapors in the con- tainment building could possibly be above the flammability limit-and perhaps the explosion limit-of hydrogenair-steam mixtures (cf. Figure III.C.4). Two variations of the TMLB' sequence are explicitly considered for an ice condenser containment in Vol. IV of Gieseke et al. (1984).

The modification of the results shown in the figures for application to other scenarios is less obvious, but can also be seen in a general way. If, for example, the primary system in a TMLB' sequence heated up enough, a loop seal might fail and release pressure prior to the time at which the reactor pressure vessel melts through. Under these hypothesized conditions, steam could enter the containment at an earlier time than shown in Figure III.C.1 for vessel melt-through. If this occurred, it could cause a pressure spike related to the initial portion of the pressure increase at melthrough in Figure III.C.1: i.e., the increase owing to release of the energetic steam within the primary system $[\Delta P=0.12 \mathrm{MPa}(17.4 \mathrm{psia})]$. Following the release, the steam would then begin to condense and the pressure would decrease. The peak total pressure spike that occurred thereafter (at the time of reactor pressure vessel failure for this loop seal failure case) would be correspondingly reduced in direct proportion to the effectiveness of the steam condensation process prior to reactor pressure vessel failure.

\section{III.C.2. Containment bypass sequences}

For sequences in which the containment is bypassed (the $\mathrm{V}$ sequences), the core must still melt or at least be badly damaged to release radionuclides. But the containment cannot act to hold up radionuclides.

In a typical containment bypass sequence, a valve in a pipe leading from the primary coolant circuit through the containment wall, opens, and the secondary side of the pipe is immediately subjected to the high primary system pressure and breaks. Then any radioactivity released into the primary system passes directly through the pipe.

However even in this case there will not necessarily be complete release of radioactivity to the environment. Each case is likely to be different. A study of the Surry plant has suggested that the pipe would break in an auxiliary building outside the containment where, during accident conditions, the break would be underwater (Warman, 1984). Then the radionuclides would be scrubbed by the water-just as the radionuclides are scrubbed in the pressure suppression pool of a BWR (Section IV.C.7). It has been suggested that in the Indian Point III reactor the secondary section of the pipe would break inside the containment vessel, so that what initially appears to be a containment bypass sequence is averted.

Even if the pipe leads directly to the environment, there is likely to be some deposition of radionuclides along the length of the pipe. The flow will be turbulent so that the surfaces will be available for deposition. At the moment of valve failure and subsequent pipe break there will be a rush of fluid (steam) passing through the pipe. If all the 
radionuclides are available for release at this time, few will be deposited. However, if the RPV depressurizes through the break before most of the radionuclides are released, then there will be little pressure to drive the radionuclides through the pipe. These deposition processes are discussed further in Section IV.C and the computer codes to describe them in V.B.7. Experiments to "validate" these codes are in progress at ORNL, Hanford (LACE program), and Sweden (MARVIKEN program).

The Reactor Safety Study (NRC, 1975) showed that the containment bypass sequence $\mathrm{V}$ was a major risk contributor for the Surry plant. Prompted by this, changes were made in the frequency of inspection of the valve leading through the containment, and the failure probability was thereby reduced. This immediate use of the RSS methodology to reduce risk was, and is, widely applauded. The study group notes here that if careful thought is given to the containment bypass sequences for each reactor, there is also potential for reduction of the consequences associated with the sequence. This is particularly true in the initial design stage of a reactor. This can be done by ensuring that all potential bypasses lead to auxiliary buildings with additional potential for radionuclide removal.

Elsewhere in the report (Section IV.A.5) it is noted that if a steam generator fails during a TMLB' accident, there is a containment bypass path to the secondary system and through a pressure relief valve direct to the environment. Appropriate arrangement of the outlet pipe can increase the potential retention in this hypothetical scenario.

\section{III.C.3. Failure to isolate containment}

If some valve or penetration of the containment has been left open, then the containment vessel cannot contain any radionuclides released into it. Any accident will proceed almost independently of the holes in the containment, except that the pressure in the containment cannot build up.

For example during the boiloff phase of the TMLB' sequence, the steam will pass out through the hole. During the period when steam is condensing in the containment, the small pressure difference will reverse and gas will flow into the containment from outside.

When radioactivity is released, just before and just after the reactor pressure vessel failure, the pressure will act to drive out the steam and radioactivity, but not at as high a pressure as was calculated in Figure III.C.1. Some holdup of radionuclides will still occur depending on the size of the hole. The exact amount is dependent upon the details of aerosol deposition and not upon the general timing of accident conditions. This is discussed further in Sections IV.E.1 and V.D.2.

The details of the calculation will depend upon where the open hole in the containment goes to. A large hole direct to the outside is almost sure to be noticed. Holes in the containment are most likely to be along penetrations to various auxiliary buildings which can allow the radionuclides to deposit. The amount of deposition is there- fore critically dependent on the details of the location and size of the opening.

The study group notes that there have been several recorded instances where a reactor has operated for a considerable length of time with a hole through the containment through careless operation (see Section IV.D.5). Such mistakes are more likely just before or just after a shutdown, and it seems that a core meltdown is also more likely at such times. This unnecessary increase of risk can be avoided by careful operational procedures; allowing operation of the containment only at subatmospheric pressures can clearly make such a mistake less likely.

Just as in the containment bypass sequences, careful thought can show ways to reduce both the probability and consequences of an accident where the containment is not isolated. For example, the penetrations that might be left open to the outside can be led to an auxiliary building with (some) potential for radionuclide retention.

\section{III.C.4. BWR sequences}

There are two important sets of BWR sequences. Sequences such as AE (loss of coolant accident and failure of ECCS) have been calculated to result in high release of radioactivity. Although these sequences were believed to have a low probability (Table III.B.3), the early reactor vessel meltthrough and early containment failure can lead to high radioactivity release and makes them important. The energy available in the core-melt can be greater than in a PWR case, and hence the radioactivity release greater, because of the large amount of zirconium in the channel boxes (Figure III.A.3). Outside NRC, the source-term community has not given much attention to these sequences and the APS study group much less.

At the other end are the more probable transient sequences. Transient events are initiated by any occurrence which requires the reactor to shutdown. Following the shutdown, steam will continue to be generated, but at a slower rate. The steam would flow to the condenser via the turbine bypass and return as a condensate by the condensate return system, maintaining a normal water level in the reactor.

The TC sequence results when the reactor protection system fails to SCRAM the reactor. Basically there are two variants of this sequence: one in which the containment is assumed to breach before severe fuel damage $\left(\mathrm{TC}_{1}\right)$ and the other in which the containment is assumed to breach after severe fuel damage $\left(\mathrm{TC}_{2}\right)$.

In the $\mathbf{T C}_{1}$ transient the main steam isolation valves isolate the reactor from the turbine generator and the condenser and the recirculation pumps trip. As the reactor continues to generate power, the pressure rises rapidly until the set point of the safety relief valves is reached. Steam would blow down' through the relief valves to the suppression pool, and the drop in the reactor coolant pressure would increase the voiding of the core, causing the 
$395 \quad$ Boundary plasma

$441 \quad$ Atomic phenomena in hot dense plasmas

Quarterly Reviews of Biophysics, Vol. 17, No. 2, 1984

125 Biomolecular dynamics: a report from a workshop in Gysinge, Sweden, October 4-7 1982

153 Electron spin polarization of photosynthetic reactants

Reports on Progress in Physics, Vol. 48, Nos. 2-4, 1985

171 The interacting boson model of nuclear structure

223 Semiconductor device modelling

227 Microwave semiconductor devices

327 Coulomb fission

375

Angular momentum transfer and charge cloud alignment in atomic collisions: intuitive concepts, experimental observations and semiclassical models

415 Compton scattering and electron momentum determination

483 Cataclysmic novae

531 High-resolution laser spectroscopy of atomic systems

Rivista del Nuovo Cimento, Vol. 7, Ser. 3, Nos. 7-10, 1984

Pure leptonic weak processes

Strangeness-conserving semi-leptonic weak processes Nonleptonic weak interactions

Galactic high-energy astrophysics after the gamma-ray astronomy mission of the ESA COS-B Satellite

Soviet Journal of Particles and Nuclei, Vol. 15, Nos. 4 and 5, 1984

325 Interaction of heavy ions: the form of the potential and estimate of its parameters

341 Investigations of nuclear structure with allowance for the continuum

$361 \quad$ Excited states of hypernuclei

$390 \quad$ Path-integral methods in polaron theory

419 Dibaryon resonances

439 Use of semiconductor detectors in high-energy physics

446 Phenomenological description and Monte Carlo simulation of multiparticle production in high-energy $N N$ and $N$ collisions

464 Geometrical analysis of nonlinear equations in the theory of relativistic strings

481 On the physical vacuum in $Q C D$

497 Problems of the theory of nuclear interactions in the relativistic approach
M. F. A. Harrison

Jon C. Weisheit

Olle Edholm, Lennart Nilsson, Otto Berg, Måns Ehrenberg,

Flora Claesens,

Astrid Graslund, Bo Jonsson, Olle Teleman

A. J. Hoff

J. P. Elliott

C. M. Snowden

J. E. Sitch

V. E. Oberacker,

W. T. Pinkston,

H. G. W. Kruse

I. V. Hertel, H. Schmidt,

A. Bähring, E. Meyer

M. J. Cooper

G. T. Bath

R. C. Thompson
V. N. Bragin, M. V. Zhukov

I. Rotter

L. N. Bogdanova,

V. E. Markushin

C. Rodriguez,

V. K. Fedyanin

M. M. Makarov

P. F. Manfredi

V. S. Barashenkov,

N. V. Slavin

B. M. Barbashov,

V. V. Nesterenko

V. N. Pervushin

V. R. Garsevanishvili,

Z. R. Menteshashvili,

D. G. Mirianashvili,

M. S. Nioradze 
lated the effects of earthquakes and have estimated that for this particular plant they would apparently dominate the risks. However, the source terms predicted in the analyses conducted for such accidents have been smaller than those predicted in the RSS results. (The analysts for the Indian Point PRA attempted to incorporate some of the newly developed models and codes for source term evaluations that have been prepared since the results of the Three Mile Island accident became apparent.) The study group did not review the Indian Point PRA in any detail. We note in passing, however, that the analysts who conducted the PRA's completed their efforts while the source term methodology was still in an embryonic stage, prior to the intensive peer review to which the methodology has recently been subjected. Consequently, we do not feel that we are in a position to express a wellsubstantiated opinion on the reliability of the Indian Point PRA results.

For completeness, it should be noted that acts of war have also been neglected in the probabilistic risk analyses that have been conducted for nuclear power plants. For perspective, it should be noted that the probability that the U.S. might be involved in a war in any given year which could affect this continent is probably of the order of $1: 100$. Under conditions of war, a variety of threats to nuclear plants might be imaginable. Some such scenarios could almost certainly lead to conditions yielding larger source terms than the accident scenarios discussed in this review. In fact, some scenarios might conceivably be developed which could lead to larger source terms than were derived in the RSS projections. The study group notes that acts of war exceed the scope of the NRC's responsibility for maintaining reactor safety. We also acknowledge that war-related scenarios leading to large source terms are quite improbable and have large uncertainties associated with them. Consequently, though we have speculated about a few such scenarios in passing, we have not addressed them in any significant manner in this review.

\section{CHEMICAL AND PHYSICAL PHENOMENA}

IV.A. Thermal hydraulics: Fluid flow, heat transfer, and in-vessel phenomena

\section{IV.A.1. Introduction}

In this section we expand upon the discussion of scenarios in III.C and discuss the thermal hydraulic phenomena that are important.

In Table III.A. 3 we showed several phases of the reactor accident that are moderately distinct. The first four phases end with the failure of the reactor pressure vessel and a large pressure increase in the containment. In the sections that follow we discuss the phenomena that must be modeled in each phase. In Chapter $\mathrm{V}$ we will describe how well the computer codes describe the phenomena listed here.
There are two sets of quantities that must be understood: the flow of water throughout the system, and the heat transfer between various quantities of water or steam, and between the water and metal surfaces. This field is often referred to as thermal hydraulics. The more general field of fluid dynamics, or hydrodynamics, and heat transfer are usually described by groups of dimensionless quantities. This carries over into thermal hydraulics. For example, the flow of coolant that is circulated through the core during normal operations will require a certain amount of pumping power that is determined in part by the frictional losses resulting from the water passing through the passages between the fuel rods and vessel wall. These losses are usually represented by formulas similar to the formulas that describe the flow of fluids in pipes. Thus, the loss can be expressed in terms of a drag coefficient $C_{D}$ and the fluid velocity $U$ as $C_{D} U^{2}$, where $C_{D}=1 / 2 \rho\left(K+f L / D_{e}\right)$. In this expression, both $f$ and $K$ represent frictional interaction between fluid and solid surface, but the latter is meant to account for the transients caused by the fluid entering and leaving the passageway while the former accounts for the "major" effect as the fluid flows along a distance $L$ of the "pipe" whose effective diameter is given in terms of the pipe area $A$ and whose wetted perimeter $s$ by $D_{e}=4 A / s$, the density of the fluid being $\rho$.

On theoretical grounds one can show that the friction factor $f$, for example, can be represented as a function of another dimensionless quantity, the Reynolds number $\mathrm{Re}$, and possibly one or more additional dimensionless quantities. The Reynolds number plays an important role in many aspects of fluid dynamics where viscous effects are significant; for $\operatorname{Re}=U d / v$, where $d$ is a characteristic distance and $v$ is the kinematic viscosity. The transition from laminar flow to turbulence is determined largely by the value of Re. For large Reynolds number the flow is laminar; for small ones it is turbulent. For that reason, the formula for the friction factor will also depend on what range of $\mathrm{Re}$ exists in the flow field. The thickness of the boundary layer between the solid surface of the walls or the fuel rods and the bulk fluid will also scale with Re; and this will be of particular interest to the heat transfer process, which can be expected to differ in manner near the walls from its behavior within the bulk fluid. Indeed, this important aspect of heat transfer usually requires the introduction of yet another dimensionless quantity, the Prandtl number, $\operatorname{Pr}=v / \alpha$, which is simply the ratio of one diffusivity ( $v$ for fluid momentum) to another ( $\alpha$ is the thermal diffusivity and $\alpha=k / \rho c$, where $k$ is the ordinary thermal conductivity, $c$ is the heat capacity, and $\rho$ is the fluid density, as above).

The rate at which heat may be expected to flow from solid to fluid (or vice versa) will be proportional to the temperature difference between the two regions. The constant of proportionality $h$ is the heat transfer coefficient. This quantity, in turn, may be obtained in terms of another dimensionless quantity, the Nusselt number, $\mathrm{Nu}=h d / k$. In a number of instances, however, it will be more convenient to obtain $h$ through the Stanton number, 
$\mathrm{St}$, which can be expressed as $\mathrm{St}=\mathrm{Nu} / \mathrm{RePr}$, whence $h=(k / d)$ StRePr, in terms of the previously defined group of dimensionless quantities. As an illustration, consider a formula proposed by Dittus and Boelter (1930) which is quite accurate for fully developed turbulent flow in smooth pipes, over a certain range of termperatures and flow conditions,

$$
\mathrm{St}=0.023 \operatorname{Re}^{-0.2} \operatorname{Pr}^{-0.8}
$$

There are three constants in this formula, in addition to the Reynolds number and the Prandtl numbers, which are fitted to data over the range of temperature and flow conditions. Expressions of this nature, for finding values of $h$ or $f$ or similar variables, are usually referred to as correlations since they correlate experimental data. It is important to observe that such correlations are most often empirical, having been determined through experimental measurements. Consequently, there may be little or no theoretical basis for extrapolating them to ranges of temperature and flow conditions that are far from the range where their validity has been well established. Quite clearly, the regimes that resemble normal operating conditions in reactors have been thoroughly explored and are well understood. So are the regimes that would develop soon after large or small pipe ruptures in the primary system. These are the accident schemes that were highlighted during the many years of studies concerned with emergency core cooling systems, and that is why one is reasonably confident that the regime of blowdown is rather well understood. The same degree of confidence, however, cannot be held with respect to regimes that can develop once the core begins to uncover and core degradation becomes significant. Such considerations that must be weighed if one is to decide whether a certain area of thermal hydraulics requires further study or not before the methodology of calculating the consequences of severe reactor accidents can be said to rest on sound scientific ground.

\section{IV.A.2. Blowdown}

When a break occurs in the primary system piping, the pressure in the primary system will drop-eventually to the level of the pressure in the containment vessel, which starts at or near atmospheric pressure. Since the temperature of the hot water $(500 \mathrm{~K})$ is higher than the boiling temperature of water at atmospheric pressure, the water will flash (quickly boil) to steam. Fluid will be forced out of the reactor vessel. This is called the blowdown. In a large break (such as the AB sequence) the rate of the loss of fluid depends upon where the break occurs. If the break is in the cold leg, the water will flash to steam as it leaves the break and the flow will be a two-phased choked flow which is slower than the flow of subcooled or saturated water. If the break is in the hot leg, the fluid will quickly turn into steam, and the mass flow will be slower than liquid or two phase flow.

For a large break, the blowdown will be very rapid and will be over in about a minute. At the end of that time the core will be uncovered. In most design basis safety calculations, the important issue is whether the Emergency Core Cooling System (ECCS) will reflood the core before the core temperature is dangerously high. For such questions, the calculation of the rate of blowdown is important. These calculations have received a great deal of attention in the period 1971-79 and the detailed phenomena are now well understood (Bankoff and Jones, 1977). The passive part of the ECCS system will almost certainly operate and the accumulators will dump the water into the reactor vessel as soon as the pressure drops below 680 psia, at which time the check valve opens. However for an accident which leads to core melt, the active part of the ECCS is assumed not to operate and the core will dry out again. The duration of the blowdown is short compared with the duration of core melt; and any small change in this duration has only a small effect on subsequent events.

For a smaller pipe break the blowdown is much slower. The duration of the blowdown is now long enough that there is no sharp distinction between boiloff and blowdown and the exact details of the blowdown affects the subsequent events much more.

\section{IV.A.3. Boiloff (until the core is uncovered)}

The simplest boiloff scenario occurs in a transient sequence such as TMLB' (see III.C.1) where the heat sink is lost, and the fluid leaves through the pressure relief valve. The heat transfer from the fuel rods to the primary coolant water is governed by "pool boiling;" this mode of heat transfer is sufficiently rapid that the steam generation rates, both in the secondary system and in the primary system, can be calculated reliably from the decay heat in the core. Only a small amount of the heat goes into increasing the temperature of the primary system piping. Very little also goes into heating of the containment gas, since the pipes are well insulated to prevent losses in ordinary operation. Figure IV.A.1 illustrates schematically the boiloff phase.

For the small pipe break, where the blowdown and boiloff are occurring simultaneously, the phenomena are more complex. It is important to describe the two phase flow at the location of the break accurately because this determines the time the core is uncovered.

\section{IV.A.4. Heatup}

After the core is uncovered, the fluid mechanical processes are no longer simple. The heat transfer from hot (uncovered) fuel rods to steam is much lower than the heat transfer to water, largely because of the lower heat capacity. As the fuel rods are uncovered, the surface area in contact with water decreases, and the rate of vapor (steam) generated diminishes. The fuel above the liquid level will only be cooled by the rising steam, and its temperature will rise. The rate at which the water boils will therefore drop and the temperature of the fuel will rise. This is shown in Figure III.C. 2 as a drop of pressure in 


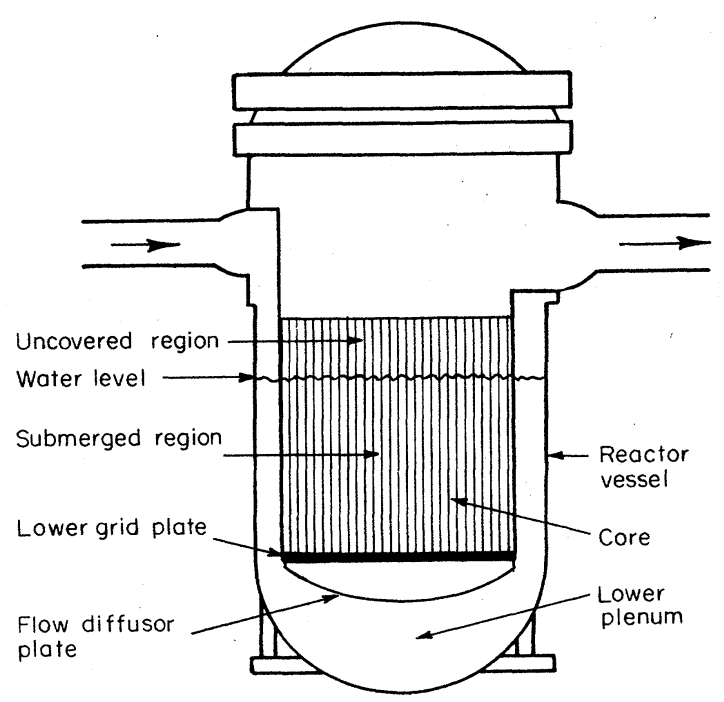

FIG. IV.A.1. Boil-off. Physical-Accident sequence has begun. Water inventory in the reactor vessel is depleting. The core has begun to uncover. Cladding has begun to degrade mechanically by ballooning and degrade chemically by oxidizing. Gap activity of fission products is released when cladding ruptures. Model-The heat rise in the exposed regions is calculated taking into account convective heat loss to flowing steam. The chemical reaction between zircalloy and steam is modeled using well-established rate laws. Ballooning is not simulated. The effect of the loss of heat with released fission products is not considered until fuel melting occurs.

the containment at 95.5 minutes when the rate of condensation of steam in the containment exceeds the boiloff rate.

Since the decay heat is higher in the center of the core than in the edges, the temperature will rise faster in the center. This difference is somewhat reduced by radiative heat transfer from the central rods to the outer rods and the outer rods to the reactor vessel. Figure IV.A.2 shows schematically the state of the core in this phase.

The heat transfer from rods to flowing steam and/or hydrogen is "usually" modeled using the standard Dittus-Boelter (1930) correlation for turbulent conditions, and a standard correlation for flow in tubes under laminar conditions. These correlations have a large data base and can be considered reliable to within $\pm 20 \%$ for normal forced convective flow conditions. Their accuracy decreases somewhat for conditions of flow accompanied by chemical reactions. When chemical reactions take place their accuracy is good to within $\sim 40 \%$ (Kress, 1984). The overall effect of the uncertainty in the heat transfer coefficients is small, however, because the amount of heat transferred is limited primarily by the heat capacity of the steam and its flow rate, not the heat transfer coefficient.

As portions of the cladding reach temperatures greater than $1300 \mathrm{~K}$, the chemical oxidation reaction of the zircalloy cladding with steam which was mentioned in Section III.B.1.e, begins to become significant. Factors determining the rate of oxidation are: availability of

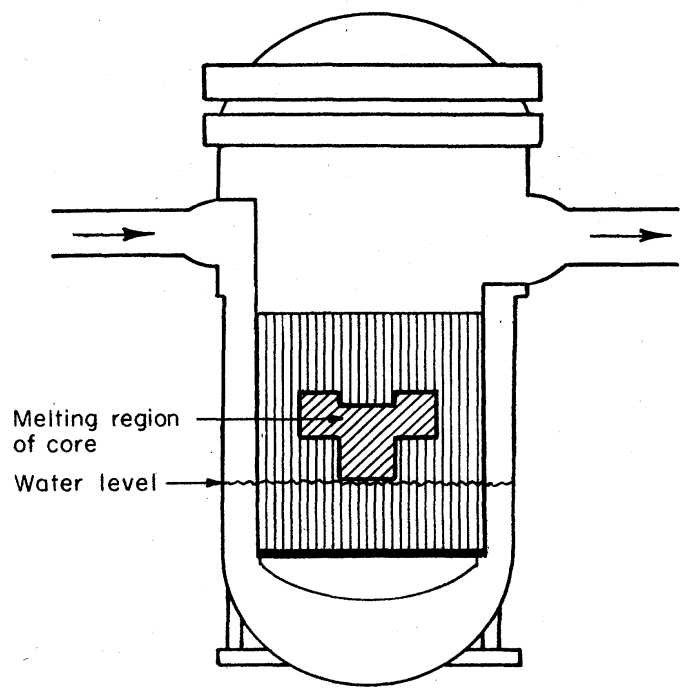

FIG. IV.A.2. Heat up. Physical-Exposed portions of the core are overheating. In the central core regions, furthest from the coolant, some of the fuel has melted. Fission product release is well established where the fuel is molten. The melting process progresses downward. Model-Heat is simulated to transfer to lower nodes representing the core. The nodes remain in place; physical movement is not simulated but is accounted for in the heat transfer analysis.

steam; decomposition of steam into hydrogen and oxygen; and mass transport (diffusion) of oxygen through zirconium oxide, from the outer surfaces to the inner part of the cladding. The energy liberated by the oxide formation is released near the outer surfaces and principally conducted through the cladding and oxide layer radially, and some is carried away by the steam and by the hydrogen formed in the reaction.

At about $2100 \mathrm{~K}$ zircalloy melts. It is known however that even at a temperature lower than $2100 \mathrm{~K}$, zircalloy can form a liquid phase with iron and uranium oxide. During this part of the accident differential expansion causes the gap between cladding and fuel to close, promoting the formation of liquids. The fuel rod may melt and flow locally. This flow may change the core geometry, the steam flow path, and the available surface area for further zirconium oxidation, and hence may alter the fuel rod heating and melting patterns.

The bottom of the core and the lower plenum can continue to be bathed in liquid coolant (with film boiling present) for a much longer period of time than the top of the core and the steaming rate from the bottom will determine, in part, the rate of fluid flow through the core. Other parts of the primary coolant system, particularly the steam generator with its high heat capacity, act as a region where steam can condense and return as liquid (reflux) to the lower plenum. By this time, the upper plenum and internal structures will have been heated by the passing steam for over an hour and will be unlikely to condense much steam. But the upper plenum may act as a filter, where aerosols can settle out upon comparatively 
cool surfaces. Thus, the thermal hydraulic behavior of the steam/hydrogen gas mixture and its interaction with walls and solid surfaces will influence the extent to which the fission products escaping from the core can pass out of the reactor vessel into the primary coolant system.

\section{IV.A.5. Natural convection}

It is widely suspected that at this stage in the accident the thermal hydraulics of the primary coolant system is dominated by natural convection and cellular (recirculating, cross flow, etc.) flow patterns. These are not modeled in the current set of risk analysis system codes discussed in Chapter V. The details of the heat transfer pattern throughout the primary system can, in the presence of natural convection cells, be significantly different from what less sophisticated zero dimensional or one dimensional thermal hydraulic codes would predict. The consequences of such departures from current modeling practice in risk analyses would be greatest for those accident sequences where there is a reasonable prolonged period (about an hour) between uncovering the core and vessel failure. These tend to be the transient induced, high primary pressure sequences, such as TMLB. Significant temperature variations across the core are expected when fuel melt starts, and the fuel will begin to block coolant passages. Table III.C. 1 shows that this will occur about 40 minutes before RPV meltthrough.

The type of convection that needs to be modeled is shown in Figure IV.A.3. Once convection cells are established, one may expect that convection will act to make the temperature distributions in the core more uniform, as well as in other portions of the primary that are connected via the circulation cells. This, in turn, should distribute the heat being released by the core over a wider region and result in the core's heating up more gradually, but also more uniformly. Some preliminary calculations (Seghal, 1984) confirm this trend, but also show very rapid core melting once the zirconium-steam ox-redox reaction is initiated.

In addition to the thermal convection within the core and upper plenum, natural circulation can provide some circulation around the primary system.

How these details of heatup will affect the details of core melt, and hence the final source term calculations is not yet obvious. The release of some fission products, particularly the less volatile ones, might be delayed as a consequence of the less rapid degradation of the core. At the same time the distribution of released fission products within the primary should become more widespread as the circulation cells tend to mix the fluid and smooth the temperature gradients. Whether such effects add to or subtract from the ease of retention of fission products in the primary is still difficult to foretell; studies of this are proceeding in several places (e.g., Johns et al., 1984).

It may be, however, that such high pressure sequences as TMLB will be affected very significantly by heat transfer processes that arise from natural convection and circulation of flow. It has been suggested, for example, that with more uniform heat distribution in the primary, the likelihood of vessel failure by the melt-through of the bottom head will no longer be the most probable route. Instead, the primary system may fail by a melt-through at a weaker spot within the primary and do so at an earlier time than might have been predicted. This could convert the TMLB sequence into a large or medium scale LOCA while the core still has a high degree of mechanical integrity. A failure at the pump seal is one possibility. The subsequent blowdown of the primary coolant system, and the slow condensation of the steam that enters the containment system, would then make it very likely that the sudden pressure steps in the containment pressure that are predicted at RPV melt-through (see Section III.C.1) would be appreciably reduced, making containment failure at this time even less likely.

The suggestion with a most dangerous consequence is that failure will occur first in the steam generator as the steam tubes on the primary side melt through or fracture. This could lead to an immediate pressure stress on the secondary system, which would be relieved through a pressure relief valve (PRV), which often leads directly to the environment (see Figure III.A.1). This would become a containment bypass sequence $(\mathrm{V})$, which has severe ramifications (see Section III.C.2).

The consequences of the considerations mentioned above may be less significant for BWR's than PWR's since the former have more massive structures in the core and pressure vessel, resulting in even less unobstructive passages than a PWR for cross-flow circulation patterns. Nevertheless, there appear to be ample reasons today to proceed with trying to understand more thoroughly the nature of natural convection and heat transfer in reactor systems, under conditions expected to exist in the event of severe accidents. This will be discussed further under Chapter VII, Research Program.

If natural convection cells are established, then vapor recirculating between the upper chamber and the core can return steam to the core, allowing a representative particle of steam to make several passes through the core region. If steam has been depleted by the zirconium-steam oxidation process this recirculation could increase the availability of steam at the surface of the fuel rods, and hence would increase the rate of the reaction between zircalloy and steam.

These aspects of the mechanism of metal/steam reaction will exist regardless of whether or not one assumes that there are recirculating, natural convection loops present. The progress of the reaction, however, can be quite different, if, for example, one adopts the oncethrough model for steam flow, rather than assuming that natural convection occurs. Then the metal/steam reaction decreases dramatically as the steaming rate drops. However, when the molten core debris falls into the bottom plenum, which is still filled with water, the reaction might start up violently once again. By this sequence of events sudden, strong bursts of hydrogen within the pressure vessel are predicted with bursts of steam escaping through the relief valve. Thus, the postulate of recircula- 


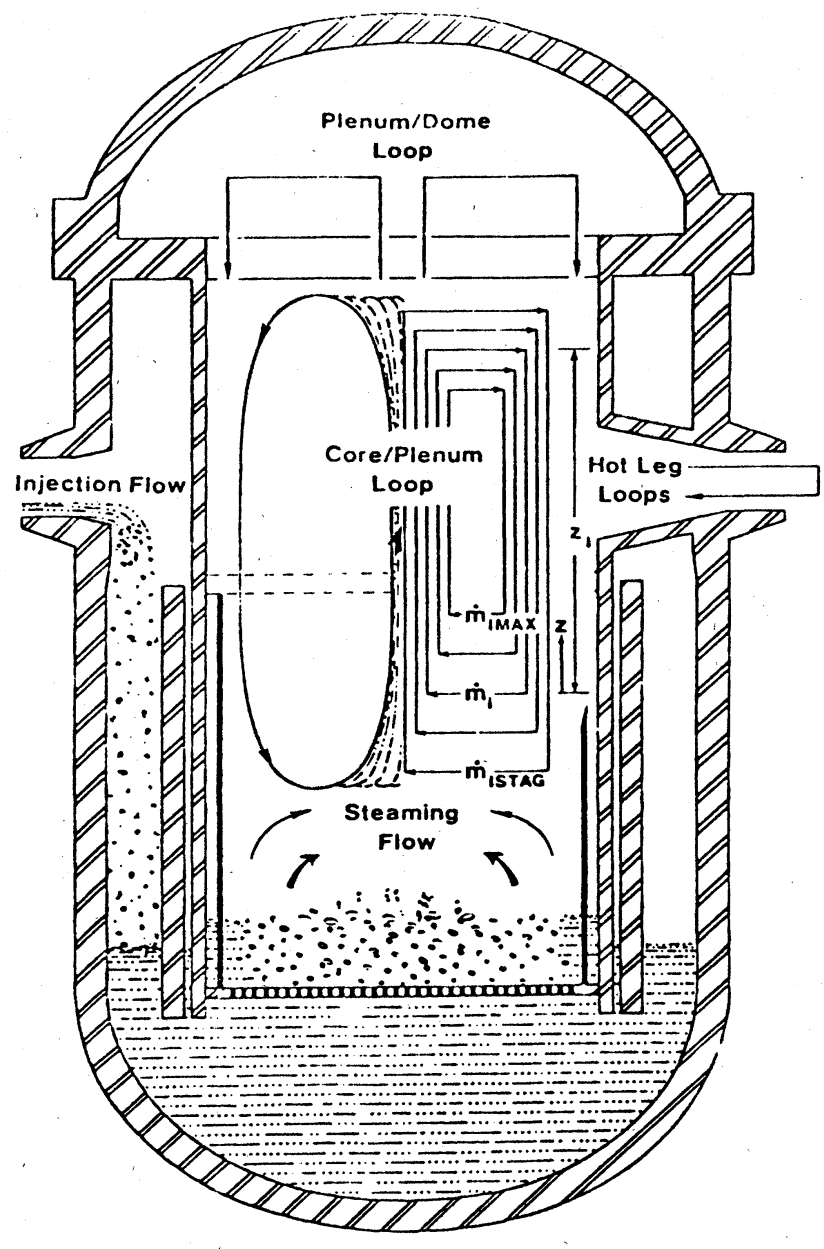

FIG. IV.A.3. Schematic of core/plenum recirculation pattern.

tion has as one consequence the smoothing out of events, and less abrupt changes in energy and gas liberation. Since recirculation also transfers heat to the upper plenum effectively, recirculation slows down the heating of the fuel rods and prevents condensation of radioactive aerosols on the upper plenum, sending them to cooler regions of the primary system.

\section{IV.A.6. Core melt}

The process of severe core degradation is complex. It involves melting of the fuel rods, along with the support structures and other solid material in the core (i.e., control rods, instrumentation rods) followed by the slumping of this mixture of molten material (referred to as "corium" in the jargon of the trade) to the bottom of the pressure vessel. The geometry of the core at this point is undetermined, and only general statements can be made about fluid flow rates (see Figure IV.A.4).

The least demanding model needed to analyze this situation requires at least a two dimensional, time dependent heat transfer calculation. If one assumes that the original axial symmetry of the core is retained through the melt down sequence, then the axial variation $(Z)$ and radial variation $(R)$ of temperature can be calculated, leading after each time-step to a two dimensional, time-dependent temperature distribution $T(Z, R ; t)$. Most safety studies adopt this approach in the interest of having numerical codes that can be run relatively quickly and cheaply in order to explore a variety of accident scenarios and reactor conditions. There are, however, more elaborate codes in existence and in the process of development by which one can try to explore the limitations of the somewhat simpler two dimensional calculations.

In such calculations it is customary to include, in addition to radiative heat transfer, axial heat conduction along the fuel rods as well as convective heat transfer to the surrounding fluid. At elevated temperatures, however, convection appears to have little influence on the course of melt down, aside from the steam starvation and hydrogen blanketing arguments presented earlier in connection with metal-steam reaction rates. Similarly, it is observed that heat conduction within fuel rods has only a small influence on the results of these calculations. (Radial conduction within fuel rods and radial temperature variations within a differencing node are neglected from the outset in the MARCH code and similar treatments.) Thus, radiative heat transfer emerges as the dominant mechanism for redistributing energy in many of these models and, not

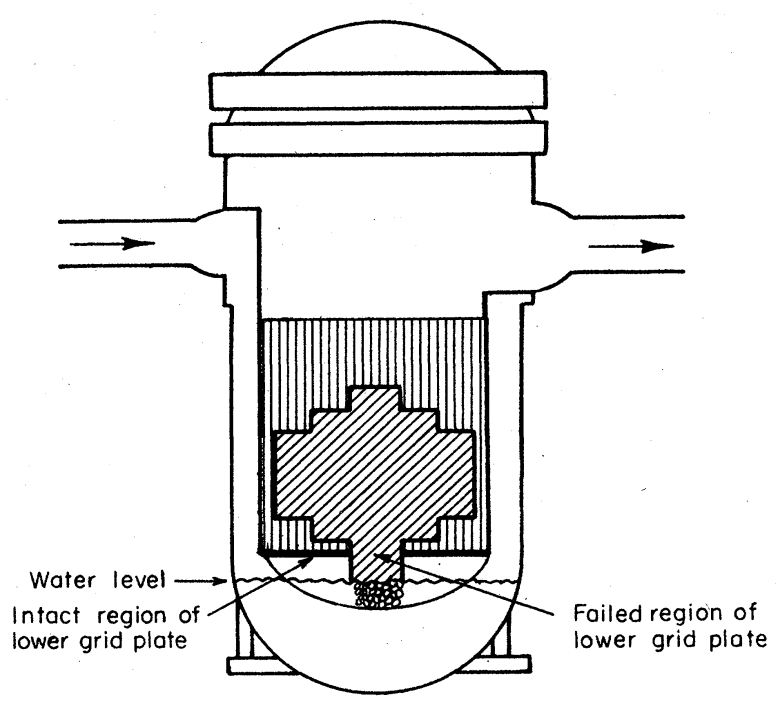

FIG. IV.A.4. Melt progression. Physical-Core has been extensively degraded. Structural materials continue to collapse. Molten corium continues to move downward and contacts the lower grid plate. The grid plate fails and corium falls into the lower plenum. Model-In the regional slumping model, when the molten zone reaches the grid plate it is assumed to fail in that region. The fuel in that radial region is then treated as if it had fallen into the lower plenum where it is cooled. Neighboring radial regions are unaffected in the model other than by the enhanced production of steam. 
surprisingly, leads to a smoothing of the temperature distribution within the core.

The mechanism of fuel rod failure, core degradation, and fission product release is far from being completely understood. Here we wish to focus on the physicochemical processes associated with core melting and slumping. During the heatup phase, some swelling and expansion of the cladding can be expected, so that in physical terms there is opportunity (and space) for zirconium-zirconium oxide-uranium oxide (fuel pellets) to interact, dissolve, and form liquid phases. Consequent$\mathrm{ly}$, the precise temperature at which the start of melting of fuel rods begins is difficult to define, but will probably depend on the chemical composition at some particular hot spot. The melting point of zircalloy is often taken as the fusion temperature in core melt calculations. As the temperature of zircalloy increases, the fuel rods may balloon and burst open, and very rapidly the noble gases and most of the volatile fission products leave the fuel (see Section IV.B). These fission products will travel with the flowing steam to the upper plenum, where the volatiles may condense, deposit on cold surfaces, and may under some conditions re-evaporate as they heat up. If recirculation in the primary system is considered, these fission products will distribute themselves around the primary system, and the noble gases will be released with the steam through the pressure release valve. This reduces the decay heat in the fuel, and increases heating of the primary piping. This accentuates the effect of heating up of the primary system through heat transfer from the recirculating fluid mentioned earlier which can change a TMLB sequence to a primary seal LOCA or a $\mathrm{V}$ sequence.

Once the cladding has failed and melting begins, the further progress of the accident is even more complex and hard to predict. The uranium oxide fuel pellet is made of ceramic material with an approximate melting point of $3100 \mathrm{~K}$. The binary and ternary phase diagrams of uranium oxide with zirconium and also zirconium oxide have been investigated and a eutectic point on the uranium rich side, at about $2700 \mathrm{~K}$, has been identified. Consequently, one may assume that in this range of temperatures, 2700 $\mathrm{K}$ to $3100 \mathrm{~K}$, the entire content of the fuel rod should become molten.

Molten corium, as it is formed, will begin to drip down the outside of the portion of the fuel rod that is intact. Melting will start near the inner ring of fuel rods, within the core, where the power factor peaked and where, consequently, the largest concentration of fission products are to be found. For the same reason, an individual fuel rod should begin to melt near its middle. The question that needs to be addressed now, is will the molten debris fall down directly into the pool of water that still exists at the bottom of the reactor vessel, or will it solidify and form a crust on the lower, cooler portions of the fuel rod, somewhat like the drip from a burning wax candle? The only problem here, of course, is that the "candle" is not burning from either end but rather from the middle.

One can fashion models in which either the region of melt progresses preferentially downward or upward or the molten debris falls promptly to the bottom, though it is believed the latter model may be farther from the truth. Since the spacing between fuel rods is quite narrow ( 2 $\mathrm{mm}$ ), the mixture of molten corium and solid crust may form a sort of slurry that could block the local passage of gases and steam and so perturb the melting and/or oxidation processes at higher levels within the core. Eventually, however, it is to be expected that the severely damaged fuel rods will slump or collapse suddenly and fall into the pool of water remaining below in the lower head of the RPV (see Figure IV.A.5).

These different modes of melting and final collapse alter the interaction of the hot corium debris with the water remaining at the bottom of the reactor vessel which can be an important source of additional heat, steam, and consequently hydrogen from zirconium oxidation and other metal water reactions. These factors can affect the further progress of core degradation significantly, producing additional sharp pressure spikes within the RPV. Small steam explosions, which are probable as molten corium falls into the water, may also alter the timing and manner by which the remaining fission products leave the core and the primary system. There remain, therefore, considerable uncertainties associated with the physical mechanism of core melting and slumping. A variety of simulation experiments and much more elaborate theoretical studies is now being conducted. In addition, if an energetic steam explosion were to occur, which is now considered unlikely as discussed in Section IV.E.3, the reactor vessel head might be lifted and, acting as a missile, destroy the containment building.

\section{IV.A.7. Melt-through}

As enough molten corium accumulates in the bottom of the pressure vessel, the remaining water will boil away, leaving the region dry. The debris-water heat transfer is another area of uncertainty. The configuration of the debris bed is unknown (average particle size, stratification, geometry, etc.). If it can be determined then the heat transfer rates can be modeled by a dryout heat flux formalism.

Some of the less volatile as well as more volatile radionuclides will have left the corium and deposited themselves throughout the primary vessel. Since the volatile radionuclides, $\mathrm{Xe}, \mathrm{Kr}, \mathrm{I}, \mathrm{Cs}$, Te, contain $40 \%$ of the decay heat, the rate of energy generation drops (within a few minutes for the TMLB' sequence). There is sufficient decay heat to form a corium-iron eutectic and melt through the pressure vessel at about $1800 \mathrm{~K}$. Typically it is calculated to take 10 minutes from core slump to reactor pressure vessel failure if pressure in the RPV is maintained.

The mass of molten material produced as the corium melts its way through the walls of the bottom head adds to the weight of molten mass already present. This molten mass heats up any gas, vapor, and water present. This in turn creates the increase of pressure in the TMLB' sequence which represents the stress that must be supported 


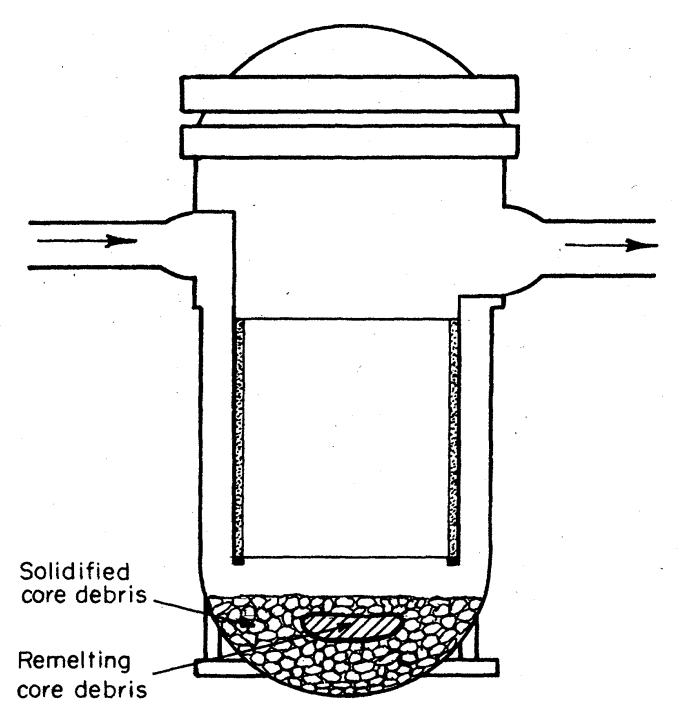

FIG. IV.A.5. Core collapse. Physical-Corium has fallen into the lower head of the reactor vessel. Molten corium is partially quenched when it contacts the residual water inventory. Corium reheats and liquifies. Thermal stresses and mechanical stresses begin to degrade the reactor vessel. Model-A debris bed (composed of core and lower plenum structures) is formed in the lower head that transfers heat to residual water. When the water is gone the debris bed reheats and liquifies. Heat is conducted from the debris bed into the lower vessel head.

by the structural portions of the vessel that remain. This was estimated on crude energetic considerations in III.C.3.

To calculate the temperature of the bottom head properly requires a two-dimensional treatment, namely radial and axial (direction of the thickness). If the debris is solid, a transient conduction equation can be used; if not a natural convection calculation would be required in the liquid zone. Thus the heat flux from the debris to the wall of the bottom head can be determined. Once the heat flux is specified, a transient conduction equation can be solved for the temperature distribution in the outer wall, and thus the interfacial temperature between debris and bottom head can be calculated. The conventional criterion for failure is the point at which the total tensile stress from the combination of sources mentioned above just exceeds the tensile strength (yield stress) at the weakest point of the vessel.

The critical areas or weak spots in the reactor pressure vessel may be welds, joints, or small intrusions containing instrumentation probes, etc. When the reactor pressure vessel fails at any of the weak spots, some molten fuel is impelled through the hole at rates depending in part on the magnitude of the internal RPV pressure, which enlarges enough to permit a rapid depressurization of the RPV, rapid erosion of the opening, and the ejection of most of the fuel through the hole.

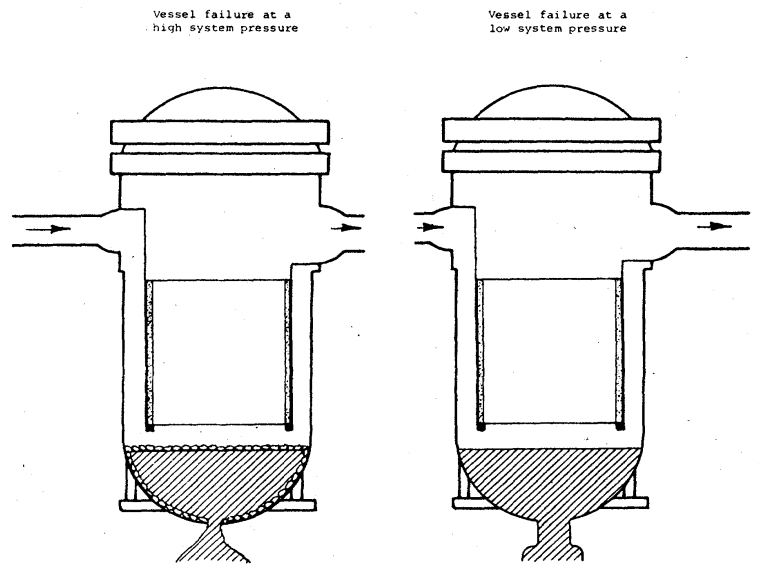

FIG. IV.A.6. Vessel failure. Physical-If the reactor system is at its operating pressure, then the corium is ejected through small breaches as a jet. If the reactor system is depressurized, then the corium flows into the reactor cavity. Model-There is no distinction made in the MARCH model between the two modes of failure and release of corium. Typically in a high pressure sequence, failure occurs virtually instantaneously following core collapse. In a low pressure sequence the corium must reheat and partially melt the lower head before the stresses are high enough to cause failure.

A cause of uncertainty is whether the corium will melt through the reactor vessel or melt through seals and pipe intrusions. If the latter, the core is likely to come out (at least initially) in a jet. Figure IV.A.6 illustrates pictorially what might happen at vessel failure.

On the other hand, if the assumption is made that all the core and reactor internal structures drop to the bottom of the reactor vessel and mix into a molten mass before melting through the reactor pressure vessel, forming a eutectic with the iron in the reactor vessel which melts at $1800 \mathrm{~K}$, then the total heat content of this mass of corium at the moment of melt through is defined by this mass and this temperature. The unknown details of what goes on during meltdown and melt-through determine the following:

(a) the amount of metal-water reaction with its consequent hydrogen release;

(b) the amount of $\mathrm{Zr}$ remaining to help drive the coreconcrete interactions;

(c) the amount of steel in the melt;

(d) the amount of fission products deposited elsewhere in the primary system;

(e) the exact time of RPV melt through;

(f) whether some portion of the core and structural supports stays intact in the RPV.

Thus it can be seen that the pressure spike $\Delta P$ at reactor pressure melt-through (calculated from total energetic considerations in Section III.C.1) can be limited reasonably well; we note that item (f) above could reduce it and that complete oxidation of iron could increase it. Items (a), (b), (c), (d), and (e) can be considered variable parameters for input into the subsequent parts of the accident 
analysis. For example, subsequent analysis can be made with the various amounts of unreacted zirconium.

More precise modeling of the meltdown and meltthrough phases may result in a smaller pressure spike than calculated in III.C.1. Some of the core can remain behind, although it is only the outer layer that one expects to stay behind and this has a smaller decay heat density. However, a delay in the melt-through might give a higher containment pressure since more heat will have been accumulated in the containment before the pressure spike arrives.

\section{IV.A.8. Core-concrete interaction}

When the molten core falls onto any water below the reactor, small steam explosions (see Section IV.E.3) are again probable. These can have two effects. In the steam explosion, the portion of the molten core participating in the violent interaction would be finely divided and could be distributed forcefully throughout the containment. This could increase the density of radioactive aerosols at a critical time. The steam explosion also produces an oxidation process in which the scattered corium aerosol elements could rapidly contribute additional energy to the pressure within the containment. The contribution of additional energy through the oxidation process at an already stressful time might stress the containment beyond its limits. These processes have been neglected in the current reports of contributions of source terms.

After the molten core has fallen to the base mat, it will interact with any water present. The fuel may form a crust (quench) as it boils the water residing in a layer above the melt.

As soon as molten material contacts the concrete, attack will begin. Gases are likely to be violently expelled from the concrete, according to experimental observations. The noncondensible gases generated will increase the pressure in the containment. In addition, the gas bubbles rising through the very hot melt present a large area for sparging "nonvolatile" fission products and other radionuclides remaining within the core and contribute strongly to their dispersal throughout the containment volume.

The core-concrete interaction itself is endothermic and the pressure stress on the containment that it causes is driven by the fission product decay heat (although there may remain some zirconium to be oxidized and add to this heat). The pressure increase in the containment until the time the core-concrete interaction commences was driven by the decay heat integrated up to that time, plus heat from the zirconium-water reaction, reduced by some transfer of heat to various walls and surfaces. The rates of concrete attack and of gas generation can be calculated from similar energy considerations. It is easy to see, on general principles and without discussing the uncertain details of the core concrete interactions, that a significant pressure rise (after the initial spike) can only occur over a time period comparable to the time between accident initiation and reactor vessel melt-through. This will also ap- ply if heat is transferred slowly to the containment atmosphere instead of being transferred to the concrete.

If the containment remains structurally sound for long periods of time (hours) after vessel failure and the onset of core-concrete attack, then it is conceivable that the earliest breach of containment may occur when the core melts through the basemat and reaches the reactor building's foundation. This so-called China syndrome, however, should present far less danger to the public than any direct release to the atmosphere. The core will not penetrate for an unlimited distance into the earth but will reach thermal equilibrium after a penetration of less than $3 \mathrm{~m}$. Migration of radionuclides through the earth will be governed by ionic transfer processes and will be slowabout $3 \mathrm{~m}$ a year. This is not the case with material escaping into the atmosphere, unfortunately. This conclusion depends upon the material being in the form of aerosols rather than as gases.

Study on the rather complex nature of core-concrete interactions has only recently begun. Experimental studies have been of molten steel and $\mathrm{UO}_{2}-\mathrm{ZrO}_{2}-\mathrm{Zr}$, poured onto concrete. Concrete does not have a uniform composition. Consisting of cement binder and an assortment of matrix substances (e.g. gravel, sand, limestone) its composition of metal oxides, carbonates, silicates, bound and free water can take on a variety of values, depending on its source materials. Ordinary concrete has a density of about 2300 to $2500 \mathrm{~kg} / \mathrm{m}^{3}$ and contains about $4 \%$ or more by weight of free and chemically' bound water. It virtually disintegrates at about $800 \mathrm{~K}$. When the hot, molten core meets the concrete, the concrete will heat up and ablate, releasing carbon dioxide and water vapor. The rate at which these reactions take place and the rate at which the concrete ablates is a function of a rather complicated series of heterogeneous reactions, involving immiscible liquids of molten metal, liquid layers of metal oxides, and solid crust, as well as solid concrete covered with a possible gas film. Through this cauldron, escaping gas bubbles up, leading to a regime of bubbly heat transfer and two phase hydrodynamics that has yet to be fully explored (Greene, 1983).

The thermal analysis here is concerned both with the heat transfer from melt to concrete and then the bubblemelt interactions. The water vapor and $\mathrm{CO}_{2}$ liberated from the concrete react with the metallic constituents of the melt and are reduced to $\mathrm{H}_{2}$ and $\mathrm{CO}$. The rising $\mathrm{H}_{2}$ can further interact with nonvolatile fission products such as $\mathrm{La}_{2} \mathrm{O}_{3}$ to form more volatile oxides such as $\mathrm{LaO}$, described more fully in Section IV.B.6. At this stage the required calculations are the rates of generation of condensible, noncondensible, and combustion gases, the rates of erosion of the concrete, the composition of the melt, and most importantly (since it determines the evaporation rates of fission products) the temperature of the melt.

Some experimental studies suggest that the corium separates into two clearly defined immiscible layers of different densities. These are taken to be (from bottom to top) uranium oxides, and the support metals (iron, zirconium, etc.). This implies that the melt can be modeled 
as separate layers, with gases bubbling through them, although if substantial quantities of gas are released the bubbling condition may tend to mix adjacent layers to an unknown extent.

As the uranium dioxide attacks the concrete, it will melt silica which will mix with the $\mathrm{UO}_{2}$ and decrease the liquidus temperature. The incorporation of silica also changes the viscosity of the melt and may reduce heat transfer rates. Eventually it may become less dense than the metal layer and change places with it.

The heat exchange processes need to be modeled at various interfaces shown in Figure IV.A.7.

(a) Between the uranium oxide and the concrete below, in region $I$.

(b) Between the various layers and the concrete at the sides (region II).

(c) Between the uranium oxide and the metal layer (region VI).

(d) From the debris (oxidic layer) top surface to the surrounding atmosphere and structure (region III). In some cases the top surface may be covered by a boiling water pool.

The heat transfer from the debris to the concrete would have to contain a convective component (through a gas film), a conductive component when the film collapses or the debris solidifies, and a radiative component.

The convective heat transfer model should account for the various postulated regimes: bubbling film region for horizontal interface (region I), a laminar gas film and turbulent gas film region for vertical interfaces (region II).

Given the heat flux to the concrete interface, a transient ablation model would be a reasonable approach to calculate the melting and removal of concrete adjacent to the melt (or the gas film). The heat of ablation is the integrated enthalpy change from ambient to the ablation temperature. This enthalpy includes the energy required to evaporate both the free and bound water in the concrete, decarboxylate the concrete, and melt the various components in the concrete. The heat source is the fission product decay heat plus heat of oxidation of any remaining zirconium.

The heat transfer from the interior of the molten pool to the gas film interface, across liquid-liquid interfaces and at the pool surface, is enhanced convection driven by the two phase bubbly effects of the gaseous concrete decomposition products. The heat transfer should account for gas flow (or no flow) across the interface and for entrainment effects.

The gas flow in the pool creates a two phase bubbly/churn-turbulent flow regime. This has the effect of elevating the pool height and generating intense circulation which maintains the pool in an almost isothermal state, except in the vicinity of material interfaces and boundary layers. Since the bubbling action has a pronounced effect on all modes of heat transfer, the void fraction needs to be determined.

The top of the pool will radiate heat to the cavity and structures above, and probably will freeze to form a porous crust. If a layer of water is on the top of the pool

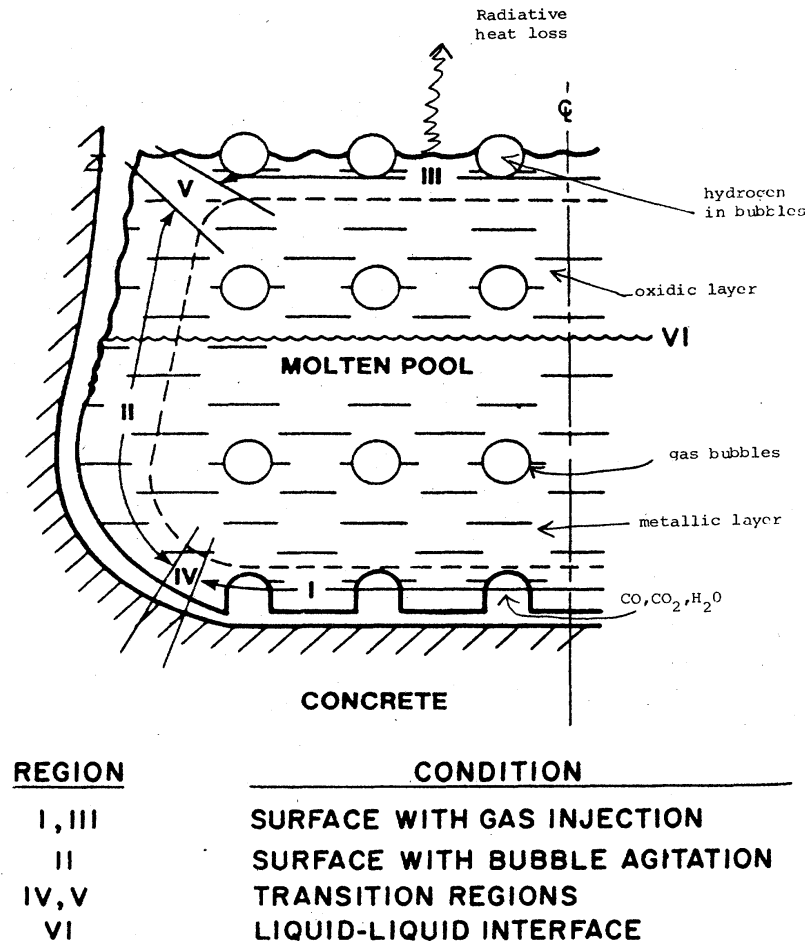

FIG. IV.A.7. CORCON representation of core-concrete interaction.

then a model for liquid-liquid film boiling with transverse gas flow would be required for the period prior to formation of a crust. The debris-concrete transfer should account for the eventual freezing of the debris.

The above described heat transfer process, especially the two phase bubbling, are poorly understood and have inadequate experimental data bases to support development of appropriate models. The data bases are noticeably lacking for prototypic reactor accident conditions and materials.

The major importance of the core concrete interaction is the potential for fragmentation of the corium and the creation of aerosols, both from the concrete and from the vaporization of fission products.

As the bubbles rise through the core melt, they will present a large surface area for evaporation. Even fission products of low volatility can evaporate at the high temperatures of the melt. These evaporating fission products will condense in the cooler atmosphere of the containment into fine aerosols. In addition the bursting bubbles can mechanically disperse portions of the fuel as aerosols analogous to the formation of sea salt aerosols by the bursting of bubbles in the ocean.

The rate of settling of these aerosols will in turn be determined by the total density of aerosols present at the time. Therefore the nonradioactive aerosols generated out of the concrete in the core-concrete interaction will act to 
agglomerate radioactive aerosols, hasten their deposition, and reduce the source term. For the accident sequence TMLB', Figure III.C.5 shows how the total mass of aerosols is calculated to reduce as the accident proceeds and Figure III.C.6 shows the relative amounts of Cs, I, and nonradioactive aerosols. The sensitivity of this behavior to the details of the core-concrete interaction still seems uncertain.

This complex nature of the processes in the core concrete interaction causes uncertainty about the detailed nature of the course of an accident following reactor vessel melt through. However, several general gross features seem firmly borne out by experiments with simulant materials at Sandia and abroad (mainly at KfK, West Germany).

The containment vessel pressure will rise slowly, and reach values that can fail the containment only after several hours. The aerosols produced during that time will continuously deposit, and more importantly, if on site power is recovered and containment sprays operated, the accident can be terminated. Thus in this case, the uncertainties introduced from the core-concrete interaction will not be important. On the other hand, if the time of containment failure coincides with a time of vigorous coreconcrete interaction, or if containment is bypassed, the details of the core concrete interaction will be important. The source term could be large, and its magnitude very uncertain.

Tests of these critically important phenomena are in progress at Sandia National Laboratory and in Karlsruhe,

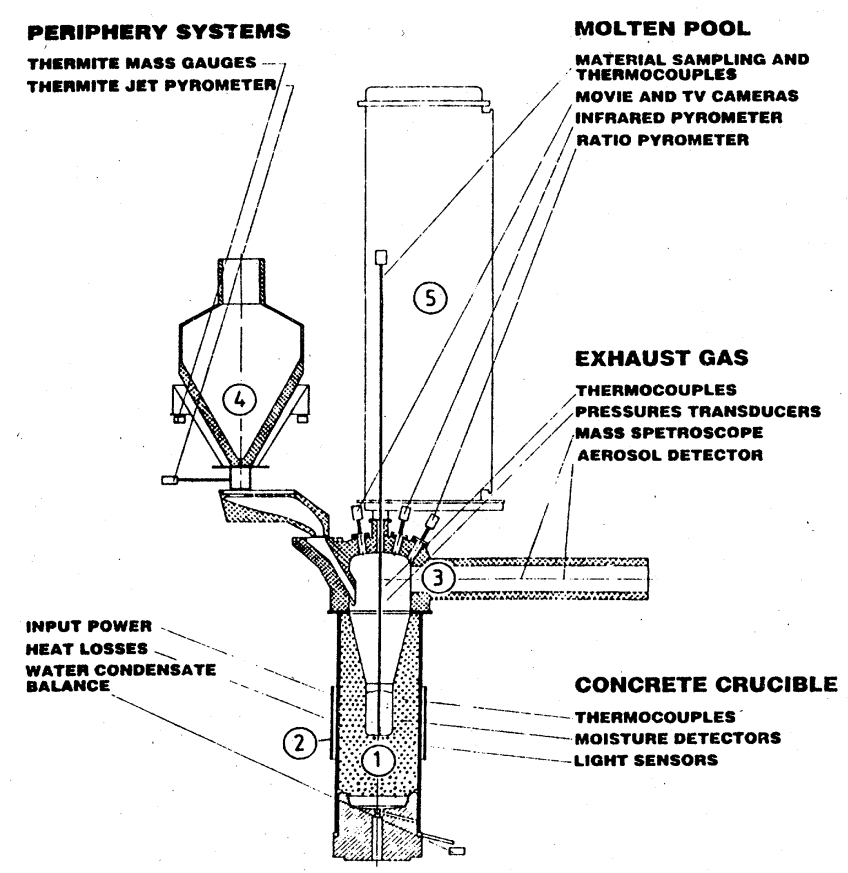

FIG. IV.A.8. Schematic view of BETA facility (from Hosemann et al., 1984). 1, Concrete crucible; 2, induction coil; 3 , offgas system; 4, thermite reaction tank; 5 , container for measurement probes.

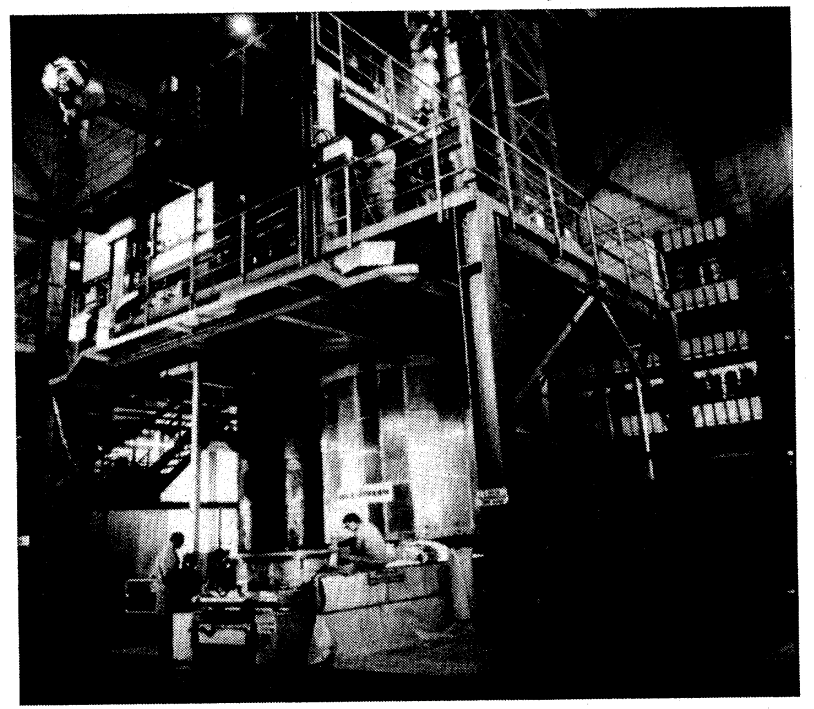

FIG. IV.A.9. BETA facility: Preparation of crucible. (Courtesy of KfK.)

West Germany. The BETA test facility at Karlsruhe is shown in Figures IV.A.8 and IV.A.9. In the largest test, a melt with $300 \mathrm{~kg}$ steel and $150 \mathrm{~kg}$ alumina and silica simulating oxides, with a temperature of $2700 \mathrm{~K}$, was prepared in a thermite reaction tank and allowed to fall into a concrete crucible, where the simulated core concrete reaction took place. Small scale experiments without further heating (the recent SASCHA tests) have shown reaction times of a few minutes, and have tested the model over short times. In the BETA tests, the melt was further heated by an induction coil with a high input power so that a high temperature at a steady state was maintained as in the real situation. Heating powers of 1.7 MW were achieved. Temperatures vary from $700 \mathrm{~K}$ to $2100 \mathrm{~K}$

The experiments at Sandia National Laboratory are similar, and more extensive (Powers, 1977, 1978; Powers and Arellano, 1982). Several test series have been performed: COIL, sustained, large-scale $200 \mathrm{~kg}$ steel melts interacting with concrete; BURN, visualization of melt behavior on concrete by $x$-ray map enhancement; and NSS, transient interactions of $15-35 \mathrm{~kg}$ core melts, $30 \%$ steel, $54 \% \mathrm{UO}_{2}$, and $16 \% \mathrm{ZrO}_{2}$ with concrete. Three further test series are in progress: SWISS, TURC, and SURC.

The study group was informed of many differences between these tests. In particular, the BETA tests show little aerosol emission, and the Sandia tests show a lot. The reason for the differences between these two findings is far from clear, although the differences in the concrete are suspected. Further investigation is vital.

In future tests, the melt will, and should, be spiked with stable isotopes of fission products so that the emission of fission products can be simulated. 


\section{IV.B. Chemical forms and interactions}

\section{IV.B.1. Introduction}

Radioactive nuclides formed in power reactors include fission products and isotopes of heavy elements such as plutonium and neptunium. The great majority of fission products present after any appreciable time of reactor operation are stable isotopes of the various elements. However, each element carries with it a certain amount of its radioactive isotopes. We are concerned here primarily with the amounts of radioactive isotopes of each element present which would escape into the environment in case of failure of the containment after a reactor accident. This depends on the chemical and physical properties of the element and its compounds. Finally, the "source term" will depend on the amount and characteristics of the radioactive isotopes carried by each element.

Release of radionuclides from the reactor core during severe accident sequences occurs primarily in two separate steps. In the first step, releases occur within the reactor vessel during heatup and melting of the core. In the second step, nuclides are released after vessel failure as the molten core debris reacts with the concrete basemat.

More than $80 \%$ of the most "volatile" elements (Xe, $\mathrm{Kr}, \mathrm{Cs}, \mathrm{Rb}, \mathrm{I}, \mathrm{Br}, \mathrm{Sb}, \mathrm{Te}, \mathrm{Ag}$ ) are released in the first step, and moderately volatile ones $(\mathrm{Ba}, \mathrm{Sr}, \mathrm{Ru}, \mathrm{Mo})$ are partially released. The remainder of the volatiles stay behind in fuel at the core periphery, which may not reach temperatures above $1470 \mathrm{~K}$ by the time of reactor vessel failure. Tellurium combines with metallic zirconium, if available, which depresses its volatility.

As the "volatiles" are carried in an atmosphere of steam and hydrogen through the upper plenum, some may condense on stainless steel or other surfaces, or on aerosols formed from vapors of control rod or structural materials. These species may be partially retained in the reactor structure without ever reaching the containment. The inert gases $\mathrm{Xe}$ and $\mathrm{Kr}$ will however all pass to the containment.

As the radionuclides are released from the molten debris during the core-concrete interaction, they pass directly into the containment atmosphere as aerosols composed mainly of nonradioactive materials.

Of all the radioactive nuclides involved, iodine isotopes have been the focus of special attention because of their volatility combined with their danger to human health. In the Reactor Safety Study it was conservatively assumed that iodine is released from the fuel as gaseous molecular iodine and transported as a gas without change of chemical form. Following the accident at Three Mile Island, it became apparent that this assumption could lead to a considerable overestimate of the iodine release. So the chemistry of the volatile fission products under the conditions present during the course of severe accidents was reexamined.

A number of chemical issues can now be identified that could affect the prediction of source term:

(a) The volatility of fission products during core degradation as affected by the oxidation potential, steam pres- sure, and temperature.

(b) Reactor coolant system chemistry including potential chemical reactions that could either fix cesium and tellurium-that is, chemically attach to reactor structures-or release more volatile forms of iodine.

(c) Chemical behavior of the nonvolatiles in the coreconcrete interaction.

(d) In-containment chemistry, particularly reactions that would release volatile species of iodine.

(e) The effects of possible chemical reactions generally not included in the models used in current accident analyses.

\section{IV.B.2. Chemical state of the fuel pins} during normal operation

The fuel elements in light water reactors consist of $\mathrm{UO}_{2}$ pellets, placed into cylindrical zircalloy containers to a density about $95 \%$ of crystalline $\mathrm{UO}_{2}$. When a $\mathrm{U}$ atom undergoes fission, the two product atoms share a kinetic energy of about $185 \mathrm{MeV}$, or $7.1 \times 10^{-12}$ calories, to be dissipated as heat along the fission track in the $\mathrm{UO}_{2}$ matrix. This will result in localized melting and vaporization of about $3 \times 10^{-16}$ moles or $2 \times 10^{8}$ molecules of $\mathrm{UO}_{2}$ which however will immediately vitrify or recrystallize. Thus, after appreciable burnup every bit of the $\mathrm{UO}_{2}$ will have momentarily melted thousands or millions of times. The resulting sintering causes the $\mathrm{UO}_{2}$ pellet to contract, increasing the gap between the $\mathrm{UO}_{2}$ and the cladding. Only a negligible fraction of the fission products is formed outside the $\mathrm{UO}_{2}$ matrix. As the fission process proceeds, the $3-5 \mu \mathrm{m} \mathrm{UO}_{2}$ grains originally present consolidate to around $35 \mu \mathrm{m}$ diameter, and the more mobile fission products such as the xenon and krypton tend to congregrate at grain boundaries (Osetek et al., 1984). As the fuel becomes highly irradiated, it contains large amounts of fission product impurities that inhibit further grain growth. Stresses tend to become high enough to cause microcracking and ultimately large radial and circumferential fractures which are typically observed in highly irradiated $\mathrm{UO}_{2}$ pellets. The cracking frequently reduces or eliminates the gap between fuel and cladding. When the cladding is breached and the pellet heated, volatile products come out faster from the more thoroughly irradiated samples (Lorenz et al., 1979).

During normal operation, a small fraction of the inventory of the volatile fission products ( $\mathrm{Xe}, \mathrm{Kr}, \mathrm{Cs}, \mathrm{I}$ ) can escape into the gap. The Cs and I will not only combine to form the salt CsI, but will also react with the zircalloy cladding to form surface compounds leading to stress corrosion.

Though the contents of the gap have occasioned some discussion, they are only a very small percentage of the total volatiles, and, by themselves, cannot be a significant contributor to the source term.

\section{IV.B.3. Release of radionuclides from fuel}

Processes involved in the release of radionuclides from fuel and the temperatures at which these occur at appreciable rates include the following: 
-Diffusion of atoms from $\mathrm{UO}_{2}$ grains $>900 \mathrm{~K}$

-Diffusion of microbubbles from $\mathrm{UO}_{2}$ grains $>1700 \mathrm{~K}$

-Grain growth release, enhanced by exposure to steam $>1700 \mathrm{~K}$

-Oxidation of $\mathrm{UO}_{2}$ increases diffusion rate $>1700 \mathrm{~K}$

-Microcracking and other grain boundary separations $>1700 \mathrm{~K}$

-Linkage of bubbles at grain boundaries $>1800 \mathrm{~K}$

-Burst release when the cladding ruptures $\sim 1900 \mathrm{~K}$

-Reaction between $\mathrm{Zr}$ and $\mathrm{UO}_{2}>1900 \mathrm{~K}$

-Melting of pure zircalloy beginning at $2100 \mathrm{~K}$

-Molten mixture of stainless steel, $\mathrm{Zr}$ and $\mathrm{UO}_{2}>2700$ K.

As the core heats up and finally melts there are several factors that influence the release of the volatile nuclides. The most important factor is the maximum temperature attained by the fuel and the length of time the fuel stays at that temperature. A second factor is the composition and rate of flow of the steam-hydrogen mixture through the core. The ratio of steam (an oxidant) to hydrogen (a reductant) sets the effective oxidation potential which in turn can change the chemical form of elements released. The steam pressure also affects the volatility of some materials. Finally, molten zircalloy cladding can react with $\mathrm{UO}_{2}$ to form liquid solutions of $\mathrm{UO}_{2}$ at temperatures considerably below the melting point of $\mathrm{UO}_{2}$ and thereby speed the release of iodine and cesium while retarding the release of tellurium.

Although it is possible to describe a mechanistic picture for releases, realistic values for individual nuclides cannot be calculated from first principles. Consequently, all releases are estimated on the basis of experimental measurements. In simple concept, irradiated fuel is heated to melting and the release of individual radionuclides is measured as a function of time. All of the experimental conditions should be adjusted as nearly as possible to match those that are calculated for a severe accident, including the oxidation potential and simulation of the constituents of the core. The experiment is then repeated at different heating rates until the rates cover the range of interest. Another experimental approach involves heating the fuel to a specified temperature, holding at that temperature, and measuring the release of the individual nuclides.

Typical experimental data are shown in Figures IV.B.1 and IV.B.2 from NRC (1980). It should be noted that the data for many elements of interest are sparse.

The data may be treated in different ways to produce release curves such as those shown in Figure IV.B.3 (NRC, 1981). Whatever method is used, it is important to recognize that the validity of calculated releases depends critically on the validity of the experimental data and their relevance to accident conditions. Some of the release curves are based on little or no experimental data. Figure IV.B.3 forms the basis for the BMI-2104 prediction of in-vessel fission product release. It should be noted that there is no provision in the calculation for the release of the nonvolatile fission products or the actinides.

The release rate $d M / d t$ is approximated by the first order law:

$$
d M / d t=-K M,
$$

where $M$ is the mass of a fission product remaining at time $t$. The release rate constant $K$ may be expressed in the usual Arrhenius form (Kelly et al., 1984; Andriesse, 1984)

$$
K=K_{0} \exp (-Q / R T)
$$

where $Q$ is the activation energy for the rate-controlling release mechanism, $R$ is the gas constant, and $T$ the temperature in degrees Kelvin. When the smoothed curves of Figure IV.B. 3 are plotted as $\ln K$ vs $1 / T$, a single straight line adequately correlates the data for each element over the entire temperature range, which suggests that the data of Figures IV.B.1 and IV.B.2 were fitted to an Arrhenius expression. Values of $K_{0}$ and $Q$ for each fission product are reported in the references.

In the analyses reported in Gieseke et al. (1984) the releases from fuel were estimated by a model described in NRC (1981a). This model was chosen instead of an Arrhenius model for ease of computation. Defining $F$ as the fractional release, then $F$ is equal to $1-M / M_{0}$, where $M_{0}$ is the initial amount of fission product. Equation (IV.B.1) then gives for constant $K$ :

$$
F=1-\exp (-K t) .
$$

The fractional release rate, $K$, is a function of temperature,

$$
K=A \exp (B T) .
$$

Values for $A$ and $B$ are determined by fitting Equations (IV.B.3) and (IV.B.4) to experimental data over small temperature ranges.

A detailed comparison of the release curves for the two models shows general agreement. However, the Arrhenius form provides a better correlation over wide temperature ranges.

Results of two series of more careful and comprehensive experiments have appeared: the SASCHA tests from West Germany and the so-called HI tests from Oak Ridge (which have absolutely nothing to do with hydrogen iodide). Results assembled by Kelly et al. (1984) are shown in Figure IV.B.4, in which the logarithm of fractional escape rates of various fission products are plotted against reciprocal absolute temperature. We include only those experiments done in streaming steam. No consistent or truly significant difference in volatility is seen among the five elements $\mathrm{Kr}, \mathrm{Cs}, \mathrm{I}, \mathrm{Te}$, and $\mathrm{Ag}$, and results may be disagreeing by an order of magnitude. The results on Sb show somewhat lower volatility. Scanty experiments on Ba show still lower volatility, which is, however, important in view of potential health effects of its radioactive isotopes. For $\mathrm{Te}$, differences in volatility shown in different tests have been explained (Lorenz et al., 1983) by a reaction of Te with metallic zircalloy to form nonvolatile tellurides; the more the zircalloy becomes oxidized during the test, the greater the release of 


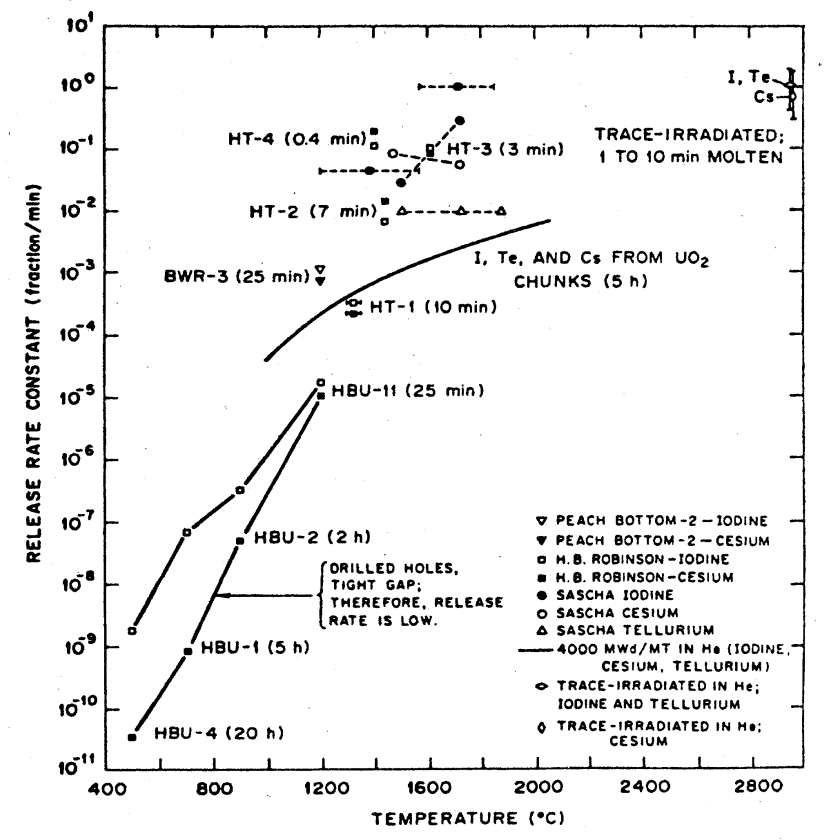

FIG. IV.B.1. Release rate constants from fuel-noble gases and volatiles (from NRC, 1981).

Te. Other irreproducibilities do not stem entirely from defects in the experiments, but from unexplained differences in different samples of exposed fuel. These tests show that the situation is not nearly as neat and reproducible as might appear from Figure IV.B.3.

The meaningful results of such experiments are obtained by integrating the fractional release rates over the time required to heat from uncovery to melting, which may take from 30-120 minutes or more, depending on the scenario considered. All estimates however agree that nearly all of the I, Cs, and noble gases are emitted prior to

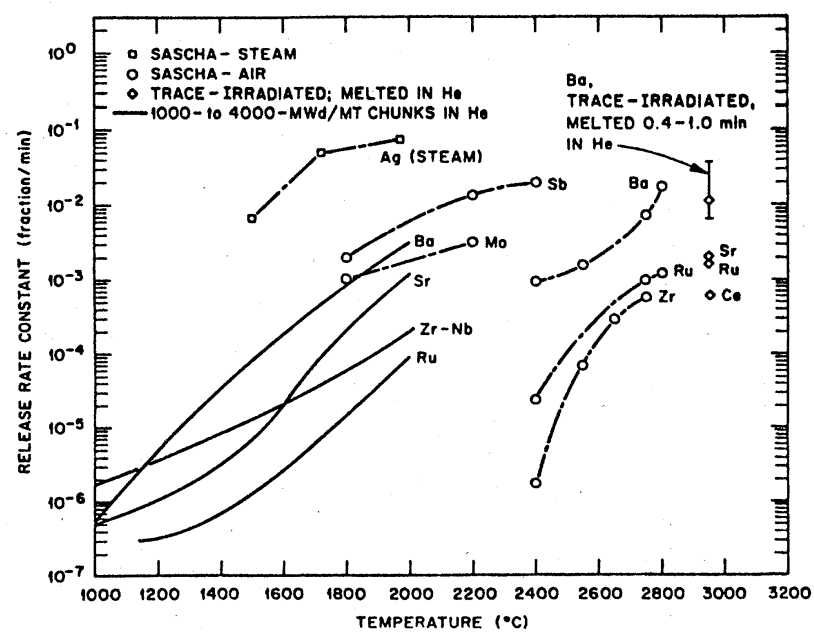

FIG. IV.B.2. Release rate constants from fuel-low volatiles (from NRC, 1981); smoothed curves used in calculations.

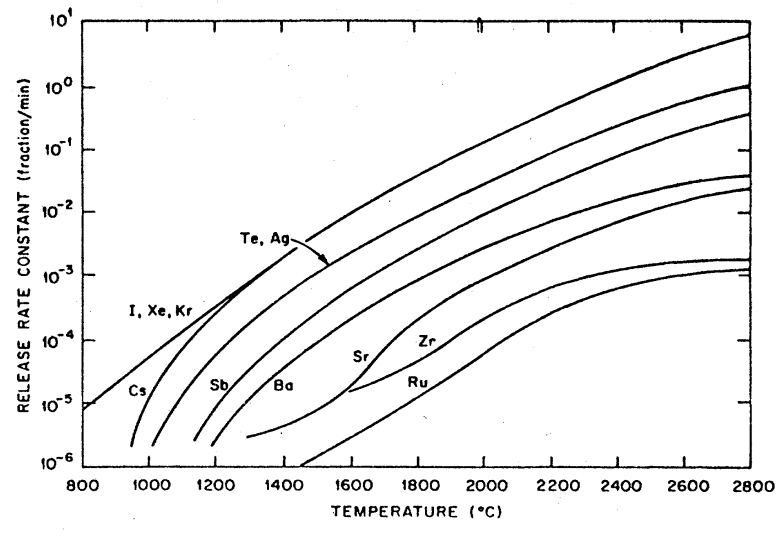

FIG. IV.B.3. Fission product release rate constants from fuel-smoothed curves used in calculation of Gieseke et al. (1984, from NRC, 1981).

fuel melting. The data shown in Figure IV.B.3 suggest that most of the Te is also emitted at this stage. However, in other tests $\mathrm{Te}$ is reported to combine with molten $\mathrm{Zr}$ clad if the $\mathrm{Zr}$ has not been oxidized, thereby reducing the $\mathrm{Te}$ release. Te can also form $\mathrm{SnTe}$, a volatile material, by interacting with one of the constituents of zircalloy. Of the order of $10-40 \% \mathrm{Ba}$ and $\mathrm{Sr}$ are volatilized.

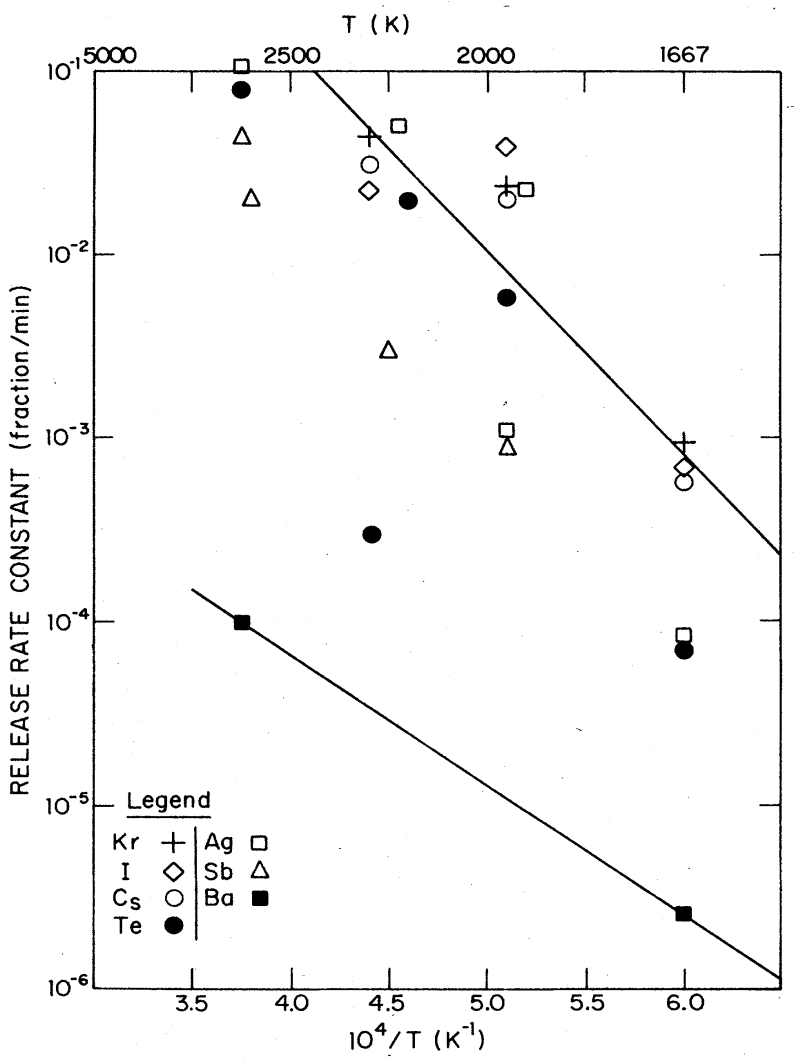

FIG. IV.B.4. Release rate constant $K\left(\mathrm{~min}^{-1}\right)$ determined in steam from SASCHA and ORNL tests. 
After melting begins, the slumping process may require some time and fission products continue to be emitted before melt-through of the reactor vessel. During this time important emissions of less volatile fission products could occur. Few data exist in this region, but experimental programs now underway should help fill this gap.

Experiments on salt volatilities suggest a possible increase in the calculated release of some fission products into high pressure steam. Subsequently the volatile species might be transported through steam leaks or relief valves into the containment. More experimental investigation is needed, which investigation should consider a variety of fission products and the range of $\mathrm{H}_{2} \mathrm{O} / \mathrm{H}_{2}$ and steam pressure likely to be of interest.

It might be helpful to review the chemical status of the molten fuel constituents at the critical point in the accident sequence just prior to reactor vessel failure. Most of the fuel is in a pool of molten $\mathrm{UO}_{2}$ in the lower head of the reactor pressure vessel at a very high temperature, in excess of $2700 \mathrm{~K}$. Liquid metallic phases are also present. Little is known about the thermodynamics of fission product compounds at these temperatures but the nonvolatile compounds are probably distributed among the liquid phases as oxides or elements. Some volatile materials are likely to be released from the molten pool, but there is little surface for mass transfer or release of bubbles to the vapor above the pool. A portion of the fuel is still in solid form in the cooler regions of the vessel; this fuel may still contain volatile as well as nonvolatile fission products. Some of the solid fuel may slump into the pool, putting volatile elements such as $\mathrm{Cs}$ and I into the pool to be released later when some more surface area develops.

There is a continuing research program related to the release of radionuclides from fuel (NRC, 1983a). The program will consist of laboratory experiments and larger scale experiments in the Power Burst Facility (PBF). In laboratory experiments, samples of hundreds of grams to $\mathrm{kg}$-size will be heated to melting and the release of the important radionuclides will be measured with a variety of instrumentation. In these experiments it will be possible to simulate some conditions resulting from severe accidents, and to study the effects of important variables. We emphasize the importance of tests of highly irradiated fuels at high pressure. Careful experiments can lead to the identification of unexpected behavior in transport of particular elements, which could lead in turn to the discovery of important new chemical reactions.

\section{IV.B.4. Chemical transformation after release} from the core

The chemical forms of fission products after release from the fuel have been inferred from the behavior of the individual elements in experiments, and by thermodynamic calculations. Efforts are now underway to identify chemical species in laboratory experiments by mass spectrometry and other analytical techniques. Thermodynamic calculations depend upon thermochemical data, and the ability to identify in advance all chemical species that might be present under the conditions of interest. An additional limitation is the assumption of equilibrium conditions that may not apply. From these considerations it may be seen that the identification of chemical species should depend on parallel programs of calculation and experiment.

As the fission products are swept from the core by the steam-hydrogen mixture they pass upward into the plenum region. In this cooler space they may undergo the following transformations:

(1) condensation on and possible subsequent evaporation from steel surfaces;

(2) condensation on and possible subsequent evaporation from inert aerosol particles;

(3) condensation to form fine aerosols which then undergo agglomeration;

(4) chemical interaction with stainless steel surfaces;

(5) chemical interaction with other vapors or aerosols formed from vapors of structural and control rod materials.

The study of chemical reactions in the plenum region is in its early stages. Even so, several important reactions have been identified and are being studied in detail, so that their effects may be incorporated in accident analyses (Elrich and Sallach, 1983). Tellurium vapors react with tin, zirconium, stainless steel, and other metals to form stable compounds. These reactions are being studied under severe accident conditions to provide a quantitative basis for incorporating the effects into accident analyses.

At the present time, there is general agreement that the dominant form of iodine when released from the fuel under reducing conditions is cesium iodide (NRC, 1980). This conclusion comes from thermodynamic calculations and from experimental observations.

As an example, Sallach (1984) calculated equilibrium distributions for iodine existing as CsI, HI, or atomic I vapors in steam-hydrogen mixtures for a range of temperatures. Conditions were chosen to simulate tests at the Power Burst Facility, INEL. Figure IV.B.5(a) models the SFD-ST test for which the overall molar concentration ratios were set as follows: $\mathrm{I} / \mathrm{H}_{2} \mathrm{O}=2 \times 10^{-7} ; \mathrm{H} / \mathrm{O}=2.0$; $\mathrm{Cs} / \mathrm{I}=10$. Under these conditions, the gas is characterized as being "oxidizing." Atomic iodine is computed to

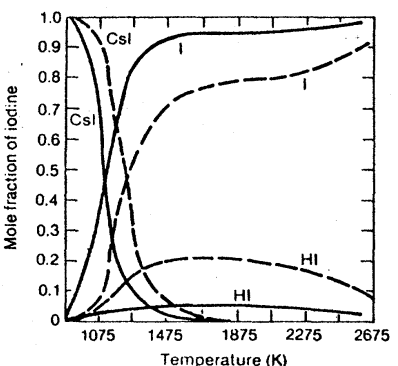

(a) $1 / \mathrm{H}_{2} \mathrm{O}=2 \times 10^{-7} ; \mathrm{H} / \mathrm{O}=2.0 ; \mathrm{Cs} / \mathrm{l}=10$. - Pressure equals $1 \mathrm{~b}$

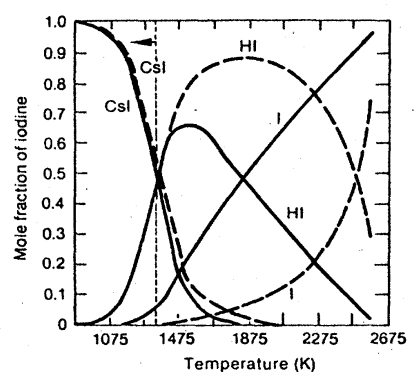

(b) $1 / \mathrm{H}_{2} \mathrm{O}=2 \times 10^{-7} ; \mathrm{H} / \mathrm{O}=30 ; \mathrm{CS} / 1=10$. - Pressure equals 150 bars
FIG. IV.B.5. Relative abundance of iodine species in the Cs-IH-O system for the conditions approximating the SFD-ST, (a), and Test SFD 1-1, (b), from Sallach (1984). 
be the dominant species above $1275 \mathrm{~K}$, but as the temperature falls below $1275 \mathrm{~K}$ the fraction of iodine existing as CsI rapidly increases until at $875 \mathrm{~K}$ virtually all of the iodine exists as CsI. The results are somewhat sensitive to total pressure, higher pressures favoring the formation of CsI. Figure IV.B.5(b) models the SFD 1-1 test for which the overall molar concentration ratios were set as follows: $\mathrm{I} / \mathrm{H}_{2} \mathrm{O}=2 \times 10^{-7} ; \mathrm{H} / \mathrm{O}=30 ; \mathrm{Cs} / \mathrm{I}=10$. Under these conditions the gas is characterized as being "reducing." Atomic iodine is computed to be the dominant species for temperatures above $2275 \mathrm{~K}$ with the fraction of iodine existing as CsI rapidly increasing at temperatures below $1675 \mathrm{~K}$ until at $875 \mathrm{~K}$ virtually all of the iodine exists as CsI. In the intermediate temperature range, 1075 to 2275 $\mathrm{K}$ (depending on pressure), a significant fraction of the iodine is computed to exist as $\mathrm{HI}$ for these reducing conditions. Osetek et al. (1984) found that the iodine release rate as measured downstream from an in-pile 32-rod bundle for the reducing conditions of the SFD 1-1 test was less than that for the oxidizing conditions of test SFD-ST (see Figure IV.B.6). These authors cite the above thermodynamic calculations as an explanation. For the reducing conditions, more of the iodine is expected to exist as CsI and the lower vapor pressure of this compound relative to $\mathrm{HI}$ or $\mathrm{I}_{2}$ provides a greater opportunity for iodine to be lost by plating out on the solid surfaces leading from the fuel bundle to the detector.

No formation of $I_{2}$ has been observed in numerous experiments in which heated $\mathrm{UO}_{2}$ containing fission products (actual or simulated) was exposed to streaming steam. The iodine which came was deposited as iodide, and all researchers involved agree that most of it was combined with cesium as CsI. Another compound that could be present is hydrogen iodide, HI, which forms rapidly at high temperatures by reaction of atomic iodine with hydrogen gas. HI should quickly react with $\mathrm{CsOH}$, present in eleven-fold excess over iodine, to form CsI. The CsI might occasionally be broken up by radiation, or

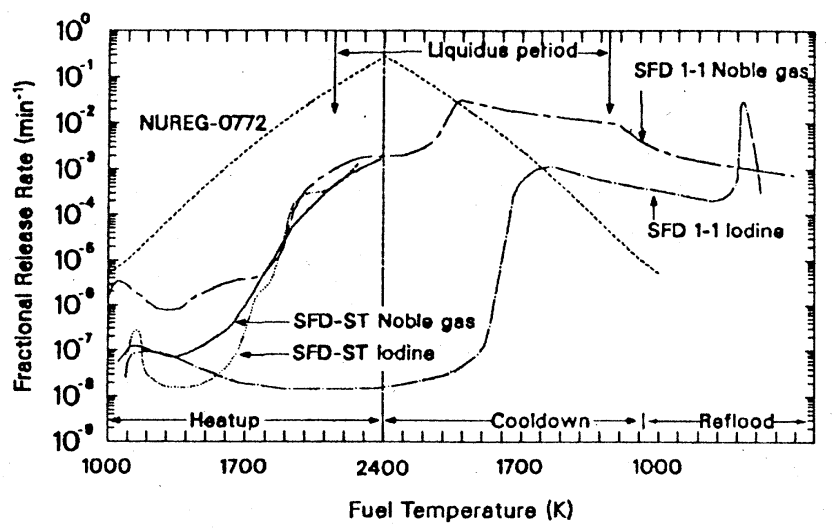

FIG. IV.B.6. Comparison of the noble gas and iodine behavior during the SFD-ST and Test SFD 1-1, from Osetek et al. (1984). by reaction with oxide layers on surfaces of zircalloy or steel, and any $I$ atoms that might be released to the gas phase in such processes would form HI.

In pressurized water reactors, boric acid is added to the cooling water, and in many accident scenarios should form deposits of boric acid in the plenum. This material may react with cesium iodide (Elrick and Sallack, 1983) to form $\mathrm{HI}$ :

$$
\mathrm{CsI}+\mathrm{HBO}_{2}=\mathrm{CsBO}_{2}(\text { solvated })+\mathrm{HI} \text {. }
$$

Hydrogen iodide, though a gas, is extremely soluble in water and is there completely ionized to $\mathrm{H}^{+}$and $\mathrm{I}^{-}$. It is very unlikely to be released to the environment as a vapor.

Cesium iodide has been observed to react with silica in Inconel to yield a vaporous iodine. The fate of this iodine has not been established.

When cesium is released from the fuel it will react with steam to form $\mathrm{CsOH}$. Barium and strontium may appear initally as the stable oxides $\mathrm{BaO}$ and $\mathrm{SrO}$ which would hydrate to $\mathrm{Ba}(\mathrm{OH})_{2}$ and $\mathrm{Sr}(\mathrm{OH})_{2}$. Antimony and tellurium are released generally in the reduced elemental form.

A final example of the reactions of interest is that of cesium hydroxide with stainless steel. Very adherent deposits of cesium were found on stainless steel lead screws taken from the Three Mile Island reactor vessel (Vinjamuri, 1984). Since that time laboratory studies have indicated that reactions occur with silica, a component in the corrosion films on steel. The product, $\mathrm{Cs}_{2} \mathrm{Si}_{4} \mathrm{O}_{9}$, appears to be quite stable and is observed in steel specimens exposed to steam at temperatures in excess of $1300 \mathrm{~K}$. The reaction rate to form cesium silicate is kinetically slow, probably because the cesium must first diffuse through an outer oxide layer that contains no silica. The reaction of cesium hydroxide with the silica in steel is important because the cesium silicate is not as easily revaporized as surface deposits of cesium hydroxide.

Considering the large number of elements arising from the primary constituents in structural materials including impurities therein, as well as the wide range in temperatures, pressures, and oxidizing potentials, it is apparent that several chemical reactions important to the source term are possible. If one adds to this complexity of reactions the influence of strong radiation fields, it is clear that a very substantial experimental program is required to give reasonable assurance that these phenomena are well understood.

A property which is little appreciated but could be important in a high-pressure accident series (TMLB) is the solubility of cesium hydroxide, $\mathrm{CsOH}$, in dense steam. Cobble (1984) has studied the solubilities in steam of a number of substances, including sodium hydroxide and sodium chloride, and based on the relations between this solubility and other properties has made estimates for $\mathrm{CsOH}$ and $\mathrm{CsCl}$. His formula for solubility $S$, in parts per billion by weight for $\mathrm{CsOH}$ in steam having molar volume $V$ liters at Kelvin temperature $T$ is 


$$
\log S=3.96 \log V-(1760 / T)+7.59 .
$$

In a TMLB sequence for a PWR, if $\mathrm{CsOH}$ were sufficiently soluble in steam that portion of the Cs would not deposit on walls or aerosols and would be directly vented to the containment. At these conditions $(637 \mathrm{~K})$ the density of steam is $0.1014 \mathrm{~kg} / 1, V=0.1776 \mathrm{1} / \mathrm{mole}$, and by Cobble's formula $S=5.23 \times 10^{7} \mathrm{ppb}$ or $5.23 \%$ by weight. Actually, the steam in a TMLB' accident sequence would be diluted with substantial quantities of hydrogen and the $\mathrm{CsOH}$ content thereby reduced. The validity of the research done by Cobble should be checked since it could have an important impact on the retention of $\mathrm{Cs}$ in the primary system. The salt CsI, though hygroscopic, is thought to be much less soluble in steam (like $\mathrm{NaCl}$ compared with $\mathrm{NaOH}$ ) and may largely be carried into the containment on aerosols.

IV.B.5. Chemical interactions

in the containment building

Chemical reactions in containment are probably not as complex as those in the reactor pressure vessel, but they also affect the source term. Some containments are "inerted" (the air is replaced by nitrogen) but others are not. When oxygen is present, iodides could be oxidized under some conditions to give a partial pressure of iodine vapor, which would depend on the time, the amount of hydrogen present, radiation intensity, and the $\mathrm{pH}$ of the iodide solution.

Iodides suspended as particulates in the containment atmosphere are subject to chemical change during hydrogen burns. This has been established in integral tests (Nelson et al., 1983) and laboratory tests (Taig, 1983) at Sandia with cesium iodide particles. Volatile iodine could be formed by the oxidation of the iodide.

Radiation-induced reactions in aerosols could release molecular species that would not settle as aerosols from the containment atmosphere.

Ionization of air or pure nitrogen results in formation of $\mathrm{N}$ atoms and $\mathrm{N}_{2}{ }^{+}$and $\mathrm{N}^{+}$ions which can react with $\mathrm{H}_{2} \mathrm{O}$ vapor or $\mathrm{O}_{2}$ to form oxides $\mathrm{NO}$ and $\mathrm{NO}_{2}$ that react in turn with water to form nitric acid, $\mathrm{HNO}_{3}$. The acid would reduce the $\mathrm{pH}$ of water pools in the containment. This reaction has been known since 1946 (Allen et al., 1947) but only one careful (but limited) study of it has been made since (Linacre and Marsh, 1981). In that study, sealed vessels containing pure water and $\mathrm{N}_{2}$ gas (pure or mixed with $\mathrm{O}_{2}$ or $\mathrm{H}_{2}$ ) were exposed in a research reactor to mixed gamma and fast neutron radiation, and nitrogen compounds formed in the water were determined. In all cases, the amount of compounds formed was proportional to the amount of $\mathrm{N}_{2}$ gas present and independent of the amount of water. The yield of $\mathrm{HNO}_{3}$, based on the energy absorbed from the radiation by $\mathrm{N}_{2}$, was $G=1.5$ molecules per $100 \mathrm{eV}$ with pure $\mathrm{N}_{2}$, and increased to $G=2.7$ or more when $\mathrm{O}_{2}$ gas was added. ( $G=1$ corresponds to $1.036 \times 10^{-7}$ g-mole per joule.) When $\mathrm{H}_{2}$ gas was added with the $\mathrm{N}_{2}$, the yield of $\mathrm{HNO}_{3}$ was much reduced and smaller and rather irreproducible yields of ammonia, $\mathrm{NH}_{3}$, appeared. In a degraded-core accident, enough hydrogen gas would enter the containment to reduce the yields of acid formation and peroxide production, and assure that the oxidation (if any) of the iodide would be a slow process.

The containment water may be subjected to as much as $10^{7} \mathrm{rad} / \mathrm{h}$ of beta and gamma rays, which is well known to decompose water to build up a steady concentration of $10^{-4}$ moles per $\mathrm{kg}(\mathrm{M})$ of hydrogen peroxide $\left(\mathrm{H}_{2} \mathrm{O}_{2}\right)$ in the presence of oxygen. Iodide ion does not appreciably react with $\mathrm{H}_{2} \mathrm{O}_{2}$ in neutral or alkaline water ( $\mathrm{pH}$ of 7 or more) but at $\mathrm{pH} 2$ to 3 it reacts in seconds to form volatile $\mathrm{I}_{2}$ : $\mathrm{H}_{2} \mathrm{O}_{2}+2 \mathrm{H}^{+}+2 \mathrm{I}^{-}=\mathrm{I}_{2}+2 \mathrm{H}_{2} \mathrm{O}$. As the reactions proceed, the radiation will build up more $\mathrm{H}_{2} \mathrm{O}_{2}$ and the iodide in these acid pools could be completely oxidized. However in the presence of much hydrogen or absence of oxygen, the $\mathrm{H}_{2} \mathrm{O}_{2}$ formation will be much reduced.

The nitric acid reaction, which has been ignored by source term researchers, thus poses a possible threat to the iodine source term in any scenario in which flooding of the containment by alkaline water does not occur. Further study of the reaction under various conditions is needed.

Tellurium, released to containment in the form of aerosols, will decay to the iodine daughter. The fate of iodine formed in this way should be included in calculating the source term.

\section{IV.B.6. Chemical phenomena in the core-concrete interaction}

As noted above the release of radionuclides in the reactor pressure vessel is dominated by iodine, cesium, and tellurium. When the molten core debris penetrates the reactor vessel it falls onto the floor of the reactor cavity where it interacts with the concrete basemat. The release of radionuclides from the core-concrete interaction to the containment gas space is calculated by the VANESA Code as described in Chapter V.

Generally, more attention has been given to releases in the reactor vessel because it was considered that the three volatile radionuclides released there constitute the major fraction of the source term. The release of some tellurium and the more refractory fission products such as lanthanides* and actinides from the core concrete interaction may contribute significantly to the radioactivity held in containment. The amount of refractory materials released from the core concrete interaction is a sensitive function of the temperature of the molten pool, as described in IV.A.

For certain containment failure modes, releases that occur late in the accident sequence could contribute to the release to the environment. Calculated releases to containment for the TMLB' sequence as reported for the Sur-

\footnotetext{
*The lanthanum group of radionuclides, as classified in the Reactor Safety Study, contains Eu, Gd, La, Nd, Pm, Pr, Ce, $\mathrm{Np}$, and $\mathrm{Pu}$.
} 
ry plant (Gieseke et al., 1984, Vol. V) are shown in Table IV.B.1.

It is worth noting in Table IV.B.1 that a substantial fraction of the tellurium which had combined with zirconium and stainless steel in the reactor vessel is expected to be released later in the sequence during the interaction with concrete. The table does not list iodine and cesium; these "volatile" fission products will also be released to the extent solid fuel debris was swept into the pool during core collapse.

The chemistry involved in the release is extremely complex. When the molten core debris contacts the concrete basemat, the high temperature causes thermal decomposition of the concrete. Large volumes of carbon dioxide and steam are released. As these gases sparge through the overlying layer of molten material they are reduced by metallic constituents to hydrogen and carbon monoxide. Some fission product oxides (such as $\mathrm{La}_{2} \mathrm{O}_{3}$ ) may be reduced to more volatile suboxides $(\mathrm{LaO})$ or metals at this point. This would enhance their release. As the gases pass through the melt they pick up materials that are vaporized at the elevated temperatures (above $2270 \mathrm{~K}$ ). The gases leave the surface of the melt where the vapors condense and are transported into the containment as aerosols.

The complexity of the chemistry arises from the large number of chemical species involved and the complex physical conditions. Twenty-eight chemical elements are listed as constituents of the core debris, thirteen different chemical compounds are listed in the composition of the concretes, and the VANESA Code considers 137 vapor species. The physical conditions involve heterogenous reactions occurring at temperatures up to $2800 \mathrm{~K}$ in multiphase systems. Modeling such a complex system requires many simplifying assumptions.

The quantities of radionuclides released as aerosols above the melt are very sensitive to the conditions of the reaction and to the composition of the melt. Release of the fission products and actinides is an exponential function of the temperature, and some fission products are influenced strongly by the oxidation potential of the melt. This latter point is illustrated by some of the calculated

TABLE IV.B.1. Calculated radionuclide release to containment for Surry TMLB' core-concrete interaction. ${ }^{\mathrm{a}}$

\begin{tabular}{lc}
\hline \hline Species & Fraction released $^{\mathrm{b}}$ \\
\hline $\mathrm{Te}$ & $0.40^{\mathrm{c}}$ \\
$\mathrm{SrO}$ & 0.12 \\
$\mathrm{BaO}$ & 0.097 \\
$\mathrm{CeO}_{2}$ & 0.001 \\
$\mathrm{UO}_{2}$ & $<10^{-4 \mathrm{~d}}$ \\
$\mathrm{La}_{2} \mathrm{O}_{3}$ & $<10^{-4 \mathrm{~d}}$ \\
$\mathrm{Ru}$ & $<10^{-4 \mathrm{~d}}$ \\
\hline \hline
\end{tabular}

$\overline{{ }^{a} \text { Approximated from Tables } 6.10 \text { and } 6.14 \text { (Gieseke et al., 1984, }}$ Vol. V).

${ }^{b}$ Fraction of the original melt inventory.

${ }^{c} 65 \%$ of the original core inventory was in the melt.

${ }^{\mathrm{d}}$ The computer calculations are not reliable below this level (Powers, private communication). results reported in the QUEST Program (Lipinski, 1984).

In studying the sensitivity of releases to the presence of metallic zirconium in the melt, Lipinski et al. (1984) calculated the releases to containment for the Surry, TMLB' sequence as the quantity of metallic zirconium in the melt (the amount not oxidized in the reactor vessel) was varied from zero to $80 \%$ of the original inventory in the core. The base case of $41 \%$ zirconium corresponds to the calculation of the TMLB' sequence reported in Gieseke et al. (1984; Vol. V). The results are shown in Table IV.B.2. Since the fraction of zirconium that would be present in the melt is rather uncertain, the high release of lanthanum and cerium for $80 \%$ zirconium emphasizes the importance of more experimental studies in this area.

These results are not surprising since the oxidation of metallic zirconium in the melt increases the temperature, and zirconium metal reduces some refractory oxides to the more volatile elemental forms. Lipinski et al. state that this range of zirconium in the melt has been reported in some studies; however, they believe that only $20 \%$ oxidation of zirconium in the reactor vessel is unrealistically low. In spite of these reservations, it is clear that the calculated releases are sensitive to this parameter. This could be especially important for BWR's which have zirconium in the channel plates as well as in the fuel rod cladding (Figure III.A.3).

$\mathrm{La}_{2} \mathrm{O}_{3}$ is one of the biologically active fission products which is reduced by zirconium to more volatile $\mathrm{LaO}$, $\mathrm{LaOH}$, or La forms. The APS study group is especially concerned about some potentially rapidly evolving BWR sequences, such as $\mathrm{AE}$, which may create zirconium metal-rich corium pools with significant potential to vaporize the lanthanum group to aerosols. These same sequences have the potential for early failure of Mark I containments.

The behavior of specific rare earths and actinides (e.g., plutonium) in such sequences require investigation.

Given the complexities of the core-concrete interaction, a substantial experimental data base is required for reliable calculation of releases. At present only limited data exist. Ideally there should be data which are easy to duplicate and analyze. In the future separate effects tests

TABLE IV.B.2. Calculated effect of metallic zirconium on release to containment of fission products (from Lipinski et al., 1984).

\begin{tabular}{cccc}
\hline & \multicolumn{3}{c}{ Fraction of } \\
Zr metal fraction & \multicolumn{3}{c}{ fission product released } \\
\hline & $\mathrm{Sr}$ & $\mathrm{La}^{\mathrm{b}}$ & $\mathrm{Ce}^{\mathrm{c}}$ \\
0 & 0.001 & $<10^{-4 \mathrm{~d}}$ & $<10^{-4 \mathrm{~d}}$ \\
41 & 0.12 & $<10^{-4 \mathrm{~d}}$ & 0.001 \\
80 & 0.70 & 0.30 & 0.20 \\
\hline
\end{tabular}

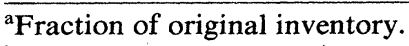

${ }^{b} \mathrm{La}$ is a surrogate for the group $\mathrm{Eu}, \mathrm{Gd}, \mathrm{La}, \mathrm{Nd}, \mathrm{Pm}, \mathrm{Pr}, \mathrm{Sm}$, and $\mathrm{Y}$.

${ }^{\mathrm{c}} \mathrm{Ce}$ is a surrogate for the group $\mathrm{Ce}, \mathrm{Np}$, and $\mathrm{Pu}$.

${ }^{\mathrm{d}}$ The computer calculations are not reliable below this level (Powers, private communication). 
will be run to measure vaporization rates of selected fission products. Tellurium, barium, strontium, and molybdenum are of primary interest in these tests. Integral tests mentioned earlier in Section IV.A will be conducted in the Large-Scale Melt Facility at Sandia National Laboratory and at the BETA facility of the Kernforschung Zentrum, Karlsruhe (West Germany), which will measure not only temperature increases but also gas releases. In these tests, melts weighing about $200 \mathrm{~kg}$ will be placed in concrete crucibles at temperatures of about $2900 \mathrm{~K}$. Stable isotopes of the fission products will be added to the melts as chemical surrogates.

The integral tests should provide reliable data for releases. The study group stresses the importance of adding the full range of biologically active materials to these tests (including plutonium), and simulating the full expected range of temperature and zirconium metal content. An extensive program may be required to elaborate the complex chemistry involved in the interaction. For example, at present only elements, oxides, and hydroxides are considered in the VANESA model; the presence of halides or sulfides arising from the concrete could produce other volatile fission product species. Such questions about the chemistry can only be answered by experiment.

\section{IV.B.7. Conclusions}

a. There is sufficient information on the release from fuel of the volatile fission products (I, Cs, Te) to allow a valid calculation of the releases of these materials in severe accident analyses. There is not as much information on the release of the less volatile nuclides such as barium, strontium, and plutonium and the calculation of their release contains broader uncertainties. Confirmatory laboratory experiments are needed over a wide range of parameters relevant to accident conditions to reduce the uncertainties in the calculated releases of the less volatile nuclides. These should include experiments at high pressure.

b. Chemical reactions of the volatile fission products that occur in the Reactor Coolant System could on the one hand lead to the formation of more volatile species or on the other hand to compounds bound irreversibly to steel surfaces. The study of such reactions is in an early stage. Experimental programs such as those currently underway should be pursued if these phenomena are to be understood well enough to be included in accident analyses.

c. The release of fission product species in the complex high-temperature environment of the core-concrete interaction could lead to substantial releases into the containment. The computer programs are complex and use boiling correlations far from tested regions. Data on the "nonvolatile" fission products to check these computer programs are particularly lacking. Both laboratory scale and large-scale experiments to search for the release of the more volatile compounds of the important radionuclides which are considered as nonvolatile in the present calculations should be continued. These experiments should cover the full range of compositions (including plutonium and other materials of interest), temperatures, and oxidation-reduction potential anticipated for accident sequences.

d. There is a possibility that reactions exist, including radiolytic reactions, that would partition iodine from aqueous solutions in containment into volatile form. Sufficient work should be done to allow an assessment of these types of reactions, to determine if they contribute significantly to the source term.

e. Chemical reactions of the fission products during transport through the reactor system are not generally treated in the computer codes used in current accident analyses. Chemical parameters which affect the source term should be modeled in the codes.

\section{IV.C. Aerosol theory and experiments}

\section{IV.C.1. Introduction}

As noted in the introductory section, the noble gases, $\mathrm{Kr}$ and $\mathrm{Xe}$, are released from the fuel as gases; these mix with the other gas flows and can be released as gases to the environment. However, volatile fission products, such as Cs, I, and Te, which are volatile at the high temperatures of a degraded core either condense to form liquid or solid particles or combine chemically to form lower volatility species which then condense. The nonvolatile fission products, together with other non-radioactive material, can be released during the hot core-concrete interaction. These then become solid aerosols or absorb water vapor to become liquid aerosols.

The behavior of these aerosols governs the flow of the volatile fission products after they leave the fuel rods (during the heatup and core-melt periods; see Section IV.A) and therefore govern retention in the primary system. Their behavior governs whether these deposit in the reactor vessel, to rejoin the core-melt at reactor pressure failure, or deposit elsewhere in the primary system. The behavior of aerosols also governs the rate of deposition of these fission products in the containment.

An aerosol is a collection of particles suspended in a gas. The particles may be liquid, solid, or a mixture. Liquid aerosol particles can be taken to be spheres owing to the action of surface tension and their small size. Solid aerosol particles may have a variety of shapes, some departing very significantly from spherical. However, for purposes of this overview we shall take solid aerosol particles also to be spheres unless otherwise noted. Empirical shape factors may be introduced into formulas derived for spherical particles to account for the influence of particle shape when necessary. The effect is to reduce the particle mobility and thereby decrease its deposition rate compared with a spherical particle of equivalent volume. The effect on coagulation is more complex; the area for contact may be increased, thus partially offsetting the reduction in mobility. Since we are taking the particles to be spheres, particle size is uniquely specified by particle radius $a$, particle diameter $d$, or particle volume $v=\pi d^{3} / 6$.

Except for aerosols prepared under very special condi- 


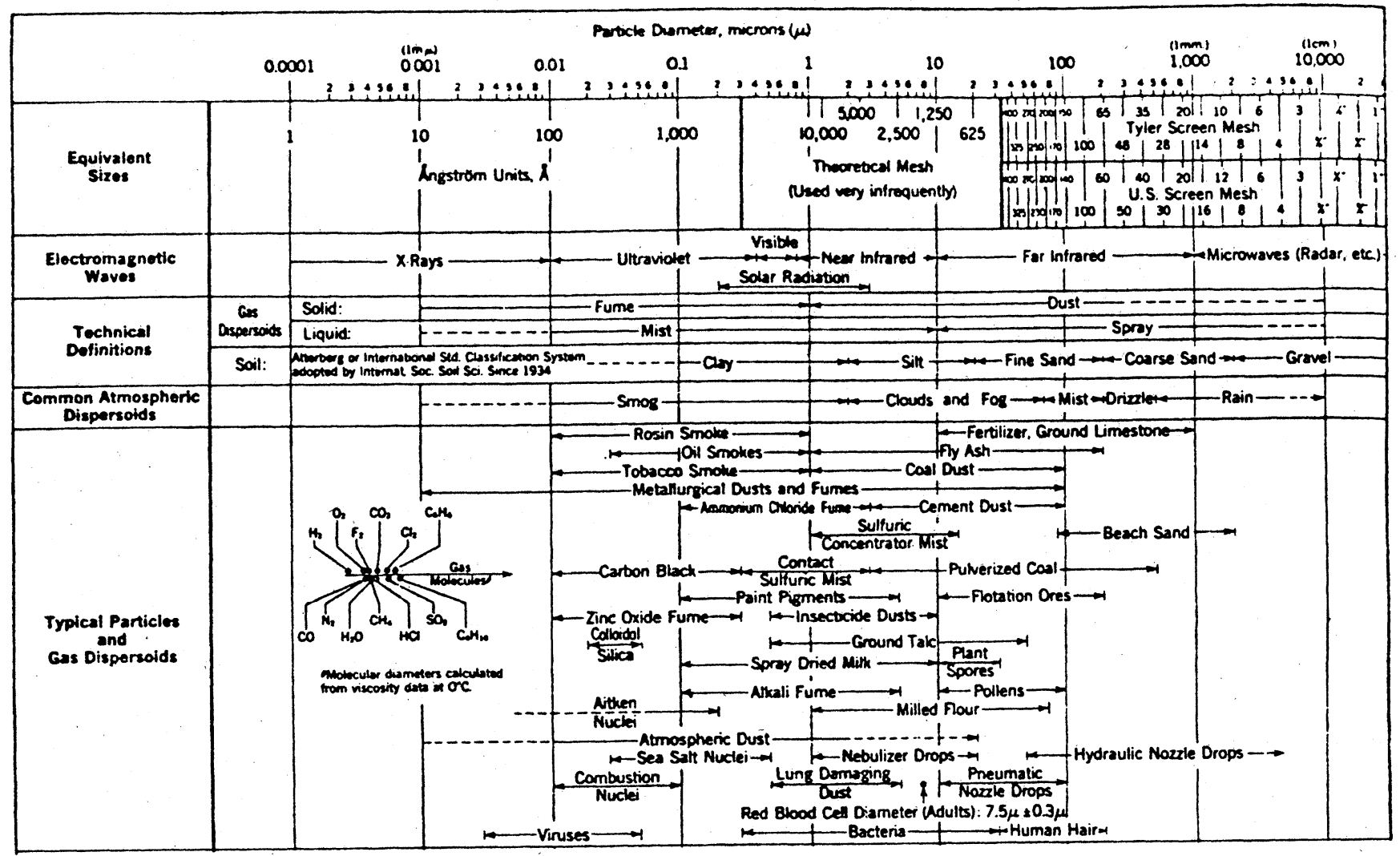

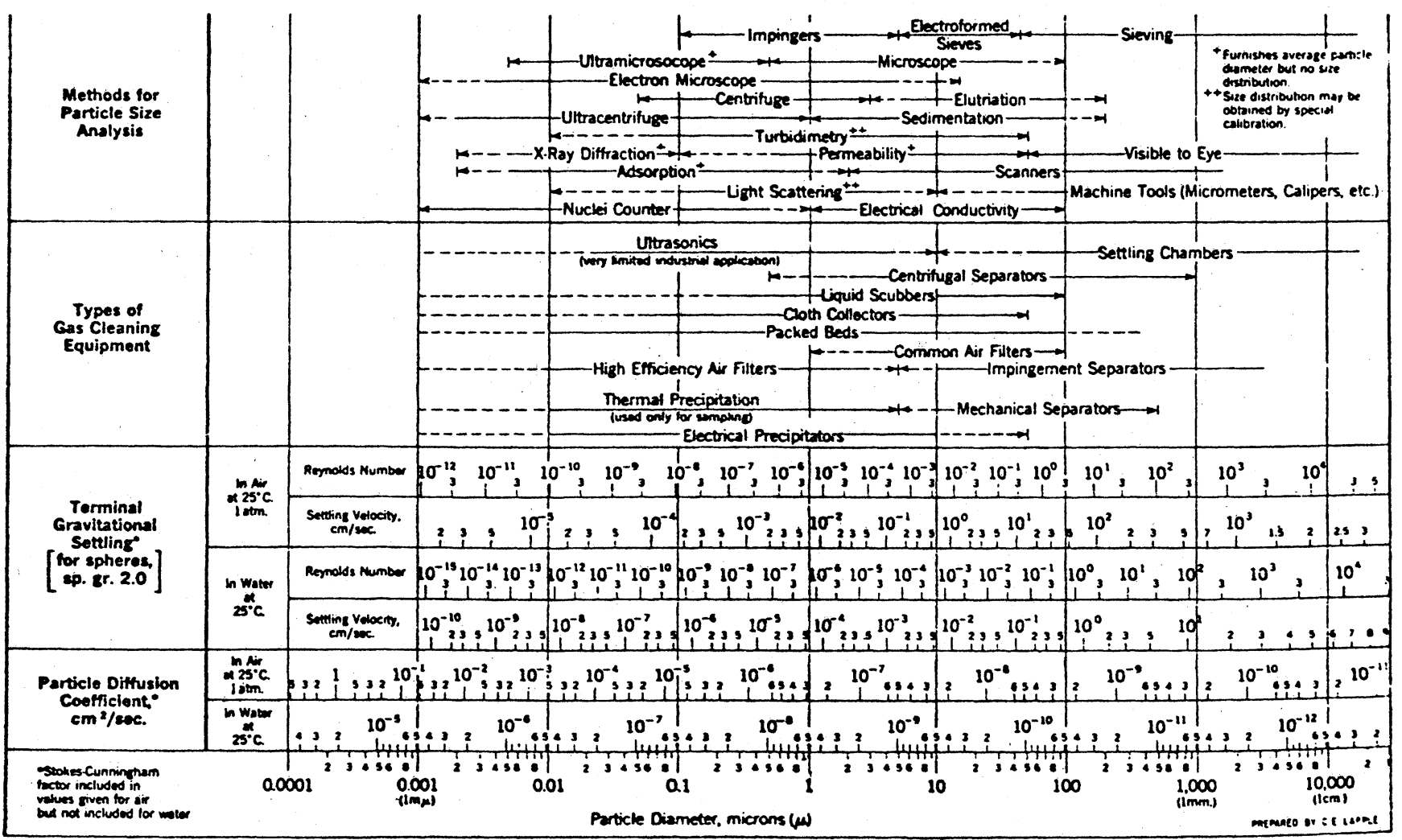

FIG. IV.C.1. Characteristics of particles and particle dispersoids. Courtesy Stanford Research Institute. 
tions, each property of the collection of particles generally is distributed over a range of values. For example, although the limits are somewhat arbitrary, aerosol diameters could range from as small as $1 \mathrm{~nm}$ (a cluster of a small number of molecules) to as large as $1 \mathrm{~mm}$. Figure IV.C. 1 is a useful summary of the likely size ranges for typical aerosols.

Aerosols are dynamic systems: Particles are convected from place to place by the flowing gas in which they are suspended. Particles move relative to the suspending gas if they are acted upon by external forces or if they possess sufficient inertia that they are unable to follow changes in the gas velocity. Particles diffuse relative to the suspending gas if the particle concentration is spatially nonuniform. New particles may be formed by nucleation from supersaturated vapors or by mechanical disintegration of larger masses. Existing particles may increase in size owing to condensation or decrease in size owing to evaporation. Particles may increase in size and decrease in number by coagulation. Finally particles may be lost from the gas by deposition onto surfaces. The kinetics of these processes, and therefore their relative importance for a given set of conditions, depend on the properties of the particles, especially particle size, the properties of the suspending gas, the geometry of the system, and the nature of the gas motion.

Many of these processes are understood reasonably well when they occur individually and in systems of simple geometry with simple composition. Excellent accounts of aerosol behavior under such conditions are available in books by the following authors among others: Fuchs (1964), Hidy and Brock (1970), Friedlander (1977), Pruppacher and Klett (1978), Seinfeld (1980), Hinds (1982), and Loyalka (1983). Current knowledge of the kinetics of the individual processes will be reviewed in this section. Application of this understanding to estimation of the source term is impeded by the facts that: during a severe accident many of the aerosol processes occur simultaneously and are strongly coupled; the geometry and chemistry are extremely complex; an accident is an unsteady situation with conditions varying in space; and the thermal hydraulics which drive the aerosol processes currently are not modeled in great detail.

IV.C.2. Evolution equation for the particle size density function

Assume for simplicity that particle size is the only important distributed property of the particles. Of course, responses that depend on particle size such as settling speed also will be distributed as can be seen from Figure IV.C.1. A quantity of fundamental importance to the description of aerosol systems is the particle size density function $n(\mathbf{r}, t, v)$. This is defined such that $n(\mathbf{r}, t, v) d v$ is the number of particles per unit volume of gas near position $\mathbf{r}$ at time $t$ having particle volume between $v$ and $v+d v$. Evolution of $n(\mathbf{r}, t, v)$ due to the processes enumerated above is governed by the following population balance:

$$
\begin{aligned}
\frac{\partial n(\mathbf{r}, t, v)}{\partial t}= & -\nabla \cdot(\mathbf{u} n)-\nabla \cdot(\mathbf{c} n)+\nabla \cdot(\mathscr{D} \nabla n) \\
& +\left(\frac{d n}{d t}\right)_{\text {source }}+\left(\frac{d n}{d t}\right)_{\text {growth }}+\left(\frac{d n}{d t}\right)_{\text {coagulation }}
\end{aligned}
$$

(IV.C.1)

The term on the left of Equation (IV.C.1) is the local rate of accumulation or depletion of particles of size $v$ per unit volume of gas.

The term $\boldsymbol{\nabla} \cdot(\mathbf{u} n)$ is the divergence of the flux of particles of size $v$ being convected with the gas at local gas velocity $\mathbf{u}(\mathbf{r}, t)$. A study of the thermal hydraulics ideally should provide the spatial and temporal variation of the gas velocity as well as the temperature, total pressure, and composition fields. Thermal hydraulics is reviewed in Section IV.A. There it is shown that during the critical time for aerosol transport-the heatup and core-melt phases-the physical phenomena are complex and it is not possible to give the gas velocity, temperature, and composition fields with a fine degree of resolution. Consequently, a spatially averaged form of Equation (IV.C.1) is used for source term estimation. The averaged form of Equation (IV.C.1) will be discussed in Section IV.C.3.

The term $\nabla \cdot(\mathrm{cn})$ is the divergence of the flux of particles of size $v$ moving relative to the gas with a size dependent (and possibly time and position dependent) velocity c. Relative motion arises when the particles experience an external force such as gravity or when the particles have sufficient inertia that they' cannot follow changes in the gas velocity. Relative motion is resisted by a drag force which depends on the particle size and the relative velocity; $c$ is found by solving the equations of motion for a particle in response to these forces. The determination of $\mathbf{c}$ for forces of interest in estimating the source term is discussed in Section IV.C.4. However, for the moment we simply cite the result for the steady velocity achieved when a particle of density $\rho_{p}$ and a diameter $d$ sediments in response to the acceleration of gravity $g$ through a gas of viscosity $\mu$, density $\rho$, and mean free path $\lambda$ :

$$
c_{\text {sed }}=\left(\rho_{p}-\rho\right) g d^{2} C_{p} /(18 \mu) .
$$

$C_{p}$ is a correction to the results in the continuum regime to account for slip and free molecular effects when the mean free path of the gas is comparable to or larger than the particle diameter. This correction is known as the Cunningham slip correction and is given by the empirical equation:

$$
C_{p}=1+(2 \lambda / d)[1.257+0.400 \exp (-0.55 d / \lambda)]
$$

(IV.C.3)

The term $-\nabla \cdot(\mathscr{D} \nabla n)$ is the divergence of the flux of particles of size $v$ relative to the gas by diffusion according to Fick's law, with a size dependent diffusion coefficient $\mathscr{D}$. The coefficient of diffusion in a gas at absolute temperature $T$ is given by the Stokes-Einstein relation:

$$
\mathscr{D}=k T C_{p} / 3 \pi \mu d,
$$

(IV.C.4) 
where $k$ is Boltzmann's constant. Diffusion of aerosol particles is discussed in Section IV.C.4. It will be seen that in most applications because the coefficient of diffusion is small, transport of particles by diffusion (especially near collecting surfaces) is strongly coupled to transport by convection. Consequently, deposition rates caused by diffusion depend also on the gas velocity. We should expect different deposition rates for laminar and turbulent flows and for forced and thermally driven flows, and of course the deposition rates are geometry dependent. Here we cite as an example of an empirical correlation the deposition rate $j$ per unit area of surface for forced turbulent flow in smooth tubes of diameter $D$ and average gas velocity $U$ :

$$
j=0.023(\rho D U / \mu)^{0.83}(\mu / \rho \mathscr{D})^{0.33}(\mathscr{D} n / D)=k_{d} n .
$$

(IV.C.5)

In general, the ratio $j / n$ of the deposition rate per unit area to the aerosol number concentration is called the deposition velocity, $k_{d}$.

The term $(d n / d t)_{\text {source }}$ is the net production rate per unit volume of gas of particles of size $v$ due to nucleation. This is discussed in Section IV.C.7. It will be seen that the rate of particle production is an extremely sensitive function of the degree of supersaturation, the temperature, and the physical properties of the condensed phase. For a single condensing species of molecular mass $m$ forming pure liquid drops of surface tension $\sigma$ and molecular volume $v_{m}$, classical nucleation theory gives the following expression for the production rate per unit gas volume of droplets of the minimum thermodynamically stable size $d^{*}$ :

$$
\begin{aligned}
(d n / d t)_{\text {source }}= & v_{m}\left(p_{i} / k T\right)^{2}(2 \sigma / \pi m)^{1 / 2} \\
& \times \exp \left[-16 \pi \sigma^{3}\left(v_{m}\right)^{2} / 3(k T)^{3}(\ln S)^{2}\right],
\end{aligned}
$$

(IV.C.6)

where

$$
S=p_{i} / p_{i, \text { sat }}
$$

and

$$
d^{*}=4 \sigma v_{m} / k T \ln (S) .
$$

Here $p_{i}$ is the partial pressure of the condensing species and $p_{i \text {,sat }}$ is its equilibrium saturation vapor pressure at the prevailing temperature. $S$ is called the saturation ratio. Since the vapor concentrations and gas temperature vary with position and time and since vapor pressure is a strong function of temperature, the particle production rate by nucleation can be extremely sensitive to fine details of the thermal hydraulics. New particles also may be formed on preexisting nuclei, and the rate at which this occurs is sensitive to the chemical and physical interactions of the condensed phase with these preexisting nuclei as, for example, the contact angle with insoluble nuclei or the vapor pressure suppression by soluble nuclei. The rate of nucleation also can be very sensitive to the scavenging of vapor and nuclei by surfaces especially the surfaces of previously formed aerosols. When sufficient aerosol area has been formed, supersaturation can be relieved by condensation of vapor onto existing particles rather than by the formation of new particles.

The term $(d n / d t)_{\text {growth }}$ is the net rate of transfer per unit volume of gas of particles from other size classes to size $v$ by the mass transfer processes of condensation and evaporation. If $G$ represents the local size dependent particle growth or shrinkage rate, then $(d n / d t)_{\text {growth }}$ can be expressed as

$$
(d n / d t)_{\text {growth }}=-\partial(G n) / \partial v .
$$

Particle growth and evaporation are discussed in Section IV.C.5. Here we simply quote the result for the diffusional growth when molecular diffusion of the vapor with diffusion coefficient $\mathscr{D}_{m}$ to the particle surface is the dominant mass transfer mechanism:

$G=2 \pi \mathscr{D}_{m} d v_{m}\left[(p / k T)_{i}-(p / k T)_{i, \text { sat }}\right] C_{m t}$,

(IV.C.10)

$C_{m t}$ is a correction to the result for the continuum regime to account for slip and free molecular effects. According to Fuchs and Sutugin (1971)

$$
C_{m t}=(1+2 \lambda / d) /\left[1+3.46 \lambda / d+5.333(\lambda / d)^{2}\right] .
$$

(IV.C.11)

Thus relief of supersaturation by condensation onto existing particles is seen to be proportional to $(S-1)$ whereas the relief of supersaturation by nucleation of new particles depends very much more strongly on $S$. The growth of hygroscopic particles (above which the vapor pressure $p_{i \text {,sat }}$ of water may be considerably reduced) by absorption of water vapor is believed to play an important role in aerosol removal from the containment vessel, by increasing particle size and thereby increasing the deposition velocity.

The term $(d n / d t)_{\text {coagulation }}$ is the net rate of transfer per unit volume of gas of particles of other size classes to size $v$ brought about by coagulation. Particles of size $v$ are lost when these collide and stick to any size particle, and particles of size $v$ are formed when two particles of total volume $v$ collide and stick. These rates are proportional to the concentrations of the particles entering collision so that

$$
\begin{aligned}
(d n / d t)_{\text {coagulation }}= & -\int_{0}^{\infty} \beta(v, \widetilde{v}) n(\mathbf{r}, t, v) n(\mathbf{r}, t, \widetilde{v}) d \widetilde{v} \\
+ & \frac{1}{2} \int_{0}^{v} \beta(v-\widetilde{v}, \widetilde{v}) n(\mathbf{r}, t, v-\widetilde{v}) \\
& \times n(\mathbf{r}, t, \widetilde{v}) d \widetilde{v} .
\end{aligned}
$$

As indicated by the arguments of $\beta(v, \widetilde{v})$ which is called the collision kernel, the collision rate per unit volume of gas depends on the particle volumes $v$ and $\widetilde{v}$ of both particles entering the collision. Different coagulation mechanisms give different dependencies on particle size (and therefore indirectly on particle volume concentration). Coagulation by Brownian motion usually dominates when the number concentration is high and coagulation by differential settling of unequal sized particles is believed to dominate at lower number concentrations likely to be 
found in the containment vessel late in an accident. Coagulation will be discussed in Section IV.C.6. Here we simply cite as an example the formula for $\beta(v, \widetilde{v})$ for Brownian coagulation when both particles are larger than the gas mean free path:

$$
\beta(v, \widetilde{v})=2 k T / 3 \mu \cdot\left(v^{1 / 3}+\widetilde{v}^{1 / 3}\right)\left(v^{-1 / 3}+\widetilde{v}^{-1 / 3}\right) .
$$

(IV.C.13)

To a certain extent, nucleation and growth can be regarded as special cases of coagulation, namely coagulation of particles with individual molecules. However, because these processes usually occur with different characteristic time scales, it is often advantageous to regard them as different processes. The time scales for growth and nucleation are usually much shorter than those for coagulation. Consequently it is often assumed that they occur under pseudo-steady state conditions. As temperature or supersaturation change, these rates also change; but their instantaneous rates are given by steady state theory for the then prevailing conditions. A similar assumption is made in the kinetic theory of nonuniform rarified gases, where, although the gas is not in equilibrium, the distribution of molecular velocities about the local mean velocity at each position and time is the Boltzmann distribution based on the local temperature. As a result of treating nucleation and growth as separate processes, separate mass balances are required to keep track of uncondensed molecular species and Equation (IV.C.1) should be applied only to particles larger than the minimum thermodynamically stable size.

New particles might be formed from existing particles by breakage when particles collide with other particles or with surfaces at high speed, by the bursting of bubbles formed during the rapid heating of particles, the development of thermal stresses when the temperature of solid particles undergoes large changes, and the shattering of charged drops when the Rayleigh limit is exceeded. These processes are poorly understood, are not included in source term modeling, and are omitted in this review. An exception is the formation of aerosols from the molten pool by the bursting of bubbles formed by the coreconcrete interactions.

\section{IV.C.3. Averaged equations for the particle size density function}

Solving Equation (IV.C.1) is impossible for purposes of source term estimation. In the first place the thermal hydraulics codes used are inadequately developed to give the spatial and temporal resolution required for the velocity, temperature, and concentrations. Secondly, the histories of the release rates of the various species from the core and their chemical conversion to other condensible species is not known with sufficient precision to warrant the calculation. And thirdly, even if the above information were available, the numerical computation would be much too lengthy to permit covering the wide range of conditions that require investigation. Consequently all source term calculations involving aerosols are based on a spatially averaged form of Equation (IV.C.1).

This averaged equation is obtained by integrating Equation (IV.C.1) over some region of physical space of volume $\boldsymbol{V}$. Since some of the terms in Equation (IV.C.1) depend nonlinearly on particle concentration, vapor concentration, and temperature, it is necessary to make some assumption about the spatial variation of these parameters. The usual assumption is that all variables are uniformly distributed within the control volume except perhaps in very thin layers adjacent to bounding surfaces. Two types of bounding surfaces are considered: open areas through which gas flows carrying with it particles, and surfaces on which particles can deposit. The latter might include the surface area of sprayed water drops which can scavenge aerosol particles. When the integration over the control volume is carried out, the first three terms on the right of Equation (IV.C.1) can be expressed as surface integrals by use of the divergence theorem.

Let $n(t, v)$ denote the averaged particle size density function for the control volume. Then the integrated equation takes the form:

$$
\begin{aligned}
V \frac{d n(t, v)}{d t}= & \sum Q_{\mathrm{in}} n_{\mathrm{in}}-\sum Q_{\mathrm{out}} n-\sum A k_{d} n \\
& +V\left[(d n / d t)_{\text {source }}+(d n / d t)_{\text {growth }}\right. \\
& \left.+(d n / d t)_{\text {coagulation }}\right] .
\end{aligned}
$$

Here $Q_{\text {in }}$ and $Q_{\text {out }}$ are the volumetric flow rates into and out of the control volume and the summation signs for them indicate the possibility of several such open areas. For these areas the transport of particles by migration and by diffusion relative to the gas are neglected compared to transport by gas convection. $k_{d} n$ is given by the average component normal to a collecting surface of area $A$ of the vector $-(\mathbf{u} n+\mathbf{c} n-\mathscr{D} \nabla n)$ evaluated at particle-surface contact. The summation sign here indicates the possibility of several such areas, for example floors, walls, ducting, spray drops, etc. In general each surface requires a different value of $k_{d}$ depending on the geometry, flow, and major deposition mechanism for that surface. The term $k_{d}$ has units of length/time and is called the deposition velocity; in the chemical engineering literature $k_{d}$ is called the average mass transfer coefficient for the area considered. Correlations for $k_{d}$ due to a variety of deposition mechanisms and geometries will be discussed in Section IV.C.4.

Equation (IV.C.14) is the basic equation for computation of aerosol transport and deposition in the reactor coolant system by the TRAP-MELT code. However the term $(d n / d t)_{\text {source }}$ is omitted it being assumed that no new particles are formed within the control volumes. All particles are taken to have been previously formed and are carried into the respective volumes by the terms $Q_{\text {in }} n_{\text {in }}$. Consequently, as a starting point it is necessary to specify the characteristics of the aerosol leaving the "immediate" vicinity of the degraded fuel. This is done by assuming a $\log$ normal distribution with user assigned geometric 
mean radius and geometric standard deviation. The number concentration is then computed so that the instantaneous mass flow rate of aerosol away from the degraded fuel matches the mass release rate from the fuel computed by the code CORSOR of those species judged to be sufficiently nonvolatile to have condensed to aerosol already. Typically an initial average particle size of $0.05 \mu \mathrm{m}$ and geometric standard deviation of 1.7 are chosen. The implied justification for this approach is the hope that when the initial number concentration is sufficiently large, the particle size distribution function rapidly approaches a form independent of the initial number and distribution due to coagulation. This will be discussed more fully in Section IV.C.6. Other user specified properties of the particles are their density, a shape factor for sedimentation, and a shape factor for cuagulation.

Equation (IV.C.14) is also the basic equation for compution of aerosol processes within the containment vessel by the NAUA code. Again, it is assumed that no new particles are formed by nucleation in the containmemt. Particles flow into the containment from the reactor coolant system at a rate and size distribution that is computed by the TRAP-MELT code. Particles are also introduced into the containment following melt through of the reactor vessel owing to the gases formed by the interaction of the molten core with the concrete. Some particles are generated by subsequent condensation of sufficiently volatile species sparged from the hot melt by the rising gas bubbles and some particles are generated by the bursting of gas bubbles at the surface of the melt. The computer code VANESA provides these inputs to NAUA. Those particles formed by condensation are assigned a single diameter determined empirically from small scale melt-concrete experiments to be proportional to the cube root of the mass production of the condensible species as computed by VANESA to have been sparged. The particles produced by bubble bursting are assigned the diameter of $1 \mu \mathrm{m}$. Aerosol formation by the mechanical processes of atomization at melt-through, bubble bursting, large droplet breakage on impact, and steam explosions may be especially important for refractory species in view of their relatively low volatility, even at molten pool temperatures.

As pointed out above, most aerosol processes are very sensitive to particle size. For example, the deposition velocity resulting from sedimentation is roughly proportional to the square of particle diameter, and the deposition velocity because turbulent ejection is roughly proportional to the fourth power of particle diameter at least for much of the size range of interest for source term estimation. The decontamination ratio usually depends exponentially on deposition velocity. Therefore modest changes in the size distribution can have large influences on the rates and locations of aerosol deposition. Equation (IV.C.1) describing the evolution of the particle size density function contains several nonlinear phonemena. $\mathrm{Nu}$ cleaction rates are extremely sensitive to the degree of supersaturation which varies with position. Coagulation is a second order process. Replacing an equation in which $n(\mathbf{r}, t, v)$ is continuously varying in space by an equation in which only an averaged value $n(t, v)$ is computed can lead to significant errors in estimating aerosol processes if the gas is not well mixed unless appropriate averages are employed or sufficiently small control volumes are used. In current computations using the TRAP-MELT code or the NAUA code, the reactor coolant system and the containment vessel are divided into a relatively small number of control volumes assumed to be well mixed. Given the large size of some of these volumes, the predicted large temperature and concentrations variations between the gases and bounding surfaces at least in some parts of the flow path, the expected nature of the gas flow field, and the sensitivity of aerosol processes to particle size, the assumption that each control volume is well mixed certainly deserves much more scrutiny than it has received to date.

A step in this direction is the RAFT code which computes aerosol transport and deposition processes in ducts. In this code the gas is assumed to be well mixed across the duct cross section but properties are allowed to vary continuously along the duct.

\section{IV.C.4. Aerosol deposition mechanisms} and deposition velocities

\section{IV.C.4.a. General comments}

The following mechanisms have been recognized to be of potential importance for removal of aerosols from gases during a severe accident at a nuclear power plant: sedimentation caused by gravity onto horizontal surfaces ( $k_{\text {sedimentation }}$ ); thermophoresis resulting from temperature differences between the gas and surfaces ( $\left.k_{\text {thermophoresis }}\right)$; deposition by the Stefan flow associated with the condensation of vapors on surfaces $\left(k_{\text {Stefan }}\right)$; inertial deposition from turbulent flow near surfaces $\left(k_{\text {turbulent }}\right)$; deposition by impaction owing to abrupt changes in gas velocity near surfaces which the particles cannot follow ( $\left.k_{\text {impaction }}\right)$; and diffusional deposition owing to particle concentration differences near surfaces $\left(k_{\text {diffusion }}\right)$. The symbol for the associated deposition velocity is shown in parentheses. For each deposition mechanism, the deposition velocity depends on particle size, flow conditions, and geometry. The dependence may be quite complex, and since these variables can vary widely it may be necessary to use several different correlations to cover the necessary range of variables even for a single deposition mechanism. Deposition velocities are usually determined theoretically or experimentally for conditions such that only one deposition mechanism dominates. When it is necessary to estimate the deposition velocity with several mechanisms operating simultaneously, it is assumed that the individual deposition velocities for that surface may be added linearly,

$$
\begin{aligned}
k_{d}= & k_{\text {sedimentation }}+k_{\text {thermophoresis }}+k_{\text {Stefan }} \\
& +k_{\text {turbulence }}+k_{\text {impaction }}+k_{\text {diffusion }} .
\end{aligned}
$$

Since in most cases it is expected that for a given surface or portion thereof and given size particle and hydro- 
dynamic conditions one deposition does dominate the others, this assumption probably does not introduce serious errors. Much more significant errors will result from applying correlations established for relatively simple geometries to the complex geometry of a nuclear reactor and for conditions where the particle properties and flow conditions are not well known.

If deposition is the only important aerosol process occurring in a closed vessel, then Equation (IV.C.14) reduces to

$$
V(d n / d t)=-\left(\sum A k_{d}\right) n
$$

and if $\sum A k_{d}$ is constant this equation is readily integrated to give

$$
n(t, v)=n(0, v) \exp \left(-t \sum A k_{d} / V\right)
$$

or

$$
t=\left(V / \sum A k_{d}\right] \ln [n(0, v) / n(t, v)] .
$$

For these conditions the number concentration of still suspended particles decreases exponentially in time at a rate reflecting the dependence of $k_{d}$ on particle size. Alternately, the time required to reach a given level of decontamination is inversely proportional to $k_{d}$ and therefore also size dependent.

\section{IV.C.4.b. Deposition by sedimentation}

A small particle acted upon by gravity acquires a velocity $c_{\text {sed }}$ relative to the gas given by Equation (IV.C.2). Listed below are the settling velocities for a range of particle diameters computed from Equation (IV.C.2) taking the particle density to be $3000 \mathrm{~kg} / \mathrm{m}^{3}$ and the gas to be air at $288 \mathrm{~K}$ and $1 \mathrm{~atm}$ (i.e., $\mu=1.8 \times 10^{-5} \mathrm{Pas}$ and $\lambda=64$ $\mathrm{nm}$ )

Settling velocities for a range of particle sizes

\begin{tabular}{llllllll}
\hline$d$ & $(\mu \mathrm{m})$ & 0.01 & 0.1 & 0.3 & 1.0 & 3.0 & 10.0
\end{tabular}

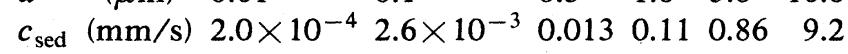

Since the terminal velocity is directly proportional to particle density, the velocities listed here can be scaled readily to other particle densities. However it is necessary to use the true particle density, which might be less than the density of the material comprising the particle if it is an aggregate containing significant voids. In computations with the TRAP-MELT code, the density is input by the user. Early computations assumed a particle density of 10000 $\mathrm{kg} / \mathrm{m}^{3}$ but more recent computations assume an input of $3000 \mathrm{~kg} / \mathrm{m}^{3}$. In computations with the NAUA code the particle density is an input from the TRAP-MELT or VANESA code according to the source of the particles to the containment. If particles in the containment are largely composed of water as might be the case late in the accident, then the appropriate density would be closer to $1000 \mathrm{~kg} / \mathrm{m}^{3}$.
Assuming that the vessel is well mixed with convection velocities greater than $c_{\text {sed }}$ everywhere except near solid surfaces where the gas velocity becomes small owing to the no-slip boundary condition of fluid mechanics, the deposition velocity resulting from sedimentation is simply $c_{\text {sed }}$ and the appropriate areas are the horizontal surfaces $A_{H}$. Retaining only the loss owing to sedimentation, Equation (IV.C.14) reduces to

$V d n / d t=-A_{H} c_{\text {sed }} n$, i.e., $\sum A k_{d}=A_{H} c_{\text {sed }}$.

(IV.C.19)

In view of the strong dependence of the settling velocity on particle size, the time required to achieve a specified level of decontamination also is very sensitive to particle size. For example, using the terminal velocities listed above, the times computed from Equation (IV.C.18) required for a decontamination ratio of 100 in a vessel of volume $70000 \mathrm{~m}^{3}$ and horizontal area of $2000 \mathrm{~m}^{2}$ are

Times for decontamination factor of 100

\begin{tabular}{lccccccc}
\hline$d(\mu \mathrm{m})$ & 0.1 & 0.3 & 0.5 & 1.0 & 3.0 & 5.0 & 10.0 \\
$t$ (days) & 710 & 140 & 61 & 17 & 2.2 & 0.79 & 0.20
\end{tabular}

In view of the long times for efficient removal of particles smaller than a few microns, growth of particles by coagulation or by absorption of water is important in acceleration of the sedimentation process.

Although the concentration of each particle size decreases exponentially with elapsed time, the overall mass concentration of suspended particles varies with time differently because of a distribution of sizes. If the initial size distribution is $n(0, v)$ and if sedimentation is the only aerosol process being considered, then the mass concentration still suspended after time $t$ is found by integration:

fraction of initial mass still suspended

$$
=\int_{0}^{\infty} \exp \left(-A_{H} c_{\mathrm{sed}} t / V\right) v n(0, v) d v / \int_{0}^{\infty} v n(0, v) d v .
$$

(IV.C.20)

We have carried out this integration numerically using the size distribution given by Friedlander (1977) for Brownian coagulation in the continuum regime under self preserving conditions (see Section IV.C.6). For particles in the continuum regime $C_{p}$ may be taken to be unity. Then the fraction of still suspended mass can be expressed as a function of the single dimensionless group $A_{H} c_{\text {sed }}^{*} t / V$, where $c_{\text {sed }}^{*} t / V$ is the terminal velocity based on the initial number median diameter $d^{*}=(6 C /$ $\rho \pi N)^{0.333}$; here $C$ and $N$ are the total initial mass concentration and total initial number concentration of aerosol. The results of this calculation are shown in Figure IV.C. 2 where they are compared with the exponential decay for a monodisperse aerosol of diameter $d^{*}$. With increasing time, smaller and smaller particles remain suspended and the rate of removal decreases relative to a monodisperse aerosol. Because of this, phenomena that might introduce small diameter particles into the gas late in the accident (nucleation after much of the aerosol has already deposit- 


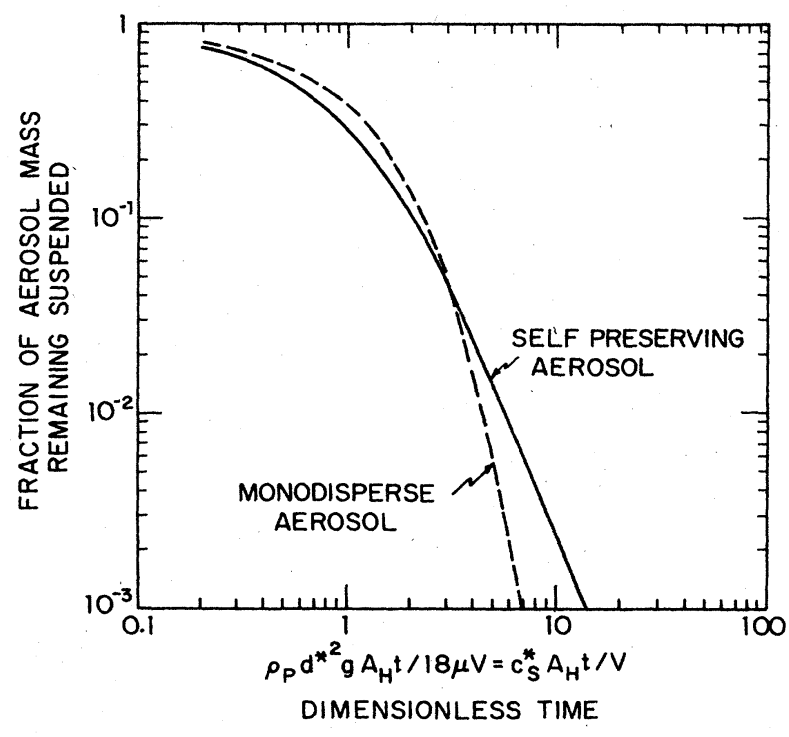

FIG. IV.C.2. Fraction of aerosol mass remaining suspended, with sedimentation as the only important aerosol process.

ed) or sustain small particles (recirculating flows which do not mix with the gas near collecting surfaces) require careful attention.

\section{IV.C.4.c. Deposition by thermophoresis}

Particles suspended in a nonisothermal gas experience a force known as the thermophoretic force, owing to the more energetic molecular impacts on the hot side compared with the cold side. In the absence of other influences the particle acquires a velocity relative to the gas given by

$$
c_{\text {ther }}=-K(\mu / \rho T) \nabla T,
$$

(IV.C.21)

where the coefficient $K$ depends on the ratio of the gas mean free path to particle diameter and the ratio of the thermal conductivity of the gas $\kappa$ to the thermal conductivity of the particle $\kappa_{p}$. There is general agreement in the aerosol literature that the form of Equation (IV.C.21) is correct but the numerical value of the coefficient is uncertain. Currently the theory of Brock is used which gives

$$
K=\frac{(1.5 C p)\left(\kappa / \kappa_{p}+4.98 \lambda / d\right)}{(1+6 \lambda / d)\left(1+2 \kappa / \kappa_{p}+9.86 \lambda / d\right)}
$$

(IV.C.22)

The dependence of $K$ on $\lambda / d$ and $\kappa / \kappa_{p}$ given by Brock has not been confirmed experimentally, partly because the thermal conductivities for most aerosols is poorly known. This also will be the case for aerosols of uncertain size, composition, and voidage formed in a severe nuclear accident. Also the numerical value of $c_{\text {ther }}$ is somewhat sensitive to the value adopted for $\kappa / \kappa_{p}$ at least for certain ranges of $\lambda / d$. Currently in calculations using the
TRAP-MELT code $\kappa / \kappa_{p}$ is assumed to be 0.01 .

Aerosol deposition by thermophoresis is believed to be an important removal process in the reactor coolant system owing to the large temperature differences between the flowing gas and solid surfaces which gives rise to large thermal gradients across the thin boundary layers adjacent to the walls. One of the difficulties, however, is estimation of this temperature gradient. In the field of heat transfer, heat transfer rates are expressed in terms of a heat transfer coefficient $h$, which is the ratio of the heat transfer rate per unit area of surface to the temperature difference driving the heat transfer. These heat transfer coefficients are correlated as a dimensionless group called the Nusselt number $(\mathrm{Nu})$ which also involves a characteristic length of the system $D$ and the gas thermal conductivity $\kappa$ :

$$
\dot{\mathrm{Nu}}=h D / \kappa \text {. }
$$

(IV.C.23)

In forced convection, the Nusselt number is found as a function of the Reynolds number $\operatorname{Re}=\rho U D / \mu$ and Prandtl number $\operatorname{Pr}=C_{p} \mu / \kappa$ where $U$ is the characteristic velocity of the gas and $C_{p}$ is the gas heat capacity. Many such correlations exist in the engineering literature for a variety of different conditions and geometries. For forced turbulent flow of gases in a pipe of diameter $D$ and average gas velocity $U$ the following equation may be used:

$$
\mathrm{Nu}=0.023 \operatorname{Re}^{0.8} \operatorname{Pr}^{0.33}
$$

(IV.C.24)

The mass transfer analog of Equation (IV.C.24) was given above as Equation (IV.C.5).

In free convection for gases, the Nusselt number is found as a function of the Grashof number $\mathrm{Gr}=g D^{3} \rho^{2} \Delta T / T \mu^{2}$ and Prandtl number where $\Delta T$ is the characteristic temperature difference between the gas and wall. Again, many such correlations exist in the engineering literature, at least for simple geometries. For example, McAdams (1954) suggests the following equations be used for the laminar and turbulent regimes of free convection of gases for vertical walls:

$$
\mathrm{Nu}=0.59(\mathrm{GrPr})^{0.25} \text { for } \operatorname{GrPr}<10^{9} \text { (laminar), }
$$

(IV.C.25)

$$
\mathrm{Nu}=0.13(\mathrm{GrPr})^{0.333} \text { for } \operatorname{GrPr}>10^{9} \text { (turbulent) . }
$$

(IV.C.26)

Since $h \Delta T=\kappa d T / d y$ at the wall, the temperature gradient at the wall is given by $d T / d y=\mathrm{Nu} \Delta T / D$. Estimation of the temperature difference driving the heat transfer is provided by the MARCH and MERGE codes. Instead of using heat transfer correlations appropriate to free convection when that mode of heat transfer dominates, the TRAP-MELT first computes an "effective Reynolds number" as $\operatorname{Re}_{\text {eff }}=(\mathrm{Gr} / 70)^{0.5}$ for $\mathrm{Gr}>10^{7}$ and then uses the larger of the true Reynolds number or this effective Reynolds number in correlations established for forced convection such as Equation (IV.C.24). The same approach is used for the estimation of the diffusional deposition of aerosols and molecular species on the walls 
both by TRAP-MELT and additions to NAUA. This approach is not used in the conventional heat and mass transfer literature and no justification for it is provided in the TRAP-MELT documentation. Once a value for $c_{\text {ther }}$ for a certain surface has been found, then it is used as the deposition velocity due to thermophoresis for that surface and the analysis proceeds exactly as above in the case of gravity.

\section{IV.C.4.d. Deposition by Stefan flow and diffusiophoresis}

When a vapor condenses on a surface, there will be a net gas velocity toward that surface known as the Stefan flow. In addition, particles suspended in a gas of nonuniform concentration experience a force known as the diffusiophoretic force owing to the different nature of molecular inpacts on one side compared with the other. For a two component system with species $A$ and $B$ representing condensible and noncondensible species, respectively, the particle acquires a velocity given by

$$
c=\left(1+\sigma_{A B} x_{A}\right) \mathscr{D}_{A B} \nabla \ln \left(x_{A}\right)
$$

with

$$
\begin{aligned}
\sigma_{A B}= & 0.95\left(M_{A}-M_{B}\right) /\left(M_{A}+M_{B}\right) \\
& -1.05\left(D_{A}-D_{B}\right) /\left(D_{A}+D_{B}\right),
\end{aligned}
$$

where $M, D$, and $x$ are the molecular weight, molecular diameter, and mole fraction of the indicated species, and $\mathscr{D}_{A B}$ is the diffusion coefficient. This result comes from Waldmann and Schmitt (1967) for $2 \lambda / d<0.25$.

Aerosol deposition by the Stefan flow may be an important removal process during an accident in which large quantities of steam are condensing. Examples include steam condensing from rising bubbles in suppression pools, steam condensing in ice beds, and steam condensing on the cold walls of the containment vessel. Researchers in source term estimation incorrectly call this deposition mechanism diffusiophoresis, whereas the dominant mechanism with condensing steam is the Stefan flow. In order to estimate the deposition velocity, it is first necessary to determine the gradient of concentration near the surfaces. This can be done using appropriate mass transfer correlations in a manner analogous to that indicated above for thermophoretic deposition.

\section{IV.C.4.e. Deposition by impaction}

The motion of a small particle subject only to drag forces is governed by Newton's laws:

$$
m_{p}\left(d \mathbf{u}_{p} / d t\right)=-3 \pi \mu d \mathbf{c} / C_{p} .
$$

The quantity $m_{p} C_{p} / 3 \pi \mu d=\rho_{p} d^{2} C_{p} / 18 \mu$ is a characteristic time for the particle velocity to adjust to changes in the applied force or changes in the gas velocity. If $U$ and $D$ are order of magnitude values of the gas velocity and a distance over which the gas velocity changes, then $D / U$ is a characteristic time for changes in the gas veloci- ty. The ratio of these two time scales is an important parameter in aerosol mechanics and is called the Stokes's number:

$$
\mathrm{Stk}=\rho_{p} d^{2} C_{p} U / 18 \mu D .
$$

The Stokes number being a measure of the importance of particle inertia is the analog in particle mechanics to the Reynolds number in fluid mechanics.

If the Stokes number is sufficiently large as in the case of high speed flow past small collectors (spray drops or filter elements) or in abrupt bends in the plumbing, then particle inertia is important and the deposition rate depends on Stk. Capture dominated by the particle's inertia is called impaction. Many correlations for impaction dominated deposition may be found in the aerosol literature. For example, the following correlation is used to estimate the rate of deposition on one falling water drop when capture is dominated by impaction:

$$
J=(\pi / 4) D^{2} U n \varepsilon \text { with } \varepsilon=[\operatorname{Stk} /(\operatorname{Stk}+0.17)]^{2} .
$$

(IV.C.30)

Here the Stokes number is based on the water drop diameter $D$ and the drop's terminal velocity $U$. (Note that for impaction dominated capture the deposition velocity is based on the projected area of the collector.) For deposition in a packed bed dominated by impaction, the rate of deposition on a single spherical grain is (D'Ottavio and Goren, 1983)

$$
J=(\pi / 4) D^{2} U n \varepsilon
$$

where

$$
\left.\varepsilon=(A \mathrm{Stk})^{3.55} /\left[(A \mathrm{Stk})^{3.55}+1.67\right)\right] .
$$

Here the Stokes number is based on the grain diameter $D$ and the superficial gas velocity $U$ through the bed; $A(\alpha, \mathrm{Re})$ is a known function of the fraction solids in the bed and the Reynolds number based on $D$ and $U$. A modification of Equation (IV.C.31) might account for aerosol deposition in ice beds.

With the exception of capture by sprays, impaction is omitted as a deposition mechanism from source term estimation probably because the thermal-hydraulics is not known with sufficient accuracy to make reliable estimates for this deposition mechanism. In this regard, it is worth noting the sensitivity of impaction dominated collection to particle size. The Stokes number is proportional to the second power of particle diameter and for small Stokes numbers the deposition velocity is proportional to the second or higher power of Stokes number. Consequently the coefficient in the exponentially decreasing concentration, Equation (IV.C.17), varies as the fourth or higher power of particle diameter. This could have an important influence on aerosol removal from the containment vessel late in the accident. If large particles do not reach the containment they will not be available there for scavenging smaller particles by differential sedimentation. Also, if large particles are efficiently deposited in localized areas by impaction, this could have important conse- 
quences for subsequent revolatilization or equipment failure due to the decay heat associated with the deposited fission products.

\section{IV.C.4.f. Deposition resulting from turbulent motion}

Turbulent flow is a highly unsteady phenomenon with fluctuating instantaneous fluid motions normal to the wall. The ability of a particle to follow these fluctuations depends on the time scale with which it adjusts to changes in applied force or changes in fluid motion. This time scale was given above by $t_{p}=m_{p} C_{p} / 3 \pi \mu d=\rho_{p} d^{2} C_{p} / 18 \mu$. The time scale for fluid velocity fluctuations owing to turbulence near a wall is related to the time averaged stress at the wall $\tau_{w}$ and the fluid's viscosity, and may be estimated as $\mu / \tau_{w}$. When the ratio of these two time scales is sufficiently large, the particle is unable, because of its inertia, to follow the reversal of fluid velocity and is propelled toward the wall with a velocity achieved from the inward directed fluid eddies. Dimensional reasoning suggests that the ratio of the deposition velocity to $\left(\tau_{w} / \rho\right)^{0.5}$ can be correlated as a function of the dimensionless ratio $t^{+}=t_{p} \tau_{w} / \mu=\rho_{p} d^{2} C_{p} \tau_{w} / 18 \mu^{2}$. This last group can be regarded as a kind of Stokes number appropriate to turbulent flows.

The only experimental results available to date are for forced turbulent flow in ducts. For example, the experimental results of Liu and Agarwal (1974) may be summarized by the equations

$$
\begin{array}{r}
k_{\text {turbulent }}=\left(\tau_{w} / \rho\right)^{0.5}\left[6 \times 10^{-4}\left(t^{+}\right)^{2}+2 \times 10^{-8} \mathrm{Re}\right] \\
\text { for } t^{+}<10
\end{array}
$$

and

$$
k_{\text {turbulent }}=0.1 \text { for } t^{+}>10 .
$$

In forced convection in tubes and ducts, the time averaged stress at the wall may be correlated as a function of the Reynolds number $\operatorname{Re}=\rho U D / \mu$ where $U$ is the average velocity and $D$ is the duct diameter. One such correlation for pipes is

$$
\tau_{w}=0.5 \rho U^{2} f=0.5 \rho U^{2}\left(0.0014+0.125 \mathrm{Re}^{-0.32}\right) .
$$

(IV.C.33)

Deposition rates from turbulent flow are known to be sensitive to the roughness of the wall for small values of $t^{+}$. Consequently, Equation (IV.C.32) can significantly underestimate the deposition velocity for forced turbulent flow. However the relationship between wall roughness and deposition velocity is not fully understood and there is no way at present to estimate the changing roughness of duct surfaces associated with deposited material during a severe accident.

Another difficulty in applying these results to estimation of the source term is the fact that in an accident the flows in the reactor coolant system and containment vessel are driven by free convection during much of the accident. There are no experimental results for deposition from turbulent free convection. The best one can do at present is to assume that Equation (IV.C.32) still applies, but to use a time averaged wall stress determined from a heat transfer-fluid motion analogy (Colburn analogy) coupled with an appropriate correlation for the Nusselt number such as (IV.C.26). For example the Colburn analogy gives

$$
\tau_{w} / \rho U^{2}=\mathrm{Nu} / \operatorname{Pr}^{0.33}
$$

(IV.C.34)

The deposition of aerosols from free convection flows deserves experimental investigation.

\section{IV.C.4.g. Deposition by diffusion}

Small particles suspended in a gas are continually bombarded by the gas molecules. This produces a random walk for any given particle, resulting in a diffusive flux when the particle concentration varies in space. The for-, mula for the Brownian diffusion coefficient is given in Equation (IV.C.4). Listed below are the diffusivities computed from this equation for a range of particle sizes in air at $288 \mathrm{~K}$ and $1 \mathrm{~atm}$

Diffusivities for different particles sizes

\begin{tabular}{lccccc}
\hline$d(\mu \mathrm{m})$ & 0.001 & 0.01 & 0.1 & 1 & 10 \\
$\mathscr{D}\left(\mathrm{mm}^{2} / \mathrm{s}\right)$ & 5.1 & 0.053 & $6.8 \times 10^{-4}$ & $2.8 \times 10^{-5}$ & $2.4 \times 10^{-6}$
\end{tabular}

It is seen that the diffusion coefficient increases with decreasing particle size but is very small even for particles as small as $0.01 \mu \mathrm{m}$. Consequently, deposition by Brownian diffusion is strongly coupled to convection. There are many correlations in the engineering literature for mass transfer for various flow conditions and geometries. One such correlation relevent to source term estimation gives the deposition of particles from forced turbulent flow in a tube:

$$
k_{\text {diffusion }}=\left(\tau_{w} / \rho\right)^{0.5} \mathrm{Sc}^{-0.66} F(\mathrm{Sc}),
$$

(IV.C.35)

where

$$
\mathrm{Sc}=(\mu / \rho \mathscr{D})
$$

and $F(\mathrm{Sc})$ is a complicated but weakly varying function of the Schmidt number, Sc, whose value is essentially constant at 0.058 for $\mathrm{Sc}>10^{3}$.

As in the case of deposition owing to particle inertia from a turbulent flow, the time averaged stress at the wall is given by an appropriate correlation such as Equation (IV.C.33). Equation (IV.C.35) is the expression used for diffusion-dominated deposition in the TRAP-MELT code. In the NAUA code $k_{\text {diffusion }}$ is set equal to $\mathscr{D} / \delta$ with $\delta$ as a user-specified parameter which is taken to be independent of particle size.

Another correlation relevant to source term estimation is the deposition rate on a single sphere of diameter $D$ much larger than the aerosol diameter and moving through the gas with velocity $U$ :

$$
J=(\pi / 4) D^{2} U n \varepsilon \text { with } \varepsilon=4(\mathscr{D} / U D)^{0.66} .
$$

(IV.C.36) 
(As in the case of impaction onto a sphere, the deposition velocity is based on the projected area of the collector.) This formula is useful in estimating removal by sprays.

\section{IV.C.4.h. Intercomparison of various deposition velocities}

The relative magnitudes of the deposition velocity resulting from various mechanisms will depend on the nature of the flow field (laminar versus turbulent and forced convection versus free convection), the geometry (tube flow versus a confined gas), the temperature difference driving heat transfer, and the physical properties of the gas and particles. To illustrate the relative magnitudes in one case, we have selected forced flow of air through a tube at a Reynolds number of $2 \times 10^{5}$. For estimation of $k_{\text {turbulent }}$, the correlation of Liu and Agarwal was selected; for estimation of $k_{\text {thermophoresis }}, K$ in Equation (IV.C.21) was taken to be 0.75 in agreement with some experimental measurements and $\Delta T / T$ was taken to be 0.1 . The results are shown in Figure IV.C.3. For this case, capture is dominated by thermophoresis for particles from less than $0.1 \mu \mathrm{m}$ to about $3 \mu \mathrm{m}$ and for larger particles capture is dominated by turbulent deposition.

\section{IV.C.5. Aerosol growth by condensation} or shrinkage by evaporation

As seen in Section IV.C.4, the deposition velocity is a strong function of particle size. Consequently it is necessary to model those processes that result in changes in particle size in order to predict reliably the rates and locations of aerosol deposition. Two such processes are condensational growth and evaporative shrinkage. The rate at which the volume of a small sphere changes because of these processes was given in Equation (IV.C.10). In that equation, $p_{i}$ represents the partial pressure of the condensing species in the gas and $p_{i \text {,sat }}$ represents the equilibrium vapor pressure of that species for conditions at the particle's surface. If $p_{i}>p_{i \text {, sat }}$, the drop grows by condensation and if $p_{i}<p_{i \text {, sat }}$, the drop shrinks by evaporation.

Several factors can alter the vapor pressure at the particle's surface, and thereby influence these mass transfer processes. First, the vapor pressure of a small particle is larger than the vapor pressure of the bulk material owing to surface tension and curvature of its surface. This phenomenon is known as the Kelvin effect and is given by

$$
p_{i, \text { sat }}=p_{i, s}^{0} \exp \left(4 \sigma v_{m} / k T^{d}\right) .
$$

Equation (IV.C.37) is essentially a rearrangement of Equation (IV.C.8) for the minimum stable drop size for the prevailing supersaturation. The fact that the vapor pressure of very small drops increases with decreasing drop size plays an essential role in nucleation theory. It is because of this fact that a sufficiently large supersaturation is required to cause the formation of new pure particles at significant rates; the formation of new pure particles is called homogeneous nucleation, and its kinetics is

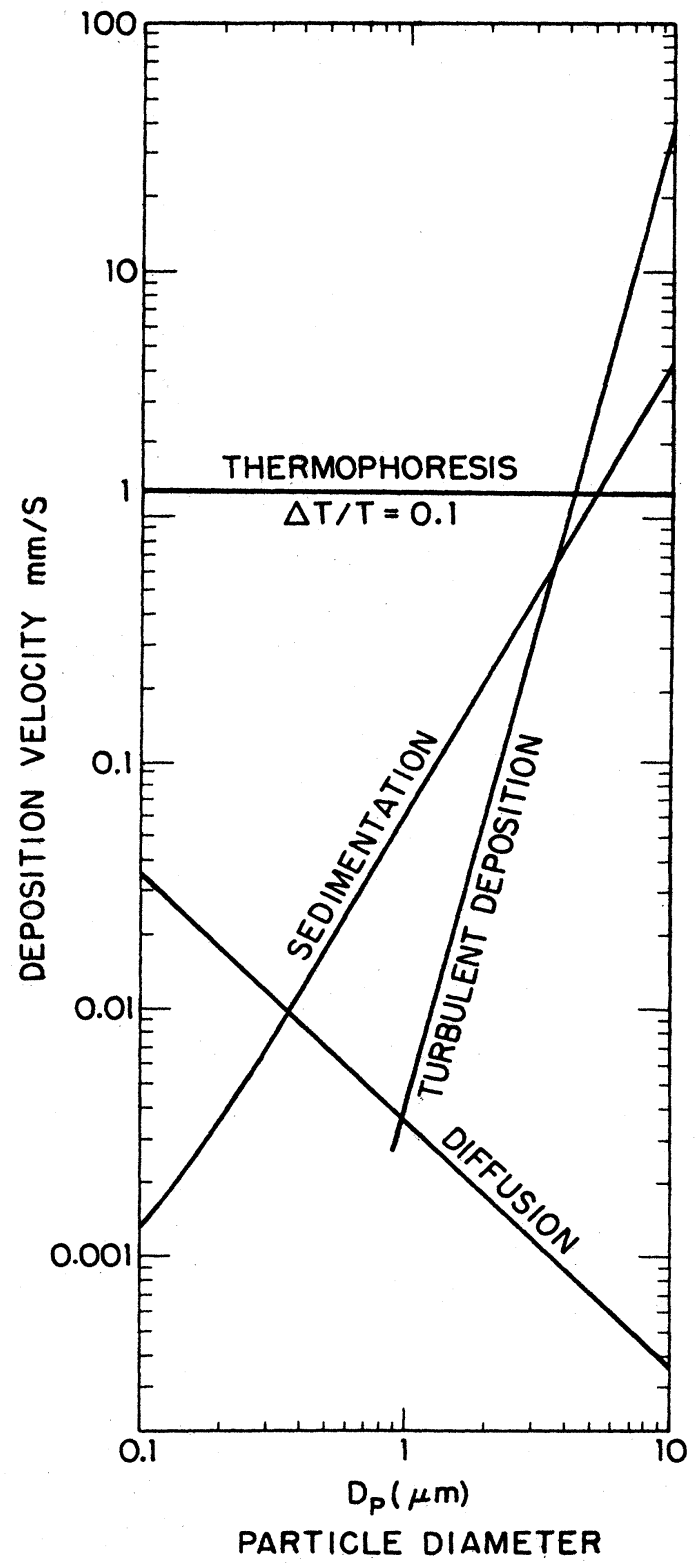

FIG. IV.C.3. Various deposition velocities as a function of particle diameter, $D_{p}$, for a hypothetical forced convection example.

given in Equation (IV.C.6). It also means that very small drops tend to evaporate more readily than large ones; given sufficient time, the large drops grow at the expense of the smaller drops.

Another important influence on vapor pressure is the presence of other species within the particle which reduce its vapor pressure. For example, a drop composed of a fixed mass $m_{2}$ of nonvolatile material reduces the vapor pressure of the volatile species to

$$
\begin{aligned}
p_{i, \text { sat }}= & p_{i, \text { sat }}^{0} \gamma_{1} x_{1} \exp \left(4 \sigma v_{m} / k T^{d}\right) \\
= & p_{i, \text { sat }}^{0}\left\{\left(v-m_{2} v_{2} / M_{2}\right) /\left[v-m_{2}\left(v_{2}-v_{1}\right) / M_{2}\right]\right. \\
& \times \exp \left(4 \sigma_{1} / k T d\right) .
\end{aligned}
$$


Here $\gamma_{1}$ is the activity coefficient of the volatile species, $x_{1}$ is its mole fraction in the droplet, and $M$ and $v$ are the molecular weight and molecular volume of the indicated species. The presence of even very small amounts of nonvolatile species can result in very major reductions in vapor pressures for the volatile species adjacent to such particles. Consequently these particles can grow at lower supersaturations than an equivalently sized pure particle. Such a process is called heterogeneous nucleation when existing particles smaller than the critical size for homogeneous nucleation [Equation (IV.C.8.)] grow at supersaturations such that homogenous nucleation would not occur with any significant rate. This process is extremely important in source term estimation. Particles formed earlier from lower volatility materials serve as sites where the supersaturation of higher volatility species can subsequently deposit. If the deposition rate is sufficient, new particles will not be formed, and there would be less tendency to produce later, in an accident scenario, small particles which have small deposition velocities. For example, the cesium iodide formed can serve as a scavenger for cesium hydroxide and tellurium. A similar process can occur for the case of "homogeneous" nucleation whereby, after sufficient aerosol has been formed, the surface so created scavenges vapor and nuclei thereby quenching the nucleation process. This has been discussed by Friedlander (1982).

Condensation and evaporation are associated with heat energy release or absorption owing to the latent heat of vaporization. Heat released on condensation tends to heat the drop surface, increasing its temperature, thereby increasing its vapor pressure and reducing the rate of growth. The opposite trend occurs on evaporation. For those processes in which drop growth or shrinkage is sufficiently slow, the collision of the drop with noncondensible species tends to keep the drop in thermal equilibrium with the surrounding gas; the drop temperature may be estimated to be the ambient temperature. However at larger mass transfer rates the surface temperature must be found by solving a simultaneous heat transfer problem. This results in the following equation relating $p_{i, s}$ and $T_{s}$ :

$$
T_{s}-T=\left(\Delta H \mathscr{D} v_{m} / \kappa k T\right)\left(p_{i, s}-p\right)
$$

(IV.C.39)

Similarly, if the particle generates significant decay heat because of its radioactivity its increased temperature would slow condensational growth. This possibility has not been addressed and probably would be important only for larger particles.

The fractional rate of change of particle volume with time given by Equation (IV.C.10) is size dependent: smaller particles show greater rates of change. The importance of this fact is that if each particle grows significantly, and if there is no nucleation of new particles or coagulation during this time, then the small particles will approach the larger ones in size. Consequently, it may not be necessary to know the initial particle size with great precision and the approach in the TRAP-MELT code of assigning the initial particles a user specified size distribution may be justified.

\section{IV.C.6. Aerosol growth by coagulation}

The particle size distribution changes as a consequence of coagulation. Several different coagulation mechanisms have been recognized to be of potential importance for the behavior of aerosols during a severe accident. These mechanisms include coagulation because of Brownian motion, coagulation owing to differential motion in a gravity field, and coagulation owing to turbulence. Each mechanism contributes a term of the form of Equation (IV.C.12) to the population balance, but the dependence of the coagulation kernel $\beta(v, \widetilde{v})$ on the sizes of the particles undergoing collision and on other parameters differs for the different mechanisms. When several coagulation mechanisms operate simultaneously, it is assumed that the kernels obtained for each mechanism operating individually can be added linearly to obtain the combined kernel.

The expression for $\beta(v, \widetilde{v})$ owing to Brownian coagulation when both particles are larger than the gas mean free path is given in Equation (IV.C.13). This may be extended to somewhat smaller particles by the use of the Cunningham slip correction in the diffusion coefficient:

$$
\beta(v, \widetilde{v})=(2 k T / 3 \mu)\left(v^{1 / 3}+\widetilde{v}^{1 / 3}\right)\left(C_{p} v^{-1 / 3}+C_{p} \widetilde{v}^{-1 / 3}\right) .
$$

(IV.C.40)

This is the form used in the HAARM or QUICK subroutines of the TRAP-MELT code and in the NAUA code for calculation of coagulation. For particles much smaller than the gas mean free path kinetic theory gives the result

$$
\begin{aligned}
\beta(v, \widetilde{v})= & (3 \pi / 4)^{1 / 6}\left(6 k T / \rho_{p}\right)^{1 / 2}\left(v^{-1}+\widetilde{v}^{-1}\right)^{1 / 2} \\
& \times\left(v^{1 / 3}+\widetilde{v}^{1 / 3}\right)^{2} .
\end{aligned}
$$

(IV.C.41)

A complicated formula has been proposed by Fuchs (1959) to cover the range of applicability of Equation (IV.C.41) to that of Equation (IV.C.40) and has received some experimental support by Wagner and Kerker (1977). However, since particles of interest in source term estimation are expected to grow rapidly into the size range where Equation (IV.C.40) is applicable, Fuchs's equation is not given here.

Particles of different sizes have different settling velocities in a gravitational field. This enables the larger particles to overtake the smaller, slower particles resulting in collision. For this mechanism $\beta(v, \widetilde{v})$ may be written as

$$
\beta(v, \widetilde{v})=0.25 \pi(d+\widetilde{d})^{2}(c-\widetilde{c}) \varepsilon(v, \widetilde{v}),
$$

where the smaller particle is indicated with a tilde and $\varepsilon$ is an efficiency factor dependent on the sizes. There is uncertainty as to the appropriate expression for $\varepsilon(v, \widetilde{v})$. Earlier computations adopted the expression $\varepsilon(v, \widetilde{v})=1.5[\widetilde{v} /$ $(v+\widetilde{v})]^{0.666}$ but more recent computations take a value one third this, i.e.,

$$
\varepsilon(v, \widetilde{v})=0.5[\widetilde{v} /(v+\widetilde{v})]^{0.666} .
$$


These efficiencies account only for a collection mechanism known as interception. The influence of particle inertia and increased resistance to approach because of hydrodynamic interactions are not included although these effects are known to be important for particles in the 100 $\mu \mathrm{m}$ size range. Gravitational coagulation has not received experimental exploration for particles of the size range of interest to source term estimation. In view of the importance of this mechanism for dry containments according to code predictions, additional small scale experimentation is warranted.

Particles suspended in a gas with spatial gradients of velocity may collide because of the relative motion of different portions of the gas. The collision kernel for this mechanism is

$$
\beta(v, \widetilde{v})=(4 G / 3)(d+\widetilde{d})^{3},
$$

(IV.C.43)

where $G$ is the local velocity gradient. This collision mechanism has not been included in source term estimation, probably because of the lack of information on the flow field.

Particles suspended in a turbulent flow also may collide. This is an extremely complicated situation. On the one hand, the collision mechanism may be regarded to be essentially like that brought about by shear flow, although the appropriate velocity gradient must be related to the properties of the turbulent motion, especially the energy dissipation rates per unit mass of fluid, $\varepsilon_{t}$. On the other hand, the collision mechanism may be regarded to be essentially like that brought about by differential sedimentation, although instead of $g$ the appropriate acceleration must be related to $\varepsilon_{t}$. The following formulas for the two approaches are due to Saffman and Turner (1956):

$$
\beta(v, \widetilde{v})=1.7\left(\rho \varepsilon_{t} / \mu\right)^{0.5}(d+\widetilde{d})^{3}
$$

in analogy to Equation (IV.C.43), and

$$
\beta(v, \widetilde{v})=0.25 \pi(d+\widetilde{d})^{2}\left(c^{*}-\widetilde{c}^{*}\right),
$$

where

$$
c^{*}=\rho_{p} d^{2} C_{p}\left[\left(5.7 \varepsilon_{t}^{0.75} \rho^{0.25}\right) /\left(\mu^{0.25} \pi\right)\right] / 18 \mu
$$

instead of $c=\rho_{p} d^{2} \mathrm{Cg} / 18 \mu$ in analogy to Equation (IV.C.42). These formulas have never received careful experimental validation. In addition there is the difficulty of estimating $\varepsilon_{t}$ in various parts of the flow paths for source term calculations, particularly in large volumes subject to free convection.

Coagulation is second order in particle number concentration. This has an extremely important consequence for source term modeling, as outlined below.

Let $N$ represent the total number of particles per unit volume of gas. In the case of Brownian coagulation, $\beta$ is only weakly dependent on particle size. Then for coagulation by Brownian motion in the continuum regime, ignoring the size dependence of the coagulation kernel, it may be shown that $N(t)$ satisfies the equation

$$
d N / d t=-(4 k T / 3 \mu) N^{2}
$$

whose solution is

$$
N(t)=N(0) /[1+4 k T N(0) / 3 \mu] .
$$

Equation (IV.C.48) shows that as the time increases, the number concentration becomes independent of the initial number $N(0)$. The larger the initial number, the more rapidly the coagulation progresses and the earlier the surviving number concentration becomes independent of the initial value. Further, it may be shown that the particle size distribution also approaches a form that is independent of the initial distribution of sizes, provided that the coagulation kernel is a homogeneous function of size with order less than 1 as is the case for Brownian coagulation. The asymptotic size distribution approached is called the self preserving spectrum, and has been computed by Hidy and Lilly (1965) and Friedlander and Wang (1966). The size distribution $n(t, v)$ scaled to the total number concentration $N(t)$ and an average particle size $v=V / N(t)$ where $V$ is the total volume concentration of aerosol, i.e., $\psi=n(v, t) V / N^{2}(t)$, can be expressed as a function of the single variable $\eta_{v}=v N(t) / V$. This distribution is shown in Figure IV.C. 4.

If self-preserving conditions are approached then details of the initial number and size distribution fade from memory and have minor influence on the subsequent behavior of the aerosol. The two items needed to be known are the total volume of aerosol per unit volume of carrier gas and the elapsed time since the completion of nucleation. This provides some justification for the approach in TRAP-MELT where the user assigns some small diameter to the initial aerosol leaving the core region, which ensures in the calculation that there will be a very large number concentration.

\section{IV.C.7. Aerosol removal by engineered safety features}

Nuclear power plants have one or more engineered safety features (ESF's) whose purpose is to limit the buildup of pressure within the containment by condensing the generated steam. For example, water sprayed from the top of the containment structure is an "active" system requiring electric power to pump the water through nozzles. Water sprays acting in the containment vessel can

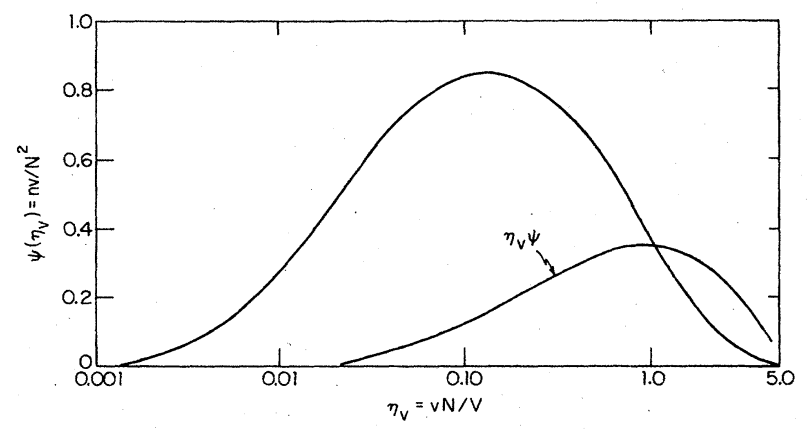

FIG. IV.C.4. Self-preserving size distributions: numerical solution (from Hidy, 1984). 
prevent some severe sequences from ever causing a containment failure. However, it is necessary that electric power be operative and, by definition, electric power is inoperative in a TMLB sequence. Some PWR's are designed with "passive" ice bed condenser systems through which the gases from the primary system must pass to reach the larger containment volumes for most accident scenarios. Although these systems have been designed to condense the steam from a large break LOCA accident, the large ice surface areas involved also afford the opportunity to capture aerosols. Suppression pools for BWR's act in a similar passive way; these are designed to condense steam, but they also afford the opportunity to collect aerosols owing to the large amount of bubble surface area. The possible mechanisms operating for aerosol capture in these engineering safety features are those listed in Section IV.C.4. For suppression pools and ice beds especially, growth of hygroscopic aerosols by the condensation of water vapor and aerosol deposition by Stefan flow (diffusiophoresis) are expected to play more important roles than in other parts of the containment, owing to the fact that the gases are computed to be rich in steam, which is condensing so long as ice is still available or the pool is nonboiling.

\section{IV.C.7.a. Suppression pools}

Because of the smaller sizes and the lower design pressures of containments for PWR reactors, the suppression pool is an important safeguard against containment failure stemming from overpressurization. For a modern Mark III containment structure, the suppression pool is a pool of water some $7 \mathrm{~m}$ deep in an annulus surrounding the reactor cavity (see Figure IV.D.6). Prior to vessel melt through, gases released from the melting reactor core are discharged below the pool surface through a large number (about 300000) of holes (spargers) 10 to $20 \mathrm{~mm}$ in diameter drilled in an array of horizontal pipes (quenchers). When the flow rate of gases becomes too large to be accommodated by these holes, especially at the time of reactor vessel failure under pressure, the gases are introduced into the pool through about 32 horizontal channels (vents) each about $0.5 \mathrm{~m}$ in diameter. At this point, the mass flow rate of gases through the channels may be of the order of $100 \mathrm{~kg} / \mathrm{s}$. As the gases rise through the pool, bubbles are formed. These bubbles break and coalesce and are expected to achieve a stable size distribution after rising through a sufficient height. General Electric (Marble et al., 1983) has measured bubble size distributions resulting from the introduction of air into water and finds a geometric average bubble diameter of about 5 to $6 \mathrm{~mm}$ with geometric standard deviation of 1.5. Bubbles this large are usually distorted from the spherical shape. Rise time through the pool is related somewhat to bubble size, but is also dependent on the fact that a localized swarm of bubbles will rise faster than an isolated bubble. The rise time is an important parameter because the modeling for suppression pool scrubbing of fission products suggests that the decontamination factor achieved is exponential in contact time, and hence ex- ponential in pool depth.

Two separate groups are developing computer models for fission product removal in suppression pools. Alleman (1984) and Kress (1984) report on a code given the name SPARC which is under development with NRC sponsorship at Battelle, Pacific Northwest Laboratories. A similar code called SUPRA is under development by SAI, Palo Alto, under EPRI sponsorship.

A key assumption in the modeling is that the gas within each bubble circulates in a vortex motion as a result of the bubble's rise through the water. Larger particles are computed to be centrifuged to the bubble surface by this circulating flow. The deposition velocity for this capture mechanism is found to be quite sensitive to particle size and bubble diameter. Smaller particles are captured at the bubble surface by Brownian diffusion, but the deposition velocity resulting from this mechanism is also dependent on the circulation patterns, because these reduce the mass transfer boundary layers in the vicinity of the bubble's surface. When steam is condensing, particles are subject to removal by the Stefan flow (diffusiophoresis) so that the computed results also are sensitive to the mass fraction of the bubble which is steam and to the pool temperature. Because small particles are more efficiently removed by diffusion as their size decreases and large particles are more efficiently removed by centrifugation as their size increases, the decontamination factor usually shows a minimum as a function of particle size. Calculations suggest the minimum occurs in the particle range of 0.1 to $1.0 \mu \mathrm{m}$.

Figures IV.C.5 and IV.C.6 (Owczarski, 1984) show the decontamination factors computed from the SPARC code as a function of particle size. For these calculations the depth of the suppression pool is $3.7 \mathrm{~m}$, the aerosol particle density is $1000 \mathrm{~kg} / \mathrm{m}^{3}$, and the bubble ellipticity is 1.5 . For Figure IV.C.5, the volume equivalent bubble size is varied from $3 \mathrm{~mm}$ to $15 \mathrm{~mm}$ and the gas is air, i.e., no capture by the Stefan flow is assumed. This figure illustrates the sensitivity to both particle size and bubble size. A $3 \mu \mathrm{m}$ diameter particle in a $6 \mathrm{~mm}$ diameter bubble has a decontamination factor of about 30 but increasing the bubble diameter to $15 \mathrm{~mm}$ or decreasing the aerosol size to $1.0 \mu \mathrm{m}$ decreases the computed decontamination factor by more than a factor of 10. Figure IV.C.6 shows the influence of capture by the Stefan flow for a bubble of initial diameter of $10 \mathrm{~mm}$ having various volume percents of steam. According to this figure, the volume percent of steam must exceed about $90 \%$ before the decontamination factors in the minimum efficiency range are increased markedly.

Computations by the SUPRA code show similar trends for the influence of steam concentration within the rising bubbles on the decontamination factor. However, the region of minimum efficiency is from 0.03 to $0.3 \mu \mathrm{m}$ as opposed to 0.1 to $1 \mu \mathrm{m}$ for the SPARC code. For example, Figure IV.C.7 is a computation based on the SUPRA code (Ohlberg, 1964).

These codes have not been validated by experimentation. General Electric (Marble et al., 1983) has carried 


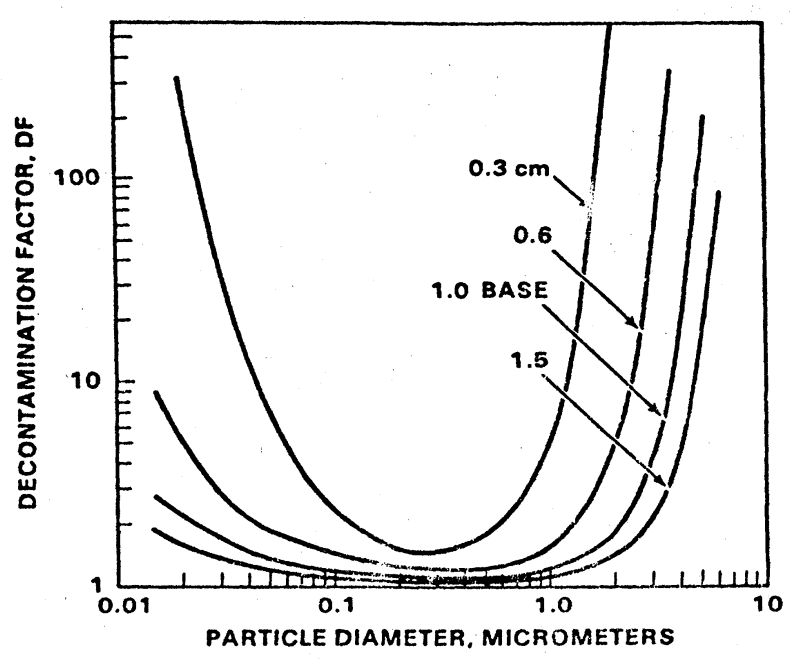

FIG. IV.C.5. Decontamination factors for suppression pools computed by the SPARC code: influence of bubble diameter variation, from Owczarski (1984).

out a limited set of bench scale experiments for removal of aerosols from a single train of rising bubbles injected through a small diameter orifice into a quiescent pool of water. Although large decontamination factors were measured, these were for $\mathrm{Eu}_{2} \mathrm{O}_{3}$ particles having a significantly larger particle size and density than might be expected for aerosols developed under accident conditions. Battelle Columbus Laboratories has begun a more comprehensive study of suppression pool scrubbing under more realistic conditions (Cunnane, 1984). Their preliminary data for bubbles emitted from a single quench hole indicate decontamination factors of less than 10 for Cs, I, and $\mathrm{Te}$ aerosols in bubbles of low steam mass fraction but much larger decontamination factors for steam mass fractions above 0.7 . The possibility of significant quantities

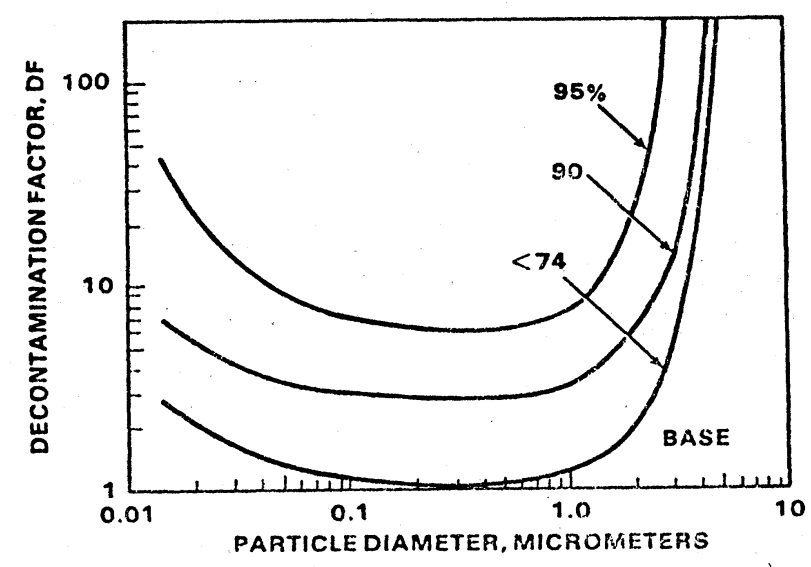

FIG. IV.C.6. Decontamination factors for suppression pools computed by the SPARC code: influence of volume percent inlet steam variation, from Owczarski (1984). of gas effectively by-passing the pool as very large bubbles when the gas flows are large needs consideration.

\section{IV.C.7.b. Ice bed condensors}

In an ice bed condensor more than $1.1 \times 10^{6} \mathrm{~kg}$ of borated ice is held in a large number of highly perforated $\left(25 \times 10^{6}\right.$ perforations) steel baskets about $0.3 \mathrm{~m}$ in diameter and $14.6 \mathrm{~m}$ in length. These baskets are in an annular compartment surrounding the upper perimeter of the containment structure. Gases released are required to flow upward parallel to the perforated baskets. The large surface area of the baskets and their low temperature may result in significant aerosol capture. A major uncertainty in predicting the effectiveness of aerosol removal by ice beds is uncertainty in the surface area of the ice at the start of an accident, owing to glaciation and its change with time through melting. A second major uncertainty is associated with the assumption that the gases can readily flow through the perforations rather than simply move vertically upward on the outside of the baskets or through channels in the ice bed formed by melting. There has been no experimental study of aerosol removal processes by ice bed condensers. However, various possible deposition mechanisms have been discussed by Winegardner

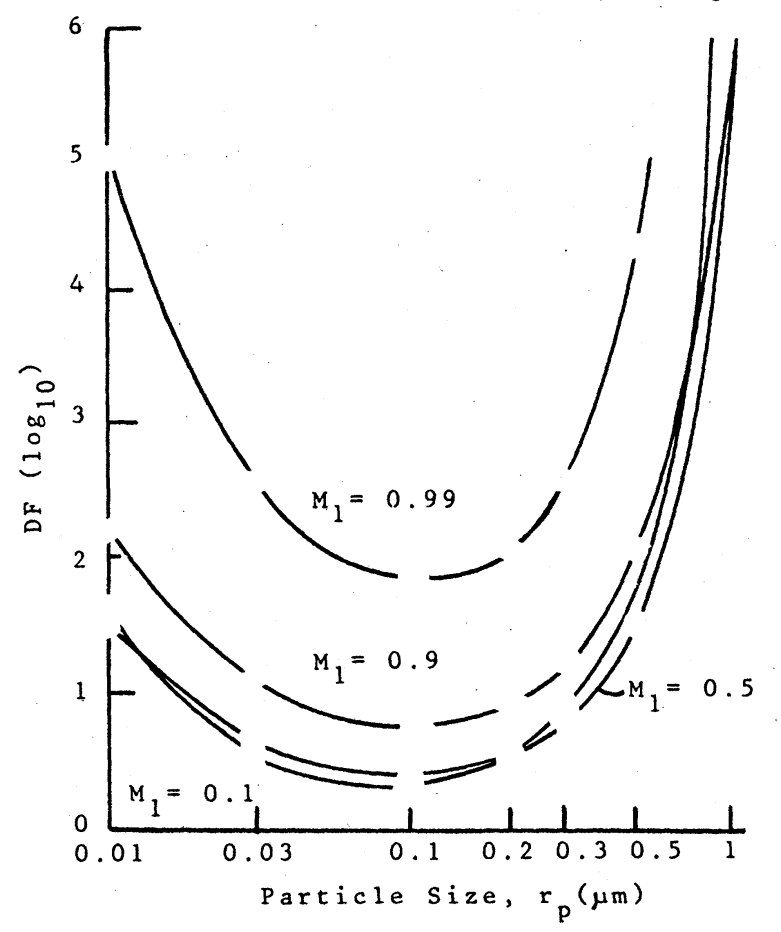

FIG. IV.C.7. Pool decontamination factor as a function of temperature EPRI (1984). EPRI's pool-scrubbing computer code SUPRA was used to calculate the effect of particle size and mass fraction of steam on DF. The case calculated was for a pool 3.5 $\mathrm{m}(11.5 \mathrm{ft})$ deep at $300 \mathrm{~K}\left(81^{\circ} \mathrm{F}\right)$. A steam-hydrogen mixture was assumed with varying mass fractions of steam $\left(M_{1}\right)$, a mixture temperature of $600 \mathrm{~K}\left(620^{\circ} \mathrm{F}\right)$, and an injected mass flow of $1.5 \mathrm{~kg} / \mathrm{s}(3.3 \mathrm{lb} / \mathrm{s})$. Note that the ordinate is the log of DF and represents the exponent of the power of 10 , ranging from 0 (a DF of 1) to 6 (a DF of $10^{6}$ ). 
et al. (1983), and a computer code called ICEDF is under development at Battelle Northwest Laboratories (Allemann, 1983).

\section{IV.C.7.c. Water sprays and filters}

Water sprays and filters are active engineered safeguard systems requiring electric power to pump water through nozzles or air through filter beds. Since aerosol capture by sprays and in filter beds has been studied extensively in the past, removal efficiences can be computed with some degree of confidence provided the spray drop size and aerosol properties are known.

\section{IV.C.8. Numerical solution approaches}

A number of computer codes has been developed to solve Equation (IV.C.14). These codes differ from one another according to the separate phenomena retained in the equation, and according to some of the expressions used for the various rate processes. The codes also differ according to whether or not they specify the form of the aerosol size distribution and compute only a few of its characteristics such as mean size and standard deviation, or whether no constraints are placed on the size distribution other than an adjustable minimum size, maximum size and number of size bins. The codes currently being used for source term calculations, i.e., QUICK, as a subroutine in TRAP-MELT, NAUA and RAFT are of the latter type. The RAFT code is the only code that addresses the question of homogeneous nucleation in a mechanistic fashion. It may be desirable to keep track of the variation of chemical composition with particle size. A relatively new code, MAEROS has the capability to do this but is not used extensively for this purpose because of the significant computer time required.

Table IV.C.1 from Loyalka (1983) compares some of the features of several codes. Since the preparation of this table, the NAUA code has been modified to include the influence of aerosol removal by sprays and work is in progress to include removal in suppression pools and ice beds.

There appears to have been relatively little cross comparison between the various codes. Also, we found no substantial effort to track down the reasons for any discrepancies where they exist. Figure IV.C.8, taken from the OECD report on Nuclear Aerosols, shows one such comparison. These calculations refer to aerosols largely of sodium oxide produced by a fire in a liquid metal fast breeder reactor. It is postulated that $1000 \mathrm{~kg}$ of $\mathrm{Na}$ producing aerosols of mean size $0.5 \mu \mathrm{m}$ with geometric standard deviation of 2.0 plus $225 \mathrm{~kg}$ of condensible fission products producing aerosols of mean size $0.025 \mu \mathrm{m}$ with geometric standard deviation 1.5, are introduced instantaneously into a vessel of volume $9.8 \times 10^{4} \mathrm{~m}^{3}$ and the various codes compute the aerosol mass still suspended as a function of time. It can be seen that the different codes differ by as much as a factor of 10 in the computed air- borne mass at long times or alternately differ by as much as a factor of 10 in the computed time required to achieve some small remaining concentration.

A more recent comparison of several codes with each other and with a specific experiment, test $A B 5$ performed at Hanford Engineering Development Laboratory, was undertaken as part of the Aerosol Behavior Code Validation and Evaluation (ABCOVE) program (Hilliard, 1983). In this experiment $222 \mathrm{~kg}$ of molten sodium was sprayed into a $850 \mathrm{~m}^{3}$ containment vessel where it burned to form sodium oxide. The mass of suspended aerosol was measured as a function of time by filter samples, and the size distribution was measured occasionally by cascade impactors. The curve labeled 1 in Figure IV.C.9 shows the experimental results. The other curves are the numerical simulations of various codes by various laboratories. Although some of the calculations track the experiment with reasonable accuracy, others do not, and there are discrepancies of at least a factor of 10. Particularly worrisome is the observation that different laboratories running the same code with ostensibly the same input data can produce markedly different output; for example, compare the curves labeled 5, 6, and 7, which are the calculations of HEDL, BCL, and ORNL all using the HAARM-3 code. The QUICK code which is currently used as a subroutine in TRAP-MELT appears to be in reasonable agreement with the experiments.

A careful, fully documented, intercomparison of the various codes is strongly warranted.

\section{IV.C.9. Experimental validation of aerosol modeling}

Several large scale experimental programs are in progress whose purpose is to provide a data base for and validation of the computer codes used in modeling aerosol processes. Some of these efforts are commented on briefly in this section.

\section{IV.C.9.a. Nuclear Safety Pilot Plant (NSPP)}

This program underway at Oak Ridge National Laboratory with NRC funding has as its objectives the performance of experiments on aerosol deposition rates in containments. The aerosols are $\mathrm{U}_{3} \mathrm{O}_{8}, \mathrm{Fe}_{2} \mathrm{O}_{3}$, and limestone concrete. These aerosols are injected into a vessel $38.3 \mathrm{~m}^{3}$ in volume and the amount remaining suspended is measured as a function of elapsed time following cessation of the injection. Special attention is being given to the influence of relative humidity on the effective mass, shape factors, and removal rates.

Earlier results from ORNL on this program have been described in the Quarterly Progress Reports from ORNL (NRC, 1981b). As an example, Figure IV.C.10 shows the mass fraction remaining suspended for four experiments, three with steam-air mixtures and one with dry aerosols. The presence of steam appears to accelerate aerosol removal relative to the dry case. In these experiments, about 150 minutes in the wet case and about 350 minutes 
TABLE IV.C.1. Comparison of various containment codes. ${ }^{a}$ (From Loyalka, 1983.)

\begin{tabular}{|c|c|c|c|c|}
\hline & CORRAL -2 & $\begin{array}{l}\text { HAARM:QUICK } \\
\text { and ZONE }\end{array}$ & NAUA & $\begin{array}{l}\text { PARIDESEKO-III } \\
\text { and AEROSIM }\end{array}$ \\
\hline Reactor type & LWR & LMFBR & LWR & LMFBR \\
\hline \multicolumn{5}{|l|}{ Containment } \\
\hline compartments & Multiple & $\begin{array}{l}\text { Single (H.Q); } \\
\text { Multiple (2) }\end{array}$ & Single & $\begin{array}{l}\text { Multiple (P); } \\
\text { Single (A) }\end{array}$ \\
\hline Fission product form & Vapor, & & & \\
\hline \multicolumn{5}{|l|}{ Natural processes } \\
\hline Brownian coagulation & Yes $^{b}$ & Yes & Yes & Yes \\
\hline $\begin{array}{l}\text { Gravitational } \\
\text { coagulation }\end{array}$ & Yes $^{b}$ & Yes. & Yes & Yes \\
\hline \multicolumn{5}{|l|}{ Steam condensation } \\
\hline on particles & Yes $^{\mathrm{b}}$ & $\mathrm{No}^{\mathrm{d}}$ & Yes & $\mathrm{No}^{d}$ \\
\hline $\begin{array}{l}\text { Vapor sorption on } \\
\text { particles }\end{array}$ & Yes $^{\mathrm{b}}$ & No & No & No \\
\hline \multicolumn{5}{|l|}{ Gravitational } \\
\hline Diffusion deposition & $\mathrm{Yes}^{\mathrm{e}}$ & Yes & Yes & Yes \\
\hline $\begin{array}{l}\text { Thermophoretic } \\
\text { deposition }\end{array}$ & \multicolumn{4}{|c|}{ Thermophoretic } \\
\hline \multicolumn{5}{|l|}{ Diffusiophoretic } \\
\hline deposition & Yes $^{b}$ & No & No & No \\
\hline Resuspension & No & No & No & No \\
\hline Leakage & Yes & Yes & Yes & Yes \\
\hline \multicolumn{5}{|l|}{ Electrostatic } \\
\hline interactions & $\mathrm{Yes}^{\mathrm{b}}$ & No & No & No \\
\hline Radioactive decay & No & No & No & No \\
\hline Phase changes & No & No & No & No \\
\hline Chemical reactions & No & No & No & No \\
\hline Aerosol concentrations & $b, f$ & $\mathrm{~g}$ & $\mathrm{~h}$ & $\mathrm{i}$ \\
\hline \multicolumn{5}{|l|}{ Engineered processes } \\
\hline Removal by sprays & $\mathrm{Yes}^{\mathrm{j}}$ & No & No & No \\
\hline $\begin{array}{l}\text { Removal by ice } \\
\text { condensers }\end{array}$ & $\mathrm{No}^{\mathrm{k}}$ & No & No & No \\
\hline \multicolumn{5}{|l|}{ Removal by } \\
\hline suppression pools & $\mathrm{No}^{\mathrm{k}}$ & No & No & No \\
\hline Removal by filters & $\mathrm{No}^{\mathrm{k}}$ & Yes & No & No \\
\hline Source term & $\begin{array}{l}\text { Fixed time } \\
\text { dependence }\end{array}$ & $\begin{array}{l}\text { Arbitrary time } \\
\text { dependence }\end{array}$ & $\begin{array}{l}\text { Arbitrary time } \\
\text { dependence }\end{array}$ & $\begin{array}{l}\text { Arbitrary time } \\
\text { dependence }\end{array}$ \\
\hline \multicolumn{5}{|l|}{ Thermal-hydraulic } \\
\hline conditions & Input & Input & Input & Input \\
\hline
\end{tabular}

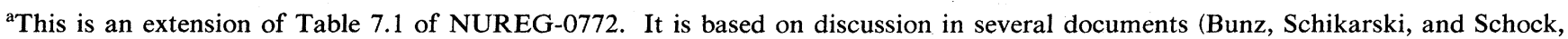
1981; Gieseke et al., 1981; Baybutt, 1981: Nuclear Energy Agency, 1979).

${ }^{\mathrm{b}}$ This process is not explicitly modeled on CORRAL-2, though because the code is empirically based, it may be thought to be included to some extent. Thus, the CORRAL-2 results cannot necessarily be expected to be appropriate for accidents in which the conditions are much different than those in the CSE's.

'This process is modeled but is not utilized due to uncertainties in the formation and/or data.

${ }^{\mathrm{d}}$ The effect of steam is partially taken into account by assuming that all particles are spherical.

${ }^{\mathrm{e}}$ Although this process is explicitly modeled, the model depends on the CSE results.

f The particle sizes are fixed within the code such that the sedimentation loss model predicts the attenuation observed in the CSE results. (In general, the CSE's had low aerosol concentrations.)

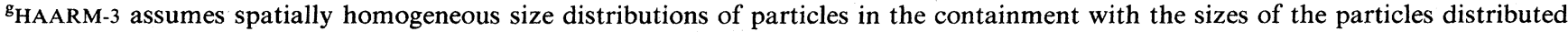
log normally. QUICK and ZONE make no simplifying assumptions about particle sizes.

${ }^{\mathrm{h}}$ NAUA assumes spatially homogeneous distribution of particles but makes no simplifying assumption about particle sizes. NAUA takes into account a size dependent composition of the particles.

${ }^{\mathrm{i}}$ Arbitrary particle size distributions can be considered.

${ }^{\mathrm{j}}$ Organic iodides are not considered for this process.

${ }^{\mathrm{k}}$ This process is not explicitly modeled but its net effect is accounted for. 


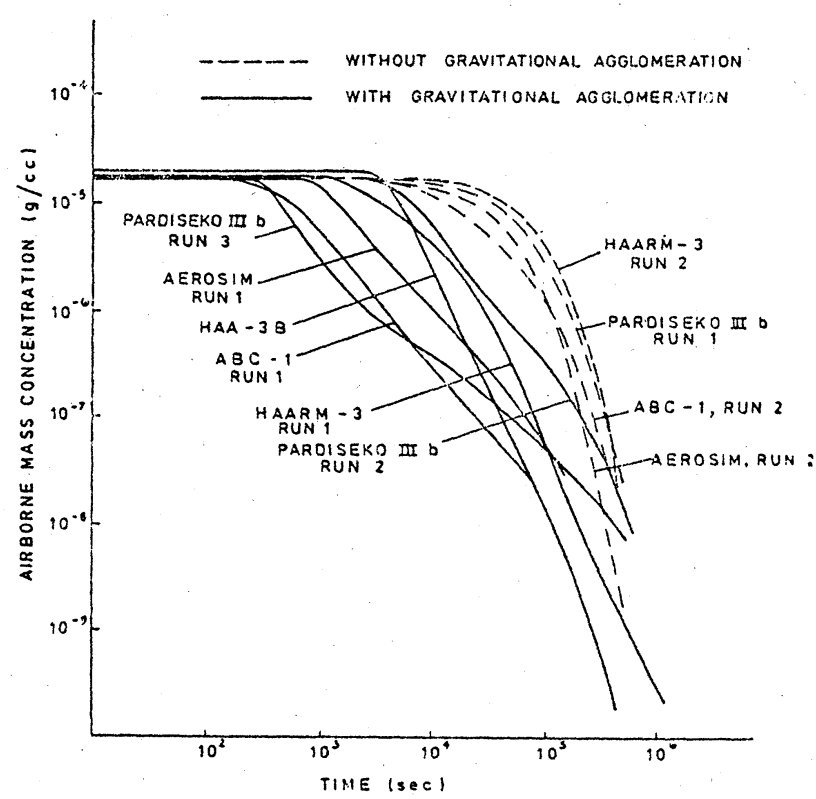

FIG. IV.C.8. Variation of airborne mass concentration/time, LMFBR base case (1000 kg sodium + $1 \%$ core) (from OECD, 1979).

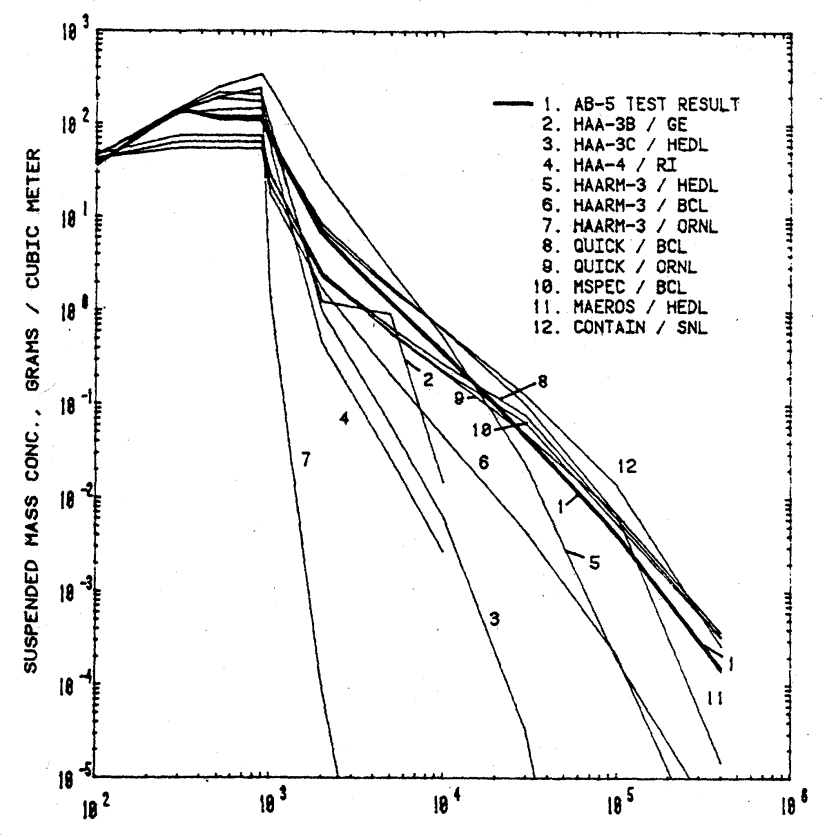

TDYE, SECOWS

FIG. IV.C.9. Comparison of several code predictions of suspended mass concentrations with $A B 5$ test (from Hilliard, 1983). in the dry case are required to reduce the initial mass concentration by a factor of 100 . The results for the wet case appear to be insensitive to the initial aerosol mass concentration over the range considered, 5.5 to $26 \mathrm{~g} / \mathrm{m}^{3}$. Figure IV.C.10 should be compared to Figure IV.C.2 which shows similarly shaped theoretical curves for the idealized case of sedimentation alone.

\section{IV.C.9.b. Demonstration of the Behavior of Nuclear Aerosols (DEMONA)}

This program underway at Battelle-Frankfurt with funding by the West German and Swiss governments has as its objective the demonstration of the effectiveness of natural removal processes and validation of the NAUA code. This program has been outlined by Hosemann and Haschke (1984). The aerosols will be mixtures of metals ( $\mathrm{Ag}, \mathrm{Fe}, \mathrm{U}, \mathrm{Sn}, \mathrm{Zr}$ ) formed from vapors produced in a plasma torch. These aerosols are to be injected into a $1 / 4$ scale model of the Biblis B reactor with a volume of 640 $\mathrm{m}^{3}$. Initial aerosol concentration will be of the order of $20 \mathrm{~g} / \mathrm{m}^{3}$. A series of seven experiments is planned, five with the vessel preheated to steady state conditions prior to the injection of aerosols and two with the vessel initially cold at the time of aerosol injection. Figure IV.C.11 is

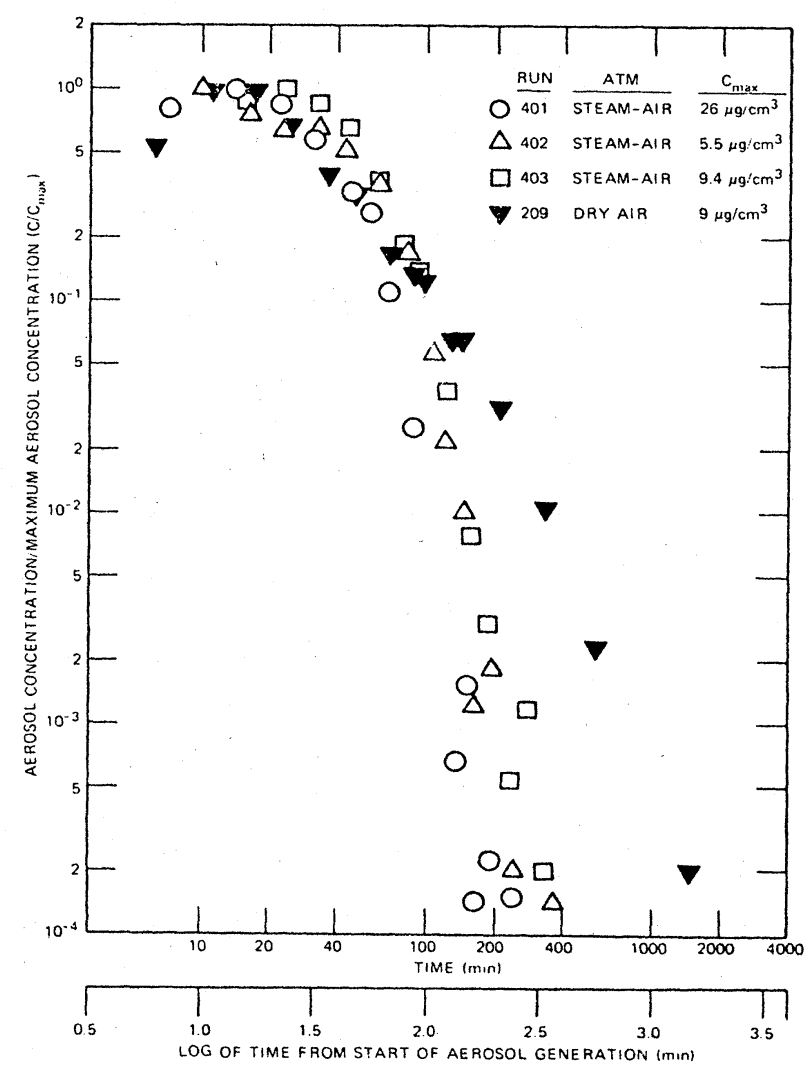

FIG. IV.C.10. Comparison of behavior of $\mathrm{U}_{3} \mathrm{O}_{8}$ aerosol under dry and steam environments (Runs 401, 402, and 403 vs Run 209). 


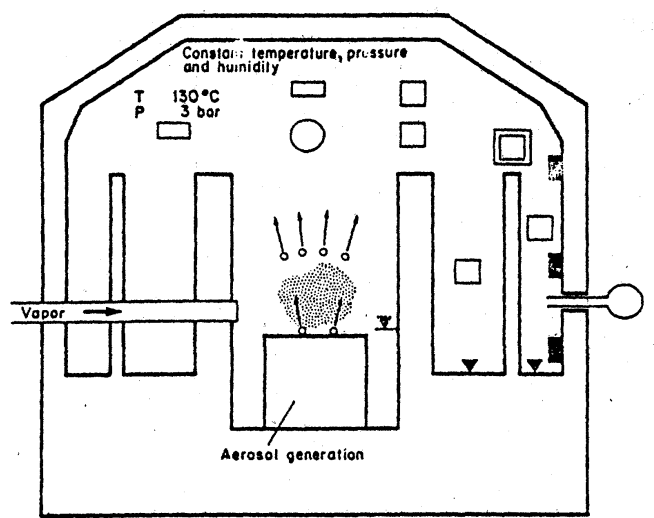

\begin{tabular}{|c|c|c|c|c|}
\hline \multicolumn{5}{|c|}{ In-Containment Instrumentation } \\
\hline $\begin{array}{l}\text { Station } \\
\text { Symbol }\end{array}$ & $\begin{array}{l}\text { Type of } \\
\text { instrument }\end{array}$ & $\begin{array}{l}\text { Nomber of } \\
\text { Stations }\end{array}$ & $\begin{array}{l}\text { Nomber of } \\
\text { Instruments } \\
\text { per Station }\end{array}$ & $\begin{array}{l}\text { Meosured } \\
\text { Quontity }\end{array}$ \\
\hline & Filter & 4 & 5 & $\begin{array}{l}\text { Particle size spectra } \\
\text { aerosol concentration }\end{array}$ \\
\hline & Impactor & 1 & 5 & particle specira \\
\hline L & $\begin{array}{l}\text { Light fronsmission } \\
\text { meter }\end{array}$ & 10 & 1 & cerosol conceitration \\
\hline & $\begin{array}{l}\text { Optical Droplet } \\
\text { Spectrometer }\end{array}$ & 1 & 1 & $\begin{array}{l}\text { size distribution } \\
\text { of water droplets }\end{array}$ \\
\hline & Out - of & Contoinmen & instrumentatior & \\
\hline & $\begin{array}{l}\beta \text { - absorbtion } \\
\text { impoctor }\end{array}$ & 1 & $i$ & $\begin{array}{l}\text { partlcle size spectro } \\
\text { aerosol concentration }\end{array}$ \\
\hline
\end{tabular}

FIG. IV.C.11. Schematic diagram of the DEMONA experimental facility, indicating instrumentation for aerosol measurements (from Hosemann and Haschke, 1984). a schematic diagram of this experimental facility indicating that aerosols will be monitored at several positions using filters, light transmission meters, and an aerosol impactor. The program is expected to be completed in 1985. Bunz and Schock (1984) report on the one test recently completed. A total of $7.8 \mathrm{~kg}$ of aerosol material was injected under dry conditions into the chamber in two puffs and the amount of aerosol remaining airborne was measured as a function of time. Figure IV.C.12 compares these measurements to calculations of the NAUA Mod-7 code. In recent thermal hydraulic experiments with this facility, Kanzleiter (1984) showed that stable thermal stratification does develop, a factor not included in current modeling.

\section{IV.C.9.c. LWR Aerosol Containment Experiments (LACE)}

This program underway at the Hanford Energy Development Laboratory with EPRI funding has as its objective measurement of aerosol retention in piping that simulates the reactor coolant system, measurement of changes in aerosol characteristics passing through the piping, and measuring aerosol deposition in a simulated auxiliary building. Emphasis is on understanding aerosol deposition and thermal hydraulics relevant to containment bypass, early containment leakage or failure to isolate, and delayed containment failure sequences. The program is briefly described by Muhlestein et al. (1984). The experimental layout is shown schematically in Figure

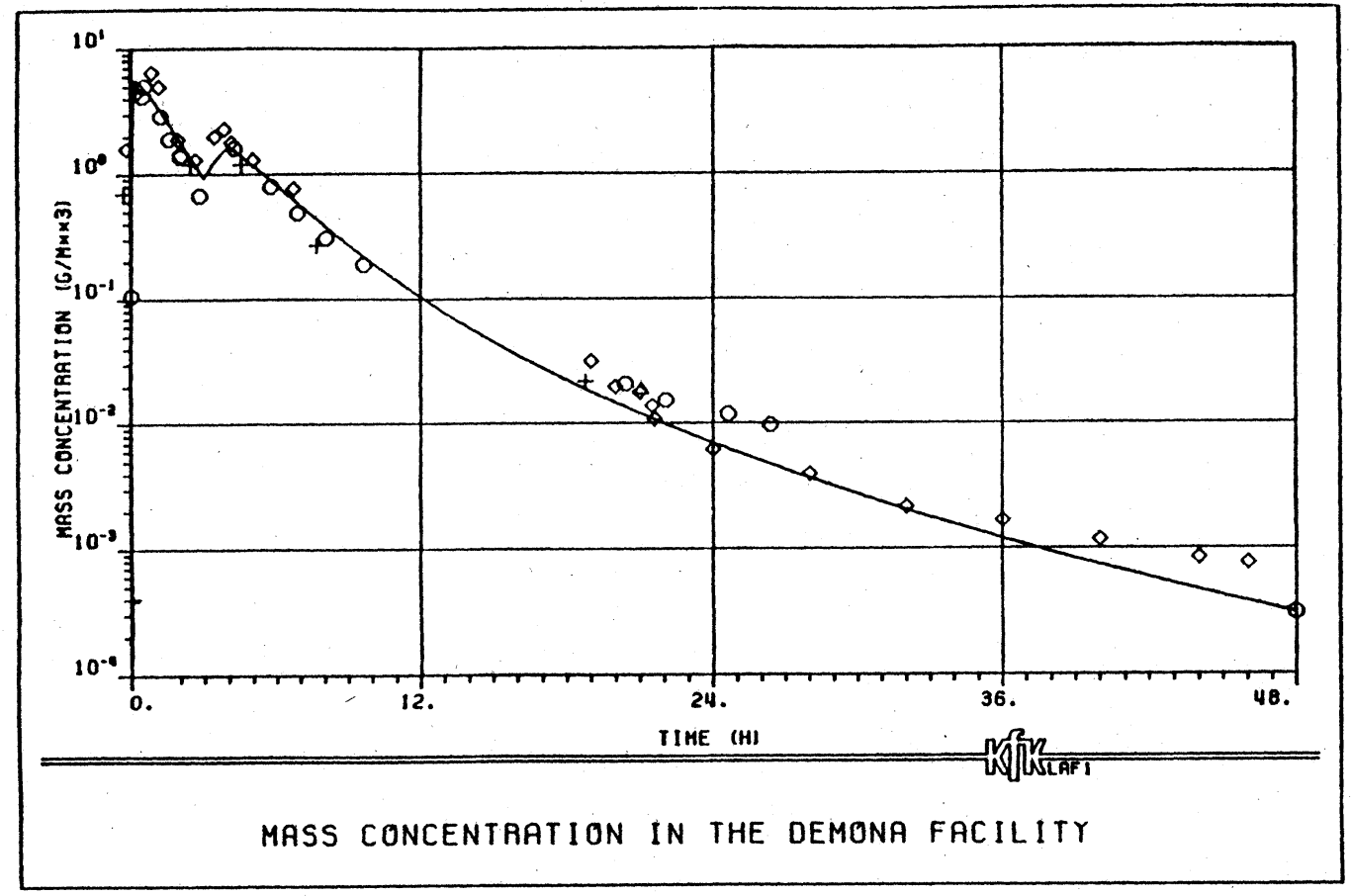

FIG. IV.C.12. Comparison of measured DEMONA data to the calculation performed after the experiment, aerosol generation rate, and leak rate fitted according to the experimental results (from Bunz and Shock, 1984). 
IV.C.13. Soluble $(\mathrm{NaOH})$ and insoluble $\left[\mathrm{Al}(\mathrm{OH})_{3}\right]$ aerosols will be used in a steam-air mixture. A large scale, 63 $\mathrm{mm}$ inner diameter pipe $27 \mathrm{~m}$ long with several elbows and valves leads from the aerosol generator to a vessel 850 $\mathrm{m}^{3}$ in volume which simulates an auxiliary building. Deposition in the pipes and containment will be measured. Two tests have been run, but the data have not yet been released because it is desired to conduct "blind" tests of the code calculations. One more test is scheduled. Additional experiments with this facility depend on obtaining additional funding. These tests are particularly important because in the sequences where the containment was not isolated, or where there is containment bypass, the only retention of fission products results from aerosol deposition as the blowdown fluid passes through piping and through the different compartments in the containment and auxiliary building. For the BWR, TM, and TW sequences this is also important.

\section{IV.C.9.d. MARVIKEN}

This is a full scale integral experiment at the MARVIKEN Nuclear Plant, Sweden, funded by the NRC, EPRI, and eight foreign governments. The aim of the experiment is to improve understanding of transport and deposition of high concentration aerosols $\left(100 \mathrm{~g} / \mathrm{m}^{3}\right)$ produced under simulated overheated core conditions. The aerosols will be cesium iodide, cesium hydroxide, and tellurium particles condensed in steam after evaporation in a plasma torch. The first experiments introduced these aerosols directly into the pressurizer and measured the retention within the pressurizer, relief tank, and connecting pipe lines. Future experiments plan to introduce the aerosols into a vessel simulating the reactor vessel and to use aerosols formed from a mixture of metals ( $\mathrm{Fe}, \mathrm{Cr}, \mathrm{Ag}$, Cd). It is hoped that the information obtained will be used to validate the TRAP-MELT code. However, information from these tests has not yet been released by the sponsors.

\section{IV.C.9.e. Smaller scale experiments}

Several small scale experiments are planned or in progress. These include aerosol transport, deposition, and resuspension in pipes and fission product capture on aerosols. The experiments are being done at Oak Ridge National Laboratory under NRC funding with completion expected in 1985 .

\section{IV.C.10. Conclusions}

IV.C.10.a. A number of mechanisms operate to deposit aerosols onto surfaces both within the primary system and within the containment. To the extent that these processes were not included in the Reactor Safety Study

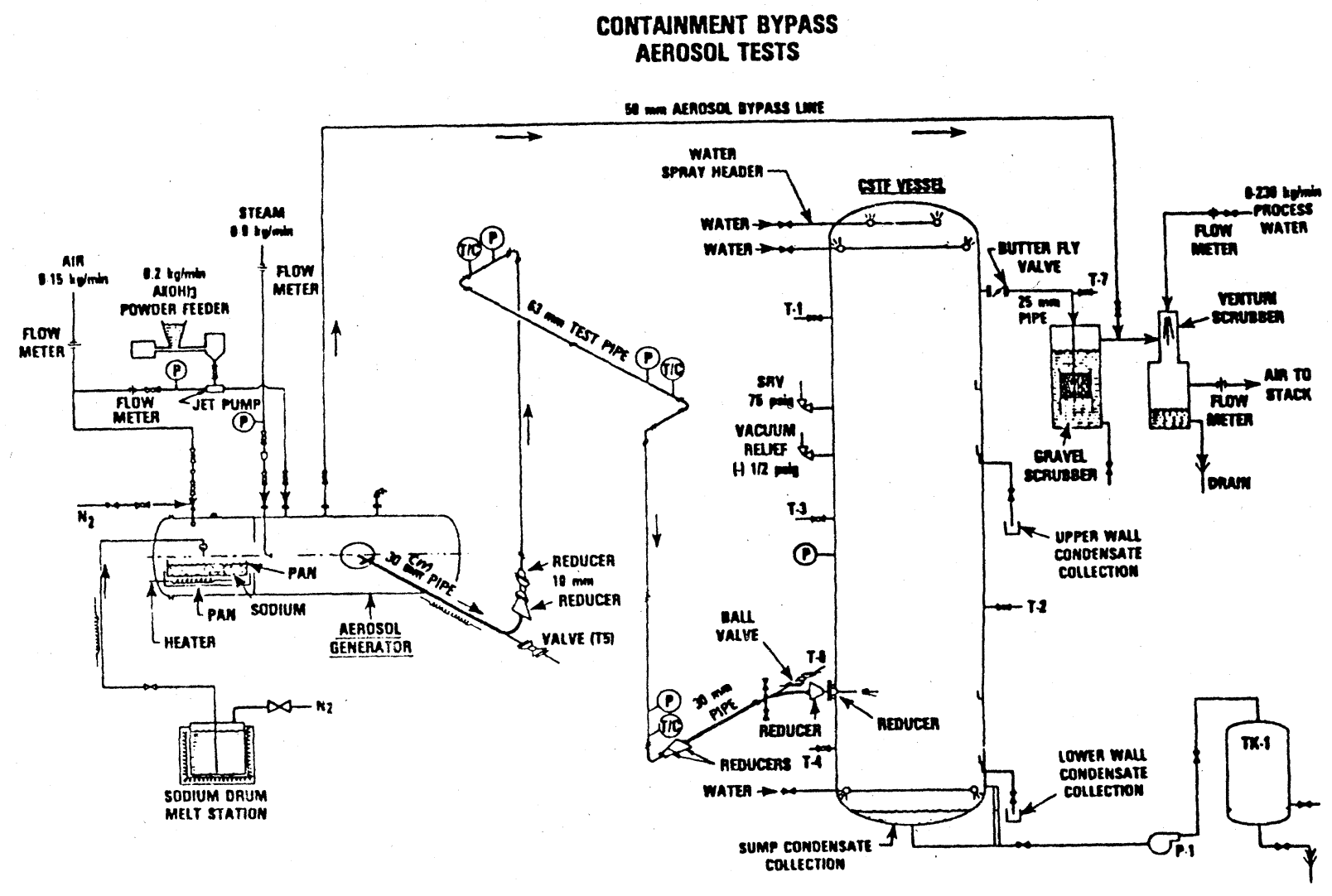

FIG. IV.C.13. Containment bypass experiment (from Muhlestein et al., 1984). 
(NRC, 1975), that study overestimated the "source terms" of condensible species for the accident sequences considered.

IV.C.10.b. Aerosol deposition rates are very sensitive to particle size. It is therefore necessary to know accurately the size distribution of aerosols in the various spatial regions and at various times of an accident in order to estimate "source terms" with some degree of reliability.

IV.C.10.c. The best method of predicting aerosol size distributions and hence the "source terms" for a variety of accident sequences and plants is to use calculations based on mechanistic principles, i.e., to account for important processes such as aerosol formation, growth by condensation or coagulation, and loss to surfaces by recognized mechanisms using the best available kinetic expressions. This is the general approach taken in Gieseke et al. (1984) although improvements can be made. The various codes for aerosol transport and deposition differ in their predictions; the sources of these differences needs to be identified and resolved.

IV.C.10.d. Some potentially important phenomena are not included in the current codes (TRAP-MELT and NAUA). These are: the formation of small particles by homogeneous nucleation of vapors, especially where gases pass from the primary system to the containment; the production of small particles by re-entrainment, resuspension, or evaporation associated with steam explosions, hydrogen burns, or rapid depressurization; the development of thermal stratification or incomplete mixing in the assigned control volumes.

IV.C.10.e. Because of the complexities of the phenomena being modeled, it is essential to validate the codes against well controlled, small scale experiments and against realistic, adequately instrumented, large scale integral experiments to ensure that all important phenomena are modeled with sufficient accuracy.

IV.C.10.f. Validation of the codes is incomplete. Large scale experiments (DEMONA, MARVIKEN, PBF) are in progress but the currently available data are limited in scope, quantity, and reliability. Smaller scale experiments have not covered as wide a range of parameters as desired.

IV.C.10.g. Large decontamination factors are claimed for engineered safety features. The experimental data base to support these claims for realistic accident conditions is limited in the case of suppression pools and nonexistent in the case of ice beds.

IV.C.10.h. Aerosol deposition is not likely to occur uniformly on surfaces. For example, large deposits by impaction may occur at pipe bends. This could have important consequences for revolatilization or structure melting owing to the associated decay heat.

IV.C.10.i. The time history of aerosols within the containment is sensitive to the duration of their introduction rate into the containment. A scenario involving a sustained release to the containment needs investigation. One such scenario is only partial loss of core at meltthrough, followed by intermittent degradation of the remaining fuel rods.

\section{IV.D. Containment integrity}

\section{IV.D.1. Introduction}

Every commercial light-water reactor in the U.S. and in non-Communist countries is enclosed within a containment vessel. The containment is nominally designed to withstand a "design basis accident," i.e., the sudden rupture of the largest cooling pipe of the primary system, releasing the hot water inventory. The structure is fabricated of steel or of reinforced or prestressed concrete with a steel liner. Various engineered safety features such as sprays, coolers, water pools, and/or ice beds are used singly or in various combinations to reduce the pressure buildup in the containment.

The containment vessel represents a major barrier to fission product release following a severe accident. At the time of the Reactor Safety Study (NRC, 1975) it was conservatively assumed that reactor containments could not withstand a complete core melt unless mitigating features such as the core spray system operated. If the shell did not fail, it was thought the basemat would eventually be penetrated-the "China Syndrome." Since the Three Mile Island accident, substantially more analyses and experiments have occurred which suggest that containment failure may be delayed substantially in time from that assumed in the RSS, depending on the accident scenarios, the particular design of the containment, and possible other leakage paths. This was briefly mentioned in Section III.C. 1 in the context of the accident sequence TMLB'.

This section explains why containment phenomena are important for defining the source term, describes typical containment designs, and summarizes the state of the art for predicting containment loads and failures. The following section, IV.E, discusses containment loads and the several causes of containment failure.

\section{IV.D.2. Why containment phenomena are important}

It is almost a tautology that if the containment vessel remains intact there can be no radionuclide release in a nuclear accident. Further, the time and manner of a containment failure are decisive in determining the magnitude of a release.

If a containment break occurs just after the volatile fission products ( $\mathrm{Cs}, \mathrm{I}, \mathrm{Te}$ ) have been released to the containment and converted to aerosols-at about 160 minutes into the TMLB' sequence shown in Figure III.C.2, for example-there are predictions that $80 \%$ of the Cs and I inventories in the reactor core would be released to the environment (Lipinski, 1984). (This is the "early" high release of the QUEST program.) On the other hand, if five days were to elapse between the reactor vessel failure and the containment break, there might be time for aerosols to deposit on all the many internal surfaces, and the Cs and I releases have been calculated to be reduced to $10^{-4}$ of 
the inventory or less (Hosemann and Hassman, 1983).

Not only is the timing of containment failure a decisive parameter in source term prediction, but the size of the hole through which the release occurs is also important. While a large hole results in a rapid release of the airborne contents of the containment, a small hole slows down the release so that fission-product aerosols are given more time to settle out on surfaces within the containment. The QUEST results (Lipinski et al., 1984) indicate that the fission product release to the environment varies over an order of magnitude when the hole area is varied from $0.001 \mathrm{~m}^{2}\left(1.55 \mathrm{in.}^{2}\right)$ to $10 \mathrm{~m}^{2}$ (15 $500 \mathrm{in} .{ }^{2}$ ). Calculations by Stone and Webster Engineering Corporation (SWEC) shown in Figure VI.3 show that the release reaches a maximum with a 1 square foot $\left(\sim 0.1 \mathrm{~m}^{2}\right)$ hole.

\section{IV.D.3. Description of various types}

of containment

Figure IV.D.1 shows schematics of various types of containment with the numbers of each in the United States as of 1980 .

\section{IV.D.3.a. Large dry}

The simplest design of containment is a large steel or reinforced concrete vessel that has sufficient volume to contain the pressure of the Design Basis Accident LOCA. No special devices such as water pools or ice condensers are used to condense the steam from the accident. Most pressurized water reactors have been constructed with this "Large Dry" containment. The Surry containment vessel (Figure IV.D.2) is typical; the main structure is of concrete reinforced by steel, with an internal steel liner varying in thickness from 0.25 to 0.5 in.

German reactors use a dual containment structure. A steel containment vessel is surrounded by a reinforced concrete secondary containment, with the space between the two evacuated through a filter. The steel vessel is expected to withstand the design basis accident (LOCA).

The most recent French large dry containment is of unlined concrete, with a secondary concrete shield building. Leakage through cracks in the concrete is expected to prevent gross overpressurization failures (Hofmayer, 1984). The French are also seriously considering adding controlled filtered venting systems to their containment structures to prevent build-up of excessive pressure and subsequent catastrophic failure.

\section{IV.D.3.b. Ice condenser}

A few PWR's, such as Sequoyah (Figure IV.D.3), use an ice bed to condense steam and thereby mitigate pressure buildup during blowdown of the high pressure steam. The internal construction is designed to force the blowdown gases to pass through the ice bed, which has a large surface area to condense the steam rapidly. By this means, these structures can have a smaller volume and a lower design pressure than the large dry type, and still contain the design basis accident (LOCA).

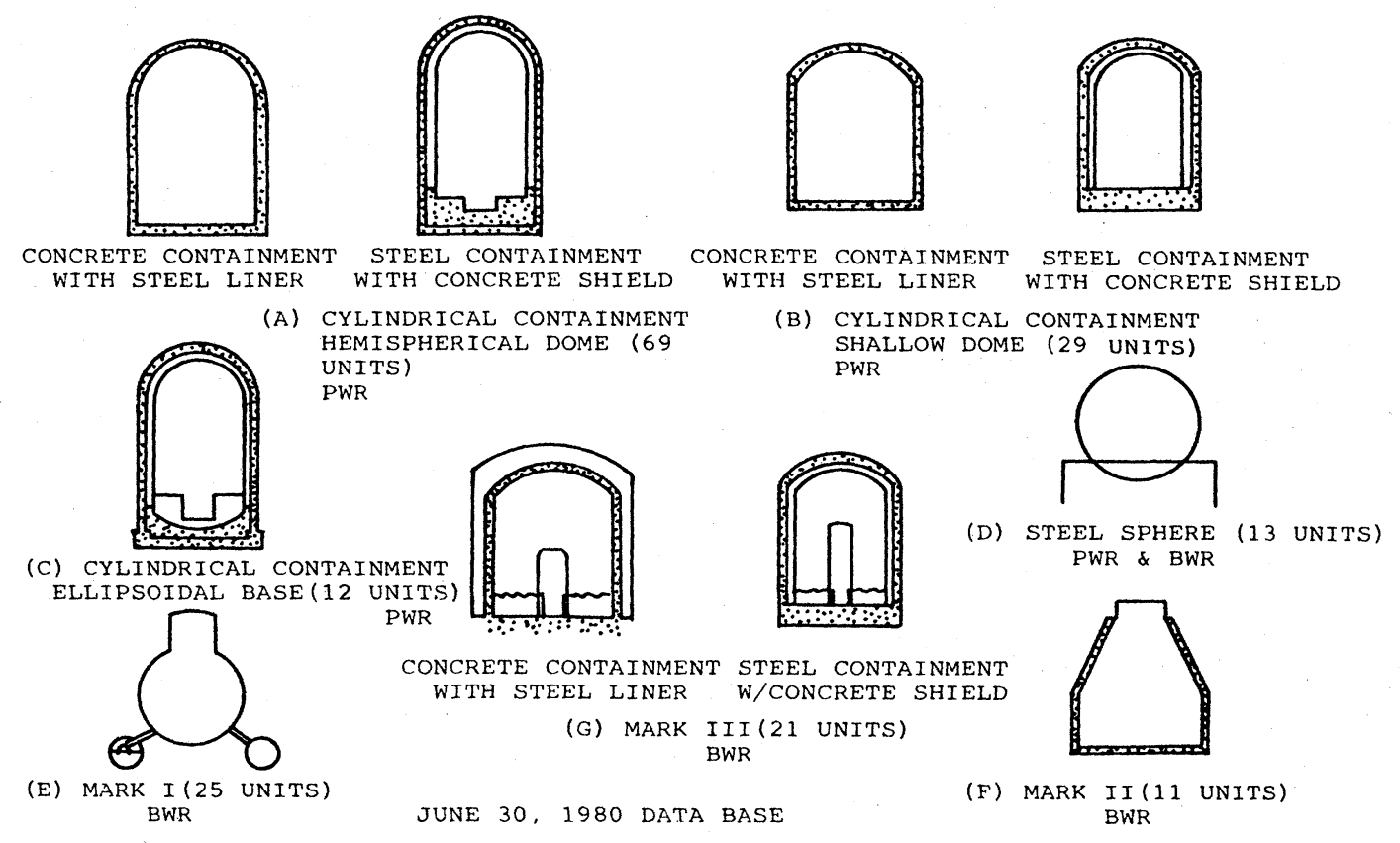

FIG. IV.D.1. Containment structural configurations as of June 30, 1980, from ANS (1984). 


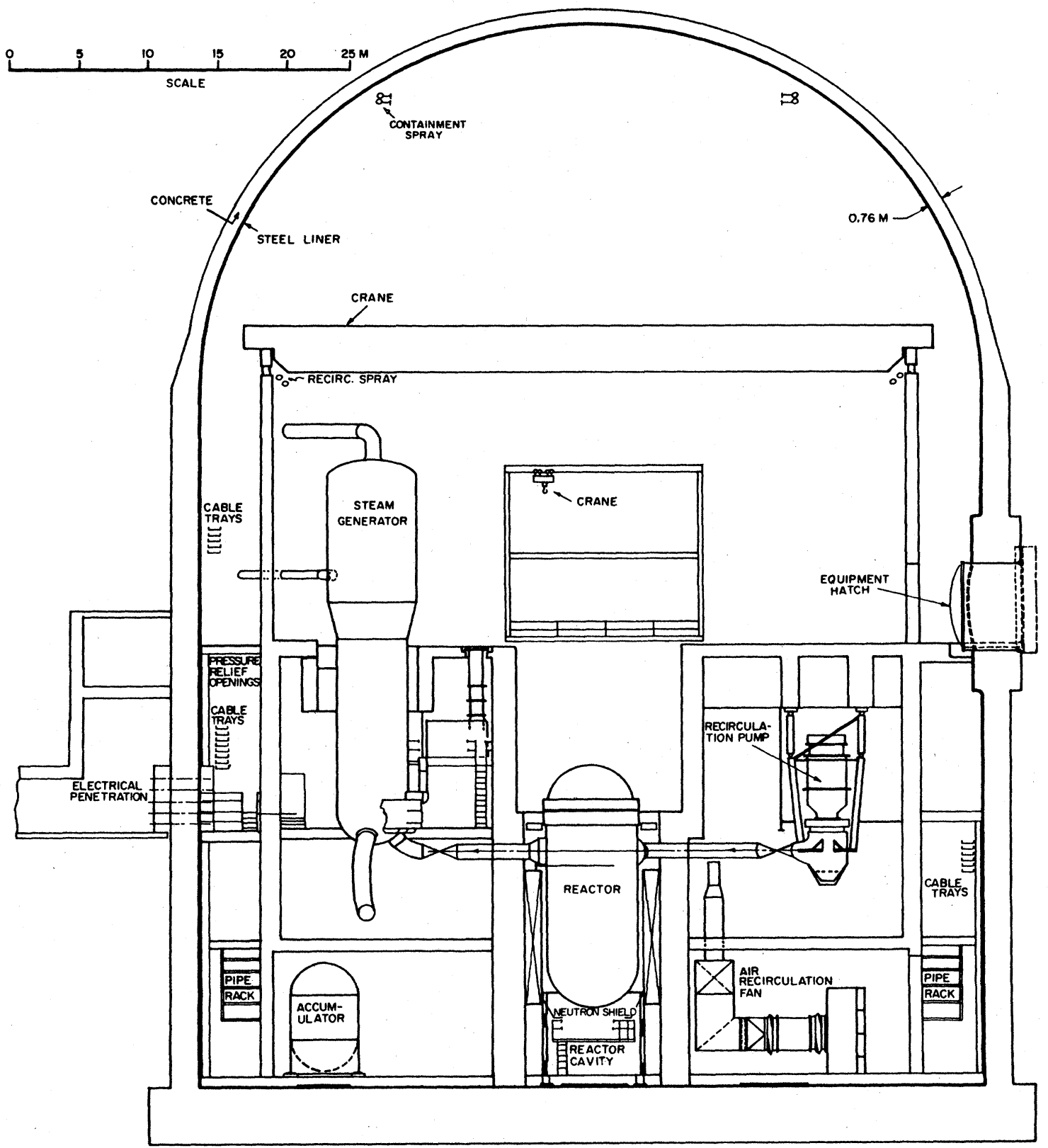

FIG. IV.D.2. Surry reactor: PWR, large dry containment.

\section{IV.D.3.C. BWR Mark I}

Boiling water reactors are generally combined with a "pressure suppression" pool in which steam condenses during an accident. This allows the volume to be relatively small and still contain the design basis LOCA. Containment design of the Mark I Peach Bottom reactor (Figure IV.D.4) is the most common containment system for U.S. BWR's. The "drywell" is the heavy light-bulbshaped structure connected to the "wetwell," a torus enclosing the pool. Mark I containments are filled with inert gas (nitrogen) to avoid hydrogen burns. A secondary structure, constructed using ordinary design practice and with no appreciable pressure resistance, surrounds the drywell and contains fans and filters to reduce potential radioactivity releases from the primary containment. Fire protection sprays within this secondary structure could also be used to reduce radioactivity releases, but they are of uncertain effectiveness.

\section{IV.D.3.d. BWR Mark II}

The more recent Mark II design (Limerick, Figure IV.D.5) places the wetwell directly below the drywell, but 


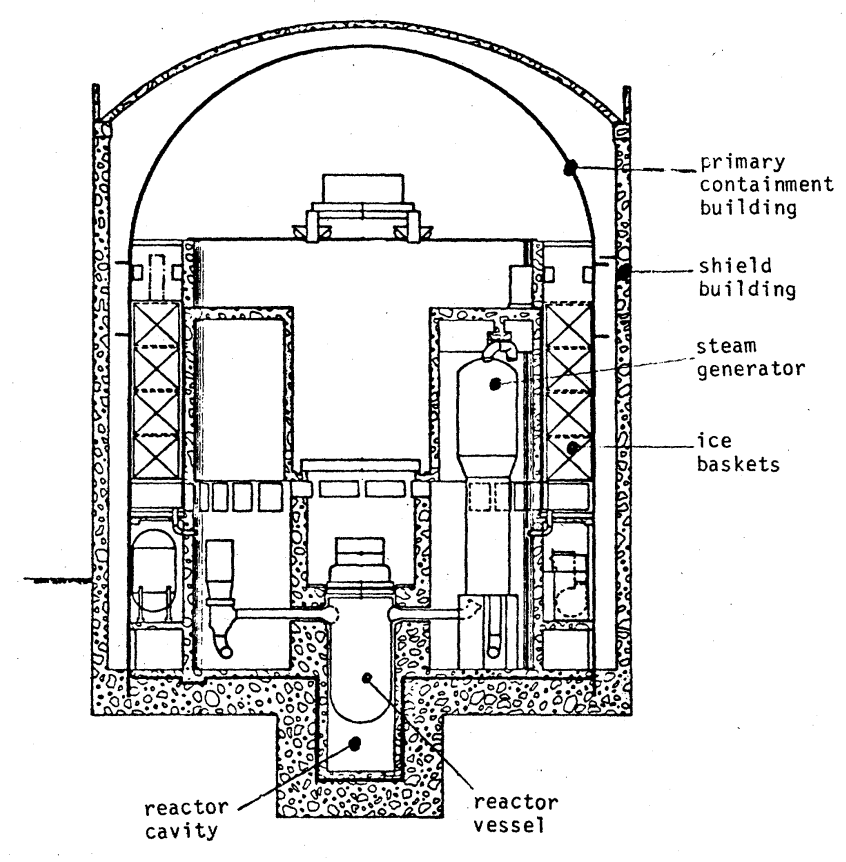

FIG. IV.D.3. Ice condenser containment (Sequoyah Reactor).

is similar in principle to the Mark $\mathbf{I}$. The containment is again inerted. The source term of Mark II designs has not been analyzed in NRC's program. 'However, some PRA's completed for Mark II designs (Limerick, Shoreham) suggest that they may have an effectiveness similar to the Mark I designs.

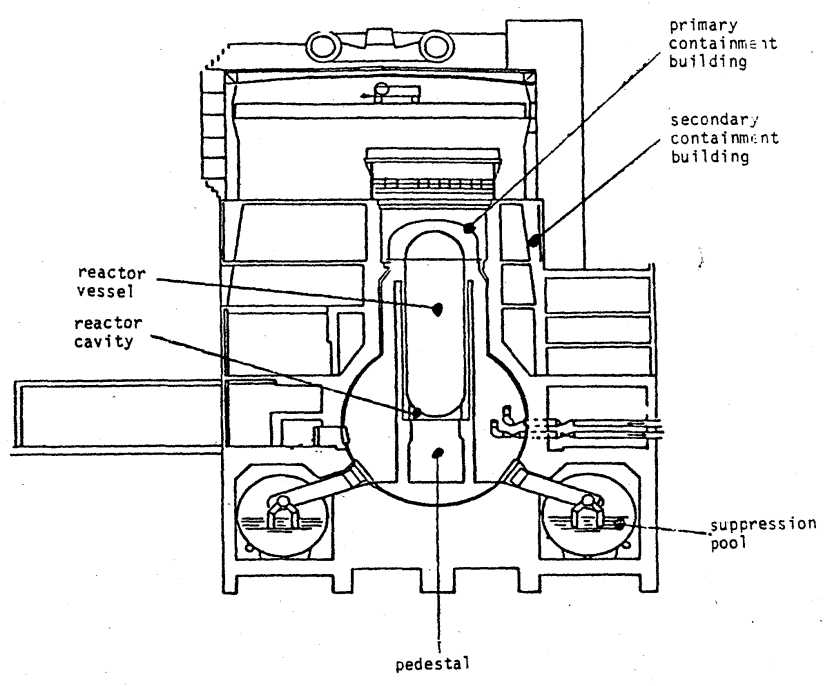

FIG. IV.D.4. BWR Mark-I containment (Peach Bottom Reactor).

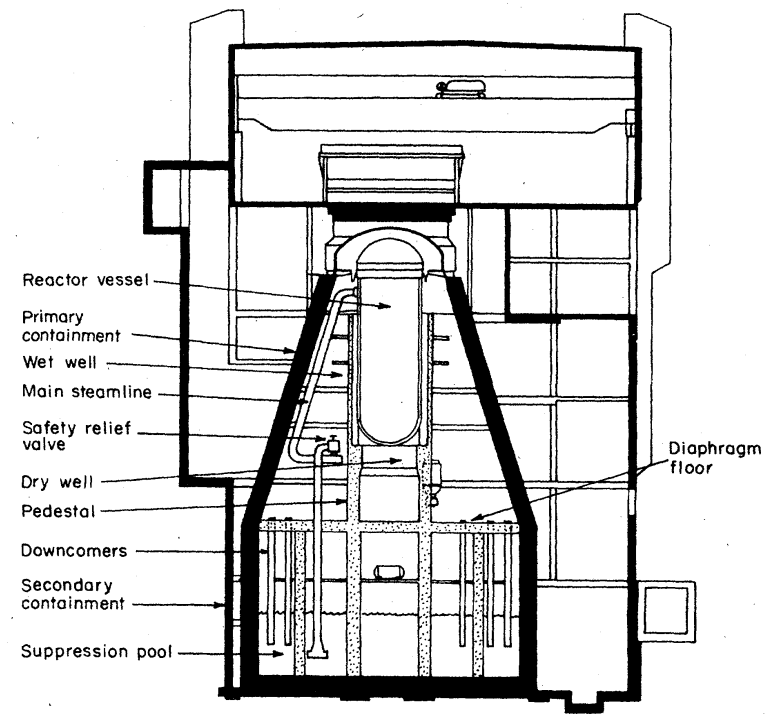

FIG. IV.D.5. BWR, Mark-II primary and secondary containment (Limerick).

\section{IV.D.3.e. BWR Mark III}

The Mark III containment (Grand Gulf, Figure IV.D.6) is intended to avoid certain mechanisms whereby steam can bypass the suppression pool which can occur with the earlier containment designs. The suppression pool forms a loop seal between drywell and wetwell, reducing the possibility of a drywell structural failure. A thin steel or reinforced concrete structure with a large volume provides an external containment structure and is an integral part of the containment system. This containment is not made inert.

\section{IV.D.4. Containment failure modes}

The Nuclear Regulatory Commission requires that the containment "design" pressure be calculated in a conservative manner. At the time of the Reactor Safety Study (NRC, 1975) it was conservatively assumed that containments would fail if stressed much beyond the design pressure limits. Recently, more careful calculations and tests $\left(\frac{1}{32}\right.$ scale) have been made for various containment structures, and it has been found that the ultimate failure pressure will generally be much higher-up to $21 / 2$ times higher for concrete containments and even ten times higher for some steel containments, assuming that good quality control practices assure that the construction matches the requirements.

Techniques for predicting the behavior of steel vessels under pressure appear to be available (Greiman, 1982). The Sandia program for pneumatic testing of steel scale models appears to be well underway; of four 1/32-scale models tested, two developed leaks and two suffered massive ruptures (Riesemann and Subraimanian, 1984). Little 


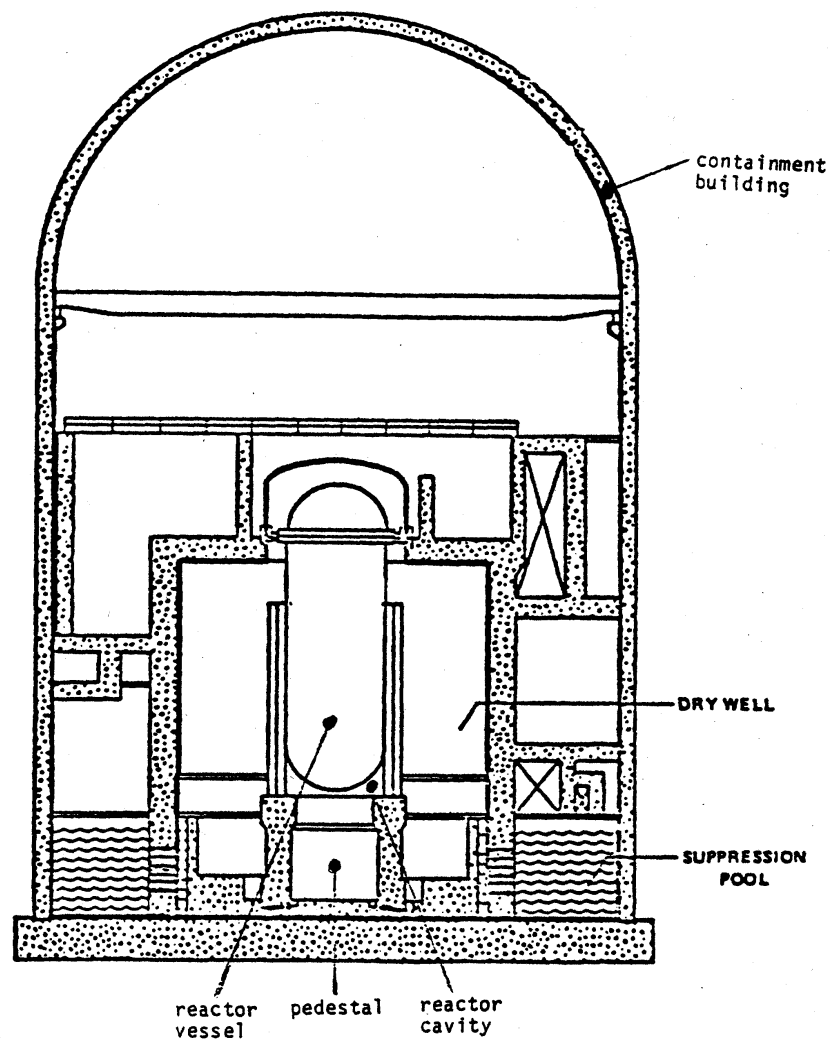

FIG. IV.D.6. BWR, Mark-III containment (Grand Gulf Reactor).

is known about the failure modes of these vessels (the size of the hole developed at failure). Sandia plans to test a $1 / 8$-scale steel vessel, a 1/6-scale reinforced concrete model, plus a variety of penetrations (Riesemann and Subraimanian, 1984). EPRI is sponsoring a program of testing and analysis of large concrete containment elements (Schultz et al., 1984).

Considerable work has been done and more is in progress to develop and prove models that will accurately predict the type of failure that can be expected to occur. In these scale model tests and calculations, the pressure increase is assumed to be gradual over several seconds or more, reaching a high plateau that is maintained along with a high temperature for some time. One question of interest is, will the containment develop leaks or small holes or will it fail massively with large holes? A massive failure is undesirable under any circumstances, while a failure with a small hole has been calculated to contain most of the radioactivity.

The strength, which has been calculated by finite element analysis (Greiman, 1982; Hofmayer, 1984b; UEC, 1983), determines whether a catastrophic failure occurs. Greiman calculated the pressure for ultimate failure of steel shells; the others calculate the pressure required to reach yield stresses in the structure, and note that the con- tainment will fail soon after yielding if the internal pressure is maintained. For a PWR, the containment is usually a large reinforced concrete structure with a steel liner. At the high temperatures of concern, the steel liner is under compression and only goes into tension at a high pressure. The failure is expected to be a tear in the liner at a discontinuity, e.g., at the bottom of the structure or at the junction between the cylindrical sides and the spherical top. The reinforcing bars in the concrete are carefully welded together with high strength butt welds, which provide most of the strength. The concrete itself serves to maintain the relative position of the steel reinforcing bars and to support the steel liner. When the concrete is stressed, cracks open up and these coincide with a tear in the liner, where the leak forms. A list of some calculations of design and failure pressures is shown in Table IV.D.1.

Tests of model steel containment vessels (Blejwas, 1984) indicate that the yielding pressure agrees with calculation to about $15 \%$. Strain gauges mounted on the models show that they elongate $10-20 \%$ before rupture. Tests of a reinforced concrete vessel with liner are being prepared.

We assume in calculating the ultimate strength of the containment that the pressure rise is slow compared with the fundamental period of the containment-on the order of a tenth of a second. There are two possible conditions in which the rise in pressure may be rapid-hydrogen explosions or steam explosions (see below). If either occurs, a pressure pulse with a rise time of $1 / 10 \mathrm{~s}$ or so can be added to the pressure which rises slowly over several minutes. This demands a dynamic behavior by the containment. Such calculations are less easy to do, and greater uncertainty exists as to their results.

The obvious question arises, how well will actual containments perform compared with the models under test? Each containment is tested under cold static pressure at 1.15 times the design pressure, and NRC regulations specify a maximum allowable leak rate-usually between $0.1 \%$ to $0.5 \%$ volume/day. Strain gauges are liberally distributed around the containment to measure the actual deformation. The same calculation that predicts the yield pressure also predicts the deformation at the lower test pressure, so that this test partially verifies the calculation. Any unusual deformation should signify the existence of an area of poor construction.

There is a Quality Assurance program for the containment construction, to ensure adherence to design. The study group did not examine the Quality Assurance programs or the testing programs in detail, but wishes to emphasize their importance.

\section{IV.D.5. Containment leaks}

Containments are leak-tested about once every 3 years by cold static pressure tests. Weinstein (1980) reported that only about $85 \%$ of containments operate at the specified leak rate, or below, based upon analysis of the test data. Containment integrity failures reported (and subse- 
TABLE IV.D.1. Calculated strength of containment shells.

\begin{tabular}{|c|c|c|c|c|c|}
\hline Plant & Type & Material & $\begin{array}{l}\text { Volume } \\
\left(10^{6} \mathrm{ft}^{3}\right)\end{array}$ & $\begin{array}{l}\text { Predicted } \\
\text { failure } \\
\text { press. } \\
\text { (psig) }\end{array}$ & $\begin{array}{l}\text { Design } \\
\text { press. } \\
\text { (psig) }\end{array}$ \\
\hline St. Lucie & Large dry & Steel & 2.5 & $95^{\mathrm{b}}$ & 44 \\
\hline Cherokee & Large dry & Steel & 3.3 & $116^{\mathrm{b}}$ & $?$ \\
\hline Perry & Mark III & Steel & $0.28+1.2^{\mathrm{e}}$ & $100^{\mathrm{b}}$ & 45 \\
\hline WPPSS & Mark II & Steel & $0.25+0.15^{\mathrm{e}}$ & $133^{b}$ & 45 \\
\hline Browns Ferry & Mark I & Steel & $0.16+0.12^{\mathrm{e}}$ & $117^{\mathrm{b}}$ & 56 \\
\hline Zion & Large dry & $\begin{array}{l}\text { Reinf. } \\
\text { concrete }\end{array}$ & 2.7 & $134^{\mathrm{c}}$ & 47 \\
\hline Surry & Large dry & $\begin{array}{l}\text { Reinf. } \\
\text { concrete }\end{array}$ & 1.8 & $119^{c}$ & 45 \\
\hline Sequoyah & Ice cond. & Steel $^{\mathrm{a}}$ & 1.3 & $50^{c}$ & 12 \\
\hline Limerick & Mark II & $\begin{array}{l}\text { Reinf. } \\
\text { concrete }\end{array}$ & $0.25+0.1^{\mathrm{e}}$ & $140^{c}$ & 55 \\
\hline Grand Gulf & Mark III & $\begin{array}{l}\text { Reinf. } \\
\text { concrete }\end{array}$ & $0.27+1.4^{\mathrm{e}}$ & $60^{c}$ & 15 \\
\hline Indian Point & Large dry & $\begin{array}{l}\text { Reinf. } \\
\text { concrete }\end{array}$ & 2.6 & $126^{\mathrm{d}}$ & 47 \\
\hline
\end{tabular}

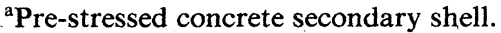

${ }^{\text {b}}$ Predicted for actual failure (Grieman et al., 1982).

'Predicted 1\% yield (Hofmeyer et al., 1984).

${ }^{\mathrm{d}}$ Predicted yield (U.E.C., 1983).

${ }^{e}$ Wetwell and drywell volumes, respectively.

quently corrected) during 1973 to 1979 averaged over five per year. Most of these were related to valve failures or valves inadvertently left open. In most cases, the leakage was between 1 and 10 times the allowable rate. If one accepts an opening of $6.5 \times 10^{-6} \mathrm{~m}^{2}\left(0.01 \mathrm{in}^{2}\right)$ as corresponding to the specification (NRC, 1984) then most failures were in the range up to $6.5 \times 10^{-5} \mathrm{~m}^{2}\left(0.1 \mathrm{in.}^{2}\right)$, the largest failure reported (an open 6 in. valve) would have an area of about $0.018 \mathrm{~m}^{2}\left(28.3 \mathrm{in}^{2}\right)$.

The NRC Containment Performance Working Group (NRC, 1984) predicts that the Surry large dry containment may develop leak areas of 0.013 to $0.026 \mathrm{~m}^{2}(20$ to 40 in. $^{2}$ ) owing to elastomer degradation in seals around penetrations through the containment after $1 / 2$ to 2 hours at $450 \mathrm{~K}\left(350^{\circ} \mathrm{F}\right)$. Similarly, Peach Bottom (Mark I) could develop drywell leaks of 0.013 to $0.0194 \mathrm{~m}^{2}(20$ to 30 in. $\left.^{2}\right)$ after less than $1 / 2$ hour at $525 \mathrm{~K}\left(500^{\circ} \mathrm{F}\right)$. Leak area projections have been made for Zion (large dry) based on a mechanical analysis of penetrations and valves (Table IV.D.2). The Zion analysis was stated to have ignored the possible effects of temperature (NRC, 1984).

The medium to high leak area projections represent significant capacity for venting slow pressure increases which occur during the core-concrete interaction phase of an accident, and it is suggested that, if the medium to high end of the range is correct, a large structural failure may never occur, even for accident sequences that would otherwise predict containment failure.

On the other hand, this cannot be relied upon because the low end of the projections might be correct. It is also probable that these leak areas only open up after long stress at high temperatures-so that any pressure rises of the order of several minutes would not be relieved.

The apparent advantage of a controlled leak in the containment building has led a French design to deliberately vent the containment (manually or automatically) in some

TABLE IV.D.2. Leak area projected for Zion following a core melt accident (NRC, 1984).

\begin{tabular}{cccr}
\hline $\begin{array}{c}\text { Containment } \\
\text { pressure } \\
\text { (psig) }\end{array}$ & Low & $\begin{array}{c}\text { Leak area }\left(\text { in. }{ }^{2} \text { ) }\right. \\
\text { Medium }\end{array}$ & High \\
\hline Normal & 0.1 & 0.5 & 1.0 \\
operating & 0.1 & 0.6 & 1.5 \\
23 & 0.1 & 0.6 & 1.8 \\
47 & 0.1 & 2.1 & 11.0 \\
105 & 0.1 & 5.3 & 23.7 \\
134 & & & 3.7 \\
\hline
\end{tabular}


new reactors under construction. These seem obvious advantages, but because there may be unforeseen problems, the study group feels that such vented containments deserve further study before implementation.

The NRC has a research program to test model electrical and mechanical penetrations in order to reduce uncertainties in failure and leak rate predictions (Riesemann and Subraimanian, 1984).

IV.D.6. The impact of hole size on the source term

If the containment fails with a large hole, $10 \mathrm{~m}^{2}$ to 100 $\mathrm{m}^{2}$ or more, the gases would leave in a puff and release much, if not all, of the aerosols suspended in the containment atmosphere. In addition, it is possible that there would be resuspension and entrainment of some of the aerosols deposited on the containment surfaces (Lipinski, 1984).

On the other hand, calculations suggest that if the containment fails with a hole size of $0.01 \mathrm{~m}^{2}\left(15 \mathrm{in}^{2}\right)$, the depressurization will be slow, and while it is occurring there is more time for deposition of aerosols. For example, some calculations suggest that if the hole size is 0.01 $\mathrm{m}^{2}$, only $1 / 10$ of the aerosols will be released, and if 0.001 $\mathrm{m}^{2}$ only $1 / 30$ (Lipinski et al., 1984) (see also Figure VI.3).

Still another phenomenon has been suggested if leakage occurs through tubes or cracks. Then, aerosols can deposit, reducing the effective leakage area or plugging the leak entirely. Morewitz (1982) reports on the behavior of $\mathrm{NaOH}$ or $\mathrm{Na}_{2} \mathrm{CO}_{3}$ aerosols in leaks; although NRC investigators have reported experimental difficulties with aerosol accumulations, nothing is documented relative to aerosols typical of a reactor accident. The applicability of this phenomenon to such aerosols is uncertain.

\section{IV.D.7. Summary}

As is later demonstrated in Chapter VI, determination of the containment failure and accurate definition of the extent of that failure are critical to accurate prediction of the source term. Currently these are exogenous parameters supplied by users of the codes.

Most core-melt accident sequences do not generate sufficient pressure to lead to an early containment failure that could result in a large release of fission products. For those sequences that proceed to containment failure, such failures are likely to occur after tens of hours in the form of seal leaks, basemat penetration, or cracks in the liner. The source terms then are relatively small.

The study group identified four important general objectives for research on containment phenomena.

1. To provide estimates of containment leak rates for realistic modeling of reactor accident scenarios; this research includes testing of seals and penetrations under representative pressures and temperatures.

2. To provide more systematic protection against containment bypass events.
3. To reduce uncertainties in the prediction of early containment failure; this research includes assessment of poorly understood phenomena such as steam explosions, earthquakes, and direct heating of the containment by molten fuel and metal.

4. To provide a scientific data base for more reliable containment design. Such a design might include deliberate attempts to cause small leaks as the pressure increases to prevent catastrophic failure. Deliberate leaks through filtered vents, as being explored by the French, might be part of such design. This last is not an objective of the present NRC program, nor have we found it to be an objective of any industry program.

\section{IV.E. Containment loads}

\section{IV.E.1. Categorization}

The suite of computer codes developed at Battelle Columbus Laboratories (Gieseke et al., 1984) is used to calculate containment pressure loading. However, the NRC has set up a Containment Loads Working Group (CLWG) to compare the computation of pressure loading for representative scenarios by different experts. There is some disagreement among the experts about the pressures developed; this might be expected since the fundamental thermal-hydraulic phenomena behind the codes are still in a state of flux. The CLWG has not published any reports thus far; however, data from their meetings have been available and are factored into this report.

The Reactor Safety Study (NRC, 1975) categorizes the following causes of containment failure:

$\alpha$, steam explosion;

$\beta$, containment isolation failure;

$\gamma$, overpressure due to hydrogen combustion;

$\delta$, overpressure failure due to steam and noncondensible gases;

$\varepsilon$, basemat melt through;

$\mathrm{V}$, containment bypass.

In addition, we can identify large earthquakes as simultaneous contributors to containment failure and accident initiation, thereby causing a sequence of events that are not independent and whose individual probabilities cannot be multiplied to calculate the overall probability.

We would regroup these in accordance with the time of containment failure:

$\beta$, containment isolation failure;

$\mathrm{V}$, containment bypass;

$\alpha, \gamma, \delta_{1}$, failure of overpressure near time of reactor vessel melt-through (early failure);

$\delta_{2}$, failure several hours after reactor vessel meltthrough;

$\varepsilon$, basemat melt-through with a natural earth filter for fission products leaked to the atmosphere.

The Containment Loads Working Group has added rapid direct heating of the containment atmosphere by fuel finely divided by its escape under pressure from the primary system (Ginsberg, 1984). This, as noted in III.C. 1 , could lead to early containment failure $(\delta)$. 
Let us examine each of these processes in the new order of the time at which they might occur in an accident.

There are many possible causes of containment isolation failure $(\beta)$, mostly related to open valves or failed seals in containment penetrations. As was reported above, those which have occurred involve small openings below $0.01 \mathrm{~m}^{2}$ and usually below $6.5 \times 10^{-5} \mathrm{~m}^{2}\left(0.1 \mathrm{in}^{2}\right)$. Only a small fraction of the fission products can escape through openings in this size range, as shown in detail later in Figure VI.3.

It is not inconceivable that a large equipment hatch could be left open during reactor operation. For a containment that is supposed to be operated at reduced pressure, this may seem unlikely, but we know of no means of total assurance of containment integrity. Fortunately, many of these failures do not lead directly to outside air, but to an auxiliary building which can play its part in holding up radioactivity.

If a penetration were inadvertently left open in subatmospheric containments (e.g., Surry) or continuously vented containments (e.g., the German type), this would soon be noticed. This would perhaps reduce the likelihood of $\beta$ failure. However, the vacuum pumps are themselves in a subatmospheric containment system that must be isolated in accident conditions, and therefore represent a potential containment bypass.

Containment bypass failures occur when a pipe connected directly to the primary reactor coolant system passes directly through the containment vessel. In principle, all such entries are protected by check valves; but a check valve can fail. In the analysis of the Surry plant, the Reactor Safety Study (NRC, 1975) found that this sequence $(\mathrm{V})$ was a risk-dominant sequence. A failure of a check valve would put high pressure into low pressure piping outside the containment and cause it to fail. The consequent LOCA could lead to core melt, with a direct route to the environment for gases and aerosols. This probability was subsequently reduced by an improved testing procedure; and it has been recently discovered that this low pressure pipe is likely to fail in a compartment that is flooded during an accident. This $\mathrm{V}$ sequence is facility specific, but if the Surry experience is any guide, both the probability of occurrence and the consequences can be reduced moderately easily once the problem is recognized. We urge continuous attention to this problem at each facility.

Another major challenge to containment is the pressure spike which occurs just after the molten fuel has melted through the reactor vessel and discharged into the containment. This is particularly serious because it occurs just at the time when the containment has the largest concentration of suspended particles. The current view is that the steam pressure spike will not cause a major containment failure although some leakage may be created at penetrations. The steam pressure spike was discussed in Section III.C.1.

The heating of the containment atmosphere by a jet of molten fuel and structural material is a phenomenon peculiar to sequences where the primary system pressure at vessel failure is at tens of atmospheres or more. Much of the containment pressure load could be contributed by the burning of metal, such as zirconium, in containment air. There is controversy over whether this is a significant phenomenon, and whether the primary system can actually retain pressure prior to vessel failure. Further experiments would be required to narrow the uncertainties. The fuel jet heating phenomenon is potentially important as an early severe challenge to containment (see, for example, Section III.C.1 and Figure III.C.8).

\section{IV.E.2. Hydrogen burning}

As noted earlier, there are several potential sources of hydrogen release into the reactor vessel or containment. The first is from the oxidization reactions mentioned in III.A.2:

$$
\mathrm{Zr}+\mathrm{H}_{2} \mathrm{O} \rightarrow \mathrm{H}_{2}+\mathrm{ZrO}
$$

and similar reactions on other materials in the reactor vessel. The second is from the core-concrete reaction. The amount of zirconium water reaction is a critical parameter.

At the time of the Reactor Safety Study, it was thought that only a small fraction of the zirconium would oxidize. In a large pipe break, the water and steam disappear so fast that the reaction is starved for steam. However, at Three Mile Island (see Section II.A.7), the dry out proceeded slowly and there was plenty of steam. As a result, the containment was partially filled with hydrogen; at about 1 p.m. on March 28, 1979, hydrogen burning occurred as evidenced by a pressure surge in the containment, and subsequently confirmed by photographs of the interior of the containment. Since then, a great deal of attention has been paid to hydrogen release and to the possibility that hydrogen will burn in reactor accidents.

A great deal is known about hydrogen combustion phenomena in air-steam mixtures. In addition, Sandia has an active experimental program dealing with accelerated flames and detonations in large systems. The LightWater Reactor Hydrogen Manual (Camp, 1983) gives the following lower flammability limits for hydrogen in steam-saturated air:

Lower limit, volume \%

\begin{tabular}{ll}
\hline Upward propagation & $4.1 \%$ \\
Horizontal propagation & $6.0 \%$ \\
Downward propagation & $9.0 \%$
\end{tabular}

Shapiro and Moffette (1957) provide a ternary diagram of flammability limits (Figure IV.E.1) generally applicable to in-containment phenomena. More recent data show that the detonation limits are slightly worse than shown here. EPRI tests of continuous hydrogen combustion in a large spherical vessel (Thompson, 1984) show that the pressure developed in hydrogen combustion is extremely sensitive to hydrogen concentration in the range 


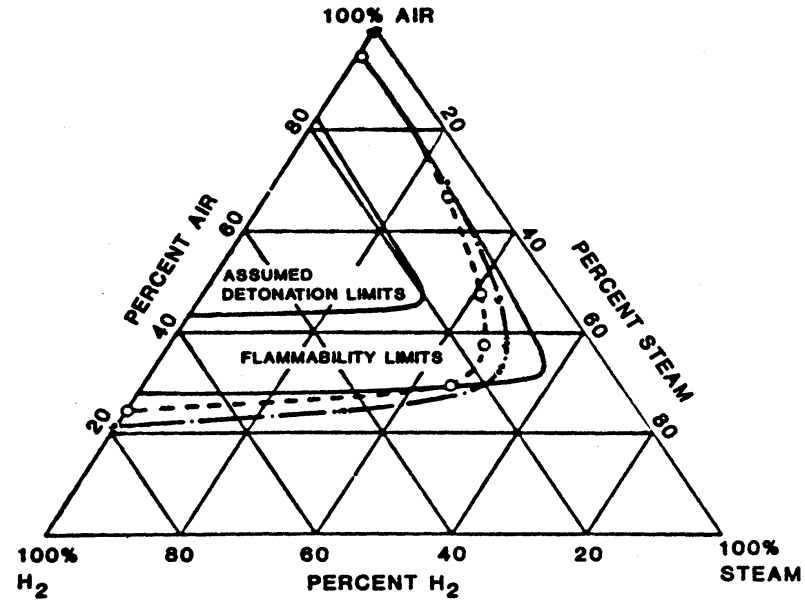

FLAMMABILITY LIMITS

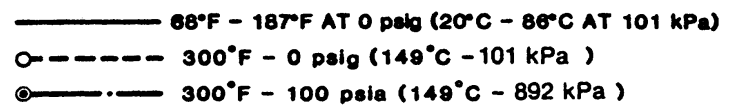

FIG. IV.E.1. Flammability and detonation limits of hydrogen:air:steam mixtures, from Shapiro and Moffette (1957). The detonation limits may be a little worse than shown here, according to recent data.

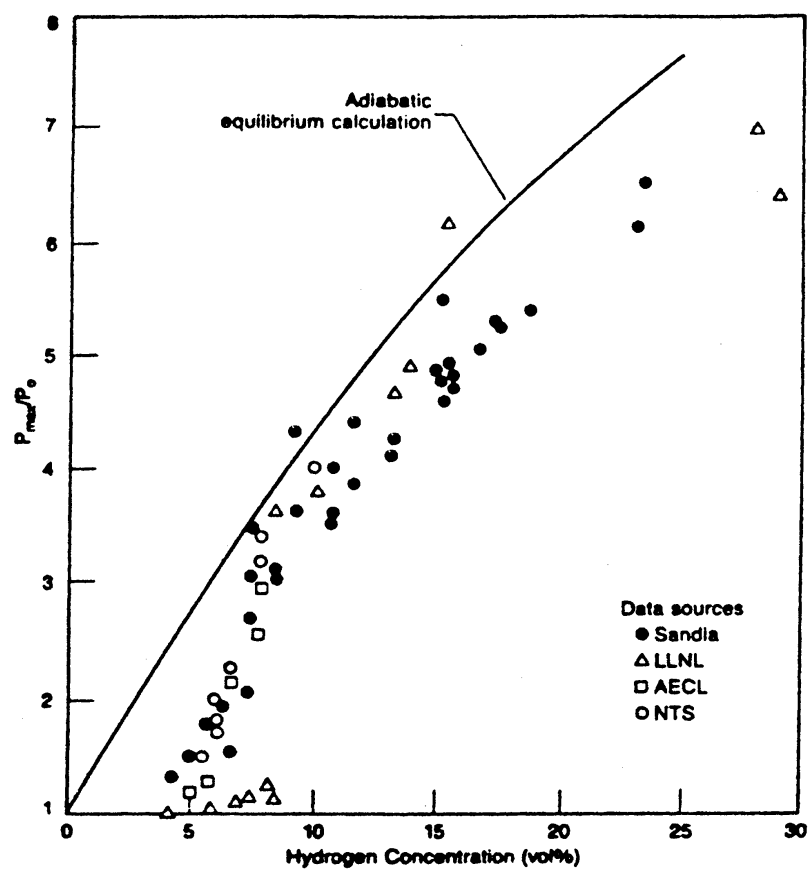

FIG. IV.E.2. Peak combustion pressure: large- and small-scale tests, from Thompson (1984). of $4 \%$ to $10 \%$ hydrogen (Figure IV.E.2).

The failures caused by hydrogen combustion $(\gamma$ failures) have been examined in more detail since the Reactor Safety Study (NRC, 1975). First, it is important to distinguish a detonation (or true explosion) from a deflagration (or rapid burning). In the former a shock wave is formed; in the latter it is not. The situation is different in different containment types.

For the large dry containments, there might be local deflagration (as occurred at Three Mile Island about 1 p.m. on March 28, 1979). At the time when the containment is first stressed by the reactor pressure vessel melt-through, there was enough steam to inhibit combustion for the calculations that the study group considered. (See Figure II.E.5.)

Hydrogen is more of a threat to the other containment types that have a much smaller volume. Moreover ice condensers can remove the steam but not the hydrogen, making both the deflagration and detonation more likely. To reduce the hydrogen concentration, igniters are often installed at many points. Should the igniters fail to function for a time, the hydrogen concentration is likely to build to a level where a general deflagration could overpressure the relatively weak shell. Alternatively, it is speculated that hydrogen could stratify in a region above the ice beds to a level which might detonate if a spark or disturbance occurred.

A large hydrogen explosion is not expected to occur since there are no confined conditions for its propagation. In a containment vessel, deflagration could be complete in a tenth of a second. The pressure rise comes from an adiabatic increase in temperature of the gas as it burns, and the rise falls away only slowly with a time constant of the order of minutes as the heat is conducted to the walls and other surfaces. This time is long compared with the natural containment response period.

The considerable uncertainty in predictions of the quantity of hydrogen produced during core melts leads to corresponding uncertainties in predicting failures. For example, Cybulskis (1984) calculates that $800 \mathrm{lbs}$. of hydrogen could be generated in the core in the TMLB' sequence at Sequoyah by reaction of $50 \%$ of the zircalloy cladding with water. The pressure increase resulting from deflagration of this hydrogen, if not slowly reduced by the igniters, is calculated to be in the range 68 to 150 psia in a containment likely to burst above 65 psia. (These calculations arbitrarily assumed $8 \%$ hydrogen at combustion.) On the other hand, Kenyon (1984) predicts that only about $350 \mathrm{lbs}$. of hydrogen would be generated in the same sequence, leading to a pressure spike of only 40-55 psia. (Both these analyses have since been revised toward consensus.) These differences point up the importance of gaining better insights into the detailed phenomenology of the core degradation process and the details of hydrogen combustion. If the igniters slowly burn the hydrogen at regular intervals, heat conduction and steam condensation will prevent the large pressure rise.

Other uncertainties relate to the modeling of the combustion process. If combustion were to occur at low hy- 
drogen concentrations, then there is less pressure buildup than if combustion occurs only after the hydrogen concentration has built up to a high threshold. For example, Cybulskis (1984) predicts pressures of only 30-48 psia for Sequoyah if hydrogen could be combusted as soon as it forms, rather than being allowed to build up to a concentration of $8 \%$ by volume as in the previous paragraph.

Hydrogen burning may not be the direct cause of containment failure but may add to the pressure spike from the other events at reactor vessel failure. Moreover the pressure rise can be rapid-less than a second-and can give a transient stress to the containment at a particularly bad time.

This emphasizes the importance of detailed calculations of the effect on the containment of multiple stresses-one varying slowly with time and another, or others, varying more rapidly, and superposed on the slow variation.

Hydrogen threats also exist in the secondary region of the BWR Mark III containment. There is some concern there that hydrogen could burn above the suppression pool leading to overheating of the dry well wall and creating openings in that wall which bypass the suppression pool (see Figure IV.D.6).

Initial pressure spikes are not a problem in a BWR if the suppression pool accepts the molten fuel or if the fuel forms a pool in the drywell. However, sequences TC and TW in a BWR might occur in which the pressure suppression pool is heated up enough to pressurize the containment, possibly to the point of failure. The core debris may fall into a containment vessel which has already or nearly failed through overpressure. If the failure is in the drywell, as is likely in Mark I or Mark II, escaping gases bypass the suppression pool. The Mark III containment, which fails in the secondary vessel beyond the pool, avoids bypass of the pool (except for the overtemperature failure possibility described in the previous paragraph).

IV.E.3. Steam explosions (rapid phase

transitions; superheat explosions)

Another phenomenon of sufficient violence to breach the containment was postulated in the Reactor Safety Study (NRC, 1975). This is a steam explosion as the molten core hits the water in the bottom of the RPV leading to the $\alpha$ sequence, in which a very large explosion sends a large fragment of the RPV through the containment. It was judged to occur in one meltdown out of 100 . In view of the potential importance of the postulated phenomenon, the subject has received considerable study. It now appears that small steam explosions usually occur, but the likelihood of an explosion large enough to fail the containment is considered by most investigators to be much smaller than assumed in the RSS and regarded as impossible by a few.

The nature of the interaction between molten fuel and water is all-important. On the one hand, the heat may be transferred slowly-over a course of a minute or sobetween the two liquids. On the other hand, if there is a mechanism to convey thermal energy promptly (within milliseconds) from one to the other, thermal energy can be converted to mechanical energy.

With a large prompt release of mechanical energy, a shock wave can be set up which will stress the various components more than any simple expansion. Such a mechanism is the superheat explosion.

In a few (non-nuclear) industrial accidents, explosions took place as molten iron fell onto wet ground. Yet there was no sign of a chemical interaction, or even of much heat generation. This is a physical, not a chemical, explosion. The basic mechanism is now fairly clear. When a hot liquid is poured onto a cold one, the cold liquid becomes at first superheated above its boiling point. This stores the energy. Some triggering mechanism starts the evaporation of the first few molecules, and the rest rapidly evaporate.

The detailed mechanism of the superheat explosions is unclear, but a few principles clearly enunciated by Fauske (1972) seem to be correct. Firstly, the rapid vapor generation needed for an explosion can only be provided by spontaneous nucleation at the liquid-liquid interface, because there are simply not enough nucleation centers from impurities or ionized molecules. In spontaneous nucleation, bubbles form in a pure liquid against the normal surface tension. The spontaneous nucleation temperature $\left(T_{s}\right)$ is well defined by the equation, $T_{s}=16 \pi \sigma^{3} / 3 p_{v}^{2} k$, leading to a well defined lower threshold for explosions where $\sigma$ is the surface tension, $p_{v}$ the pressure of the vapor, and $k$ is Boltzmann's constant. This quantity is sometimes called the superheat limit temperature $\left(T_{\mathrm{sl}}\right)$, because no liquid can be heated beyond this limit.

The next point is that the interface temperature between the two liquids, $T_{i}$, must be above the spontaneous nucleation temperature. Fauske's (1972) necessary criterion for liquid/liquid explosions is that

$$
T_{i}>T_{s}\left(=T_{\mathrm{sl}}\right) \text {. }
$$

This lower limit for superheat explosions seems well verified in a series of experiments. Henry et al. $(1974,1975)$ demonstrate the reproducibility of the threshold (327 K) for water at $349 \mathrm{~K}$ in freon 22 (at $313 \mathrm{~K}$ ) and similarly for mineral oil poured on propane. In the few cases where it appears to be violated, the violation can be explained by postulating that the cold liquid (or a small portion of it) at first warms slowly up to this temperature. There seems to be no disagreement that in a LWR accident the interface temperature will exceed the spontaneous nucleation temperature and this condition will be met.

An additional requirement is that the difference between the interface temperature and the spontaneous nucleation temperature be not too large-of the order of tens of degrees. If it is, the interface between the two liquids is likely to be blanketed by a layer of vapor that prevents further contact. It is evident that this upper limit of temperature is not well defined and is critically dependent on the details of the mixing of the two liquids. For example, explosions were not initially observed when liquid methane [the principal component of LNG (liquified 
natural gas)] was poured on water (Burgess et al., 1972) even though the interface temperature exceeded the spontaneous nucleation temperature-although explosions were observed when liquid propane was poured upon water. However more recent experiments produced explosions when liquid methane was injected onto water in vacuo by breaking a Dewar flask, and more recently in tests of larger scale (Koopmans et al., 1981). These LNG/water tests are of a cold liquid ( $\mathbf{L N G}$ ) poured onto a hot liquid (water). Yet these are similar to the uranium melt (hot liquid) poured onto a cold liquid (water) in that the interface temperature greatly exceeds the spontaneous nucleation temperature, and therefore blanketing can and frequently does occur.

Still a further condition for a large explosion is the obvious one that there must be a large surface area where the liquids are in contact so that much material can interact simultaneously. This can be achieved by fragmenting the fuel below $1 \mathrm{~cm}$ diameter. If one liquid is gently poured upon another it seems that it is hard to create a large surface area. However if one liquid is forced by pressure upon another, it might fragment to generate a large surface area. Further, Board and Hall (1974) have suggested that a first explosion itself might be the fragmenting mechanism, causing a detonation wave-and perhaps a source of nucleation centers as well.

There thus appear to be three requirements for a superheat explosion: a hot liquid at above the spontaneous nucleation temperature of the cold liquid, avoidance of vapor blanketing at the interface, and large contact area.

Whether these requirements can be satisfied to a sufficient extent to cause a large invessel explosion (sufficient to lead to an $\alpha$ containment failure) is now thought unlikely. The Reactor Safety Study was primarily concerned with an in vessel explosion. It was assumed that (1) substantial amounts of molten core material can enter the water in the lower plenum within a time less than 100 $\mathrm{ms}$; (2) the debris is instantaneously fragmented to particles of $1 \mathrm{~cm}$ diameter or less and dispersed throughout the pool; and (3) the explosive energy is collected on a liquid overlying slug which is propelled upward against the vessel. This could break the vessel and carry the reactor vessel head upward to fail the containment.

There was no detailed calculation to show whether this was possible and it was somewhat arbitrarily assumed to occur in 1 out of 100 core melt accidents.

Based on interpretation of their experiments, workers at Sandia (Snyder, 1982) assign probabilities of large explosions of $10^{-4}$ per core melt. Although they assign large uncertainties to this assignation Henry et al. (1983) believe that energetic steam explosions large enough to fail the reactor vessel cannot happen because of the limit of the amount of fuel which can interact with water in a short time. It is unfortunate that this probability must remain judgmental. But the judgment of experts seems unanimous that the probability is low as discussed further in Appendix III.

An effect of a (very probable) small steam explosion in the vessel might be to influence the course of an accident in an uncalculable and possibly adverse way, and in particular to cause the resuspension of deposited radioactivity. In addition it can fragment the fuel which would accelerate the release of the low volatile radioactive species and make the oxidization of the fuel more rapid, that in turn would heat up the containment atmosphere and further stress the containment.

Recent Sandia tests (Berman et al., 1983) indicate modest steam explosions to be a likely outcome when hot fuel drips into water. These phenomena would redistribute core internals and debris to an extent that might affect thermal-hydraulic processes. Probability studies indicate that vessel rupture is a less probable outcome of a larger steam explosion. The extreme possibility is a very large event somehow involving many tons of molten fuel interacting with water, leading not only to vessel failure but to a containment failure. The experimental base with molten fuel-type materials is weak. Experiments up to 100 times the scale of earlier tests are planned. Sufficient large-scale testing should be conducted to determine if there is a natural limit to the scale of these events. (A brief review of some existing data on liquid-liquid explosions is given in Appendix III.)

Steam explosion phenomena are likely to occur exvessel when molten fuel drops into pools of water. While these events are not likely to cause containment to fail directly, they can influence debris configurations (disperse fuel in fine particles), influence thermal-hydraulic phenomena, and possibly disable in-containment equipment. This is an unexplored area.

\section{IV.E.4. Late containment failures}

After the core has fallen to the concrete base mat, and still assuming no mitigating features such as sprays, the core will generate gases, hydrogen, and $\mathrm{CO}$, and the gases already in the containment will heat up further. If there is no leak, this is expected to cause a containment failure $\left(\delta_{2}\right)$ after many hours or several days. During this time, some of the suspended aerosols will deposit.

It is also possible that the core may melt through the concrete base mat. Basemat melt-through $(\varepsilon)$ is predictable using the CORCON code for sequences where a molten pool of fuel melts its way through the floor of the containment building. The source term released to the biosphere by this mechanism is several orders of magnitude less than through even a late $\delta$, because the ground acts as a very effective filter of nearly all radioactive isotopes excépt the noble gases, which it holds up and delays. The failure does pose a threat to local aquifers. However, fission product travel time is slow and countermeasures to retain the fission products within a limited region are capable of containing the accident. This is a problem that contributes to property damage but, if recognized and controlled, need not contribute to public health effects.

However, some calculations suggest that the core will solidify before going through the basemat, and the containment might never fail by this mode. 


\section{IV.E.5. Earthquakes}

An earthquake greater than the design basis earthquake might be extremely troublesome if it not only sets off a Loss of Coolant Accident but also makes holes in the containment. We are aware of no detailed analysis, in the context of source term issues, of these correlated possibilities, although in the Probabilistic Risk Analysis for Indian Point, the probability of core melt caused by an earthquake is estimated, and is one of the dominant risk sequences.

\section{IV.E.6. Summary}

It is necessary to define containment loading accurately in order to predict containment failure and therefore to calculate the source term. As was discussed in III.C.1, calculations of the initial steam spikes can be made with reasonable accuracy and they are not expected to cause gross containment failures. The late challenge to containment from core-concrete interactions is also reasonably predictable. Significant needs exist for research into those mechanisms and rare events that could conceivably lead to early containment failure and a relatively large source term, i.e., direct heating of the containment by molten fuel and metal-steam explosions, and earthquakes. For some containment types (Mark III BWR, and ice condenser) there are also residual uncertainties regarding hydrogen burning which should be investigated further.

\section{COMPUTER CODES AND THEIR VALIDATION}

\section{V.A. The uses of computer codes}

The central part of the program of the Nuclear Regulatory Commission is a suite of computer codes which are supposed to predict the course of an accident once it has been initiated down to the final release of radionuclides. However it is obvious that the output of a computer program is only as good as the completeness of the important phenomena included, the validity of the equations incorporated, and the accuracy of the input data.

The minimum result of using a good suite of computer programs is to transfer the understanding gained in the study of one reactor to a similar reactor with slightly different characteristics. A more important use of complex computer programs is to study the interrelationships among different phenomena.

In Section III.A general features of reactor accidents were described. In Chapter IV the various physical and chemical phenomena important for discussing these accidents were described. A series of models has gradually evolved and has been developed by various user organizations (such as the NRC, IDCOR, etc.). These models have been collected in several sets of codes for evaluating and integrating the separate parts of the accident as it progresses from its initiation to the point at which radioactive material is released to the environment. The models incorporated in these codes range in sophistication from the exclusively empirical, in which experimental data are conveniently parametrized, to others that utilize the basic physical laws in a mechanistic way to calculate the dynamical progression of a part of the sequence. In this chapter we discuss the various codes and their reliability.

Estimating the consequences of a particular accident sequence requires the sequential running of the codes using appropriate reactor parameters for each of the models. After proper manipulation, the output of each code provides input to the next code in the sequence. Since no light water reactor (LWR) accidents or experimental studies have involved complete meltdown and containment violation, the models cannot be checked by comparison to observations. For that reason one must be especially wary of the use of these models for detailed estimates of what will occur in a particular complex situation. However, isolated portions of the accident sequence or individual mechanisms in a particular model can be tested by smaller-scale simulation.

The use of the models and the associated computer calculations provides an indispensable tool to sharpen our intuition and to suggest new ways to conduct experiments to gain understanding of accident mechanisms. These models also permit us to explore the sensitivity of individual mechanisms to changes in reactor parameters and to assess their significance in the fission product release or retention processes. New ideas may be tested in a straightforward way by exercising the codes and may be incorporated into the models if they prove to be important. More important still, this is the only way to understand the iterative feedback effects.

Approximations made in developing models for use in computer codes include compromises whose effects are uncertain. Since our knowledge of the phenomena and the experimental data base is incomplete, the technical judgment of the analyst must be relied upon to choose the key elements in constructing and operating the code. Different analysts may choose different elements. The effect of these different choices needs investigation. Clearly the result of a complex calculation may be significantly affected by these different choices. The reason for such effects may be poorly understood, even by the analysts themselves.

As our understanding has grown under the stimuli of new experiments and improved calculational techniques, the numerical models of the individual codes have gone through a continuous process of evolution. For this reason, one finds that a particular code may have vestigial parts that have been superseded by other codes in the sequence. This can cause an internal lack of consistency among the parts of a complete calculation; such examples will appear later as we discuss the models in more detail. Another possible problem with consistency arises because at present each code feeds into the next without provision for feedback into the code elements that have been run previously; it is in just this feedback that a computer code is of most use. As a result, for example, in current calculations the dense clouds of vapor and aerosol released during the core melt period cannot influence the heat transfer 
calculations that provide the bases for estimating the temperature dependent release rates from the molten fuel. However, new codes that are now being developed have at least partially corrected the generic feedback deficiency. Fully integrated codes are projected for the future if the research program of the NRC continues in its projected path.

The detailed results of complex codes must be treated cautiously. Insights gained may not be generally applicable. However, the codes do provide understanding of complex phenomena which cannot be studied in other ways. This is their primary utility.

\section{V.B. A sample suite of accident model codes}

The models used in the Accident Source Term Reassessment Study (ASTRS) by the NRC and their contractors provide a coherent example of how the processes given above are described by a set of computer codes (see Figure V.1). The shortcomings of these codes are typical of any rapidly changing field; they will be reduced with time and improved data. We could equally well have chosen a set of codes used by the IDCOR project; however, they make use of many of the models (old and new) from the codes we shall describe. Where another code contains an alternative to the model we discuss, we shall try to indicate that at the appropriate point.

In general in this chapter, an attempt is made to follow the chronological steps in an accident sequence, as was done in the general discussion of nuclear accidents in Section III.A.6. But a comparison of the accident steps in Table III.A.2 and the computer code progression in Figure V.1 shows that this is not completely possible.

\section{V.B.1. The inventory of radionuclides}

in the fuel (ORIGEN)

As an initial condition for the hypothesized accident scenarios, it is customary to assume that the reactor has already been operated at steady, full power conditions for an extended (e.g., three-year) period. During this time, it is assumed that the fuel in the reactor has been changed in accordance with normal refueling procedures, in which one-third of the fuel would be replaced at each of two prior annual refueling operations for a three-year cycle. It is further assumed that radioactive products have built up in the fuel elements and the structural materials in a normal fashion over the three years of full power operation. Thus, the first information that is needed for the estimation of the source term is a detailed inventory of the radioactive isotopes in the core. It is determined using ORIGEN-2 (Croft, 1983). This code must be supplied with the reactor type, and the fuel consumption and the power level versus time at each point in the core. Internally, the code requires nuclear reaction cross sections, fission yields, and decay schemes for all nuclides that will be involved in the chain of reactions. The set of coupled, linear, first order differential equations is solved numerically to give the decay heat and the inventory of isotopes. The results are in reasonable agreement with the observed

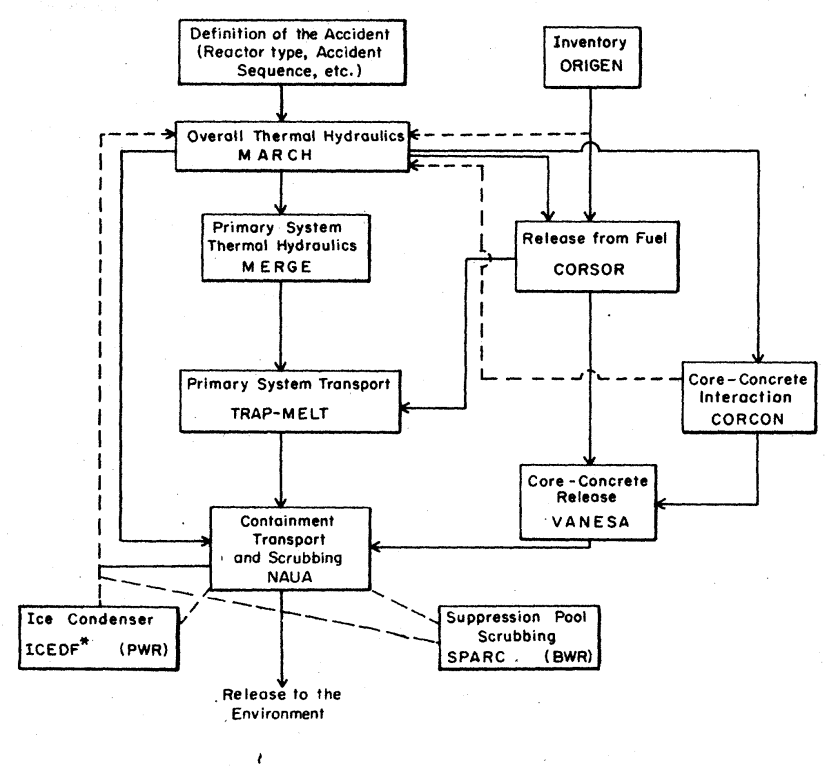

FIG. V.1. The suite of codes used by the NRC (and their subcontractors) in evaluating the consequences of hypothetical reactor accidents. The solid lines indicate that the results of a particular code are required as input by other codes in the sequence. Dashed lines indicate that MARCH uses internal subroutines with functions similar to those of ORIGEN, CORCON, SPARC, and ICEDF. *ICEDF is unfinished; a modified version of NAUA is used now.

decay heat and the abundances of selected isotopes in fuel elements from a number of reactors. Where the final product (e.g., tritium or ${ }^{14} \mathrm{C}$ ) arises from an illcharacterized contaminant in the fresh fuel, the comparisons are less favorable. Generally, the accuracy of the calculation of radioactive product inventory is thought to be sufficient for the source term determinations. However, in the United Kingdom somewhat different inventories are obtained with their code FISPIN (e.g., comparable Cs, but smaller amounts of $\mathrm{I}$ and $\mathrm{Te}$ ). This may reflect the assumption of a flatter radial power distribution in the reactor, to which the final inventory is moderately sensitive (Butland, 1983). These differences are probably not important in themselves, but they make the task of comparing computer output, to discover the underlying physical reasons for the differences, somewhat more difficult.

\section{V.B.2. The thermal hydraulics code (MARCH)}

Figure V.1 shows the key role played by the code that calculates the thermal and hydraulic behavior of the reactor coolant system (RCS). The code MARCH-version 2.0 is the latest in a series of such codes that provides the basic pressure, temperature, and material inventory information used by the codes that follow it in the calculation of a particular accident (Wooton and Cybulskis, 1983). A replacement, MELCOR, is planned (Camp et al., 1983) to remedy some of the patchwork that characterizes $\mathrm{MARCH}$, 
but at the moment we have only MARCH and its counterpart in IDCOR studies, MAAP (Jaycor, 1983).

\section{V.B.3. Details of $\mathrm{MARCH}$}

Starting with the decay heat output from a subroutine which takes the ANSI 1979 Standard (Section III.A.3) (plus the fission generated power if the reactor protection system is assumed to fail), MARCH calculates the thermal input to the water in the reactor cooling system. The ANSI Standard is a good approximation to the output from ORIGEN. ORIGEN is used when the fraction of decay heat from each group of radionuclides is needed. MARCH keeps a detailed inventory of the water and steam including the intermittent flow contributions from the various external cooling sources such as the emergency core cooling systems (ECCS), and in particular the accumulators. The set points of pressure relief valves (PRV) are considered, as well as the location of any leaks or breaks in the cooling system. This part of the calculation, until the core is uncovered, is very simple, and in MARCH the primary system is modeled as a single volume. Empirical (experimentally derived) correlations are used to describe the heat transfer and fluid flow. For example the flow of coolant in the channel between the fuel rods within the core is described in terms of an incompressible fluid in a pipe. This can be checked against simple, back of the envelope calculations such as those of Section III.C above.

In MARCH the reactor core is treated as a cylinder of axially stacked, concentric rings. The rules for heat conduction and radiation among these rings and to the surrounding structures crudely reflect the actual distribution of material in the fuel rods. As water is lost from the RCS, the core is uncovered and the rules for the uncovered rings are modified to include the loss of conduction to the coolant, the addition of heat from the oxidation of zirconium present (assumed to be mixed with the fuel), and the associated generation of molecular hydrogen, $\mathrm{H}_{2}$. One should note that such oxidation rate data as functions of temperature and oxide thickness are sparse. The effect of the zirconium channel boxes in BWR's is modeled very crudely by increasing the effective thickness of the cladding that is adequate for calculations in which the total amount of zirconium is important, but is not likely to be a very good approximation when spatial variations of zirconium reactions are important.

As a reactor accident progresses, the water level continues to drop and the temperatures of the core regions rise. As a region reaches the "melting point" selected for the $\mathrm{Zr}-\mathrm{UO}_{2}$ mixture, the MARCH code prescribes "rules" for dealing with the melting of the region. These are probably the greatest uncertainties in the model. Models, such as the "MARCH" code, assume melting starts once the assigned melting temperature is reached. In some other models, for example those developed in West Germany where considerable research has been done on core melting, cladding failure is treated in a probabilistic manner; the character of the surface being attacked is, after all, random and this will affect how rapidly the cladding will burst. A variety of options exists in the code, but basically the geometry of the fuel is assumed to be constant, so that any fuel damage has no effect on coolant flow or conduction until under a particular option the molten fuel is dropped into the lower head of the reactor vessel. In the alternate code MAAP (used by IDCOR) there is an attempt to model the melting of the core regions individually, taking into account changes in the area available for coolant to interact.

As molten core material accumulates in the lower head under the option chosen in MARCH, it begins to attack the reactor vessel. This attack must also be modeled because it leads to penetration of the RPV and the injection of hot, molten core material into the containment building. During this process the code must track the amount of molten material, its composition, its remaining heat sources (fission products, metallic $\mathrm{Zr}$, and steel), and its temperature. Although it is expected that failure of the RPV will first occur at welds and instrument penetrations, the attack on the lower head is modeled by a onedimensional, uniform erosion calculation. The combination of the attack and the thermal and hydraulic loading cause the eventual failure of the vessel, the timing of which is determined by the MARCH calculation. The failure of the vessel with release of steam and $\mathrm{H}_{2}$ creates the pressure spike discussed in III.C.1 and IV.A, that challenges the containment integrity. This challenge includes interaction of the core material with standing water in the reactor vessel cavity.

To complete the overall thermal-hydraulic evolution of the system, MARCH contains its own models for $\mathrm{H}_{2}$ and $\mathrm{CO}$ combustion, suppression pools, sprays, and ice condensers even though all these features are handled in more detail and with greater accuracy by other codes. It seems crucial that these parts of $\mathrm{MARCH}$ be made as accurate as possible because they influence the estimates of the loading on containment that allow the timing of possible containment failure to be determined. An example is provided by the uncertainties in the $\mathrm{H}_{2} / \mathrm{CO}$ combustion level and in the operation of igniters, which are supposed to burn $\mathrm{H}_{2} / \mathrm{CO}$ before it reaches dangerous levels. In MARCH combustion is not treated mechanistically but is a user specified process that does not calculate burn time, flame propagation, etc. The new code CONTAIN will provide a better treatment of combustion in containment (Bergeron, 1984).

\section{V.B.4. MERGE}

The flow of steam and $\mathrm{H}_{2}$ through the RCS is calculated with MERGE (Freeman-Kelly and Jung, 1982) using the input pressure, temperature, and composition data from MARCH. The flow is considered to be one dimensional through a sequence of series-connected, well-mixed volumes that represent the portions of the reactor pressure vessel above the core, the piping, the pressurizer, etc. In each volume the equations of state for steam and $\mathbf{H}_{2}$ are used together with the conservation of energy and the heat transfer to the structure to calculate the flows and 
temperatures in the RCS. These results thus establish the residence times, condensation and evaporation rates, phase partitioning, and thermophoresis (deposition of aerosols resulting from temperature gradients near surfaces) for the transport of materials from the melting core through the primary system. The momentum equation for the flow is not solved; the output of MARCH is taken as correct. No calculations have been performed to determine if the MERGE solution obtained in this way satisfies the momentum equation. Instead it is assumed that the pressure equilibrates in each time interval calculated.

The approximation in the MARCH/MERGE combination that probably creates the greatest uncertainty is that of a one dimensional series flow. This omits the natural circulation mentioned in Section IV.A.5. From the expected flow rates and temperature gradients during some parts of the accident sequence, two-dimensional flow calculations show that recirculation within the core and upper plenum volumes of the reactor vessel should occur (Seghal,1984).

The new EPRI code (COREMELT) that is being developed (Denny, 1983) models natural circulation as well as more detailed fuel slumping. This code predicts much longer times for the core heatup period, with large $\mathrm{H}_{2}$ production and important consequences for containment loading. This program is not predictive, since the convective cell patterns are prescribed.

Recirculation patterns within the pressure vessel itself cause mixing and support the assumption of well-mixed volumes used by MERGE and TRAP-MELT. It is, however, not clear that piping is accurately treated as a well-mixed volume; this probably influences the estimate of trapping of radionuclides in these pipes at high flow rates. One must also mistrust this treatment of the complex upper plenum region.

The NRC is sponsoring code development at two places. SNL has a computational program aimed at obtaining a more thorough understanding of the core melt down process. The code is called MELPROG. A thermal hydraulic code called TRAC, developed at LASL is being adapted for use with MELPROG. The TRAC code will handle both two and three dimensional hydrodynamics. At INEL a new version, RELAP5-MOD2, of an old, onedimensional hydrodynamic code, RELAP, has been developed in order to adapt RELAP code to the two- and three-dimensional problem of flow past an obstacle that develops as a consequence of core degradation. Thus, RELAP5 has some capability to handle the higherdimensional, more realistic fluid flow configurations required in a serious research program on core melt down. An example of the use of RELAP5 can be found in Schultz et al. (1984).

A new model, SCDAP, is being written at INEL to deal with the fuel damage part of the sequence. This will be incorporated into RELAP5, and probably also into the IDCOR program MAAP. It should provide a better treatment of fuel melting. The intense generation of steam and $\mathrm{H}_{2}$ produced as the molten material falls into the water in the lower head is very sensitive both to the slumping models and to the heat transfer between the molten metal and the water. This leads to a large uncertainty in the thermal-hydraulic behavior at a critical point in the sequence and has been handled by assuming limiting conditions as discussed in III.C.1 and IV.A.6.

A detailed study of codes and a numerical analysis of core melt down would be of relatively little value were it not possible to compare the output of the theoretical effort with experimental results. Both SNL and INEL have experimental in-pile programs to study core degradation. The progress in these programs deserves to be watched carefully to make sure that they are well coordinated with code development.

EPRI is sponsoring scaled flow experiments, using water or $\mathrm{SF}_{6}$ in a scaled down model of a PWR primary system at Westinghouse that simulates reactor conditions using resistive heating elements. ANL is developing a fully three dimensional thermal hydraulic code known as COMMIX-1 for EPRI. This is probably the most ambitious one in attempting to represent the wide range of flow patterns and heat transfer modes that may arise under real accident conditions. The presence of solid, material structures in the flow field, i.e., the core and its support structure, etc., complicates the thermal hydraulic calculations. Such structures occupy space and thus restrict the volume and area available to the fluid; they also offer resistance to the flow (via friction, drag, etc.) and they represent sources or sinks for heat. These aspects of solid-fluid interaction are modeled in COMMIX in terms of appropriately defined volume porosities, surface permeabilities (to take into account the space occupied by solids), distributed resistances to flow and distributed heat sources and sinks. Within the framework of these approximations, COMMIX is then able to carry out either one-dimensional, two-dimensional, or fully three-dimensional calculations as needed.

It is unlikely that these new three dimensional codes will be incorporated into the NRC suite of codes for routine calculations, because the length of time for a complete calculation becomes very long. However it is very important to run them for a few selected sequences to make sure that the approximations made in the old one dimensional codes do not lead to significant errors in the calculated source term.

One factor that deserves more attention is the neglect by MARCH/MERGE of the decay heat generated by material transported out of the reactor core. For some accident scenarios the calculations indicate that significant quantities of the volatile fission products are deposited on surfaces in the upper plenum of the reactor coolant system. This source of heat to other surfaces within the RCS will modify the overall thermal hydraulics, and thus could play an important role in the re-evolution of some of the deposited material. Such effects have been estimated to be important in IDCOR calculations, in which they are patched onto the overall system behavior given by MAAP.

A group at the New York Power Authority (NYPA) has written a vectorized code that integrates the functions provided by MARCH, MERGE, CORSOR, and TRAP-MELT (Deem and Bieniarz, 1984). This has allowed them to 
provide estimates for the TMLB' and $S_{3} D$ sequences at the Indian Point reactor. These results indicate that the temperatures of surfaces in parts of the RCS outside the RPV are much higher than those determined without including the effects of fission product heating. They calculate that retention of $\mathrm{CsI}$ and $\mathrm{CsOH}$ are significantly reduced on these surfaces (a factor of $\sim 3$ ) and that one should even consider the possibility of local RCS failure owing to this heat source. As already noted in Section IV.A.5, if such a failure occurs at the steam generator, this could transform the TMLB sequence to a containment bypass sequence (V). Even if this does not occur, the absorption and rerelease of the fission products on these surfaces can lead to calculated final releases higher than if there were no absorption at all, for they might form small aerosols just at the time that the rise in pressure from the core-concrete interaction causes containment failure, and thus be re-dispersed.

\section{V.B.5. Modeling of fission product releases} (CORSOR)

During the heating and melting of the fuel, vapor is emitted from the uncovered core. Thus, in order to provide quantitative estimates for the release rates of radioactive material into the core regions, MARCH, the code describing the thermal hydraulics of the accident, must interact with the code CORSOR that describes the model for fission product emission from the molten fuel.

Although Power Burst Facility (PBF) tests have shown an enhanced release of fission products as the molten fuel is quenched on falling into the water in the lower head, this effect is not yet incorporated into MARCH. Such effects can also happen if the hot core is reflooded; even though slumping has not occurred, this can lead to fragmentation of the fuel and enhanced fission product release.

CORSOR uses the core element temperatures provided by MARCH to calculate the emission of material from the melting core (Lorenz, 1983). The model used is completely empirical (see Section IV.B). The mass element $x$ is emitted at a rate $d M_{x} / d t=-k_{x} M_{x}$, where $k_{x}$ is obtained by fitting the experimental data to the functional form, $k_{x}=A_{x} \exp \left(B_{x} T\right), T$ is the temperature and $A_{x}$ and $B_{x}$ are fitting parameters chosen separately in three temperature regions. It is curious that an Arrhenius form for the emission rates $[\exp (-$ Activation energy $/ k T)]$ was not chosen instead; however, the present approach is probably adequate and includes (where they are known) effects such as the modification of emission rates owing to the concentration of metallic $\mathrm{Zr}$ present. This effect is influenced by the $\mathrm{H}_{2}$ /steam mixture and can change the emission of $\mathrm{Te}$ by a factor of 40 . It is not understood if such effects also occur for $\mathrm{Ba}, \mathrm{Ru}, \mathrm{La}$, etc., owing to the presence of $\mathrm{Zr}$ or stainless steel; however, such questions are being examined in small-scale tests at ORNL and PBF. As one might expect the emission data are best for the higher volatility substances; better data are needed for lower volatility materials.
The deficiencies of the empirical approach in CORSOR lie in the paucity of high quality data taken under conditions appropriate to the accident sequence considered (e.g., the time of fuel irradiation, high pressure, or the amounts of steam, $\mathrm{H}_{2}$, and $\mathrm{Zr}$ present). In addition, effects from the control rod, structural, and channel box (BWR) materials are handled crudely. The interaction of these materials with the molten fuel may produce chemical species or alloys that appreciably modify the emission or deposition of the materials leaving the core; thus, it is important that a better model for the melting of these materials be developed. Such effects can be subtle; for example, minor components in the stainless steel (e.g., Mn) or the cladding (e.g., Sn) could be more important than their concentrations would imply, because they have higher vapor pressures than the major components. CORSOR also ignores effects on the emission processes caused by changes in the surface area to volume ratio of the molten core during the late stages of the meltdown.

The chemical form of the materials at this point is taken from separate equilibrium gas phase kinetic calculations. These calculations do not involve all constituents at once, but attempt to determine only the most stable products, e.g., I is emitted as CsI, the remainder of the Cs as $\mathrm{CsOH}$, etc. (see Section IV.B). The code does not keep track of all possible compounds, but only those that are most probable-even though several may be likely. This treatment does not consider the change in the chemical environment from a highly oxidizing one (steam) to one that is more reducing as the fraction of $\mathrm{H}_{2}$ increases. The effect of control rod elements (Cd, $\mathrm{Ag}, \mathrm{In}, \mathrm{B})$ on these equilibria have not been considered in detail. A new code, VICTORIA, is being written to incorporate most of these effects (Camp et al., 1984).

\section{V.B.6. Transport and deposition}

of fission products (TRAP-MELT)

The code MERGE uses the information from MARCH on flow of vapors and coolant to calculate the system pressure and the temperatures of the individual components. The code MERGE can then use this information to calculate the flows through the whole RCS, and the code TRAP-MELT calculates the transport of material from the melting core under these flow conditions. MARCH calculations were in good agreement with small-scale tests at PBF; however, as shown in similar calculations in the United Kingdom (Butland, 1983) the distribution of deposited material is very sensitive to the details of the thermal hydraulics.

As vapor that has been emitted from the core region moves through the RCS it is subject to a variety of depositional processes. Taking as input the flows and gas and surface temperatures from MERGE together with the source rates from CORSOR these effects can be estimated. Figure V.2 provides a schematic diagram for the processes included in the code TRAP-MELT (Jordan et al., 1979).

Airborne materials are retained in the RCS owing to condensation or chemisorption on structures, or condensation on aerosols which subsequently deposit on struc- 


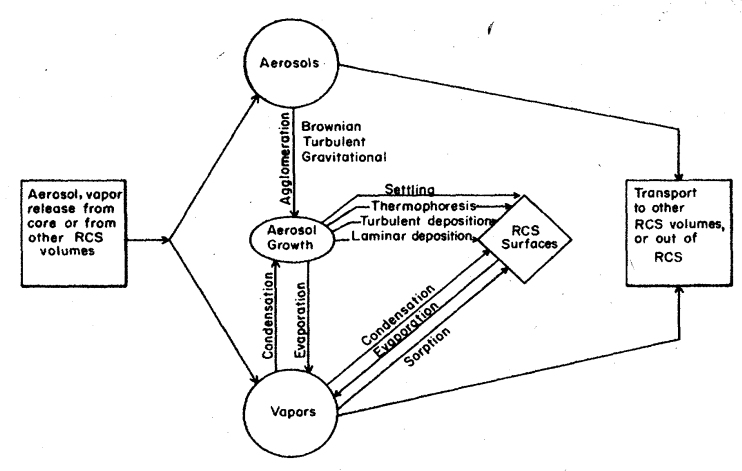

FIG. V.2. Aerosol/vapor deposition mechanisms modeled in TRAP-MELT.

tures because of a variety of processes. Some of these are considered to be irreversible (chemisorption), and others may be reversed if the surface temperatures rise enough to evaporate the substances. The exact nature of the chemical reactions with surfaces must be understood in much more detail before the extent of re-vaporization is determined adequately.

During transport, the vapor may encounter cooler regions or surfaces at which aerosol nucleation and depositional processes may occur. In this manner, deposited materials may be removed from the flow; but they may be re-evolved at subsequent stages of the accident if temperatures increase and/or flow rates change.

Aerosol formation is driven by the degree of supersaturation of the vapor which is determined in part by the original amount formed. This process is probably enhanced by the presence of ions formed in this high radiation environment (like a cloud chamber), although this effect is not specifically considered in the calculation. A small particle size is used as input; the particles then achieve larger sizes under the action of growth and coagulation processes. No new aerosols are assumed to form in the RCS after the material leaves the core region. The properties of the aerosols (density, shape) are not well known and can have a very large effect on aerosol retention.

Generally, TRAP-MELT is a reasonable approach to estimating depositional effects; however, the code contains a number of approximations that compromise its accuracy. For example, TRAP-MELT considers only the steam (ignoring the $\mathrm{H}_{2}$ ) despite the fact that $\mathrm{H}_{2}$ has a very different kinematic viscosity (five times greater than steam). Thus, if the $\mathbf{H}_{2}$ were included one would expect different temperature gradients and mass transfer coefficients. In addition, TRAP-MELT is a dilute system model, despite the fact that the calculations indicate very high aerosol mass densities in some parts of the system, which probably lead to violations of the well mixed assumption and appropriateness of some of the equations describing the rate processes involving aerosols. (No experiments have been performed at such high aerosol densities.)

There are several potential problems with respect to the effect of thermal-hydraulic approximations. As mentioned before, the heating by deposited fission products could be important, but is completely neglected. Where well developed flow does not exist the boundary layer thickness is not fully developed and the effective wall heat transfer coefficients is probably under-estimated in current computations. In addition, the heat transfer correlations are not always consistent among MARCH, MERGE, and TRAP-MELT.

Some changes in the MARCH, MERGE, TRAP-MELT combination have been made by Haller et al. (1984). For a large break LOCA significantly less reduction in the primary system is predicted.

Although when close to the core, CsI is expected to be molten, elsewhere it is solidified, and the assumption that the aerosol particles are spherical may be incorrect; thus, the settling velocities are not likely to be accurate unless appropriate shape factors are known. A considerable uncertainty in the thermophoretic depositional velocities arises from poor knowledge of the gas-to-particle thermal conductivities.

In many areas where a substantial amount of material is deposited, the assumption that the surface properties are unchanged may have a large effect on chemisorption reactions such as those of $\mathrm{CsOH}$ or $\mathrm{Te}$ compounds with surfaces. In this respect, the retention is very sensitive to the effective deposition velocity used. Lowering the deposition velocity by a factor of 10 for $\mathrm{Te}$ (well within the uncertainties) reduces what would be a desirable $100 \%$ retention of $\mathrm{Te}$ in the RCS to a less desirable 70\% (Gieseke et al., 1984). Similarly, changing surface roughness can significantly enhance aerosol deposition owing to turbulence. However, resuspension of deposited material in high flows is also neglected.

Many of these aerosol deposition/resuspension effects are being addressed in tests in $3 \mathrm{~m}$ pipes in the TRAP-MELT verification experiments at ORNL. Largescale simulation experiments at MARVIKEN (Sweden) will also address the issue, as will the LACE program at Hanford.

\section{V.B.7. The core-concrete interaction (INTER/CORCON)}

As the core material attacks the concrete basemat noncondensable and combustible gases are produced. The attack on the basemat and the associated loading are modeled within MARCH by subroutines that have been replaced in other parts of the calculation by more advanced codes. For example, the core-concrete interaction is modeled within MARCH by the subroutine INTER for the purposes of calculating containment loading and leakage rates. INTER (Murfin, 1977) is a preliminary code which is now outdated. For the subsequent calculation of gas and aerosol generation from this interaction the more recent CORCON (Muir et al., 1980) is used. This inconsistency means that the time dependence of the thermalhydraulic loading that could lead to containment failure and basemat penetration is being calculated with a much 
less accurate code. The original INTER code did not properly conserve mass and energy. Although the study group was informed that this was changed in the version of INTER used by Gieseke (1984), the precise changes are unclear. For the TMLB' sequence at the Surry reactor with the molten core falling onto a dry base mat INTER predicts faster penetration of the basemat with much greater gas production than predicted by CORCON, although, again, it is not sure which version of INTER was used (Ritzman, 1984). Thus INTER predicts much greater containment loading than does CORCON. If indeed CORCON is a better representation of the process, then the likelihood of containment failure at this time when radioactive aerosols are at a maximum is correspondingly lower than presently calculated.

The code CORCON takes the temperature and composition of the molten fuel and structural material from MARCH and CORSOR and deposits it as separate oxide and metal layers on the concrete basemat (Muir et al., 1981). It does not, however, consider the possibility of the spatial dispersion of this material within containment (for instance by ex-vessel steam explosions) nor does it include in the inventory of material the radioactive material deposited previously in the core region as condensed vapors or settled aerosols. The type of concrete for the reactor being considered (e.g., basaltic or carbonate) is given as input; the basaltic type erodes more quickly but the carbonate form produces more $\mathrm{CO}_{2}$ and $\mathrm{CO}$. The calculation treats the ablation of the concrete and the associated release of gases (e.g., $\mathrm{H}_{2} \mathrm{O}$ and $\mathrm{CO}_{2}$ ); the chemical products of the reactions are allowed to move into the appropriate layers in the pool, and gas bubbles either rise or flow as a continuous film around the sides of the pool depending on the point of formation. Heat transfer between layers and at the surfaces of the pool is calculated in detail, taking into account the bubbling.

The output of the code gives as functions of the time the temperature of the pool layers, the rates of $\mathrm{CO}_{2}$ and $\mathrm{H}_{2} \mathrm{O}$ production, and the rates of material from the concrete added to the melt. The rate of basemat penetration and the shape of the pool versus time are also outputs of the calculation.

Whenever possible CORCON employs models and correlations for the physical and chemical processes involved that have been at least partially verified by experiment. The heat transfer processes are complex two phase bubbling processes dependent upon the void fraction. These have been tested in some regions (Greene, 1983) but outside the range needed for describing the core-concrete interaction. This can lead to difficulties as described below.

During studies of the validation of the CORCON code, (Greene, 1983) a serious heat transfer problem came to light. A slurry was assumed to occur at the boundary layer between the metal and the uranium oxide layers. Under some conditions (some types of concrete) this slurry was calculated to be almost solid, and its high viscosity ascribed to the layer beneath. This would inhibit the calculated heat transfer without inhibiting the calculated bubbling - an unrealistic situation. This in turn would lead to calculations of a high temperature of the melt and of a high release rate of lanthanum into the containment. This has been corrected in a BNL version of CORCON MOD1, and in CORCON MOD2. Although many of the computer calculations in Gieseke et al. (1984) used the older version CORCON MOD1, it appears that this did not cause problems.

The critical role of the temperature of the melt in these calculations emphasizes the importance of experimental verification, even if the verification is only of the corium temperature. A preliminary comparison (Figure V.3) has been done by Greene (1983) who compared the results of his version of the CORCON code with the (unpublished) Sandia Code Comparison tests $\mathrm{CC} 1$ and CC2 (Powers, 1980) where $200 \mathrm{~kg}$ of molten stainless steel was dropped into crucibles of limestone concrete. The agreement is encouraging but more comparisons are necessary, and the tests should be published.

CORCON MOD2 also considers the reduction of heat loss from the top surface of the melt by the overlying aerosol cloud, and the small consequent increase in melt temperature and aerosol production (Lipinski et al., 1984).

A variety of other problems needs to be addressed as well. For example, the interlayer metal mixing and the presence of a stable gas film between the melt and the concrete are important elements in CORCON whose accuracy is ill defined. If the experiments at Karlsruhe are correct, the layers mix completely after about 10 minutes and the model must describe this. Since the melt viscosity is important in determining the heat transfer rate, the role of addition of the highly viscous $\mathrm{SiO}_{2}$ to the melt must also be better understood (Lipinski et al., 1984).

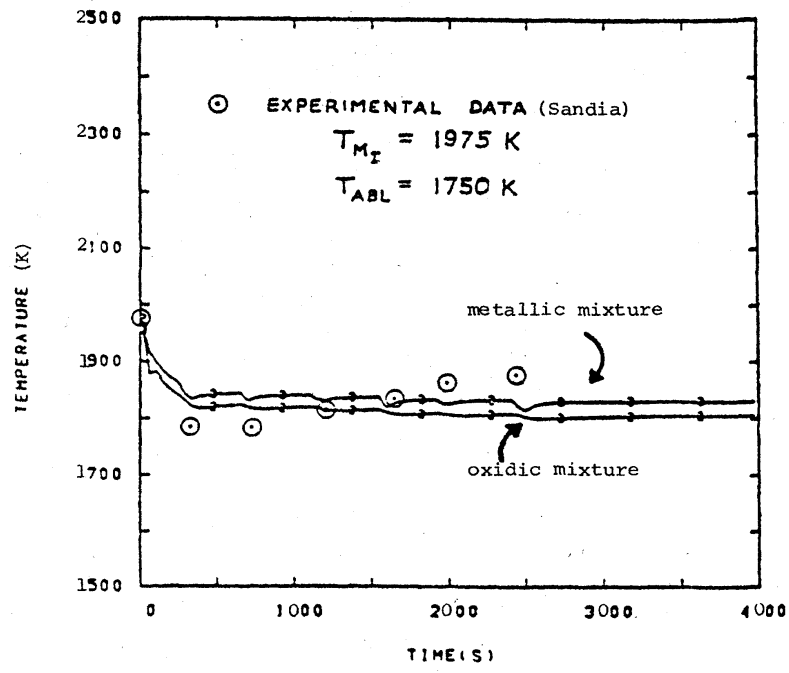

FIG.V.3. Comparison of predicted and measured melt temperature histories for Sandia test CC-1 (Greene, 1983). $T_{M_{I}}=$ initial melt temperature; $T_{\mathrm{ABL}}=$ assumed concrete ablation temperature. 
A program which seems almost completely independent is being carried out in West Germany (Hosemann and Hassmann, 1984). The computer code WECHSL (Reimann and Murfin, 1981) has been developed to describe the heat transfer processes. Like CORCON, this program was also developed from INTER and therefore has similar features. The temperatures predicted for a core interaction are $2600 \mathrm{~K}$ for the first 10000 seconds, falling to 1700 to $1800 \mathrm{~K}$ as the $\mathrm{UO}_{2}$ mixes with the low melting point component $\left(\mathrm{SiO}_{2}, \mathrm{FeO}, \mathrm{CaSiO}_{3}\right)$.

\section{V.B.8. Production of $\mathrm{H}_{2}$ and CO (VANESA)}

VANESA takes the CORCON output and models the reduction of the $\mathrm{H}_{2} \mathrm{O}$ and $\mathrm{CO}_{2}$ to $\mathrm{H}_{2}$ and $\mathrm{CO}$, as well as the loss of other materials from the pool as aerosols (Powers and Brockman, 1983). On entering the melt, the $\mathrm{CO}_{2}$ and $\mathrm{H}_{2} \mathrm{O}$ are assumed to be in thermal and chemical equilibrium with the constituents of the metallic layers. This results in a gas of $\mathrm{H}, \mathrm{H}_{2}, \mathrm{OH}, \mathrm{O}, \mathrm{O}_{2}, \mathrm{CO}$, and $\mathrm{CO}_{2}$ and any vapors from the product metallic oxides present at that temperature. The oxidic products of these reactions are put into the oxide layer of the pool. The gas is assumed to be in bubbles of constant size, and the transfer of materials to the bubbles from the melt is tracked. The chemical reaction of the gases in the bubbles is calculated as they rise through the melt. On reaching the surface, the vapor species are assumed to be aerosols whose sizes are taken empirically. Other aerosols are assumed to form through the breaking of each bubble as it reaches the surface generating a constant number of constant size aerosol particles.

The gas release from the core-concrete interaction is an important part of most accident sequences because it provides a severe load on the containment at the same time that a large amount of airborne material is being produced. Thus, CORCON/VANESA represents an especially important model whose output is a major ingredient in source term estimates. As VANESA is a newly developed and undocumented code, it has been impossible for the study group to evaluate it. However, its author claims that there has been a determined attempt to put into this model all physical and chemical mechanisms that should be present; however, although experiments have begun at Sandia, they are not far enough advanced to provide a detailed test of the model. Improvements to the model are obviously necessary. For example, the effects of solidified debris over the molten pool have not been evaluated. This is also true of the case of a water layer. Experiments at Sandia have shown that the presence of a water layer does not affect the gas production rates (Lipinski et al., 1984). But the water layer does remove some aerosols from the gas bubbled through it; however, when the water is gone the material in it returns to the melt where it is again subject to vaporization.

Although the gas production rates are probably known within a factor of 2 by the energetic considerations mentioned earlier, this is not true of the radionuclide and oth- er aerosol emission. It is especially important, therefore, to test these against experiment.

\section{V.B.9. Aerosol deposition code (NAUA)}

This code was already mentioned in the section on aerosols, Section IV.C. The aerosol deposition is very important. It is the increased realization that most airborne iodine and other fission products are in the form of aerosols which can be deposited, and the calculated increase in time available for this deposition before containment failure, that reduce, in some cases, the calculated source terms below those calculated in RSS.

Within containment (and other parts of the reactor building) a variety of depositional processes may occur owing to the action of natural and engineered phenomena. The mechanics of fission product removal as a function of aerosol particle size are important parameters at this stage of the accident. Since this is the last step before the released material gets into the environment, it is important that these processes be treated carefully. The code NAUA models the interaction of the aerosol particles with water vapor and their agglomeration and settling (Bunz et al., 1982). (See Figure V.4.) Comparison of these calculations to aerosol lifetime data seems to be quite reasonable; however, only two species, water and "aerosol," are tracked, which amounts to the improbable assumption that the aerosol particles have a uniform composition. This may have a substantial effect on source term estimates. The calculations indicate that agglomeration and settling are major factors for the removal of large particles; small (submicron) particles are removed mainly in the condensing steam by Stefan flow and by agglomeration into larger particles. (Diffusiophoresis was added to the original NAUA code for the purpose of ASTRS.) Turbulent agglomeration is not included.

Sandia's sensitivity studies have shown that adding turbulent agglomeration acts in a synergistic manner with the aerosol properties (density, shape) and that together they strongly affect the aerosol lifetime. This is also true when multi-species aerosols are considered (Lipinski et al., 1984).

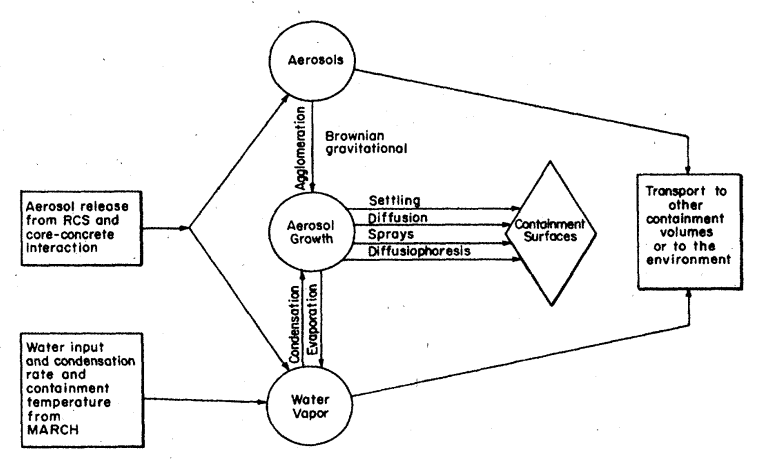

FIG. V.4. Aerosol deposition mechanisms modeled in NAUA. 
Since the size and shape of the aerosol particles affects their settling one should also consider how they are changed during $\mathrm{H}_{2} / \mathrm{CO}$ combustion. This might tend to remove some of the adsorbed water that makes the particles more spherical, thus making them both smaller and less spherical. Both results would tend to prolong the aerosol suspension.

It is quite likely that the lack of integration between MARCH and NAUA causes an unnecessary inaccuracy in the aerosol behavior in the containment volume. A new code, CONTAIN, has been written that corrects many of these deficiencies. This code also uses the approximation of a series of well mixed volumes but provides an integrated treatment of the thermal-hydraulics and the aerosol behavior. This allows a complete treatment (with feedback) of the aerosols that includes the operation of ESF's and $\mathrm{H}_{2} / \mathrm{CO}$ combustion. In tests in West Germany that involve a full-scale blow-down of a decommissioned reactor, CONTAIN accurately described both the thermalhydraulics and the aerosol deposition.

As mentioned earlier one should be careful to consider any long term chemical reactions or radioactive decay of the deposited materials (fission products, core, control rods, etc.) that could allow their further movement. Iodine is, of course, the major worry in this regard. The decay of ${ }^{132} \mathrm{Te}$ to ${ }^{132} \mathrm{I}$ and of ${ }^{131 \mathrm{~m}} \mathrm{Te}$ to ${ }^{131} \mathrm{I}$ have been identified as such sources of delayed I emission. This effect is more important than was believed at the time of the RSS because some of the calculations predict higher $\mathrm{Te}$ releases but lower I releases. But this process has not yet been put into any of the detailed calculations (Lipinski et al., 1984).

\section{V.B.10. Removal by ice condensers (ICEDF)}

In some PWR's the loadings on containment and the removal of airborne materials are to be reduced by using fans to circulate the steam through large ice condensers. Since MARCH does not permit recirculating flows, the code ICEDF is being written to handle this part of the accident sequence (Allemann, 1984). Using the thermalhydraulic data from MARCH the code must track the inventories of ice and water as well as dealing with the depositional mechanisms that occur in the ice condenser. At the moment a modified version of NAUA is being used until ICEDF is ready. This code includes the effects of Stefan flow, interception, inertial impaction, thermophoresis, and gravitational settling on the aerosols in containment. The biggest effect comes from the condensation of steam in the ice condenser, i.e., deposition by the Stefan flow. A decontamination factor (DF) is calculated for each pass through the condenser, and the greater the number of passes the lower is the amount of removed airborne aerosols. Although Westinghouse has made largescale tests of the effects of ice condensers on containment loading, there are no data to confirm their decontamination efficiency (see Section IV.C.8.b).

\section{V.B.11. Water suppression pool removal (SPARC)}

In a BWR, the gases and aerosols leaving containment are bubbled through a large water suppression pool. This serves in the same way as an ice condenser to reduce the pressure and temperature loadings as well as scrubbing the airborne material from the gas. A variety of scrubbing mechanisms is included in the code, SPARC (Allemann, 1984). As the bubbles form, scrubbing occurs by Stefan flow from steam condensation, thermophoresis, and inertial impaction. As the swarm of bubbles rises, material in the bubbles is calculated to be taken up by the water through centrifugal deposition, gravitational settling, and Brownian diffusion to the bubble surfaces. In general, the ratio of the amount of material input to the pool to the amount that comes out (decontamination factor, DF) has been shown in these calculations to be sensitive to a number of variables. The least scrubbing is computed to occur for sizes between 0.1 and $1 \mu \mathrm{m}$, with decontamination factors increasing markedly for particle sizes above and below this range. Particles with high densities are removed more effectively than those with lower densities. Higher DF values are achieved by small, oblate bubbles saturated with steam in colder and deeper pools (Owczarski, 1984).

Owing to the sensitivity of decontamination factors to particle size computed by SPARC, and the uncertainty of the aerosol size distribution computed by TRAP-MELT, one should not claim more credit at the present time than the minimum in the DF as a function of particle size for the other prevailing conditions. This reinforces the need, as already noted in Sec. III.D.7.a, for better data for the performance of suppression pools and for the distribution of aerosol sizes in accident conditions. Of course, any correlation of elemental composition and particle size would be especially important. It is also of great importance to define more precisely the modes of containment failure that could allow released radioactivities to bypass the suppression pool.

Generally, SPARC has served a very useful function in exposing the sensitivities to particle and pool variables. However, these sensitivities make it unrealistic to place too much faith in the calculations beyond the minimum decontamination factors as a function of particle size until they rest on a more secure empirical foundation.

\section{V.C. Calibration and validation of codes by experiment}

In developing models and codes to describe the behavior of particular systems, one often begins by assuming that only a few processes contribute, that these are relatively simple and well understood and that the processes are independent. To the extent that the parameters of the model correspond to actual physical parameters, their values may be available from outside sources. If such values are not available or if, instead, the model parameters fail to characterize the functional relation between physical parameters, small-scale experiments 
designed to provide that information may be necessary.

If the system to be modeled requires extrapolation to conditions far from the calibration conditions, or if the several contributing processes are not independent, it may be necessary, to have confidence in the validity of predictions, to perform larger-scale experiments encompassing the necessary ranges and allowing for the possibility of interdependence of phenomona. However, for large-scale experiments to have value, they must meet certain conditions:

(i) Situations being modeled by the experiments must be addressable by the code under test;

(ii) The conditions of the experiment should correspond to parameters whose values are appropriate for the description of systems ultimately to be modeled;

(iii) Experimental conditions must be well controlled and well known;

(iv) It must be possible to measure parameters whose values are predicted by the code-and preferably many such parameters;

(v) If a series of experiments is to be carried out, as few exogenous conditions as possible should be changed.

Several large-scale experiments have been performed or are currently under way, intended to serve a benchmark function for the models and suites of codes used in source term calculations. Every attempt should be made to assure that these experiments can and do satisfy considerations such as those listed above.

\section{V.D. Summary}

As we have seen most clearly in the discussion of SPARC code in V.B.11 above, an important role that should be played by the models and codes has been to determine the sensitivity of the amount of released material to the accident parameters. Another important potential role is to discuss the feedback between several processes; for example how the heat from aerosols deposited in the RCS alters the fluid flow.

However, because the release to the environment is so strongly dependent on a variety of ill-determined events (e.g., the time and nature of the breach of the containment) and on the detailed configuration of the particular reactor involved it would be unrealistic to consider the code output alone to be an accurate guide to specific quantitative estimates of environmental release. Fortunately, as discussed earlier, some of the general features such as the maximum size of a pressure spike at RPV failure are not critically dependent upon the details of the code output. An important task therefore, is to define the uncertainties better by sensitivity studies. In addition, many of the simulation experiments mentioned earlier are just now at the point of producing data; these results are likely to have a major impact on the models.

We hope that, when a detailed analysis of the TMI-2 accident is complete, we will be able to check some of the assumptions inherent in the core slumping models and in the transport of the vaporized fission products.
The sensitivity of the code output to input data, to the models, and to the individual reactor parameters are three separate important topics that have not yet been adequately addressed. In the absence of a reliable model for core slumping, bounding parameters must be chosen, although it must be recognized that the output may not be linear with these parameters. Such sensitivity studies are a logical part of the work of every user of the codes. At present the NRC's sensitivity study (QUEST) (Lipinski et al., 1984; Rivard et al., 1984) is too loosely coupled to the task of determining the accuracy of the code predictions.

We recognize that the "BMI Suite of Codes" being used today by the NRC and its contractors to help analyze the risk associated with severe core accidents marks an advance in the state of the art of such code development programs and in the understanding of hypothetical accidents. Similar remarks can be made with respect to codes being used and developed by other organizations (e.g., IDCOR, Stone and Webster, EPRI) for similar purposes.

Parts of the source term research community feel that today's codes require significant improvement before one can be confident of their predictions. Indeed, a very considerable portion of the NRC's research budget is dedicated to further code development work and the associated experimental verification. There must be a carefully woven hierarchy of code development and experimental research. The necessity for experimental research is to reveal and quantify the proper phenomena and their scaling laws that underlie the models that the codes represent. The necessity for theoretical calculations, aided by appropriate numerical calculations of specific phenomena, is important in deducing and confirming these scaling laws.

Systems codes, such as the "BMI Suite," must be simple enough to handle a large variety of permutations and combinations of accident "scenarios," and to do so at modest computing expense. At the same time they must be sufficiently comprehensive to include all the relevant phenomena. But, one can place little reliance on any elaborate systems code unless each appropriate segment of it has been thoroughly tested (bench marked) against a detailed "component" code for an individual phenomenon, when that particular component code in turn has been tested experimentally.

The suite of codes does not yet meet both of these requirements simultaneously.

The particular codes described in this report fall into three general categories:

(1) ORIGEN includes all the phenomena necessary for a complete description of the processes modeled. Although one can imagine improvements to the code, its basic form is adequate for its task;

(2) CORSOR provides an empirically based tool for calculating emission rates from the melting core that can only be as accurate as the modeling of the sparse and divergent data it uses in parametric form. Thus, any improvement of this calculation requires better data, particularly for the less volatile species. 
TABLE V.1. Newer codes that have the potential for upgrading components of the Battelle suite of codes used in Gieseke (1984).

\begin{tabular}{|c|c|c|}
\hline Description & BMI-2104 & Newer code \\
\hline RCS thermal-hydraulics & MARCH, MERGE & TRAC, RELAP5 \\
\hline Fuel heatup and degradation & MARCH & $\begin{array}{l}\text { SCDAP, MIMAS, } \\
\text { MELRPI, } \\
\text { MELPROG }\end{array}$ \\
\hline $\begin{array}{l}\text { Fission product release } \\
\text { from fuel (in vessel) }\end{array}$ & CORSOR & $\begin{array}{l}\text { GRASS, } \\
\text { VICTORIA }\end{array}$ \\
\hline RCS fission product transport & TRAP-MELT & TRAP-MELT \\
\hline $\begin{array}{l}\text { Molten fuel interaction } \\
\text { with coolant }\end{array}$ & MARCH & WISCI \\
\hline Debris-concrete interactions & CORCON & CORCON \\
\hline $\begin{array}{l}\text { Fission product release from } \\
\text { core-concrete melt (ex-vessel) }\end{array}$ & VANESA & VANESA \\
\hline Containment thermal-hydraulics & MARCH & CONTAIN \\
\hline Hydrogen behavior & MARCH & $\begin{array}{l}\text { CONTAIN } \\
\text { (HECTR })^{*}\end{array}$ \\
\hline $\begin{array}{l}\text { Containment fission product } \\
\text { transport }\end{array}$ & $\begin{array}{l}\text { NAUA, SPARC, } \\
\text { ICEDF }\end{array}$ & $\begin{array}{l}\text { NAUA, CONTAIN } \\
\text { (SPARC, } \\
\text { ICEDF, } \\
\text { MAEROS)* }\end{array}$ \\
\hline
\end{tabular}

*Subroutines in CONTAIN.

(3) The backbone of the calculations is determined by four code combinations (MARCH/MERGE, TRAPMELT, CORCON/VANESA, and NAUA/SPARC/ICEDF). All these combinations have faults. The phenomena included are modeled crudely and often contain parameters that are based on incomplete knowledge; some important phenomena are omitted or depend entirely on the judgment of the user of the code. The result of a particular calculation

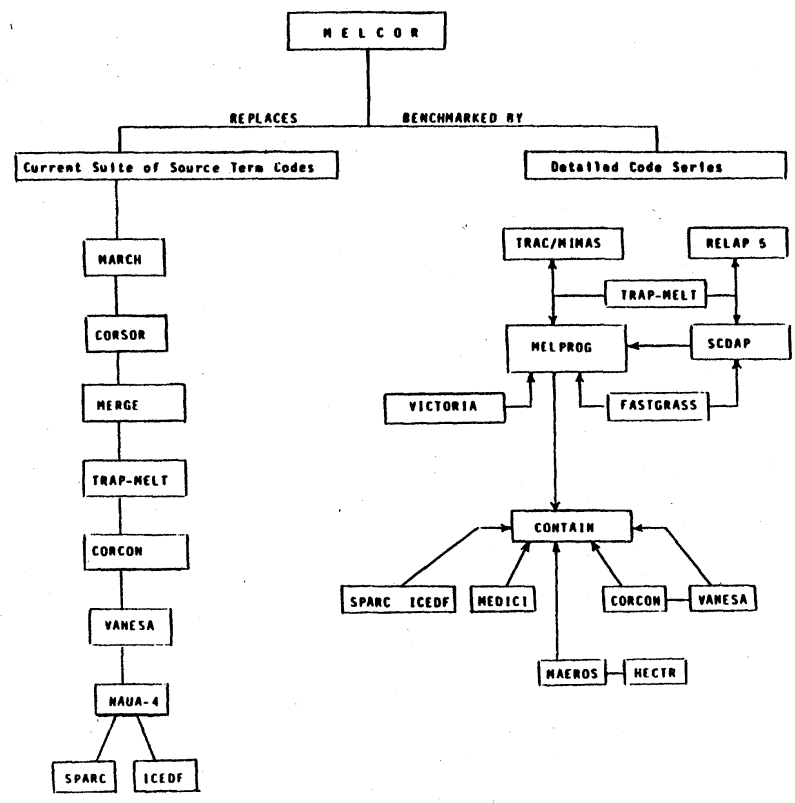

FIG. V.5. Flow diagram of MELCOR illustrating the relationship of the "old" suite of codes to the new generations. is often extremely sensitive to the input from the previous code in the sequence. In addition, this output may strongly suggest that the previous calculation must be modified. Thus, an iterative feedback is implied that usually is not performed. However the New York Power Authority group (Deem and Bieniarz, 1984) have written a vectorized code that integrates the functions of MARCH, MERGE, CORSOR and TRAP-MELT, for the specialized conditions of the Indian Point Reactors. This approach is a considerable improvement and needs extension.

Several new codes, commissioned by the NRC, are being developed that should correct many of the identified defects in those currently in use. These are listed in Table V.1, along with the codes they will replace; their flow is shown in Figure V.5. Many of these codes are substantially more sophisticated, complex and long running than their forebears. In some cases therefore, the codes will not replace the codes in Gieseke et al. (1984), but merely bench mark them.

In some instances, codes will be updated to reflect new data and better appreciation of some phenomena that have not yet been properly treated. These new codes will be discussed further in Chapter VII under research needs.

\section{V.E. Conclusions}

The following conclusions can be drawn from this code assessment.

V.E.1. Natural mechanisms or engineered processes may reduce the environmental source term. However, the exact amount of reduction is strongly dependent on a great number of variables that include the particular reactor involved, the details of the accident, and the precise 
timing of a number of events in the accident sequence.

V.E.2. The models and codes are impressive in their ability to determine the roles played by various source and depletion mechanisms and to establish a rough time scale for the events that might occur. However, the codes are much too sensitive to the lack of complete data, to our lack of knowledge of many of the processes, and to their own lack of sophistication to provide accurate generic source term estimates. This conclusion is supported by the fact that new phenomena are still being found and that many parameters of the codes are being reevaluated, that significantly affect the calculated accident consequences.

V.E.3. When considerations of conservation of energy are important, it is possible to make useful calculations even without a computer code as demonstrated in Section III.C.1, where the pressure spike at the time of reactor vessel melt-through was calculated. The use of a computer can improve the precision of such calculations and lends support to the general conclusion that pressure spikes at this time are unlikely to cause the containment to fail. This in turn led to the general conclusion that containments fail, if at all, at later times than previously assumed. Although the detailed calculation of the failure time, and of the aerosol deposition before that time need the codes and are uncertain, the general observation that aerosol deposition will reduce the release to the environment under such circumstances is still valid.

V.E.4. There is a pressing need for further study of the sensitivity of the code output to the reactor parameters, to the models used, and to the uncertainties in the experimental data base. These studies should be undertaken as an integral part of the development and use of the codes, as well as being part of an external review.

V.E.5. The examination of the codes by the APS study group has been hampered by the poor quality of the documentation of their theoretical bases, of their validation against experiment, and of the codes themselves. In general, these codes have not been publicly released, nor have their theoretical and experimental bases been described in the form that would be required by archival peer-reviewed journals.

V.E.6. The publication (in report form) of the results of calculations using the NRC suite of codes (Gieseke et al., 1984) should be considered the beginning and not the end of the study of their use. Potential users of the codes must have a listing, a code manual, a description of the approximations, and a standard problem on a standard reactor. At present most groups fail to compare their calculations with those of others, and it becomes difficult to determine whether differences in output are caused by differences in physical modeling, computer implementation of the model, choice of input parameters, or some combination of these factors.

V.E.7. The study group has not found in a publication or report of the computer calculations done so far an adequate justification for believing particular numbers in the code output. Such justification might include: simple checks, such as those in III.C. 1 and VI.B on crucial parts of the calculation; a check on the output for one or more standard problems; use of the identical code for predicting the results of a large scale test, and a detailed comparison of the prediction and the experiment. Such comparisons are often called "code validation." We have not seen adequate code validations for most of the codes.

V.E.8. Probably not all the complex, coupled, nonlinear physical processes that determine the outcome of accidents have been identified. Even some that have been identified, such as heating by deposited fission products and its effect on thermal hydraulics, have not been modeled.

V.E.9. The present situation may be expected to change appreciably in the next few years as new data appear and simulation experiments are completed. In this regard the PBF (INEL) and ORNL and Sandia (ACRR) studies of fuel melting, the MARVIKEN simulations of aerosol transport, and the Sandia and KfK (Karlsruhe) core-concrete interaction experiments are especially important.

V.E.10. The research program of the NRC should be restructured to guarantee that sufficient attention is paid to research on the basic mechanisms that may be involved (e.g., multi-phase flows, liquid-vapor interactions, aerosol formation and growth). Such effects are best studied in small-scale experiments, and form a necessary complement to the more complicated "realistic" experiments that were mentioned in IV.C.9.

\section{SENSITIVITY STUDIES \\ OF KEY PARAMETERS \\ AFFECTING THE SOURCE TERM}

\section{VI.A. Introduction}

The American Nuclear Society study (ANS, 1984) lists results of many full-scope, computer calculations for the source term. A few of these results are presented here and discussed in the context of a highly simplified analytical model. In this manner, it is hoped that the reader will gain some insight into the sensitivity of source term calculations to a few critical parameters, some of which are calculated by the codes but others of which are exogenous inputs. The parameters include the time of containment failure (exogenous input), the half-life for flow of gases from the containment to the environment as determined by hole size (exogenous input), the duration of the input of fission products into the containment gas space (calculated), and the half-life for plate-out of aerosols onto containment surfaces (calculated). Unfortunately, some of these parameters are not easily quantified at present. Nevertheless, it is the current acceptance of longer times to containment failure, longer half-lives for gas loss to the environment, and shorter half-lives for plate-out that lead to calculated releases smaller than those calculated in the Reactor Safety Study (NRC, 1975). The longer half-life for escape to the environment comes from assumption of smaller hole sizes to the environment, and the shorter half-lives for plate-out come from the 
realization that most fission products exist as aerosols or soluble species rather than in the vapor state.

\section{VI.B. Stylized model illustrating the times of significance influencing the "source term"}

The source term for a particular accident sequence involving a particular reactor system may be viewed as the result of a sequence of events in which fission products and other radioactive nuclides are alternately released, transported, trapped, and possibly re-released, until a portion is finally able to escape into the environment. It is convenient to divide the release and migration of these radionuclides throughout the reactor system into different stages, each involving a physically distinct region of the system. Thus, the initial barriers acting to prevent the release of radioactive material are the fuel rod itself and its cladding (Section III.A.4.c). In a severe accident such as is discussed here, the integrity of the fuel rod will have been damaged sufficiently to allow some of the fission products to escape and to enter the reactor vessel and other portions of the primary coolant system, or in some cases to enter directly into the containment after reactor vessel melt-through.

The ability of different species to escape from damaged fuel rods depends on their volatility. Thus, in Section IV.B of this report the radioactive material was split into two coarse divisions. One category includes those elements whose chemical states were sufficiently volatile that, under the circumstances likely to be encountered during core melt-down, a large fraction of their original inventory would escape from the fuel. The second category includes those belonging to just the opposite situation, in which the inventory of fission product can only escape from the fuel by thermodynamic and mechanical processes driven by the core concrete interaction following reactor vessel melt-through. The noble gas elements krypton and xenon belong in the first category, along with such volatile species as compounds of iodine and cesium. The much more refractory species, such as the oxides of lanthanum and plutonium, belong to the second. There are borderline cases, barium and strontium perhaps, in which one is not so certain about just what fraction will escape and what fraction will be retained in the fuel within the pressure vessel.

These categories are introduced for two reasons. Firstly the primary system itself can act as a temporary or permanent barrier to the further migration of fission products belonging to the first category of relatively volatile species mentioned above. Even here the ability of the primary to retain radionuclides may be of no consequence for particular accident sequences. In similar fashion, one can argue that the fate of refractory species that are quite unlikely to escape from the fuel during the core-melt stage will also not be affected by processes through which some chemical species may be retained in the primary system. Secondly, the two categories of radionuclides are released at different times, and this may be of great importance.
Important and not yet fully answered questions relate to how effective the primary coolant system of various reactors might be in retaining some fraction of the fission products which escape from the fuel. These involve questions of chemistry, as discussed in some detail in Section IV.B, questions concerned with thermal hydraulics and mass transport, as noted in Section IV.A, and questions of aerosol transport and deposition, as illustrated in Section IV.C. Here we simply wish to emphasize that these open questions can affect only contributions of the more volatile components of the fission product inventory to the source term.

In Section IV.E.1 distinct ways in which radioactivity can be released to the environment following a severe accident were discussed. There is the bypass mode-the $\mathrm{V}$ sequences-whereby fission products released from the damaged fuel find their way directly to the atmosphere. There is the base mat melt through, sometimes called the China Syndrome, in which physical integrity of the containment remains intact but, after a sufficient amount of time, the basemat can be penetrated by molten core, allowing some of the radioactivity to escape the plant and migrate through the underlying ground. Escape through openings that result from containment failure are categorized as $\alpha, \beta, \gamma, \delta$.

The transfer of fission products from the fuel to the primary system, from the primary system into the containment, and from containment into the environment form a sequence of essentially irreversible steps. Except for those accident sequences in which there is a direct path from fuel rupture to environment-the containment bypass or $\mathrm{V}$ sequences discussed in Section III.C.2-the rates at which radioactive elements arrive in the containment volume will determine in part the possible rates at which these species can escape into the external environment and thereby contribute to the source term. Also important are the rate at which radioactive material deposits on the walls or other surfaces within the containment volume, and the rate at which air and other gases carry the suspended radioactive material with them through the openings of the containment.

Here we present a highly simplified analysis to provide a framework for understanding the key time scales that directly influence the "source term." We deal only with the release of fission products from the containment to the outside environment, but a similar model can be used to deal with the release of fission products from the reactor vessel to the containment volume.

One assumes the containment volume to be represented by $V$, and its gaseous content, including suspended particulate matter, to be well mixed and uniform in composition. The airborne concentration of a particular species of interest is written as $C(t)$ to emphasize that its value will change with time $t$. $C(t)$ increases at the time dependent rate $R(t)$ at which this species is injected into the containment's gaseous environment. $C(t)$ decreases by two different processes. In the first place, aerosols containing radioactive material can deposit on the solid surfaces within the containment volume. The rate at which 
this takes place is directly proportional to the concentration of the species under examination, the surface area $A$ available for deposition, and a time dependent deposition velocity $k(t)$ that is a function of a variety of factors, including perhaps the concentration $C(t)$ itself. The other loss mechanism is the one of principal concern here, namely loss of radioactive material by escape through the openings in the containment once the containment fails. The rate of escape is the product of $C(t)$ and the time dependent volumetric flow rate of gaseous matter out of the containment $Q(t)$. Thus

$$
V[d C(t) / d t]=R-C k A-C Q .
$$

This simple rate equation approximates in crude fashion the more elaborate models in such computer codes as TRAP-MELT and NAUA (Sections V.B.6 and V.B.9).

For each species of interest, one can define a fractional release factor for the containment $S_{c}$ as follows: the total amount of material leaked to the external environment is $\int_{0}^{\infty} C(t) Q d t$, while the total amount of material of this particular species that is injected into the containment is $\int_{0}^{\infty} R d t$. The ratio of these two terms is the fractional release factor accounted for by containment leakage

$$
S_{c}=\int_{0}^{\infty} C(t) Q d t / \int_{0}^{\infty} R d t
$$

One could, in principle, define analogous release factors for a given species for escape from the fuel as well as escape from the primary. The product of such release factors, multiplied by the total original inventory of the radioactive material in the fuel at the start of the accident, would then. represent the contribution of that particular species to the source term.

Calculation of the fractional release factor $S_{c}$ is greatly simplified if one adopts simple expressions for the time dependent terms $R, Q$, and $k$ in Equation (VI.1). Thus, for example, $R$ is zero until the time at which the primary system has failed so that injection of the species in question into the containment can take place. We denote this time as $t_{v}$, and clearly the value of $t_{v}$ may be different for the more volatile species as compared with the more refractory species. For the volatile species such as Cs and I this time is likely to coincide with the core uncovery whereas for the nonvolatile species such as lanthanides and actinides this time is likely to coincide with melt through and core-concrete attack. We might assume for simplicity that between the time of start of injection $t_{v}$ and the end of injection $t_{e}, R$ is the constant $I /\left(t_{e}-t_{v}\right)$ where $I$ is the total inventory of the species released to the containment. After $t_{e}, R$ is again zero. Similarly, $Q$ will be zero until such a time as the containment fails and the openings appear; this time will be denoted as $t_{c}$, and we note that $t_{c}$ could precede or follow $t_{v}$, depending on the circumstances of the accident. We might assume for simplicity that $Q$ is a constant between the times $t_{c}$ and $t_{f}$, after which $Q$ is again zero. These variations are shown in Figure VI.1. We also assume that $k$ is constant. The assumption that the injection rate $R$ is constant over the interval $t_{v}$ to $t_{e}$ and zero otherwise; that the leakage rate
$Q$ is constant over the interval $t_{c}$ to $t_{f}$ and zero otherwise; and that $k$ is constant for all times, of course, may be gross simplifications.

However, the detailed numerical calculations of SWEC (Stone and Webster Engineering Corp.) for the TMLB sequence for the Surry reactor with a preexisting hole give some support to these simplifications, at least for some sequences. Figure 21 (Appendix B) of the ANS (1984) report shows the calculated size distribution of aerosols within the containment at several times of the accident; although the particle number density does change with time, the size distributions are very similar, suggesting that the deposition velocity $k$ for sedimentation, which is the dominant removal mechanism for this case (see Figure 25 of Appendix B of the ANS report), is likely to be nearly constant. Figure 45 (Appendix B) of the ANS report shows the volumetric leakage rate $Q$ as a function of time for several different assigned hole sizes. In each case, after an initial rise the leakage rate does remain fairly constant for long time spans. It is more difficult to justify the constancy of $R$.

Figure VI.1 introduces three time scales mentioned above, namely $t_{s}=\left(t_{e}-t_{v}\right)$, the duration of the leakage of fission products to the containment, $t_{l}=\left(t_{f}-t_{c}\right)$, the duration of the leakage from the containment to the environment, and $t_{d}=\left(t_{c}-t_{v}\right)$, the time lag between the onset of leakage into the containment and from containment to the environment.

The three parameters, the containment volume $V$, the available surface area $A$, and the deposition velocity $k$, define a characteristic plate-out time period, which we designate as $t_{p}$ :

$$
t_{p}=V / k A \text {. }
$$

The determination of this time from calculations and experiment was discussed in Section IV.C.4.

Another important characteristic time is the residence time of material in the containment gas phase, which we designate as $t_{R}$ :

$$
t_{R}=V / Q
$$

For the idealized situation described above, it is easy to solve the problem of calculating $S_{c} . S_{c}$ is expressed as a function of five dimensionless ratios (only four are independent) of the times we have designated $\left(t_{s}, t_{p}, t_{d}, t_{R}, t_{l}, t_{f}-t_{e}\right)$. These five ratios, which we call $\lambda$, $\mu, v, \pi_{1}$, and $\pi_{2}$ are defined as follows:

$\lambda=t_{d} / t_{p}=$ ratio of time for the onset of containment leakage to plate-out time;

$\mu=t_{s} / t_{d}=$ ratio of duration of fission product input to containment to time for onset of containment leakage;

$v=t_{R} / t_{p}=$ ratio of containment gas phase residence time to plate-out time;

$\pi_{1}=t_{l} / t_{R}=$ ratio of duration of containment leakage to residence time

$\pi_{2}=\left(t_{f}-t_{e}\right) / t_{R}=\pi_{1}+\lambda(1-\mu) / \nu$ 


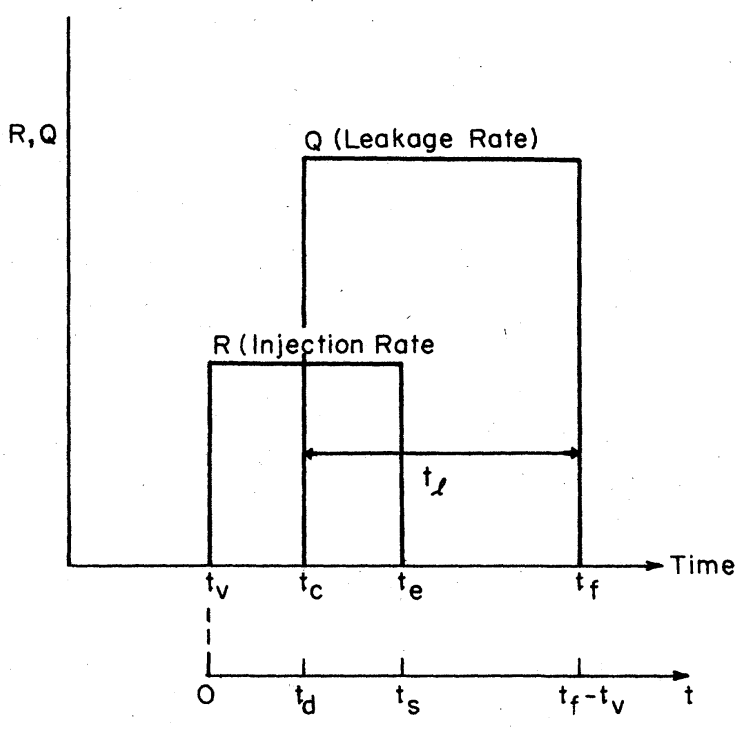

FIG. VI.1. Assumed variations of $R$ and $Q$ with time for the simplified model presented herein (arbitrary units).

The resulting formulas are given below: (1) For $t_{e}<t_{c}$ (leakage begins only after release to the containment has been completed):

$S_{c}=\frac{1}{(1+v)} \frac{e^{-\lambda}}{\lambda \cdot \mu} \cdot\left(e^{\lambda \mu}-1\right)\left[1-\exp -(1+v) \pi_{1}\right]$.

(2) For $t_{e}>t_{c}$ (leakage begins before release to the containment has been completed):

$S_{c}=\frac{1}{(1+v)} \cdot\left[1-\frac{1}{\mu}+\frac{\left(1-e^{-\lambda}\right)}{\lambda \cdot \mu}\right]\left[1-\exp -(1+v) \pi_{2}\right]$.

(VI.6)

From Equations (VI.5) and (VI.6), one may observe the importance of the relative values of such parameters as the time of containment failure, the time interval between the latter and the time when injection of radioactive material to the containment begins, the speed of decontamination via deposition mechanisms and, finally, the ease of escape by entrainment in gas flow as represented by the volumetric flow rate. These trends are illustrated in Figure VI. 2 for the special case where $\pi_{1}$ or $\pi_{2}$ are sufficiently large that the exponential terms containing either is

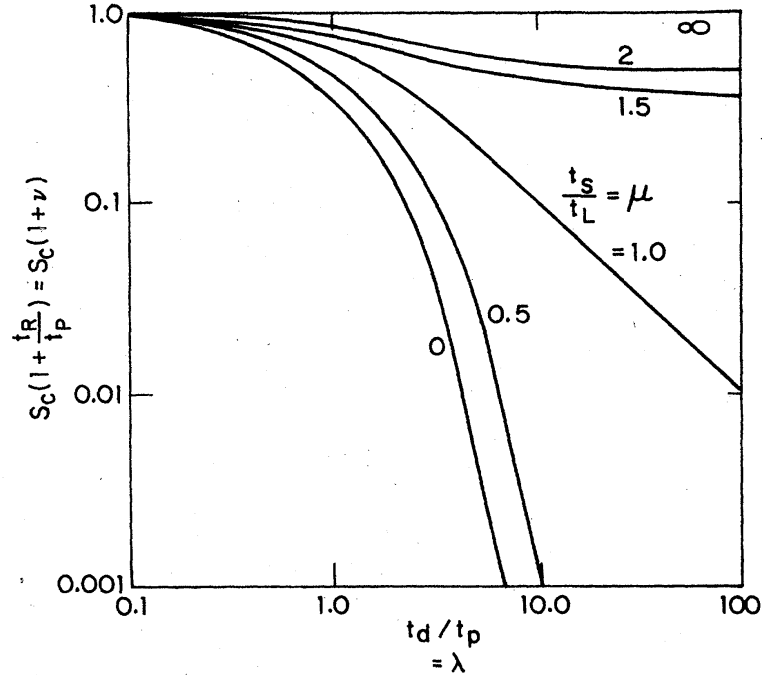

FIG. VI.2. Fractional release factor $S_{c}$ from containment computed by simplified model. $\lambda=$ ratio of time for onset of leakage to plate out time. $\mu=$ ratio of duration of fission product input to time for onset of containment leakage. $v=$ ratio of containment residence time to plate out time.

negligible. Figure VI.2 shows $S_{c}$ multiplied by $\left(1+t_{R} / t_{p}\right)$ as a function of the other two dimensionless time ratios. Since the value of $1 /\left(1+t_{R} / t_{p}\right)$ is always less than unity, we see that the factor $S_{c}$ can be quite small if the source persists for only a small fraction of the time to onset of leakage, and if the time for plate-out is shorter than the characteristic leakage time. On the other hand, if the source persists for a time period comparable to the time for onset of leakage, then the value of $S_{c}$ depends dominantly on the ratio $t_{R} / t_{p}$ and can be a significant fraction of the input to the containment. This is true especially if $t_{R} / t_{p}$ is of order unity or less, namely if retention time is small compared to plate-out time.

To illustrate with a numerical example, consider the TMLB sequence for the Surry reactor. This reactor has a containment volume of $5.1 \times 10^{4} \mathrm{~m}^{3}$ and an estimated surface area of $1.04 \times 10^{3} \mathrm{~m}^{2}$. According to SWEC calculations, the major release of iodine/cesium into the containment starts at $182 \mathrm{~min}$ and ends at $252 \mathrm{~min}$. Table VI.1 presents some of the input for the stylized model. The average containment leakage rate $Q$ and the deposition velocities, $k$, were provided to the study group by SWEC. With these numbers, we have estimated the containment release factors presented in Table VI.1.

TABLE VI.1. Comparison of the fractional release factor $S_{c}$ as computed by the simple model with SWEC computer calculations.

\begin{tabular}{llcccccc}
\hline \hline & $\begin{array}{c}\text { Hole size } \\
\left(\mathrm{m}^{2}\right)\end{array}$ & $\begin{array}{c}t_{c} \\
(\mathrm{~min})\end{array}$ & $\begin{array}{c}Q \\
\left(\mathrm{~m}^{3} / \mathrm{min}\right)\end{array}$ & $\begin{array}{c}k \\
(\mathrm{~cm} / \mathrm{s})\end{array}$ & $\begin{array}{c}t_{R} \\
(\mathrm{~min})\end{array}$ & $\begin{array}{c}t_{p} \\
(\mathrm{~min})\end{array}$ & $\begin{array}{c}\text { Simple } \\
\text { model }\end{array}$ \\
\hline case 1 & 0.0093 & 0 & 114 & 1.66 & 447 & 50 & 0.10 \\
case 2 & 0.093 & 0 & 708 & 1.1 & 72 & 74 & 0.51 \\
case 3 & 0.65 & 0 & 1140 & 0.94 & 45 & 87 & 0.06 \\
case 4 & 0.093 & 180 & 990 & 1.2 & 52 & 68 & 0.36 \\
\hline \hline
\end{tabular}


TABLE VI.2(a). Surry (PWR), sequence: AB.

\begin{tabular}{|c|c|c|c|c|c|c|}
\hline \multicolumn{3}{|c|}{ Containment breach } & & \multicolumn{3}{|c|}{ Percent of iodine inventory } \\
\hline $\begin{array}{l}\text { Mode of } \\
\text { failure }\end{array}$ & $\begin{array}{l}\text { Area } \\
\left(\mathrm{m}^{2}\right)\end{array}$ & $\begin{array}{c}\text { Time } \\
\text { (h) }\end{array}$ & Source & $\begin{array}{l}\text { Retained } \\
\text { in RCS }\end{array}$ & $\begin{array}{l}\text { Ret. in cont. } \\
\& \text { other struct. }\end{array}$ & $\begin{array}{l}\text { Released } \\
\text { to env. }\end{array}$ \\
\hline$\beta$ & $3.3 E-02$ & 0 & $\mathbf{B M I}^{\mathrm{c}}$ & 2.7 & 88. & 8.7 \\
\hline$\beta$ & $3.3 E-02$ & 0 & $\mathrm{BMI}^{\mathrm{a}}$ & 2.7 & 92. & 5.0 \\
\hline$\beta$ & $3.3 E-02$ & 0 & SWEC $^{\mathrm{b}}$ & 2.7 & 93. & 4.7 \\
\hline$\beta$ & $9.3 E-02$ & 0 & SWEC $^{b}$ & 2.7 & 89. & 6.4 \\
\hline$\beta$ & $9.3 E-02$ & 0 & SWEC & neglected & 9 & 6.6 \\
\hline$\beta$ & $9.3 E-03$ & 0 & SWEC & 2.7 & 99. & 1.2 \\
\hline$\gamma$ & $6.5 E-01$ & 4.5 & BMI & 2.7 & 92. & 5.7 \\
\hline$\delta$ & $9.3 E-02$ & 0.5 & SWEC & neglected & 91. & 8.6 \\
\hline$\delta$ & $9.3 E-02$ & 3.0 & SWEC & neglected & 99. & 0.86 \\
\hline$\delta$ & $9.3 E-03$ & 0.5 & SWEC & neglected & 98. & 1.6 \\
\hline$\varepsilon$ & & 24.2 & BMI & 2.7 & 97. & $4.8 E-03$ \\
\hline$\delta$ & $9.3 E-02$ & 24.0 & SWEC & neglected & 99. & $4.0 E-02$ \\
\hline$\delta$ & $9.3 E-03$ & 24.0 & SWEC & neglected & 99. & $3.0 E-02$ \\
\hline
\end{tabular}

asame as above but, instead of one node of the containment, this calculation uses four.

${ }^{b}$ Retention in RCS is assumed (based on Gieseke et al., 1984). Includes effects of multicompartmentation of the containment and retention in structures outside containment.

${ }^{\mathrm{c}}$ Includes retention in structures outside containment.

TABLE VI.2(b). Surry, sequence: TMLB.

\begin{tabular}{|c|c|c|c|c|c|c|}
\hline \multicolumn{3}{|c|}{ Containment breach } & & \multicolumn{3}{|c|}{ Percent of iodine inventory } \\
\hline $\begin{array}{l}\text { Mode of } \\
\text { failure }\end{array}$ & $\begin{array}{l}\text { Area } \\
\left(\mathrm{m}^{2}\right)\end{array}$ & $\begin{array}{l}\text { Time } \\
\text { (h) }\end{array}$ & Source & $\begin{array}{l}\text { Retained } \\
\text { in RCS }\end{array}$ & $\begin{array}{l}\text { Ret. in cont. } \\
\& \text { other struct. }\end{array}$ & $\begin{array}{l}\text { Released } \\
\text { to env. }\end{array}$ \\
\hline$\beta$ & $9.3 E-02$ & 0 & SWEC & neglected & 85.0 & 15.0 \\
\hline$\beta$ & $9.3 E-02$ & 0 & SWEC & 90. & 8.5 & 1.5 \\
\hline$\beta$ & $9.3 E-03$ & 0 & SWEC & neglected & 98.0 & 2.1 \\
\hline$\beta$ & $9.3 E-03$ & 0 & SWEC $^{a}$ & 90. & 7.9 & 0.21 \\
\hline$\delta_{e}$ & $6.5 E-01$ & 2.55 & BMI & 85. & 11.0 & 4.6 \\
\hline$\delta$ & $9.3 E-02$ & 3.0 & SWEC & 90. & 9.8 & 1.5 \\
\hline$\varepsilon$ & & 12.3 & BMI & 85. & 15.0 & 0.28 \\
\hline$\delta$ & $9.3 E-02$ & 27.0 & SWEC & neglected & 99. & $3.6 E-03$ \\
\hline$\delta$ & $9.3 E-02$ & 27.0 & SWEC $^{a}$ & 90. & 9.9 & $3.6 E-03$ \\
\hline$\delta$ & $9.3 E-03$ & 27.0 & SWEC $^{a}$ & 90. & 9.9 & $2.8 E-03$ \\
\hline
\end{tabular}

${ }^{\text {a Retention in RCS is assumed (based on Gieseke et al., 1984). Includes effects of multicompartmentation of the containment and re- }}$ tention in structures outside containment.

The release factors, $S_{c}$, for SWEC were taken from Tables B.11 and B.13 of ANS (1984, Appendix B). These SWEC numbers are different from those in Table VI.2(b) because the latter take credit for further deposition in the structures outside the containment and also because of the effects of multicompartmentation. Considering the simplifications made, agreement with the more elaborate calculations of SWEC is quite good, especially because in this simple model the "diffusiophoresis" effects were neglected. These effects are estimated, based on SWEC sensitivity analysis, to reduce the fractional release by a factor of $1.3-1.5$.

The model presented is a highly simplistic abstraction of any real system, and the specific values shown in Figure VI. 2 would differ for different temporal histories selected. The source rate will vary with time in a more complex manner than a simple step release. The volumetric flow rate from the containment depends over time on pressure, temperature, and orifice characteristics, and will not be constant with time following $t_{c}$. The deposition time depends on the aerosol size characteristics, the concentration of aerosols, the effective area for deposition, and a variety of thermal-hydraulic factors. Similarly, the sign of $k$ need not be positive always; that is to say, conditions may arise that promote re-suspension of material that settled out at some earlier time and this would have the same effect (within the confines of our simple representation) as if the sign of the deposition velocity became negative. Even the sign of $Q$ may be reversed for parts of the accident as in the $A B$ sequence with large opening if sufficient steam condenses to produce a net negative containment pressure that would draw air back into the containment. Nor is the rate at which material can be injected into the containment volume necessarily a simple function of time. For the volatile species there are likely to be two release periods: the major release through the primary system after core uncovery, and a minor release following initiation of the core-concrete interaction. Indeed, it has been proposed that under some circumstances there could be late bursts 
TABLE VI.3. Peach Bottom, sequence: TC.

\begin{tabular}{|c|c|c|c|c|c|c|c|c|}
\hline \multicolumn{3}{|c|}{ Containment breach } & & \multicolumn{5}{|c|}{ Percent of iodine inventory } \\
\hline $\begin{array}{l}\text { Mode of } \\
\text { failure }\end{array}$ & $\begin{array}{r}\text { Area } \\
\left(\mathrm{m}^{2}\right)\end{array}$ & $\begin{array}{c}\text { Time } \\
\text { (h) }\end{array}$ & Source & RCS & Drywell & $\begin{array}{l}\text { Suppression } \\
\text { pool }\end{array}$ & $\begin{array}{l}\text { Secon. } \\
\text { cont. } \\
+ \text { SGTS }\end{array}$ & Envir. \\
\hline$\gamma^{\prime}$ & $6.5 E-01$ & 0.97 & BMI & 6.0 & 1.5 & 69.0 & 0 & 24.0 \\
\hline$\gamma$ & $6.5 E-02$ & 0.97 & BMI & 6.0 & 1.5 & 69.0 & 13.7 & 10.0 \\
\hline$\gamma$ & $7.4 E-02$ & 1.4 & IDCOR & 4.0 & 0 & 27.0 & 56.0 & 13.0 \\
\hline$\gamma$ & $7.4 E-02$ & 1.4 & IDCOR $^{a}$ & 73.0 & 0 & 27.0 & 0 & 0.1 \\
\hline$\tau^{*}$ & $1.9 E-02$ & 12.8 & $\mathrm{IDCOR}^{\mathrm{b}}$ & 1.0 & 0 & 60.0 & 36.0 & 3.0 \\
\hline \multirow[t]{2}{*}{$\gamma$} & $7.4 E-02$ & 1.4 & IDCOR $^{\mathrm{c}}$ & 27.0 & 2.0 & 55.0 & 13.0 & 3.0 \\
\hline & no failure & & IDCOR $^{d}$ & 25.0 & 0 & 75.0 & $2 E-02$ & $6 E-02$ \\
\hline
\end{tabular}

Peach Bottom, sequence: TW.

\begin{tabular}{|c|c|c|c|c|c|c|c|c|}
\hline \multicolumn{3}{|c|}{ Containment breach } & & \multicolumn{5}{|c|}{ Percent of iodine inventory } \\
\hline $\begin{array}{l}\text { Mode of } \\
\text { failure }\end{array}$ & $\begin{array}{l}\text { Area } \\
\left(\mathrm{m}^{2}\right)\end{array}$ & $\begin{array}{c}\text { Time } \\
\text { (h) }\end{array}$ & Source & RCS & Drywell & $\begin{array}{c}\text { Suppression } \\
\text { pool }\end{array}$ & $\begin{array}{l}\text { Secon. } \\
\text { cont. }\end{array}$ & Envir. \\
\hline$\overline{\gamma^{\prime}}$ & $6.5 E-01$ & 29.3 & BMI & 14.0 & 0.54 & 80.0 & 0 & 4.8 \\
\hline$\gamma$ & $9.3 E-03$ & 32.0 & IDCOR & 1.0 & 0 & 2.0 & 78.0 & 19.0 \\
\hline$\gamma$ & $9.3 E-03$ & 32.0 & IDCOR $^{\mathrm{e}}$ & 98.0 & 0 & 2.0 & $2 E-03$ & $<1 E-03$ \\
\hline
\end{tabular}

${ }^{*} \tau$ is failure by overtemperature in drywell (at $920 \mathrm{~K}$ ).

a Same as above but excludes revaporization.

${ }^{b}$ Assumes operator intervention (venting drywell through wetwell at 115 psia).

${ }^{\mathrm{c}}$ Assumes operator intervention (refilling condensate storage tank of CRD flow).

${ }^{\mathrm{d}}$ Assumes operator intervention as in both $\mathrm{b}$ and $\mathrm{c}$.

${ }^{\text {e}}$ Same as above but excludes revaporization.

of material injected as it becomes revolatilized within the primary.

Thus, the simplicity of Equation (VI.1) can be quite misleading were the reader not aware of the underlying complexity of the phenomena being represented in this crude fashion. Nevertheless, it may help to guide the reader through the compilation of results, and to illustrate the key importance of the relative timing of the release of radionuclides from the fuel and the containment breach. The scale of times that are important is given by the plate-out time. Of course, in view of the complexities involved, a quantitative prediction of $S_{c}$ requires consideration of a plethora of details that can only be addressed through complex models embodied in computer codes for calculational purposes.

A similar analysis could be applied to the primary system, using identical concepts for the retention in the fuel vs holdup times and removal times in the primary reactor vessel. One could thereby obtain a factor that we might call $S_{p}$ for fractional release from the primary system to the containment, as a function of corresponding time ratios appropriate for that system.

VI.C. The key factors influencing the "source term" for actual reactors

For an actual reactor, the "source term" calculation is the integral of the release of the hazardous radioactive species over time. This clearly involves the set of factors discussed in the stylized model above, but understood at the level of detail appropriate for the real system.

Before discussing the few factors for which we feel confident that some insights can be obtained, it is necessary to present the "results" of the several studies that will form the basis for our discussion. Tables VI.2-VI.3, compiled from the recent ANS source term review (ANS, 1984), BMI reports (Gieseke et al., 1984) and IDCOR (1984), show a large number of full scope calculations made on the four sequences mentioned earlier as forming the focus of this discussion. Study of that table reveals that comparisons are available for only a small number of parameters, although this is being extended (Lipinski et al., 1984).

\section{VI.C.1. Size of containment opening}

A very important parameter is the size of any containment opening, which was discussed in Section IV.D.5. It is self evident that a very large containment breach should lead to larger releases than would a very minor opening. What is of interest as an insight is the dependence of the releases on the approximate range of effective area for escape. One would expect that if the same "accident sequence" were analyzed by varying only the size of containment opening, the total amounts released to the outside environment would increase with increasing opening size, but not linearly-after a certain size of hole, the total amount released would reach its maximum value, such 


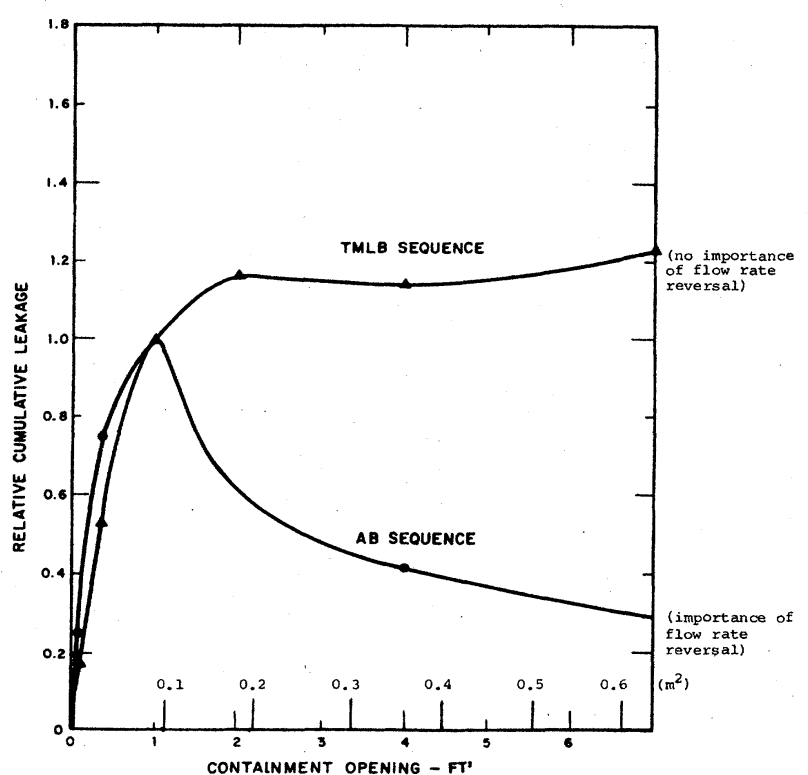

FIG. VI.3. Effect of size of preexisting opening on leakage of iodine and cesium (ANS, 1984). Note: normalized to a leakage of 1.0 for $1.0 \mathrm{ft}^{2}$ opening $\left(=0.09 \mathrm{~m}^{2}\right)$.

that for larger sizes only the rate of release would change but not the total amount released. Indeed, one would expect that for quite small openings the main parameter in determining the total amount of release would be $v$, which describes whether release was sufficiently slow that further settling and removal would occur between the start and completion of release. This is approximately what is found in the Stone and Webster calculations of the fractional loss term $S_{c}$ for iodine, as well as some other fission products, for 6 different pre-existing hole sizes $\left(t_{c}=0\right)$ ranging in value from $0.01 \mathrm{~m}^{2}$ to $0.65 \mathrm{~m}^{2}$ and for five different values of $t_{c}$ ranging from 0 to 7 hours, where in each case the hole size remained fixed, in this instance, at $0.09 \mathrm{~m}^{2}$. Some of the results of these calculations are shown in Figure VI.3. A simple regression analysis of the SWEC results leads to the following correlation for iodine

$$
\begin{aligned}
& S_{c}=0.432[1-\exp (-20.3 a)] F\left(t_{c}\right), \\
& F=1 ; t_{c}<3.1 \mathrm{~h}, \\
& F=\exp \left[-\left(t_{c}-3.1\right)\right] ; t_{c}>3.1 \mathrm{~h},
\end{aligned}
$$

where $a$ is the hole size in $\mathrm{m}^{2}$ and time is measured in hours.

The behavior of the factor $F$ here may be understood by noting that in SWEC calculations core uncovery begins at about $2.5 \mathrm{~h}$. into the accident and that for iodine this determines the value of $t_{v}$ to be about $3.5 \mathrm{~h}$ (see Sections IV.A.6 and IV.A.7). A comparison of the formula given by Equation (VI.7) with that of Equations (VI.5) and (VI.6), will indicate that there is a reasonable agreement between these, given the crudities of the approximations used to obtain Equations (VI.5) and (VI.6), and the uncertainties in model building. It should also be noted that to the extent cases calculated by BMI or IDCOR are comparable to the above SWEC series of calculations, these other results are also well represented by the correlation given in Equation VI.7 above.

What is assumed in both the crude model developed here and in the more elaborate calculations of SWEC is that over a range of accident conditions the final stages of fission product transport, accounting for leakage out of the containment, behave in a linear manner and the nonlinearities contained in such terms as the deposition velocity $k$ do not show up in any dominant fashion. It is interesting to see if this holds for more complex analyses. Consequently, any decontamination obtained at any stage of fission product transport through the plant will show up as a reduction in the source term in direct proportions. In addition one will note the fundamental importance that such parameters as $t_{c}$ and $a$ will play; they are both intimately related to the final process of radioactivity release since the onset of the volumetric flow $Q$ is determined by the time of containment failure and its magnitude will be directly proportional to the hole size.

What is found for TMLB at Surry (a protracted accident sequence) is that the critical opening size corresponds to an effective area of between one and a few square feet (about 0.1 to 0.5 square meters). The total iodine released varies by a small factor ( 3 to 5 ) over this range, but does not increase markedly for much larger openings. The detailed numbers are shown in Figure VI.3, but the general insight does not depend on the specific numbers. These numbers are also confirmed by Lipinski (1984).

For the $A B$ sequence at Surry (a PWR), the results in Figure VI.3 show a different behavior: as pre-existing hole size increases, the release at first increases but then passes through a maximum, and for much larger hole sizes the release is smaller. As one notes, the variation of the fractional release with hole size is no longer a monotonic function in the AB case, as it was in the TMLB case [and incidentally in the results given by Equations (VI.5) and (VI.6) as well]. The explanation can be found in the time dependence of $Q$, which is far more erratic in the AB sequence than in the TMLB one: The pressure in the containment volume does not increase in continuous fashion with time, because steam injected into the containment is predicted to condense and thus lower the pressure. In fact, when condensation takes place on a large enough scale, the sign of $Q$ can reverse so that one has inflow of air into the containment (from the outside) rather than outflow to the environment. This is calculated by SWEC to occur for this sequence. During such periods of inflow the escape of radioactive material ceases. There are no such periods of inflow computed for the TMLB cases so that the dependence on hole size remains monotonic.

However, the calculated flow reversal in the AB sequence is very dependent on the details of the assumptions made in the calculations. Bergeron et al. (1984) have recently reported on the results of some calculations using the CONTAIN code in which they find a monotonic increase of release with hole size. This they attribute to 
the assumption of a larger steam spike at RPV failure, or to the assumption of a hydrogen burn at that critical time, either of which would prevent the pressure going below atmospheric.

\section{VI.C.2. Primary system retention}

As with the case of containment opening size, one would expect a monotonic dependence of iodine release on whether significant material is retained inside the primary system, including the reactor vessel, the loops and piping, and ancillary surfaces. The more retained inside, the less should be released to the containment; hence, one would expect there would be less available for ultimate release to the outside environment. Here the central issues are two.

First, we ask whether the process is indeed always monotonic - that is, whether there are processes or effects whereby retention of greater amounts of certain species within the primary system does not automatically imply smaller environmental releases. So far, no non-monotonic processes seem to be found to be important, although a few are known to exist in principle.

Second, there is the question as to whether the ultimate environmental releases are approximately proportional to the amount released from the primary system to containment-that is, whether one can factorize the analysis problem into first determining retention in the primary vs release from primary to containment, and then separately determining containment retention vs containment release. If the amount ultimately released into the environment were reasonably proportional to the amount entering containment, then the analytical problem would be greatly simplified. Some important potential nonlinearities are known, among them the possible dependence of aerosol agglomeration and settling on the square power of aerosol concentration, which latter may or may not depend on the concentration of fission products in containment. While we know of no direct comparison among full-scope calculations on this issue, some smaller-scale experiments indicate that factorization may be an appropriate description of the accidents at issue.

These two findings may not be fully general for all important reactor accidents, but they seem to be true for the sequences and reactors considered here, limited to radioiodine and radiocesium. It is important to note that the numbers in Table VI.2(b) cannot be used to demonstrate factorization since factorization was assumed in the calculations.

\section{VI.C.3. Timing of containment breach}

Only a few direct calculational comparisons are available in which the time of containment breach is studied for a range of times that are all in the "late" period, meaning late enough to allow the important removal processes in containment to affect the ultimate release. The issue is how much difference there would be in the overall "source term" as containment-breach time becomes later and later (see Figure VI.4).

Unfortunately, the phenomena being calculated are quite complex in detail, and the calculations reveal only

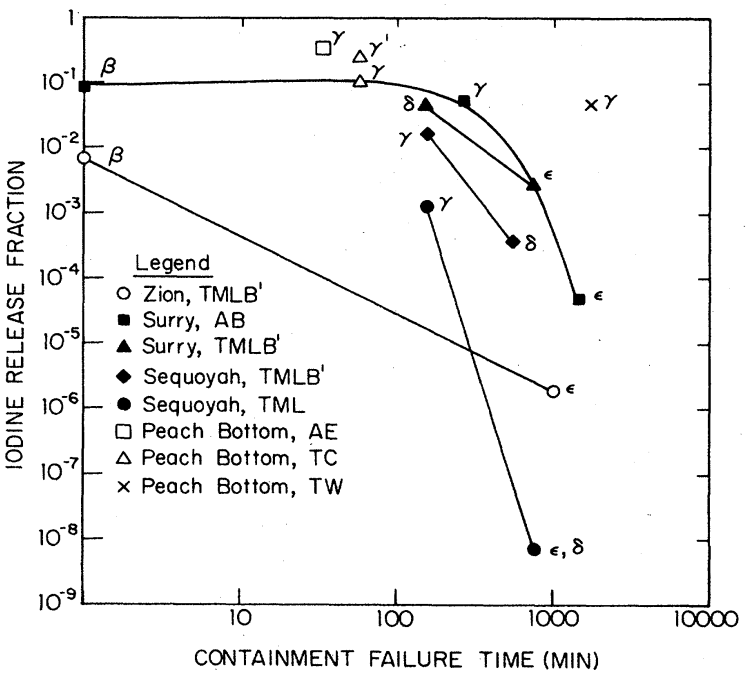

FIG. VI.4. Iodine release fractions vs containment failure time for combinations of accident sequences, failure modes, and reactor types.

the most general trends. It is difficult to derive broader insights with any confidence. The insight mentioned above that "later is better" seems to be a valid generalization, because mechanisms that cause increased plate-out and settling require time to affect the aerosols. The problem is that the parameters influencing the plate-out and settling rates are numerous and only poorly understood at present. The uncertain phenomena include aerosol shape factors, especially when relative humidity is low; the agglomeration rates in turbulent conditions; the extent of and influence of convection; and the role of any resuspension effects. Although the codes all either treat these effects explicitly or choose to ignore them, so much uncertainty exists that the code results have only weak quantitative meaning.

\section{VI.D. Summary}

Despite what appears to be an extensive information base of "source term" calculations, we conclude that it is very difficult at the present time to arrive at more than a few generalizations from them. All too many of the calculations have been performed in a way that makes their detailed interpretation either impossible or obscure. This is because the number of phenomena is quite large, and the various calculations treat these phenomena at many different levels of detail. Also, the number of calculational parameters, amongst which the analyst can choose, is large and not well constrained by experimental information. Finally, the calculations themselves involve approximations and computer-based computations of great complexity. For all these reasons, the most reliable insights are qualitative rather than quantitative, even though they arise from quantitative calculations; and are obtained from sensitivity studies rather than from full-scope calculations themselves. 


\section{THE SEVERE ACCIDENT RESEARCH PROGRAM}

\section{VII.A. The Nuclear Regulatory Commission program}

In this chapter we discuss the research program on severe accidents, emphasizing the work of the NRC and only cursorily discussing other programs. The Three Mile Island accident, as has been noted, caused serious reconsideration of the RSS source terms because the actual fission product releases, especially for iodine, varied so greatly from those predicted.

In the United States, the Nuclear Regulatory Commission, after Three Mile Island, initiated a program to develop new or improved safety systems for nuclear power plants (NRC, 1978b). The role of the Office of Nuclear Regulatory Research in supporting the NRC's mission is set forth in the following excerpts from the introduction to the FY85-FY89 Long-Range Research Plan (NRC, 1984c):

"The Nuclear Regulatory Commission's missionregulation to ensure that civilian activities involving the use of nuclear materials and facilities are conducted in a manner consistent with protecting the public health and safety, the quality of the environment, and the national security-calls for the exercise of the regulatory functions of rule making, licensing review, and inspection and enforcement.

In the process of carrying out its mission, the Commission makes policy decisions involving complex technical issues and varied and conflicting public attitudes. The Commission must base these decisions on an accurate understanding of the technical factors involved, and the NRC staff is responsible for ensuring that the Commission is fully informed."

"... The staff is assisted in these areas by the research program of the Office of Nuclear Regulatory Research (RES)."

In the Commission's Policy Statement and Planning Guidance for the Long-Range Research Planning exercise, we learn that:

[Policy:] "1. The purpose of the research program is to provide the technical basis for rule making and regulatory decision; to support licensing and inspection activities; to assess the feasibility and effectiveness of safety improvements; and to increase our understanding of phenomena for which analytical methods are needed in regulatory activities.

2. There should be continued emphasis on using research results in the regulatory process and on obtaining results that are useful therein. Staff should not engage in research merely to postpone tackling difficult regulatory issues.

[Planning Guidance:] 1. The research resources identified in NRC's budget should be allocated to support a balanced program between research to reinforce or revise the current regulatory base and conceptual research for improved reactor safety. The staff should be alert to research which shows that we ought to change our regulations. NRC regulations should be changed when research shows them to be either too stringent or not stringent enough."

The RES Severe Accident Research Program includes the following elements:

1. Accident Likelihood Evaluation, the reassessment of severe accident scenarios and their related probabilities;

2. Severe Accident Sequence Analysis, the analytical assessment of plant accidents within and beyond the design basis to provide strategies for severe accident prevention, management and mitigation;

3. Accident Management, the integration of strategies combining plant systems design and operation with operator guidelines and procedures to prevent, arrest, or mitigate the consequences of potentially severe accidents;

4. Hydrogen Generation and Control, the generation of information and analytic models to quantify the loads on containment from hydrogen burning;

5. Behavior of Damaged Fuel, the determination of the general behavior of damaged fuel in the $1,100 \mathrm{~K}$ to 3,000 $\mathrm{K}$ temperature range, the fission product release and invessel attenuation, hydrogen release, and the coolability limits in various stages and configurations;

6. Fuel-Structure Interaction, the generation of data on the consequences of high-temperature core fuel debris interaction with structures below the reactor vessel following escape from the vessel in severe accidents;

7. Containment Analysis, the development of an analytical tool for the assessment of the challenge to the containment system from postulated severe accidents;

8. Fission Product Release and Transport, the development of models and generation of data (to support the development and assessment of the models) to determine the potential radiological source term released from LWR plants during severe accidents;

9. Containment Failure Mode, the treatment of three possible failure modes-valve failure, materials failure, and mechanical failure of containment;

10. Fission Product Control, the evaluation of the effectiveness of engineered-safety feature systems under severe conditions;

11. Risk Code Development, the periodic improvement of the set of computer codes presently used in analyzing severe accident physical processes for PRA;

12. Accident Consequence and Risk Reevaluation, the application of the risk codes in concert with the results from other elements of the program to produce current assessments of the consequences and risk of severe accidents in LWR's, and 
13. Risk Reduction and Cost Analysis, the development of methods and analyses for the systematic evaluation of the costs and benefits of alternative concepts for reactor design and operation.

In 1980, the Commission ordered a review and a report on the best technical information then available for estimating the release of radioactive material during postulated severe accidents in commercial light water reactor power plants (NRC, 1981).

The NRC also established an Accident Source Term Program Office to oversee and coordinate a research program that would further develop the technical data base for source term issues and review the validation of codes used to predict fission product releases in selected accident sequences.

The essential elements of the program are the review and validation of the accident release codes which were prepared at Battelle Columbus Laboratories (Gieseke, 1984), an experimental program designed to provide additional experimental data for the phenomenological models upon which the codes are constructed (ORNL, ANL, SNL, INEL), extensive peer review by the technical community in the United States and abroad, and the appraisal of the risk and regulatory significance of modified source terms.

NRC plans to release the results of this program in a technical report, NUREG 0956, A Reassessment of the Technical Basis for Estimating Fission Product Behavior During LWR Accidents. A draft will be available for public review and comment because any significant revision in the source terms will require re-evaluation of regulatory policies on such matters as emergency preparedness, siting, and the design of reactors.

The source term research continues to be assigned first priority in the RES plans; and the ACRS, in its annual report to the Congress commenting on both the Commission's objectives and on the research program, gives highest priority to the RES Accident Evaluation and Mitigation program.

The Nuclear Regulatory Commission program has, as its focus, the set of complex computer codes discussed in Chapter V which incorporate models of phenomena occurring in selected accident sequences. There have been no full-scale experiments in which fission product behavior could be followed as a reactor core degrades. Therefore, the models rely in turn on a great number of experiments and theory which constitute the scientific and technological data base.

Figure V.1 (Chapter V) shows the codes and their relationship and notes that part of an accident sequence which each code describes. Table V.1 lists some newer codes, dealing with separate effects, which may replace the older codes when they have been validated.

Another project within the source term research program is the development of the MELCOR risk-assessment code. This code will include thermal-hydraulic fission product behavior, consequences, and economic modules. The code, less detailed than the Battelle Suite, would contain less mechanistic detail and would run faster. Use of the MELCOR code would provide an approximate method of estimating the timing and extent of key events in accident sequences which is required for risk assessment. The newer codes mentioned above will be used to benchmark MELCOR. Figure V.5 illustrates how MELCOR is related to the other codes. It is expected that, if circumstances arise in which MELCOR's results would be inadequate for a highly specialized problem, recourse would be had to the more highly specialized codes that derive from detailed models of phenomena of particular interest.

\section{VII.B. Program of other U.S. organizations}

Several other organizations, knowing of the NRC source term program, have begun independent reviews of the source term issue: among these are EPRI, ANS, and IDCOR. There has been responsible exchange of information among all those participating in this work, and the study group has had the benefit of access to and presentations on results to date.

\section{VII.B.1. American Nuclear Society (ANS)}

The American Nuclear Society's (ANS) Special Committee on Source Terms was asked in 1982 to develop a consensus within the technical community on the state of knowledge about the source term, and to assess the methods and assumptions used to describe fission product behavior and retention. The Committee's charge included examination, review, and evaluation of the establishment of source terms for particular accident sequences, quantification of fission product retention, and comparison with assumptions and conclusions of the RSS and other related documents. The Committee was also charged with an educational mission: providing a readable report to the technical and lay community. As part of the Committee's work, the Stone and Webster Engineering Corporation (SWEC) undertook parametric investigations of factors affecting retention of fission products in the containment and in auxiliary structures. The American Nuclear Society released its report on November 13, 1984.

\section{VII.B.2. Industry Degraded Core Rulemaking Program (IDCOR)}

The Industry Degraded Core Rulemaking Program (IDCOR), managed by the Technology for Energy Corporation, is a program organized and funded by the nuclear industry (utilities, NSSS suppliers, and architect engineers) to develop a comprehensive, integrated, welldocumented, technically sound position on the issues related to severe accidents in nuclear power plants.

As part of the program, some new models and computer codes were developed to be used in the analysis of accident sequences (such as MAAP and RETAIN). 
VII.B.3. The Electric Power Research Institute (EPRI)

The Electric Power Research Institute (EPRI) has begun experimental programs that study, measure, and define the physical and chemical conditions under which fission products can be released and transported in a severe reactor accident.

Among the projects bearing upon the source term issue which EPRI supports are:

a. Development of an in-vessel fission product release and aerosol formation model.

b. Investigation of fission-product release from heated, fully pre-irradiated fuel pins.

c. Source Term Experimental Program at the TREAT facility at INEL.

d. Investigation of the chemical and physical transformation and deposition characteristics of a mixture of volatile fission products flowing in a hot duct.

e. The MARVIKEN experiment.

f. Event "V" Demonstration Tests at HEDL.

g. The comparison and validation of aerosol transport codes.

h. The study of aerosol behavior in simple geometries.

i. Hydrodynamic experiments with and without aerosols accompanied by the development of appropriate models.

j. Corium-steam interactions.

VII.B.4. The Stone and Webster Engineering Company (SWEC)

SWEC organized an internally-funded source term study group to examine a number of issues related to source accidents in nuclear power plants about two years ago. This group has done parametric study of fission product retention in PWR containment structures and contiguous structures (assuming that no active engineered safety features function), which carefully examines parameters considered to have been neglected or oversimplified in other analyses.

VII.B.5. The New York Power Authority (NYPA)

The New York Power Authority (NYPA) in 1983 undertook detailed analyses of the radionuclide releases for risk-dominant accident scenarios in the Indian Point
Probabilistic Safety Study. The group examined the physical and chemical behavior of four fission products in the primary system in the containment and in the environment, given failure of containment.

\section{VII.C. Work outside the USA}

There is much work in progress on source terms outside the United States. A list of that known to the committee follows.

\section{VII.C.1. Nuclear Energy Agency (NEA)}

The Committee on the Safety of Nuclear Installations of the Nuclear Energy Agency (NEA).

NEA has established a Group of Experts on the Source Term (GREST) which will compare the mathematical modeling, numerical techniques, and predictions of codes used to model the transport of fission products in the containment of an LWR following a severe accident. This group has been asked to coordinate its activities with those of the NRC's Accident Source Term Program Office. The work is to be completed by 1985 , and the plants and accident sequences to be considered are: AB (hot leg) and $\mathrm{S}_{2} \mathrm{D}$ (cold leg) sequences for the Surry $1 \mathrm{PWR}$ and the large break LOCA for the German Biblis B PWR (steel/concrete double containment). No failure of the containment is assumed. The U.S. Nuclear Regulatory Commission is the lead organization for this project and assumes overall responsibility for the implementation of the exercise. The NRC will be assisted in this task by EPRI and ORNL.

\section{VII.C.2. Commission of European Communities}

Besides allocating a number of study contracts to research organizations of Member countries of the Community which address open questions such as aerosol resuspension, diffusiophoresis, stratification, iodine partition coefficients, and fission product chemistry at high temperature, the CEC is organizing a sensitivity study for the AB hot-leg sequence for Surry 1 PWR. The parameters to be studied in this exercise are

(a) Steam condensation rate;

(b) Duration of aerosol source;

(c) Granulometry of aerosol source;

(d) Emission of aerosol source;

(e) Collision efficiency;

(f) Aerosol soluble/unsoluble;

(g) Hydrogen combustion;

(h) Leak rate.

\section{VII.C.3. Federal Republic of Germany (FRG)}

The Federal Republic of Germany undertook a risk study, published in 1979, which calculates risk sequences for the German reactors in the same manner as the RSS. 
The source term research program is part of the German severe fuel-damage research program, and of the core melt research programs for PWR's. Separate experimental programs to explore the behavior of certain radionuclides (iodine, cesium, and tellurium) are also in progress.

The severe fuel-damage research program investigates the physical, chemical, and metallurgical phenomena in the temperature range of $1500 \mathrm{~K}$ to $2100 \mathrm{~K}$. The goal is to quantify the safety margins of operating reactors. The program will be completed in 1986 .

The core-melt research program, which is scheduled for completion in 1985, has as its goal providing bestestimate data for the source term to be incorporated in a revised version of the German Risk Study.

The exploration of the fission-product and aerosol release into the containment includes the SASCHA program, which provides data on release for gaseous and particulate species. The behavior of the iodine release has been of special interest since 1982, and a model has been developed which will be revised as more data become available.

Large-scale verification and demonstration experiments are currently underway as part of the DEMONA test program. The aims of this program are:

- to demonstrate the efficiency of natural aerosol removal processes in a sufficiently large experiment and under realistic (core-melt) conditions.

- to demonstrate the predictive capabilities of the NAUA code.

- to demonstrate the applicability of the COCMEL code as the appropriate tool for simulating containment thermodynamics.

Tests are performed at the PWR-Model containment at Battelle-Frankfurt (BF) which is similar (1:4 linear scale) to the Biblis A PWR containment.

The BETA test program will provide data on physical and chemical processes in the interaction between a hotcore melt and the concrete basemat sufficient to verify the WECHSL, CORCON, and KAVERN codes.

\section{VII.C.4. France}

The French source term program includes investigation of volatile fission-product aerosol behavior to validate the French aerosol code; determination of the efficiency of sand bed filters and water pools to remove iodine and cesium aerosols; iodine deposition on concrete and steel; re-emission of iodine from sump water, and aerosol removal mechanisms under dry conditions. Other experiments will try to measure fission-product release in-pile at Grenoble from pre-irradiated fuel under the conditions of the TMI 2 accident. Transport aspects of aerosol physics will be tested during 1986 in the $3 \mathrm{~m}^{3}$ containment, HEVA, at Cadarache.

\section{VII.C.5. Sweden}

The Swedish source term program is intended to provide the technical basis for the development and verification of computer codes used to evaluate specific accident sequences for designated Swedish nuclear power plants. The program, to end in 1985, includes participation in the MARVIKEN project and a special experimental investigation of cable pyrolysis in steam and nitrogen atmosphere.

The Reactor Accident Mitigation Analysis (RAMA) project has been organized to collect and digest the results of relevant research and development work and to provide these results to those who require such information. A complete set of accident sequences for each of the Swedish reactors, the results of the first phase of the work on computer codes for the analysis of severe accidents, is now available.

\section{VII.C.6. Belgium}

In Belgium, the results from recent source term research are of interest primarily for use in that country's systematic re-evaluation program for commercial power plants and for emergency planning. A proposal to study certain aerosol processes relevant to the radioactive containment in a reactor after core melt is under review. Belgium has supplied irradiated fuel pins for the USNRC Severe Fuel Damage Experiments.

\section{VII.C.7. Canada}

The source term research program in Canada, which is designed to understand the particular design of the CANDU-type reactor, is driven partly by licensing requirements that place very stringent limits on fission product release during small-scale accidents which can be expected to occur with high frequency. In this type of reactor, individual tube failures are likely to be quenched by the large $\mathrm{D}_{2} \mathrm{O}$ pool, and the particular failures discussed in this report cannot occur.

The Atomic Energy of Canada, Ltd. (AECL) funds research on in-core and out-of-core fuel release, thermal hydraulics, hydrogen production and combustion, fission-product chemistry, and the development of computer models.

Canada also participates in the MARVIKEN project (with access, therefore, to the DEMONA test results), and the TREAT tests at INEL.

Ontario Hydro has commissioned tests at PBF at INEL to study the thermomechanical behavior of zircalloy fuel cladding and cladding oxidation.

The University of Toronto is studying the partition and transport of iodine during the steam flashing of an iodine solution. 


\section{VII.C.8. Denmark}

The Danish source term program includes modest research in aerosol physics and chemistry. Danish utilities formed a small source term group two years ago to utilize recent research results to calculate more realistic off-site releases from power plants of potential interest to Denmark.

\section{VII.C.9. Finland}

In Finland, USNRC Regulatory Guides 1.3 and 1.4 are used to evaluate the radiological consequences of accident sequences. A project to establish the capability to assess severe accident sequences for existing and future power plants using selected computer codes is under way. Finland also participates in the MARVIKEN project and the IDCOR program.

\section{VII.C.10. Japan}

The Japan Atomic Energy Research Institute (JAERI) has established a task force to identify source term and other areas where further research is needed. Japan participates in several international research projects such as: TMI, LOFT/FP, SFD, Mx-V, 2D/3D, LACE, and MARVIKEN 5 ATT. Figure VII.1 summarizes the areas of source term research now under investigation.

\section{VII.C.11. Netherlands}

Source term research in progress in the Netherlands includes work on the thermochemistry of the fission products, namely, iodine, cesium, tellurium, and oxygen. These studies are to be completed in 1986. Research is also in progress on diffusiophoresis, a CEC study contract, and on work at ICEMA laboratories on the release rates and the chemical composition of the fission products emitted from fuel.

Three proposals for a study of the thermal hydraulic behavior in the containment are under consideration.

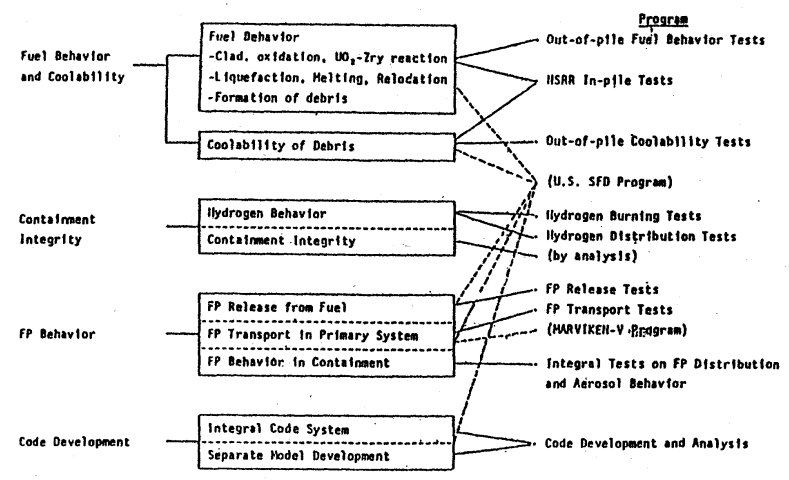

FIG. VII.1. SCD research program at JAERI.
This program may be done in cooperation with Belgium and France, and would be expected to last four years. Possible participation in EPRI's LACE program is also under review. The Netherlands also participates in the NRC's SARP program, in the PBF program at INEL, and in the MARVIKEN project.

\section{VII.C.12. Switzerland}

The source term research program in Switzerland includes the development of a model for iodine absorption in the water of the fuel pool, experiments on the evaluation of bubble size and decay in a fuel pool, iodine chemistry in water/water vapor-air systems, and investigation of the influence of strong gamma-ray fields on the redox chemistry in an iodine/water system. Switzerland also participates with Germany in the DEMONA experiment, the BETA experiment, and studies of fission-product release to the environment (DRS, phase B). In 1984, work on iodine chemistry modeling will be enhanced, and work on core-concrete interactions will begin.

VII.C.13. Italy

Italy participates in several international research projects such as: TMI, LOFT/FP, SFD, MARVIKEN 5 ATT, and LACE.

VII.C.14. U.K.

The United Kingdom contributes to the Nuclear Energy Agency and Commission of European Communities and also has studies of its own in connection with the proposed construction of an LWR at Sizewell (Butland et al., 1984).

\section{VII.C.15. USSR}

The committee made enquiries, both official and unofficial, of appropriate authorities in the USSR but received no response to requests for information on the research program or any accident experience.

VII.D. The organizational structure of the Office of Nuclear Regulatory Research (NRR)

In the course of its work, the study group has had occasion to examine the structure, function, and operation of the Office of Nuclear Regulatory Research to assess the support the organization brings to the program. Figure VII.2 shows the organization of the Office, and Figures VII.3, VII.4, VII.5, VII.6, and VII.7 show the funding by fiscal year, phenomena, laboratory, research type, and research application, respectively. 


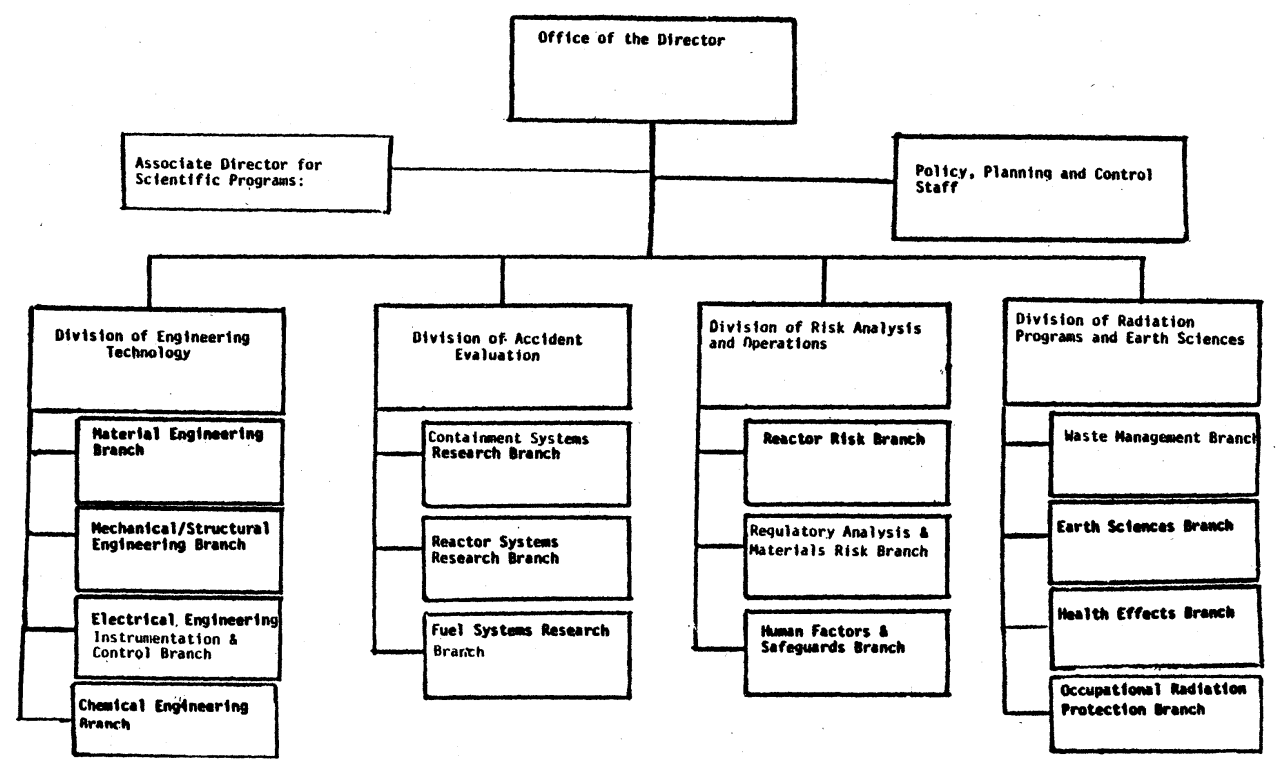

FIG. VII.2. Organizational structure of the NRC Office of Research.

\section{VII.E. Coordination}

Each group listed above in Section VII.B has carried out its own assessment of the source term, although each makes use of the experimental data, and sometimes the computer programs, of the others. The results of the experiments have been discussed at various technical meetings. The NRC has organized "peer review" meetings at which the Battelle Columbus and IDCOR work have been compared. There have also been a number of meetings organized by the American Nuclear Society in which the source term work has been an important segment of the agenda (Cambridge, MA, August 1983; New Orleans, LA, June 1984; Snowbird, UT, July 1984). Several members of the study group have attended one or more of these

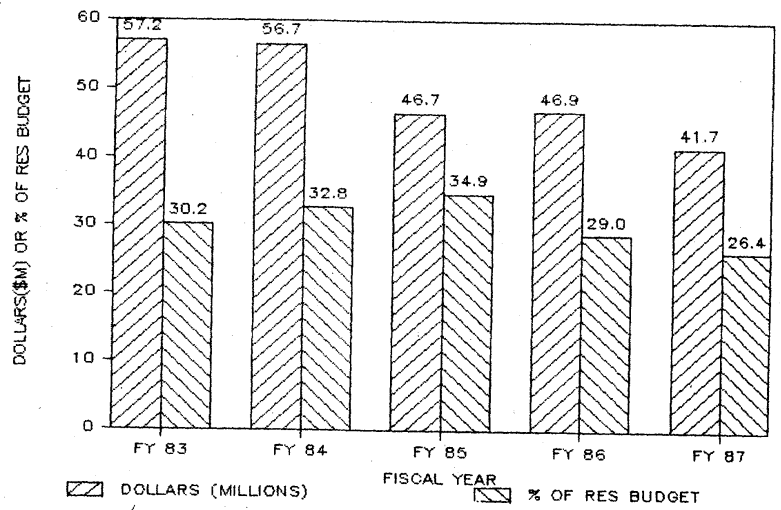

FIG. VII.3. SARP funding by fiscal year. meetings, and there cannot be any doubt that the professionals at these meetings are dedicated to resolving these questions. The diversity of groups, of computer codes, and of approaches to understanding the source term have resulted in a type of competition to identify phenomena, ignored in the past, which might significantly alter the source term. This competition is valuable in that it reduces the chance that any phenomenon of importance has been overlooked.

The work of the study group was hampered in that it was difficult to compare these studies. Each group incorporates in its calculations a different reactor, or set of reactors, and different sequences. This makes it hard to identify the reason for the inevitable differences in the results of the calculations. For example, in the work on pressurized water reactors, NYPA calculates its results

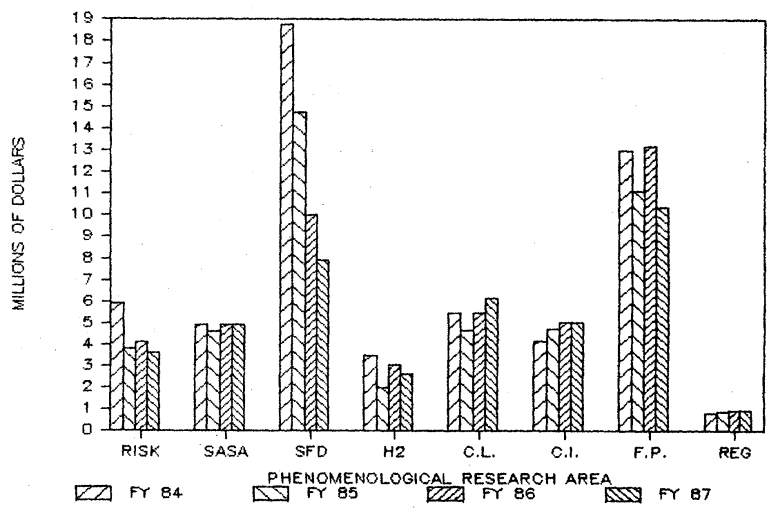

FIG. VII.4. Distribution of funds by phenomena for severe accident research program. 


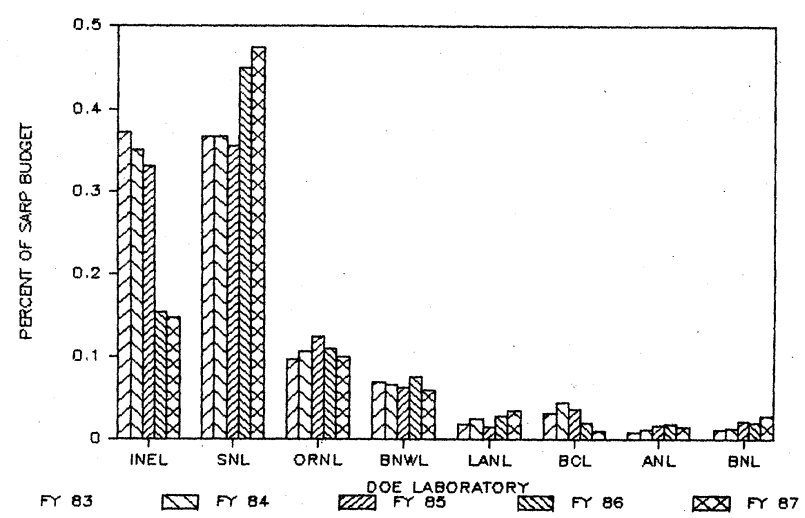

FIG. VII.5. Distribution of laboratory funding for severe accident research program.

for Indian Point; Gieseke et al. use Surry and do an abbreviated analysis for Zion, and IDCOR did calculations only for Zion. The Germans do their calculations for their own reactors.

The study group recommends that a reference reactor and a set of initial conditions be chosen, and that all groups then compare their calculations for given accident sequences. It is also important that all the computer codes that are used be generally available and clearly described.

\section{VII.F. Recommendations for future research}

The study group has identified some specific elements of the source term technical data base which deserve inclusion by the technical community in the overall research program. These are listed by group.

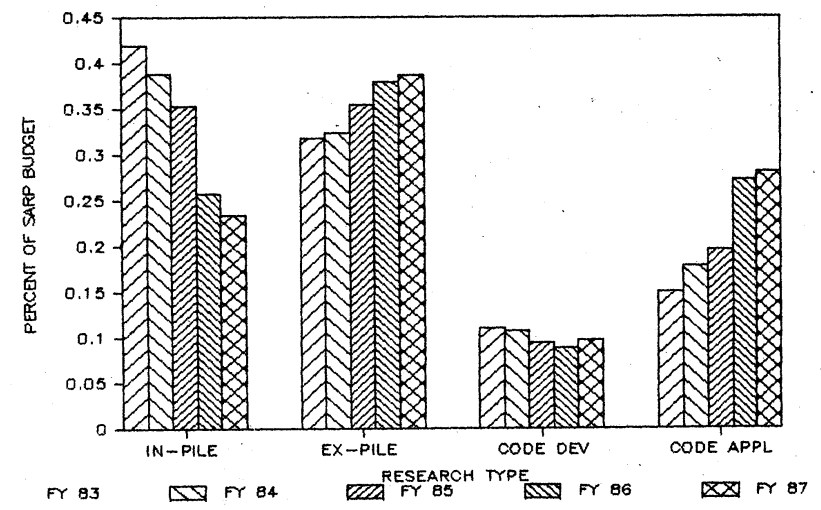

FIG. VII.6. Distribution of funds by research type for severe accident research program.

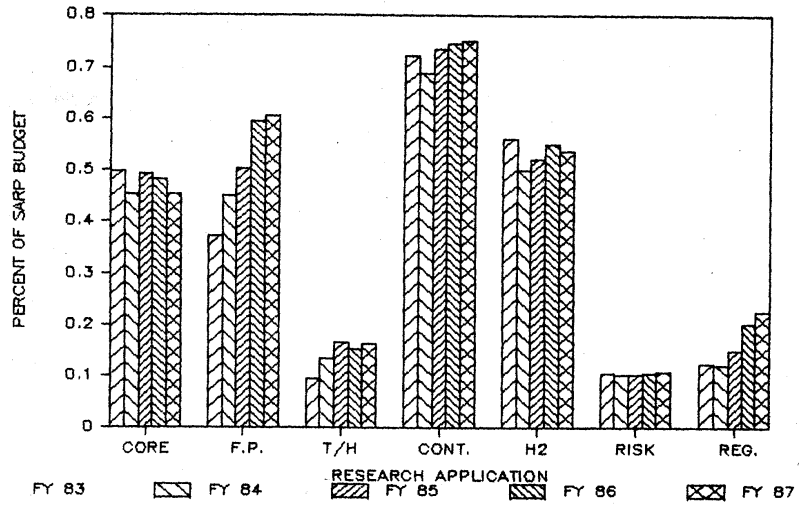

FIG. VII.7. Distribution of funds by application for severe accident research program.

VII.F.1. Vaporization of low volatility fission products

The release of fission products and actinides of low volatility during fuel degradation should be measured more extensively at realistic temperatures and under conditions duplicating as closely as possible those that would exist during an accident sequence (see IV.B.3).

These species should be considered in as much detail as are iodine and cesium in evaluating the mechanisms and quantitative contributions to source term releases. These relatively nonvolatile radioactive source term elements could contribute substantially to lung and ground doses. The biological dose conversion factors of many of these isotopes are sufficiently high that even the small increases associated with uncertainties in their releases could result in substantial increases in their contributions to radiological doses and to associated health effects (see I.B.6).

VII.F.2. Thermal hydraulics

of the core-concrete interaction

There is an urgent need for a reliable comparison of large scale tests and computer calculations on the core concrete interaction; the important physical parameter to be determined is the temperature as a function of time because this is the driving force for chemical and aerosol releases. The BETA experiments at KfK Karlsruhe, West Germany, and the experiments at Sandia National Laboratory, if successfully carried out, should go a long way toward satisfying this need.

Without these comparisons we cannot be completely sure of the radionuclide releases from the core concrete interactions and, in particular, the releases of normally nonvolatile materials (Sections IV.A.8 and V.B.8). 
VII.F.3. Release of refractory materials

in the core-concrete interaction

More experimental data are needed which describe the release of fission products and actinides in the core concrete interaction. The fission products of interest are all those other than iodine and cesium. Experiments of this type are being conducted at Sandia National Laboratory and Kernforschungcentrum at Karlsruhe. In this program emphasis should be placed on achieving experimental conditions that duplicate as closely as possible those that would exist in a degraded core accident. The important data that should be collected in these experiments include temperature of the melt, gas generation rates, gas composition, aerosol production, and aerosol composition. The materials studied should include plutonium and other elements of particular interest (see IV.B.5).

\section{VII.F.4. Transport of radionuclides} through the reactor

Extensive experimental programs should be conducted to identify and quantify chemical reactions of the fission products and actinides that would influence their transport through the reactor system.

Examples of such programs include the study of the reaction of cesium hydroxide with stainless steel and other materials of construction, its reactions with silver, boron carbide, tin, and other special metals, and the postulated reaction of cesium iodide with boric acid. The experimental conditions should duplicate in detail those that would exist in accident situations (see IV.B.4).

\section{VII.F.5. Tellurium behavior}

More attention should be given to the behavior of tellurium during the accident sequence, including the fate of iodine formed by the decay of tellurium released from the core concrete interaction (see IV.B.5).

\section{VII.F.6. Release of volatile forms of iodine}

Mechanisms (including radiolytic reactions) for releasing volatile forms of iodine in containment should be assessed.

These experimental results would substantially reduce uncertainties in predicting the source terms for sequences postulating late containment failure (see IV.B.5).

\section{VII.F.7. Damage progression in the core}

A better understanding of the rate and modes of damage progression in the core is highly desirable.

The importance of understanding these phenomena was recognized in the earliest analyses of accident sequences and the mitigation of their consequences. It is widely accepted that the problems of designing and mounting such large-scale experimental programs are difficult, complex, and probably intractable. Any experimental work on this problem, even on a modest scale, will continue to be important. These data are important because the complexity of the system makes any prediction of the effects that may be observed somewhat uncertain, as described in Section IV.A.6.

\section{VII.F.8. Fragmentation of the corium at RPV melt-through}

Experimental exploration and development of a theory on fragmentation of corium as it is expelled from a pressure vessel onto water is needed. These should include experiments on small steam explosions which, while not energetic, can fragment the fuel and accelerate the heat transfer to the containment gas, and work on the fragmentation of high-pressure jets.

This research is needed to resolve a small lingering doubt about the circumstances where the pressure spike at reactor vessel melt-through would crack the containment. The research would also provide information about the dispersion of corium and production of aerosols in the containment (see IV.A.7).

\section{VII.F.9. Research on containment breach}

Research on and analysis of phenomena that pose a threat of early, large-scale, containment failure should be continued.

The results would improve predictions of source terms and the probabilistic risk assessment for extremely unlikely sequences for which, however, very large releases of radioactive nuclides are likely.

The results of such research would improve the understanding of the timing of containment failure (early or late) and, therefore, the size of the source term (large or small) (Section IV.E).

\section{VII.F.10. Containment-failure modes}

It is important to complete the NRC and EPRI test programs designed to understand containment failure modes, pressures, and leak rates.

The accurate prediction of containment failure parameters is essential to accurate source term prediction (see Chapter VI).

\section{VII.F.11. Generation mechanisms for aerosols}

The potential for generation of aerosols of refractory species by mechanisms such as bubble bursting, large droplet breakage on impact, and steam explosions needs experimental investigation on at least a small scale. This may be an important contribution to the source term for the lanthanide series of elements (see Section IV.C.3). 
VII.F.12. The effectiveness of suppression pools

and ice beds

Aerosol removal by suppression pools and by ice beds should be measured with experiments of sufficient scale which cover a wide range of parameters to determine the decontamination factors for these engineered safety features over the range of accident conditions. There have been no experimental studies of aerosol removal in ice beds, and experimental study of decontamination factors by suppression pools is underway (see Section IV.C.7).

\section{VII.F.13. Growth and deposition of aerosols}

Experiments on the growth and deposition of aerosols suspended in confined spaces that have internal structure and are subject to free convection should be continued. Attention should be paid to transient thermal influences, potential thermal stratification, and the presence of aerosol sources in the chamber for sustained time periods. The results should be compared with code predictions and all fitting parameters, (e.g., shape factors, effective density, etc.) should be clearly indicated (see Section IV.C.4.b).

\section{VII.F.14. Change of sequence by fission} product heating

The possibility and consequences of failure of the primary reactor system resulting from the decay heat associated with large localized deposits of aerosols containing fission products requires investigation, because such failure can alter the accident sequence (see Section IV.C.4.e).

\section{VII.F.15. Intercomparison of aerosol codes}

A critical, detailed intercomparison of the codes used to compute aerosol transport and deposition should be undertaken. Where predictions of the various codes differ significantly, the source of the discrepancy should be identified and a recommendation made of the preferred approach. This work requires improved documentation of these codes so that they can be used with confidence and understanding by independent research groups (see Section IV.C.8).

\section{VII.F.16. Aerosol deposition on pipes}

The research on leakage of aerosols from the containment to the environment through pipes and other leakage paths should continue. This is being done at the Containment S Test Facility (CSTF) at the Hanford Engineering Development Laboratory (HEDL) and is funded by EPRI (see Section IV.C.9.c).

This research is important to identify any factors that may reduce radionuclide release in $V$ sequences and sequences involving containment isolation failure.

\section{VII.F.17. Natural circulation research}

It is important to expand theoretical analyses of code development to superimpose natural circulation phenomena onto the reactor vessel, primary system, and containment thermal hydraulics models. Some modeling experiments might be useful to increase confidence in these predictions (see Section IV.A.5).

\section{VII.F.18. Integrated severe-accident code}

Development of a fast-running computer program that integrates the suite of severe accident codes should be continued. The subroutines of this program should be carefully checked against specialized codes and experiments. When the integrated code is at an appropriate level of completion, it should be subjected to peer review, and then published in a form accessible to users (see Section V.E).

\section{CONCLUSIONS AND RECOMMENDATIONS}

\section{VIII.A. Conclusions}

VIII.A.1. The study group finds that considerable progress has been made since publication of the Reactor Safety Study (NRC, 1975) in developing both a scientific basis and calculational ability for predicting the source term. In a number of cases, new calculations indicate that the quantity of radionuclides that would reach the environment is significantly lower than that calculated in the Reactor Safety Study. This reduction can be attributed to three principal factors: (i) the recognition that reactor containments are stronger than assumed in the Reactor Safety Study and therefore fail, if at all, at later times; (ii) inclusion in the modeling of previously neglected physical and chemical phenomena that lead to the retention of fission products; and (iii) inclusion of additional sites (suppression pools, ice beds, auxiliary buildings) that trap radionuclides more efficiently than previously assumed. These factors are discussed in more detail in Sections VIII.B. 1 to VIII.B.8 below.

VIII.A.2. The study group examined the chemical and physical phenomena considered by the technical community since the Reactor Safety Study was completed. For most sequences and most radionuclides, these phenomena reduce the source term from that calculated in the Reactor Safety Study.

However, one mechanism that might, for some sequences, increase the radionuclide releases above those calculated in the Reactor Safety Study is the release of nonvolatile radionuclides in the core-concrete interaction. It is important to complete the experiments now underway to improve our knowledge of the physics and chemis- 
try in this crucial area. Moreover, the analyses performed in the recent studies that we have surveyed have not treated all types of reactors nor all types of containments in equal detail. It is impossible to make the sweeping generalization that the calculated source term for any accident sequence involving any reactor plant would always be a small fraction of the fission product inventory at reactor shutdown. Although further studies may improve this situation, some of the reasons for this inability are enumerated in Sections VIII.C.1 to VIII.C.5 below.

\section{VIII.B. Detail of conclusion VIII.A.1}

VIII.B.1. It is now generally believed that large scale failures of reactor containments will not occur until their yield stresses are exceeded-at internal pressures about $21 / 2$ times greater than the nominal design pressures. Some leakage may occur at lower pressures; in fact, earlier leakage could limit stresses to values below the yield stress. Quality assurance and testing programs are necessary to ensure that an individual containment achieves and retains the strength that is possible. The study group noted that such programs exist, but did not review them or their efficacy (see Section IV.D).

VIII.B.2. There are many accident sequences in the Reactor Safety Study in which large scale early failure was assumed. Detailed careful calculation of several risk dominant sequences, such as TMLB', suggest that such large early failures predicted for them do not occur if the containment is as strong as calculated. One reason for this is that accident-induced pressures within the containment are not expected to exceed yield stresses until many hours after the reactor pressure vessel failure. Another significant reason is that steam explosions large enough to challenge the containment directly are now considered very unlikely (see Sections IV.E.2 and III.C.1).

VIII.B.3. A delayed containment failure can allow time for natural, passive, mitigating processes to act. Several mechanisms operate that deposit aerosols onto surfaces both within the primary system and within the containment. To the extent that the Reactor Safety Study underestimated the time to failure and did not fully model these removal processes, the RSS overestimated the "source terms" for the accident sequences (see Sections III.C.1 and IV.D).

VIII.B.4. A delayed containment failure can also allow time for the plant operators, if they are adequately trained, to recover failed systems and to make effective use of active mitigating systems to achieve a safe shutdown (see Section III.C.1).

VIII.B.5. The source term for the release of noble gases, krypton and xenon, is better understood than any other source term. Almost all of these radionuclides are released from the fuel; they are chemically inert, and are not affected by most of the retention mechanisms that reduce the importance of other radionuclides. On the other hand, they are not absorbed by the human body and do not deposit on the ground. Their releases are not believed to differ significantly from those calculated in the Reactor Safety Study, except insofar as radioactive decay reduces their radioactivity. If containment failure is delayed, the reduction is a factor of five between a two-hour release and a twenty-four-hour release (Section II.B).

VIII.B.6. The chemical form of some important fission products favors retention rather than release. Cesium hydroxide $(\mathrm{CsOH})$, the dominant form of cesium that is observed in release from fuel irradiated in water cooled reactors, can interact chemically with surfaces in an irreversible way. Iodine is usually observed to take the form of cesium iodide $(\mathrm{CsI})$ rather than molecular iodine $\left(\mathrm{I}_{2}\right)$, and CsI can deposit more readily than $\mathrm{I}_{2}$ because CsI has a lower vapor pressure and higher solubility in water. In many sequences, tellurium tends to form nonvolatile compounds with zirconium or stainless steel (see Section IV.B).

VIII.B.7. Fission products are calculated to be trapped, to a greater extent than was formerly assumed, in auxiliary buildings and related structures, suppression pools, and ice condensers, even though these were not designed to remove fission products. The configuration of auxiliary buildings, and the penetrations from them to the containment are very plant specific. The ice beds and suppression pools may remove large quantities of fission products. However, well designed, appropriate experiments are necessary to establish the effectiveness of removal under accident conditions. No experimental program has investigated the removal of fission products by ice condensers, and only recently has an appropriate program for suppression pools been started. The decontamination factors are expected to be sensitive to particle size and the relative humidity of the gases, as well as to other variables. Any credit taken for fission product removal by these devices must reflect the uncertainty in the knowledge of these controlling parameters (see Section IV.C).

VIII.B.8. The calculation of the source term when the containment has not been isolated or has been bypassed is very sensitive to the details of the failure. Accidents are more likely just before and just after maintenance periods, and this is just the time when isolation failure is also most likely. The containment bypass sequences $(V)$ are specific for each reactor; once recognized, their probability and consequences can often be reduced by simple steps. We urge special attention to these potential problems by the designers and operators of nuclear installations (see Chapter VI).

VIII.B.9. The diversity of the various government, industrial, and foreign groups engaged in source term research makes it unlikely that important phenomena will be left unconsidered. We urge these groups to continue to support the investigation of source term phenomena until more of the areas of uncertainty are resolved (see Section VII.F).

\section{VIII.C. Detail of conclusion VIII.A.2}

VIII.C.1. The selection of the accident sequences for the source term assessment is a very significant process. It is difficult to be sure that enough sequences have been 
studied to encompass all the physical phenomena involved. The study group believes that NRC and its contractors have selected the sequences reasonably well. However, several of these sequences no longer appear to be risk dominant, and other sequences have become relatively more important. In order to make sure that the risk dominant sequences have been adequately identified and investigated, we strongly urge another iteration of the process of selecting the sequences in the light of the understanding gained so far. Sequences that might be considered include containment isolation failure and containment bypass sequences, including the possibility of steam generator failure during a TMLB sequence, and events externally initiated by an event such as an earthquake, fire, or flood (see Section III.C).

VIII.C.2. Analyses of the Pressurized Water Reactors with large dry containments have been more extensive than those with ice condensers and of the Boiling Water Reactors. We urge that comparable attention be paid to these other reactor types.

VIII.C.3. If large amounts of the volatile elements cesium and iodine were released, they would dominate the health hazard. For that reason, most of the studies to date have correctly concentrated on the magnitude of cesium, iodine, and to some extent, tellurium releases. However, if the calculations predict releases of cesium and iodine of less than a few percent of inventory, this by itself does not ensure a small source term. Considerable attention must then be paid to releases of the nonvolatile elements (see Sections II.B and IV.B).

VIII.C.4. There is a tendency to accept the premise that a containment failure late in the accident will lead to small releases. However, some phenomena, not fully analyzed, might lead to higher releases than often calculated. These include the following.

(a) Volatile fission products retained in the primary system might revaporize from decay heating at a time when there is less aerosol in the containment to scavenge these newly liberated species.

(b) Deposited aerosols might be resuspended as a result of a sudden depressurization of the containment, or because of mechanical forces associated with steam explosions or hydrogen combustion.

(c) The calculations for the core concrete interaction for some accident sequences suggest far larger releases of hazardous nonvolatile radionuclides than were assumed in the Reactor Safety Study. At this time it is neither clear that the physical and chemical phenomena involved have been correctly modeled nor clear that the calculations have been done correctly.

(d) The deposition of the aerosols may not be as rapid as calculated, as a result of thermal stratification or lack of complete mixing.

(e) The airborne concentrations of aerosols within the containment are sensitive to the time when condensed species are introduced. Conclusions must reflect the uncertainty in the mass release rates and aerosol characteristics (size, density, and shape) of aerosols from both the primary system and the core concrete interaction (see Sec- tion IV.C).

III.C.5. Direct calculations, complex computer codes, small-scale experiments, and large-scale experiments are all necessary to resolve the source-term questions. The relative role of these needs continual reevaluation. In particular, the large scale experiments such as BETA, DEMONA, MARVIKEN, PBF, by their nature take a long time. It is important to continually reevaluate their experimental protocols to be sure that they provide data to validate the computer codes under conditions as close as possible to those occurring in reactor accidents (see Chapters V and VII).

\section{VIII.D. Possible implications}

The Nuclear Regulatory Commission has used the methodology and conclusions of the Reactor Safety Study as the basis for emergency planning. The NRC has established an emergency planning zone of ten miles radius primarily on the premise that beyond ten miles few, if any, prompt deaths would occur in even the worst calculated accident. A fifty mile zone was established for considering health implications of contaminated food and drink.

Although recent calculations indicate that the source terms for several radioisotopes in a number of important sequences are smaller than the values obtained in the Reactor Safety Study, other considerations contribute to present regulations on emergency planning. Because these were not within its charter, the study group takes no position on the desirability of changes in those regulations.

The methodology of the Reactor Safety Study has also been used to evaluate proposed changes in reactor and nuclear plant design and operation-either for future reactors or for retrofits to existing reactors-to reduce the probability of accident. The study group has not studied the question of reducing the probability of accidents in detail and, therefore, merely notes the obvious general point that it is desirable to prevent accidents as early in the chain of events as possible-for then the reactor may well stay intact in addition to the public being protected.

The insights gained from source term research and modeling should be reflected in the design and operation of light water reactor plants so as to minimize the source term-and therefore the risk to the public-in costeffective ways.

\section{VIII.E. Major recommendations}

The study group believes that the source term research cannot yet be regarded as adequate.

VIII.E.1. The NRC should continue to ensure a strong, integrated, program of experimental and analytical studies in order to provide a sound data base for calculation of the source term.

VIII.E.2. The NRC should undertake uncertainty analyses so that calculated radionuclide releases can be stated within explicit limits. 
VIII.E.3. The study group recommends that the theoretical and experimental studies be published in archival, peer-reviewed journals, and that the computer codes, together with a clear and complete technical description of the models and the assumptions, be made available to interested parties.

\section{APPENDIX I: TRANSPORT OF RADIONUCLIDES}

\section{I.A. General theory of effluent dispersion}

In this appendix we develop the model of radionuclide dispersion in more detail.

A cloud of gaseous effluent, once released into the atmosphere, moves along a path determined primarily by prevailing winds and temperature gradients. Local atmospheric turbulence, characterized by atmospheric stability and vertical temperature gradients, leads to dispersion of effluent about that path. Experiments to characterize the time-averaged densities of plumes show that the distributions transverse to the average path are Gaussian-like. A simple model (Turner, 1975) that treats the local plume fission product distribution in a Gaussian form as the result of turbulent diffusion superposed on the mean velocity with which the entire medium moves, provides an adequate description of the space-time characteristics of the effluent density at distances within $10-20 \mathrm{~km}$ of the source. The resulting expression for the integral of concentration over time, $\chi$ (measured in $\mathrm{Cis} / \mathrm{m}^{3}$ ), resulting from the release of $Q$ units of effluent (measured in $\mathrm{Ci}$ ) from a height, $z=h$ (measured in $\mathrm{m}$ ), and into a wind of mean velocity $u_{x}$ (in $\mathrm{m} / \mathrm{s}$ ) blowing in the $x$ direction can be expressed in an equation developed by Sutton (1932):

$$
\begin{aligned}
\chi(x, y, z)= & \frac{Q}{2 \pi u_{x} \sigma_{y} \sigma_{z}} \exp \left(\frac{-y^{2}}{2 \sigma_{y}^{2}}\right) \\
& \times\left[\exp \frac{-(z+h)^{2}}{2 \sigma_{z}^{2}}+\exp \frac{-(z-h)^{2}}{2 \sigma_{z}^{2}}\right],
\end{aligned}
$$

where $\sigma_{y}, \sigma_{z}$ (measured in $\mathrm{m}$ ) are the standard deviations for the distribution of the plume in the $y$ and $z$ directions, respectively. The coordinate system and the behavior of the terms is shown in Figure AI.1. The second term in the last large bracket arises from a reflection, or bouncing, of effluent particles or molecules from the ground. Values for $\sigma_{y}$ and $\sigma_{z}$ are customarily chosen so that they yield reasonable agreement with experimental observed variations of plume density. The values for these quantities depend on atmospheric conditions and are customarily associated with increasing functions of $x$, as long as stability conditions remain constant. For instance, $\sigma_{z}$ increases very rapidly with distance for unstable atmospheres but much less rapidly for stable atmospheres. Sets of values for $\sigma_{y}$ and $\sigma_{z}$ and for atmospheric conditions of differing stabilities have been obtained from experimental data by Pasquill (1962, 1968), Turner (1975), and many others. These experimentally derived values of

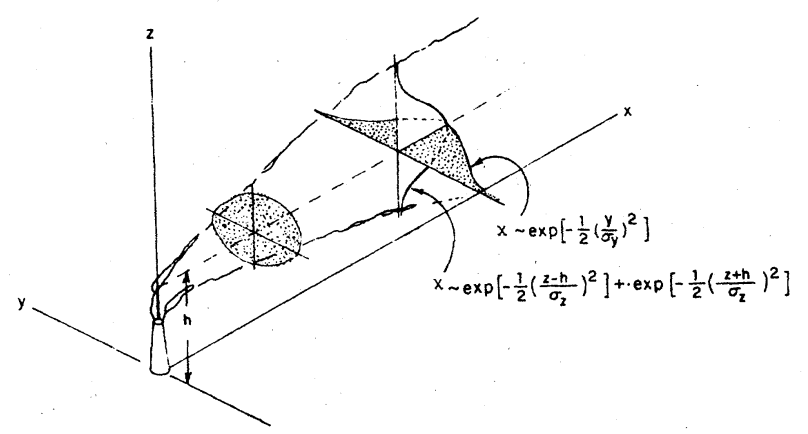

FIG. AI.1. Coordinate system for Gaussian plume dispersion (from Wilson et al., 1980).

$\sigma_{y}$ and $\sigma_{z}$ are most reliable for distances of up to a few tens of kilometers. At large distances, usually greater than many kilometers, $\sigma_{z}$ can sometimes approach the height of a temperature inversion layer. Then additional terms in $\chi$ are necessary to describe the containment of the radioactivity below this layer. For distances approaching $100 \mathrm{~km}$ (or more), the dispersion parameters and predicted concentrations become increasingly less accurate (NRC, 1983b, pp. 9-23). Table AI.1 describes typical meteorological conditions and Table AI.2 shows the values of $\sigma_{z}$ for various meteorological conditions, and the probability of occurrence of these conditions averaged over a number of typical sites.

For any radial distance $x$ from the release point, the maximum ground level $(z=0)$ time-integrated concentration directly downwind occurs beneath the center line $(y=0)$ of the cloud. The value there, useful as a conservative estimate for the time-integrated concentration at off-centerline positions, is

$$
\chi_{0}(x)=\frac{Q}{\pi u_{x} \sigma_{z} \sigma_{y}} \exp \left(-h^{2} / 2 \sigma_{z}^{2}\right) .
$$

The quantity, $\chi_{0}(x) / Q$, can be called the centerline dilution factor $(F)$ at ground level. It gives the timeintegrated concentration at $x$ at ground level per unit release. For releases from an elevated point and for increasing distance, $x$, downwind, $\chi_{0}(x)$ first increases as the effluent disperses vertically toward ground level, after which $\chi_{0}(x)$ decreases with $x$ as the cloud continues to disperse both horizontally and vertically, with the maximum occurring approximately where $\sigma_{z}=h$. Figure AI.2 illustrates the variation in position of the maximum for a variety of atmospheric stability conditions.

The noble gases, and molecular iodine if released, are transported as gases. Other constituents are transported as aerosols. Aerosol fallout leads both to a reduction of effluent plume concentration and to the buildup of a surface deposit $S$ per unit area, at ground level. The ground deposit builds until it reaches a value $S=\chi_{0}(x) V_{d}$, where $V_{d}$ is called the deposition velocity. This deposition imposes a further exponential attenuation factor on effluent concentration. One can define an approximate attenuation length, given by $L_{d}=u_{x} \bar{z} / V_{d}$ where $\bar{z}$ is the average 
TABLE AI.1. Key to stability categories. The neutral class, $D$, should be assumed for overcast conditions during day or night (Turner, 1972).

\begin{tabular}{cccccc}
\hline \hline $\begin{array}{c}\text { Surface wind } \\
\text { speed } \begin{array}{c}\text { (at } 10 \mathrm{~m}) \\
\mathrm{m} \mathrm{s}^{-1}\end{array}\end{array}$ & Strong & $\begin{array}{c}\text { Day } \\
\text { Incoming solar radiation }\end{array}$ & $\begin{array}{c}\text { Night } \\
\text { Thinly overcast or } \\
\geq \frac{4}{8} \text { low cloud }\end{array}$ & $\begin{array}{c}<\frac{3}{8} \\
\text { cloud }\end{array}$ \\
\hline$<2$ & $A$ & $A-B$ & $B$ & & \\
$2-3$ & $A-B$ & $B$ & $C$ & $E$ & $F$ \\
$3-5$ & $B$ & $B-C$ & $C$ & $D$ & $D$ \\
$5-6$ & $C$ & $C-D$ & $D$ & $D$ & $D$ \\
$>6$ & $C$ & $D$ & $D$ & $D$ & $D$ \\
\hline \hline
\end{tabular}

plume height. Typical values of the deposition velocity $V_{d}$ for dry fallout are $0.01 \mathrm{~m} / \mathrm{s}$ or less, while for deposition by rainfall (wet fallout), $V_{d}$ can rise several meters per second. For a nominal mean plume height of $100 \mathrm{~m}$ and a mean wind velocity of $2 \mathrm{~m} / \mathrm{s}$, the attenuation length for dry conditions could be greater than $20 \mathrm{~km}$ (and the attenuation unimportant), yet, for wet conditions, it could decrease to $1 \mathrm{~km}$. It appears that effects of fallout and hence the contribution of the radionuclides deposited on the ground would have their maximum impact locally under rain conditions.

Finally, there will be a reduction in effluent activity in the cloud of released radioactive material due to radioactive decay. The characteristic attenuation length, $L_{r}$ is $u_{x} / \lambda$, where $\lambda$ is the usual radioactive decay constant (equal to $\ln 2$ divided by the half-life). Combining all of these, the expression for center-line ground level dilution factor becomes

$$
\begin{aligned}
F=\frac{\chi_{0}(x)}{Q}= & \frac{1}{\pi u_{x} \sigma_{y} \sigma_{z}} \\
& \times \exp \left(\frac{-h^{2}}{2 \sigma_{z}^{2}}\right] \exp \left[\frac{-x}{L_{d}}\right] \exp \left[\frac{-x}{L_{r}}\right] .
\end{aligned}
$$

\section{I.B. Consequence analysis}

The dose at any position subsequent to a large scale release would depend not only on the source characteristics, but on atmospheric conditions. The consequences to the public health of that dose, measured by the magnitude of its biological impact would, in addition, depend on the local density and distribution of the exposed population and on possible emergency plans (e.g., evacuation or shelter). The characteristics of the population in the vi-

TABLE AI.2. Meteorologic data for atmospheric release calculations. From Rogers and Gamertsfeld-

\begin{tabular}{|c|c|c|c|c|c|c|c|}
\hline Weather type & $A$ & $B$ & $C$ & $D$ & $E$ & $F$ & $G$ \\
\hline \multicolumn{8}{|l|}{$\begin{array}{l}\text { Probability } \\
\text { of weather }\end{array}$} \\
\hline $\begin{array}{l}\text { condition } \\
\text { Wind velocity, }\end{array}$ & 0.019 & 0.081 & 0.136 & 0.44 & 0.121 & 0.122 & 0.08 \\
\hline$u_{x}(\mathrm{~m} / \mathrm{s})$ & 2 & 3 & 5 & 7 & 3 & 2 & 1 \\
\hline \multicolumn{8}{|l|}{$\begin{array}{l}\text { Distance, } \\
\quad x(\mathrm{~m})\end{array}$} \\
\hline 200 & 28.8 & 20.3 & 14 & 8.4 & 6.3 & 4.05 & 2.63 \\
\hline 500 & 100 & 51 & 32 & 18 & 13 & 8.4 & 5.5 \\
\hline 1000 & 470 & 110 & 59 & 32 & 21.5 & 14 & 9.2 \\
\hline 2000 & 3000 & 350 & 111 & 51 & 34 & 21.5 & 13.7 \\
\hline 5000 & & 1900 & 230 & 90 & 57 & 35 & 23 \\
\hline 10000 & & & 400 & 140 & 80 & 47 & 31 \\
\hline 20000 & & & 650 & 200 & 110 & 58 & 37 \\
\hline 50000 & & & 1200 & 310 & 150 & 75 & 48 \\
\hline 100000 & ' & & 1800 & 420 & 180 & 90 & 55 \\
\hline
\end{tabular}
er, 1971. 


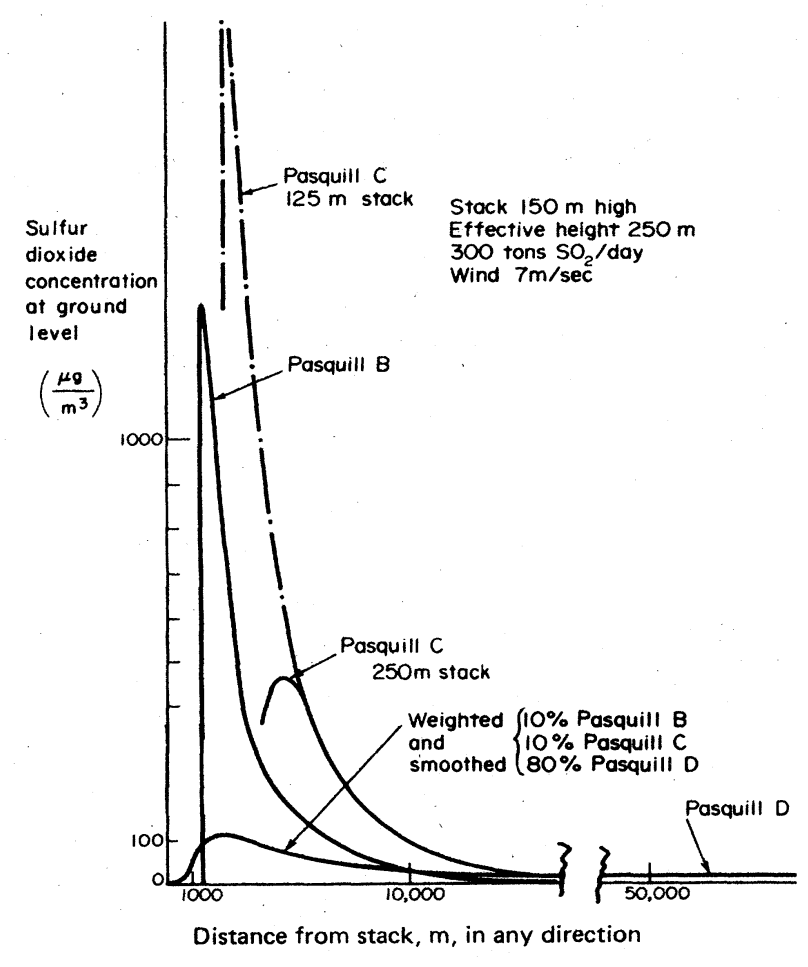

FIG. AI.2. The use of the dispersion formula and coefficients $\sigma_{z}$ from Table AI.2 (from Wilson et al., 1980).

cinity of a given plant are known or knowable and the number of reasonable emergency actions is quite small. But weather conditions at the time of an accident cannot be predicted. However, the conditions would probably not be correlated with the accident occurrence, and the probability spectrum of weather conditions can be inferred from past meteorological observations at a given site, so one can perform a probabilistic analysis.

Such statistical estimates of consequences of accidents at a site with a specified population density in the vicinity of the plant and for a given source and interdiction scheme are usually performed by making many repeated discrete calculations of the distribution of acute and latent doses over the population area. Typically 100 such calculations are made for each statistical estimate of consequences. Each individual calculation includes the meteorological dispersion that would have resulted from an hourly sequence of weather conditions, from one (or more) year(s) of past weather history at the site, for which the initiation time was randomly selected. The consequences derived from individual dose-distance estimates may be evaluated in terms of the doses themselves, or by applying them to models which associate certain incidences of health effects with doses. The set of results achieved is then used to infer the relevant probability distributions of doses (or other consequences) at various distances and directions from the site. Since in emergency planning severe consequences are emphasized, such as in 100 year floods or hurricanes, the upper 95 th or 99 th per- centile of the probability distribution is often taken as the most important parameter.

\section{I.C. General features of dose distributions}

The time of a release of radionuclides $Q$ (in $\mathrm{Ci}$ ) in an accident is not expected to be correlated with the weather conditions. Therefore it is useful to discuss the probability distribution of $\chi(x)$ at each location $x$, and therefore the probability distribution of dose as the meteorological conditions take the various values throughout a year. While the weather at each site is unique, this probability distribution of doses for a number of different sites is found to have strong similarities. This is particularly true of the low probability, high dose end of the consequence frequency spectrum (i.e., where the probability of projected doses being exceeded is five percent). Under these conditions, the calculated high dose results are found to be similar from site to site regardless of unique site meteorological conditions. This similarity exists largely because some rainfall occurs at nearly every location around every currently operational nuclear plant site at some time during a period of a year. Such weather conditions generally yield the local high dose, low probability conditions in a set of calculations. Performing the statistical calculations is relatively long and tedious and consequently the calculations are carried out on large scale computers. In the following, a model of the dominant features of dose distribution calculations is developed using very simplified methods. Subsequently, the model is compared with the results of detailed sets of calculations to gain insight into the calculational results.

Let an amount $Q$ (in $\mathrm{Ci}$ ) of a particular radionuclide, $i$, be released. The dose at ground level $(z=0)$ at a distance $x$ downwind from the source is the sum of three of the four components mentioned in Section II.B of the main report; the fourth component, ingestion of food and drink, $D_{f}$, is omitted:

$$
\begin{gathered}
D_{t}=\underset{c}{D_{c}}+\underset{\text { internal }}{D_{i}}+\underset{\text { ground }}{D_{g}} \\
\begin{array}{c}
\text { dotal } \\
\text { dose }
\end{array} \text { external } \\
\text { cloud } \\
\text { dose }
\end{gathered}
$$

If the gaseous material were dispersed uniformly as a semi-infinite cloud of concentration $\chi$ (measured in $\mathrm{Cis} / \mathrm{m}^{3}$ ) defined in the half space above the ground, the (external) dose $D_{c}$ at ground level from the gamma rays emitted by the radionuclides in the cloud would be

$$
D_{c}=\frac{\chi \kappa_{e}}{2 \pi}=F Q \frac{\kappa_{e}}{2 \mu},
$$

where $\mu$ is the linear absorption coefficient for these gamma rays, $\kappa_{e}$ (measured in rem $\mathrm{m}^{2} / \mathrm{Ci}$ ) is the total (external) dose delivered per unit gamma ray fluence (in $\mathrm{Ci} \mathrm{s} / \mathrm{m}^{2}$ ), and $F$ is the centerline dilution factor calculated above.

The inhalation dose, $D_{i}$, for a person immersed in the cloud is given by the product of the amount of material 
inhaled per unit time and the dose per unit amount inhaled $\left(\kappa_{i}-\right.$ measured in $\left.\mathrm{rem} / \mathrm{Ci}\right)$,

$$
D_{i}=\chi B \kappa_{i}=F Q B \kappa_{i},
$$

where $B$ is the volume of air inhaled per unit time (in $\mathrm{m}^{3} / \mathrm{s}$ ). If the person moves out of the cloud, and stays only for a time $T_{i}$ short compared with the duration of the radionuclide release $T_{p}$, the dose is reduced by $T_{i} / T_{p}$. The dose per amount inhaled has been determined by experiment and includes the effect of the biological half-life of the material.

The deposition of aerosol from the cloud would be uniform and the surface deposit $S$ would be $S=\chi V_{d}=F Q V_{d}$. The ground dose resulting from exposure to that source for a time interval, $T_{2}$, at a height, $z$, above an infinite plane covered with that source is

$$
D_{g}=\frac{1}{2} \chi V_{d} E_{1}(\mu z) \kappa_{e} T_{2}=\frac{1}{2} F Q V_{d} E_{1}(\mu z) \kappa_{e} T_{2},
$$

where $E_{1}(x)$ is the exponential integral. In our cases, $z$ is about $2 \mathrm{~m}$ and $E_{1}(\mu z)$ varies from 3 to 5 . It is assumed that the time interval $T_{2}$ is much less than the half-lives of the radionuclides concerned. For any radionuclide whose half-life is less than $T_{2}, T_{2}$ must be replaced by $\left(t_{1 / 2}\right) / \ln 2$ in the sum over radionuclides.

Summing these, the total dose is

$$
D_{t}=F Q\left[\frac{\kappa_{e}}{2 \mu}+B \kappa_{i}+\frac{V_{d} \kappa_{e} T_{2}}{2} E_{1}(\mu z)\right] .
$$

Of these parameters, $\mu, \kappa_{e}$, and $\kappa_{i}$ are all dependent on the particular radionuclide $i$.

In an actual release, the releases and deposits would not be of infinite spatial extent, and therefore not of uniform concentration. The dose delivered to an individual at ground level and a distance, $x$, from the point of release of an isotope, $i$, and for some nominal set of weather conditions, must be rewritten to account for these differences:

$$
D_{t}=F Q\left[\frac{G_{1}(x) \kappa_{e}}{\mu}+B \kappa_{i}+G_{2}(x) V_{d} T_{2} \kappa_{e}\right] \text {. }
$$

The factors, $G_{1}(x)$ and $G_{2}(x)$, correct for the effects of finite source geometry and also provide any remaining necessary corrections. $G_{1}$ and $G_{2}$ can be written explicit$1 y$, as functions of $x$ and now include the factors of 2 and $E_{1}(\mu z)$. Since the contributions to dose are dominantly from sources close to the dose point, it is evident that $G_{1}$ and $G_{2}$ do not depend strongly on meteorology. Their dependence on the radionuclide, $i$, is due largely to differences in the energies of their gamma radiations and so on their attenuation coefficient $(\mu)$ in air. The effect of varying delays between the time of reactor shutdown and time of release may, because of differences of half-life of individual radionuclide components, change the overall radionuclide composition in each group and hence change the dose differently for different groups.

Each additive term in the dose is a product of three major factors. The first, $F Q$, depends upon the magnitude of the source term; $G_{1}(x)$ and $G_{2}(x)$ are geometric factors; and the factors, $\kappa_{e}, \kappa_{i}$, and $\mu$ depend on the radio- logical properties of the radionuclide, properties of air and human tissues.

It has been traditional in accident analysis to categorize various isotopes into groups according to their chemical and physical properties. The largest releases are expected from the noble gases, which are hard to retain. However, the biological dose to humans from these gases is expected to be small. The halogens, the cesium group, and the tellurium group, are fairly volatile and in a severe accident most of these could be released from the core. In the severe accidents discussed below, several hours are projected to elapse between reactor shutdown and containment failure. Even if slow wind speeds are projected at the time of the release, perhaps less than an hour would elapse between radionuclide release from the containment and exposure at a distance of two miles which is the edge of the exclusion zone where much of the public can be found. Thus the relative fraction of radionuclides within each group will not change appreciably over this time period, so that, if the ratios of the source terms for the several radionuclide release groups are known, the ratios of the doses can be calculated for the different groups. The release fractions for most of the release groups depend on the detailed history of the accident.

It is interesting to compare doses for various release groups to a hypothetical $100 \%$ release of the noble gases. Karahalios (1984) has noted that the shape of the spatial distribution curves of dose appears to be relatively independent of weather patterns, particularly for the high dose-low probability tail of the annualized probability distribution. At the request of the study group a set of calculations was made (Karahalios and Gardner, 1984), using the CRAC2 code (Ritchie et al., 1983), to calculate the dose that would result from sources consisting of single release groups only. A typical set of annual meteorological data was used and alternative time intervals of 2 and of 24 hours were assumed for the delay between reactor scram and containment failure. The results cited in the remainder of this section and in Figure II.B.1 are based on their results.

The dependence of dose on the distance from the source was tested by examining the doses that would be delivered by a source composed of $100 \%$ of the core inventory of noble gases and with an arbitrarily chosen $1 \%$ of the core inventory of each of the other radionuclide groups for a given set of weather conditions. Except for the noble gases, each of the radionuclide groups was assumed to have a uniform aerosol depositional velocity which was identical for all other radionuclide groups. Other conditions are listed in Table II.B.4. Weather conditions were statistically sampled from those observed historically at a particular site. The value of the upper 95th percentile of the probability distribution of dose for each group for an array of distances was used to characterize the dosedistance relation for that group. The ratio of the dose for each group to the dose from the noble gas group was calculated for a set of distances and normalized to unity at a distance of 5 miles. The results are presented in Table II.B.4. 
The spatial dependence of these ratios and of the noble gas dose delivered are shown in Figure II.B.1 for the two time intervals assumed for the delay time between reactor shutdown and containment failure. The plotted ratios for all groups are nearly indistinguishable, which is consistent with the assumption that all components have identical transport properties. There is a small, but weak, coupling between the dependence on distance and on radionuclide composition and this causes the ratio curves for the differing decay times to be slightly spread into a narrow band. Finally, there is a remaining spatial variation (variation in $x$ of a factor ranging from 2 to 0.7 ) in that band, corresponding to distances $x$ between 1 and 10 miles. This arises primarily because of the settling out of the aerosols which carry the non-noble gas radionuclides.

It is convenient to take as a benchmark that, in a severe accident with degraded core and failed containment, all of the noble gases would be released. Thus, for such an accident, the minimum dose delivered must be at least that from the noble gases. In Table II.B.4 are listed the fraction of the group inventory at the time of reactor shutdown that, if released, could deliver the same dose at 5 miles as would the entire noble gas source. If the release for any group were an order of magnitude less than the tabulated value, the dose from that group would not make a significant contribution to the total dose. Thus, each tabulated value serves to define a significant release for its group.

Some of the isotopes of xenon and krypton are shortlived. This is the reason the dose for a $100 \%$ release after a 24-hour delay is decreased by a factor of 5 below that for a 2-hour delay. From Table II.B.4, the corresponding decrease in the iodine group is a factor of about 2, while the other components are almost unchanged. As a result, for a 24-hour delay, a smaller release for any group is required to deliver the same dose as would the noble gas group.

If containment fails in a severe nuclear reactor accident it is expected that most of the noble gases will be released. This, then, is a useful "benchmark" for considering the importance of the release fraction for radionuclides. From Table II.B.4, the study group concludes that if the release fraction of iodine, cesium, and tellurium can be shown to be $1 \%$ or less, then they will contribute no more than the noble gases. From the same table, the potential importance of releases of nonvolatile radionuclides can be seen.

\section{APPENDIX II: HEALTH EFFECTS}

A severe nuclear accident with a large release of radioactive materials has the potential of exposing humans to very large doses of ionizing radiation. Among the constituents of the "source," the fission products and activated core structure material constitute the major source of beta and gamma radiation. The fuel and actinides formed by neutron capture in fuel act as the major sources of alpha radiation and emit beta and gamma radiation as well.
The physical form of the release would be as gases and aerosols, transported to the public by atmospheric winds. Some fraction of the aerosols, depending on atmospheric conditions and aerosol properties, would "fall-out" and be deposited on horizontal surfaces.

Humans could be exposed to gamma radiation originating from radionuclides remaining in that cloud or on ground surfaces. Gamma radiation is indirectly ionizing and so is capable of delivering a radiation dose to a system even if the source is external to that system and there is material interposed. The gamma component dominates any effects from the external radiation source. The most significant characteristics of each radionuclide would be the number of atoms, the half-life, and the relative intensities and energies of its gamma radiations. The exposure duration from cloud components would be limited by the transit time of the cloud past the dose site. Exposures from deposited components, on the other hand, could continue on (with decreasing activity) for long periods of time (perhaps for years) if long half-lived radioisotopes were included among the components of the cloud and no cleanup activities were conducted to reduce potential population doses.

As cloud components approached ground level they could be inhaled or ingested by humans. Once inside the body, the radionuclides would act as internal exposure sources with contributions from alpha and beta as well as gamma radiations. Alpha and beta radiations are directly ionizing and easily stopped by quite small amounts of materials. If the alpha and beta emitters entered the body, the energy of those emissions would be completely absorbed. The chemical and physical forms of the aerosols and isotopes would determine the biological uptake and excretion rates and so influence the effective time of exposure for various bodily organs. These times, together with the number of atoms, the beta or alpha energies, and the radiological half-life control the total dose to the organs and so characterize the sensitivity of the exposure to the particular distribution of isotopes in the source.

The interest in a source term derives ultimately from a desire to characterize the range of magnitudes of health effects resulting from such a release. In order to do so it is necessary to consider the relationship between radiation exposure and health effects. The exposure of individuals or populations to high levels of radiation may result in the incidence of a variety of severe health effects whose symptoms depend stochastically upon exposure dose and may vary with the time elapsed after irradiation. The most definitive pertinent human data on radiation health effects has been obtained from the very high exposures experienced by victims of atomic bombs and by medical patients treated with massive doses of radiation. The effects observed for these groups span the range from death occurring soon after exposure to the onset of various fatal and nonfatal malignant tumors which may appear soon after exposure or may continue to be a potential threat for many years following exposure.

The relationship between dose and human response at relatively low radiation exposures is much more difficult 
to establish. Although radiological effects can only be defined probabilistically at any level of exposure, at some low level of exposure neither early deaths nor early severe illnesses will be observed. However, even at these relatively low exposure levels, delayed effects may occur. Although again, the occurrence of delayed effects will be a low probability, and apparently random effect with respect to exposures received. Among the harmful biological impacts that may occur as a result of even low level exposures are neoplastic (carcinogenic) and hereditary (mutagenic) effects. Carcinogenic effects may not appear for many years after exposure. By definition, mutagenic effects cannot be observed until a following generation. This delay contributes to the difficulty in determining the quantitative relationships between radiation exposure and resultant harm over the range of very high to very low exposures. Moreover, the carcinogenic effects that may result from radiation exposure are identical to effects arising from other (usually uncontrolled) sources. Humans are, of course, exposed to a large variety of carcinogenic substances-often at low exposure levels. Consequently, the problem of differentiating between cause and effect of low-level exposures to carcinogens is very complex and difficult in humans-particularly when long latency periods between exposure and cancer induction are considered. Predictions of the expected consequences under these circumstances must of necessity depend on calculational models whose functional forms are derived from animal and cell experiments and whose parameters are determined inferentially and by extrapolation from existing high dose human data. The quantitative and qualitative uncertainties in predictions for human subjects at very low doses are fundamentally a reflection of the complexity of the process of radiation carcinogenesis for humans as well as the poor statistics in data involving humans. These limitations are reflected in the uncertainty associated with the choice of models for biological effects of low doses on humans, since the several models differ qualitatively as well as quantitatively in their predictions for quite low doses.

Physical radiation effects are usually specified in terms of absorbed dose, defined as average energy deposited per unit mass of absorbing material. Its units are the rad, where $1 \mathrm{rad}=0.01 \mathrm{~J} / \mathrm{kg}$. The deposition releases secondary electrons generated by the interactions of the primary charged radiation along its trajectory (a gamma ray is indirectly ionizing, typically by transferring its energy to an electron which acts as the charged primary). Each secondary electron leaves the track with relatively low energy which is thereby distributed to a volume enclosing the primary track. The resultant density of energy deposited is quite variable on a microscopic scale and is independent of the nature of the primary radiation.

For primary radiations such as gamma rays, $x$-rays, or electrons whose rate of linear energy transfer (LET) is sufficiently low, the secondary electrons are spatially well separated and only energy depositions from a single secondary electron contribute to any microscopic volume. Both theory and observation on a microscopic level show that the delivery of an amount of energy exceeding a particular threshold value into the critical effective target volume of a cell may lead to a biological effect. If, stochastically, a severe nonuniformity in deposition occurs, it is possible (but rather improbable) for that threshold to be exceeded as the result of the interaction of a single secondary electron. While the number of secondary electrons released depends on the energy of the primary radiation, the density with which they are released depends on LET. For high-LET radiations (such as alpha particles) the spacing of secondary electrons is sufficiently close that more than one secondary electron from a single primary track can contribute to energy deposited in a given volume. Thus, for high-LET radiations the probability of exceeding the threshold is much larger and much more uniform than that for low-LET radiations.

The biological effects resulting from injuries associated with radiation exposure fall into two general categories depending on whether single- or multicell interactions dominate (Bond, 1981a). At high radiation levels, while both single- or multi-cell interactions may occur, multicell effects dominate. Multicell effects involving particular organs are observed soon after exposure and are termed organ effects. When a large fraction of the functional cells of a particular organ are injured or killed, the organ fails or has its function impaired. Organ effects generally have a dose threshold below which they are not generally observed. That threshold can usually only be achieved with a high-level radiation exposure (often at levels of hundreds or thousands of rad). Once that threshold has been exceeded, the severity of injury increases as the dose to any part of the organ is increased.

At sufficiently low levels of radiation, effects may be restricted to single cell perturbations. Interactions lead to energy deposition in or near a cell volume. If the threshold for sufficient energy deposition is exceeded in a critical volume of an individual cell, that cell may undergo alterations or impairment of function. The observed effects are termed single cell effects. The probability of interaction with any given cell, the amount of energy deposited in that interaction, and the probability that the cell will be affected are all random variables.

If a cell population is exposed, the number of observable effects is related to the doses to individual cells. However, the determination of which members of that population suffer an effect is random even for a uniformly distributed dose. For a given type of radiation, the amount of energy that can be deposited in a single interaction is independent of the average energy delivered to all cells. The probability of the occurrence of effects is dependent on dose (since higher dose corresponds to more interactions) but there is neither threshold in incident dose nor is the severity of the effect clearly dependent on dose. Thus, for low levels of radiation, the incidence of effects will increase linearly with radiation dose.

The amount of damage in some cells may be too small to cause the effects described above, but may still injure the cell in some way. If a cell, once hit, is hit again before its previous injury has been repaired, the combined 
multi-hit deposition may increase the damage above the energy deposition threshold for singlecell effects. Multihit effects become important at high doses and high dose rates. For high-LET radiation the probability of large single-hit energy deposition tends to be constant so that the incidence of health effects continues to be linear with dose even at higher dose. For low-LET radiations, large energy deposits have low probability and occur randomly. As the dose increases, the probability of multiple hits increases. At first, the probability of multiple hits on a cell increases quadratically as the dose increases and then as higher powers of the dose. In this case, the expected dose-effect relationship for single cell effects will be linear for very low radiation exposure but will rise with a higher power of dose as the dose increases.

Note that it is the number density of secondary electrons that determines the number of cell effects. While the absorbed dose serves as a surrogate for the number of electrons released, the LET of the primary radiation has an effect as well. A secondary quantity, $H$, called the Dose Equivalent, is used to include both of these contributions. $H$ is defined as

$$
H=D Q N,
$$

where $D$ is the absorbed dose; $Q$ is the quality factor (a continuous function of LET); and $N$ contains any other dependence on the particular organ $(0<N<1)$. The unit of dose equivalent is the rem ( $1 \mathrm{rem}=0.01 \mathrm{~J} / \mathrm{kg}) . Q$ and $N$ are so defined that, for $D$ in rad, $H$ is in rem. For low LET radiation, $Q=1$.

The consequences of whole body irradiation depend both on the dose and on the time elapsed after exposure.

At a dose equivalent level of several krem, massive and prompt injury to the nervous system is the most significant effect. The symptoms include convulsions, coma, and early death (within a few hours to as long as a week or so).

At dose levels between about 600 and 2000 rem, injury to the gastrointestinal tract dominates with symptoms occurring such as nausea, vomiting, diarrhea, dehydration, and probably death (within a relatively short period of time-e.g., within 60 days of exposure).

At still lower doses, between about 200 and 600 rem, there are several groups of symptoms including depression of blood cell formation primarily due to hemorrhage from a platelet deficiency. A deficiency of granulocytes permits the development of infection and there is anemia from hemorrhage and cessation of blood cell production. There is the possibility of death (again within about 60 days of exposure) depending on dose levels and the availability of medical facilities for treatment of victims.

These high dose level-consequence data have been derived primarily from animal exposure experiments and from victims of direct and fallout radiation from atomic bomb explosions. The health effects of such high doses have been assessed by a number of investigators. A typical characterization of such high dose level consequences is that an external gamma source producing an air dose of about 300 to 350 rem will kill $50 \%$ of exposed but un- treated people in 60 days (LD-50/60) (Cronkite, 1958). It is believed that $100 \%$ mortality would be reached at about 500 rem unless extensive medical treatment such as massive blood transfusions and lung lavage were available. Such treatment would raise the LD-50/60 to about 500-600 rem. The availability of such extensive medical treatment would depend, at least in part, on the number of casualties relative to the capacities and capabilities of nearby hospitals. Sufficient data for human exposures are available to reduce the uncertainties over lethal effects of radioactivity to relatively low levels. Hence there is little controversy over the biological health relationships for lethal consequences of exposure to radioactivity (Cronkite, 1981).

Animal studies show similar effects to those reported above for high level dose effects on humans. The distribution of fatalities observed for a controlled animal population is typically sigmoidal. While the range of doses for the transition between $0 \%$ and $100 \%$ fatalities is observed to be quite narrow, the application of these data to humans suggests that the distribution should be broadened somewhat to account for the variability of an arbitrary human population. Further, the exposures in the cases from which these animal data were drawn were all delivered externally at very high dose rates $(>1$ $\mathrm{rem} / \mathrm{min}$ ). Controlled studies made on animals show the effects of repair of radiation injury leading to a demonstration that LD-50/60 increases sharply with decreasing dose rate as a consequence of repair of that injury. There is reason to believe that similar repair processes also operate in man. However, if lethal exposures occur from radiation released from reactor containments, the dose rates will generally be sufficiently high to justify the usage of the standard models for estimating fatalities. It should be noted, however, that survival from early fatality effects of exposure does not necessarily imply freedom from delayed carcinogenic effects of irradiation.

For releases such as those postulated in the RSS, the dominant contributors to early lethal effects are $\mathrm{Kr}-88$, Te-132, I-131, I-132, I-133 and I-135, Xe-133, and Ba-140 (NRC, 1975). The relative significance of the contributions of various fission products depends, of course, on the nature of the source term. The above categorization is representative of a large release involving substantial quantities of iodine. Very severe events with large source terms and adverse meteorological conditions would be required to achieve lethal and near-lethal conditions beyond distances of about five miles downwind from a nuclear power plant accident. Even if a core melt accident were assumed to occur, the probability of exceeding lethal doses beyond these distances would be very low.

When single ("point") values are given for a probabilistically determined parameter, such as the LD-50/60 values cited above, it must be recognized that the probabilistic definition of the parameter is incomplete without some specification of the range of uncertainty in the given point value. The uncertainty in the nominal LD-50/60 estimates cited above for early fatalities (510 rem, assuming the availability of extensive supportive treatment) cov- 
ers a range from 400 to 600 rem (Lewis et al., 1978, p. 19). This range in uncertainty in dose may be interpreted in terms of uncertainty with respect to a distance from the source of the accidental releases at which the dose might be received. Results of consequence analyses indicate that the LD-50/60 dose uncertainty cited above is essentially equivalent to uncertainties in the limiting radial distances of no more than about plus or minus one mile from the reactor to the locations where the dose would be observed. Thus, assuming that low population densities exist in the immediate vicinity of the reactor, the uncertainty in dose-effects relationships for early effects would not be expected to contribute substantially to uncertainties in early fatalities. Neither would the uncertainties in dose effects be expected to contribute in a very major way to uncertainties in early illness, or to have a substantial impact on emergency planning.

Early lethal effects of whole body radiation exposure are not significant for doses less than about 150 rem (Conrad et al., 1980). However, individuals exposed to doses of several hundred rem will probably exhibit clinical evidence of early illnesses as a direct result of their exposures. The symptomatic external evidences of early illnesses are dominated by cases of respiratory impairment and/or temporary discomfort from vomiting. The range of doses over which the probability of early illnesses goes from zero to one is also quite narrow, although not as narrow as the range for prompt lethal effects. The individual risks of early illness range from a $30 \%$ chance at about $100 \mathrm{rem}$, to $80 \%$ at $280 \mathrm{rem}$, and $100 \%$ for those who survive lethal effects at doses above 400 rem. The chances of incurring early illnesses that might require treatment approach negligibility at doses on the order of 50 rem or less (NRC, 1975, App. VI). For exposures near that value, the sources of supply of mature functional cells are reduced such that the organ and the host individual have impaired function. This depletion can be detected at doses as low as 40 rem in some organs. Blood cell platelet count reductions (affecting the ability of the blood to clot) are observable over a wide range of dose levels (from high exposures to doses as low as 25 to 30 rem). Platelet count reductions are roughly proportional to doses received by an individual and reduced levels may persist for years after exposure.

If the individual survives the effects of the initial exposures, damaged organs regenerate their normal complement of cells (but the regenerated cells may not necessarily be normal) and the individual recovers. For those who do survive, the most serious somatic effect is the increased probability of cancer incidence as a result of the multiplication of the abnormal cells. Dormant periods on the order of ten years normally occur between radiation exposure and the earliest evidence of cancer incidence. One of the principal problems with obtaining reliable data for cancer incidence in humans is this long period of dormancy. Although 10 years is a typical dormant period, there is evidence that in some cases the period may extend over 30 years or more before cancer incidence is observed. At doses lower than about 100 rem (for low-LET radia- tion) there is great uncertainty over the appropriate models to use for estimating cancer incidence in humans. At these relatively low doses, the paucity of human data makes it essentially impossible to choose rationally between cancer incidence models on the basis of such data. Consequently, increased reliance has been placed upon theoretical models and the use of animal data. It is commonly acknowledged that theoretical considerations are very useful for defining dose-effect relationships for individual (autonomous) cells. At this time, moreover, it is widely acknowledged that animal data cannot be used with assurance to determine dose-effect relationships for the complicated process of radiation carcinogenesis in man (Rossi, 1980). There are a variety of reasons why animals are not necessarily good subjects for developing models of the carcinogenic effects of radiation on humans-not the least of which is the relatively short life span of animals compared to the potentially long latency periods for cancer development in humans. Since neither theoretical models nor animal data provide a definitive means for establishing the dose-effect relationships for low-dose radiation carcinogenesis in man, a substantial amount of controversy exists within the scientific community concerning the appropriate relationship to be used under such conditions.

As a consequence, there are currently (at least) three different extrapolation models (based on radiobiological experience) that have been proposed to estimate excess cancer incidence at dose levels below 100 rem (NAS, 1980). These are:

Cancer incidence is proportional to dose. This is consistent with the assumption that a very small degree of cell damage is required to induce cancer in higher animals. It is also considered to be a conservative relationship and so is often used to generate radiation protection guidelines for public protection.

Cancer incidence is a quadratic function of dose. This is consistent with the assumption that the degree of cell damage required to induce cancer in higher animals is so high that multi-hit effects dominate as predicted by theoretical models.

Cancer incidence is a mixed linear, quadratic function of dose. This is consistent with animal data. The initial slope corresponds to single cell effect relationship and a quadratic term is added (perhaps corresponding to multihit effects) to fit high dose data.

Since all three models are normalized to provide equivalent estimates of cancer incidence rates at about $100 \mathrm{rem}$, the health effects estimates from the models for very low doses differ by relatively large amounts. The linear model produces the largest estimates of low dose radiological effects; while the quadratic model produces the smallest effects. The mixed linear-quadratic function, of course, produces intermediate effects. Until recently, major support for the quadratic model had been found in comparison between the Hiroshima and Nagasaki atomic-bomb leukemia incidence studies. Recent reevaluation of the doses in those two instances has changed estimates of the appropriate doses and suggests 
TABLE AIII.1. Experiments on superheat explosions.

\begin{tabular}{ll}
\hline \multicolumn{1}{c}{ Material } & \multicolumn{1}{c}{ Author } \\
\hline $\mathrm{A} 1$ on $\mathrm{H}_{2} \mathrm{O}$ & Long, 1957 \\
$\mathrm{U}$ on $\mathrm{H}_{2} \mathrm{O}$ & Higgins, 1955 \\
$\mathrm{Metals}$ on $\mathrm{H}_{2} \mathrm{O}$ & Higgins, 1955 \\
$\mathrm{Al}$ on $\mathrm{H}_{2} \mathrm{O}$ & Wright, 1966 \\
Freon $22-\mathrm{H}_{2} \mathrm{O}$ & Board et al., 1974 \\
Freon $22-\mathrm{H}_{2} \mathrm{O}$ & Henry et al., 1974 \\
$\mathrm{LNG}-\mathrm{H}_{2} \mathrm{O}$ & Burgess et al., 1972 \\
$\mathrm{Al}$ on $\mathrm{H}_{2} \mathrm{O}$ & Lemmon, 1980 \\
Thermite- $\mathrm{H}_{2} \mathrm{O}$ & Buxton and Benedick, 1979, 1980 \\
$\mathrm{Corium} /$ thermite- $\mathrm{H}_{2} \mathrm{O}$ & Buxton, Benedick, and Corradini, 1980 \\
Thermite- $\mathrm{H}_{2} \mathrm{O}$ & Mitchell et al., 1981 \\
Fe $\mathrm{O}_{4}-\mathrm{H}_{2} \mathrm{O}$ & Nelson and Duda, 1981 \\
$\mathrm{NaCl}-\mathrm{H}_{2} \mathrm{O}$ & Henry et al., 1979 \\
$\mathrm{LNG}-\mathrm{H}_{2} \mathrm{O}$ & Koopmans et al., 1981 \\
Review & Reid, 1983 \\
\hline
\end{tabular}

that a major adjustment in interpretation of the data may be needed (Loewe, 1981). For this reason, we will consider only the comparison between the linear and mixed linear-quadratic forms.

For doses to individuals greater than a few rem, the ratios of the differences between the cancer incidence probability estimates for the two models are typically smaller than the uncertainty in the source term so that selection of either model may be considered adequate. However, the linear model suggests that the incidence of health effects in a large group of exposed individuals is dependent only on the integrated population dose (i.e., the number of incident cancers is proportional to the sum of the doses received by each member of the exposed population multiplied by the size of the population-usually expressed in person-rem). It would be expected that the bulk of a population dose in a severe nuclear accident would be delivered to the many individuals exposed to low doses at large distances (on the order of hundreds of miles) from the sites. In the mixed linear-quadratic model, much less weight would be placed on low dose contributions and so the number of health effects predicted would generally be substantially lower than predictions of the linear model.

These differences should be viewed in context. For in-

TABLE AIII.2. (a) Areas of consensus (Berman, 1983), and (b) disagreements.

1. Some of us (Berman and others at Sandia) subjectively feel that direct containment failure by a steam explosion and a resultant missile is unlikely for a large, dry, PWR.

2. Steam explosions in a PWR cavity are possible, or likely, and they will result in dispersal of fuel and water.

(b)

We (Berman and others at Sandia) do not believe current data support the following assumptions (alleged to be made by Henry, 1983):

1. A large-scale steam explosion cannot occur in- or ex-vessel.

2. Coarse fragmentation to a particle size of $1 \mathrm{~cm}$ or less cannot occur.

3. Coarse fragmentation to a particle size of $1 \mathrm{~cm}$ or less is a necessary condition for a steam explosion.

4. A continuous liquid slug is necessary for upper head failure, and such a slug is inconsistent with a large-scale steam explosion.

5. The Henry Fauske film boiling fragmentation model is appropriate for reactor accident calculations.

6. Mixing energy requirements specified in the IDCOR report (Henry, 1983) provide an important limit to mixing.

7. Enough is known about explosion triggering to state that triggers sufficiently strong to induce explosions at high pressure are "incredible."

8. No significant fragmentation will occur in- or ex-vessel. Hence, steam and hydrogen generation rates will be negligible. 
TABLE AIII.3. Efficiencies of large scale LNG explosions (from Koopmans et al., 1981).

\begin{tabular}{ccccc}
\hline $\begin{array}{c}\text { Time of } \\
\text { explosion } \\
(\mathrm{s})\end{array}$ & $\begin{array}{c}\text { Mass of LNG in } \\
\text { the interaction zone } \\
(\mathrm{kg})\end{array}$ & $\begin{array}{c}\text { Maximum energy } \\
\text { yield } \\
(\mathbf{M J})\end{array}$ & $\begin{array}{c}\text { Measured } \\
\text { energy yield } \\
(\mathbf{M J})\end{array}$ & $\begin{array}{c}\text { Range of } \\
\text { thermodynamic } \\
\text { efficiencies } \\
(\%)\end{array}$ \\
\hline 6.5 & 390 & 39 & 0.3 & 0.7 \\
7.1 & $36-426$ & $3.6-42.6$ & 0.5 & $13.9-1.2$ \\
9.2 & $126-552$ & $12.6-55.2$ & 2.4 & $19.0-4.3$ \\
21.4 & $732-1280$ & $73.2-128$ & 15.3 & $20.9-12.0$ \\
35.1 & $822-2100$ & $82.2-210$ & 28.4 & $34.5-13.5$ \\
43.2 & $486-2590$ & $48.6-259$ & 0.2 & $0.4-0.08$ \\
46.0 & $168-2760$ & $16.8-276$ & 0.3 & $1.8-0.1$ \\
54.1 & $486-3250$ & $48.6-325$ & 0.3 & $0.6-0.09$ \\
54.9 & $48-3290$ & $4.8-329$ & 0.4 & $8.3-0.1$ \\
66.9 & $720-4010$ & $72.0-401$ & 1.0 & $1.4-0.2$ \\
72.7 & $348-4360$ & $34.8-436$ & 0.3 & $0.9-0.07$ \\
\hline \hline
\end{tabular}

stance, a population dose of 100000 person-rem could correspond to the exposure of 1000 persons to a dose of 100 rem or, instead, to the exposure of 100000 persons to a dose of $1 \mathrm{rem}$. The linear model would predict the same number of latent cancer deaths, about 15 to 50 , for either case. While the mixed linear-quadratic model would predict the same number of deaths for the first case, its prediction for the second would be much closer to 1 . For perspective, the expected number of cancer deaths occurring over the lifetimes of the exposed population of 100000 persons from preexisting "natural" causes is about 15000 . The fluctuations in the number of naturally occurring cancers would be such that it would be impossible either to distinguish between the models or to demonstrate that there had been any change in the number of cancer deaths.

\section{APPENDIX III: EXPERIMENTAL DATA BASE ON STEAM EXPLOSIONS}

The requirements postulated for occurrence of steam explosions are not fundamental ones and must be viewed as ways of correlating the experimental data. In Table AIII.1 we summarize some of these data. There exist two competing models to correlate these. One by Henry et al. (1983) and another by Corradini (Buxton, Benedick, and Corradini, 1980). In Table AIII.2(a) and AIII.2(b) we show a list, due to Berman (1983), of the consensus and disagreements.

As we examine the tests carefully we note that the tests of Koopmans et al. (1981) where LNG was poured on water have a scale similar to that of a reactor accident. They are particularly interesting because earlier Burgess et al. (1972) had failed to produce LNG/water explosions unless there was a large fraction of ethane in the LNG (old LNG), and various authors had postulated that an explosion with pure methane is impossible. Yet not only did Koopmans et al. (unexpectedly) find such explosions, they were large and efficient.

In test number 9 when LNG was poured upon water (Burro 9) several explosions occurred (Table AIII.3). Of these the one at $35 \mathrm{~s}$ was particularly large. Taking account only of the fuel in the interaction zone $(800-2100$ $\mathrm{kg}$ ) the thermodynamic efficiency could be $35-14 \%$ and

TABLE AIII.4. Large scale LNG-water experiments. Test: Burro 9. LNG volume flow rate $=0.31$ $\mathrm{m}^{3} / \mathrm{s}$ (from Koopmans et al., 1981).

\begin{tabular}{ccccc}
\hline \hline $\begin{array}{c}\text { Explosion } \\
\text { number }\end{array}$ & $\begin{array}{c}\text { Time from } \\
\text { injection } \\
\text { initiation } \\
(\mathrm{s})\end{array}$ & $\begin{array}{c}\text { Volume } \\
\text { spilled } \\
\left(\mathrm{m}^{3}\right)\end{array}$ & $\begin{array}{c}\text { Measured } \\
\text { overpressure } \\
(\text { atm })\end{array}$ & $\begin{array}{c}\text { Extrapolated } \\
\text { pressure at } \\
\text { 1 m radius } \\
\text { (atm) }\end{array}$ \\
\hline 1 & 6.5 & 2.0 & 0.008 & 7.2 \\
2 & 7.1 & 2.2 & 0.010 & 9.0 \\
3 & 9.2 & 2.8 & 0.018 & 16.2 \\
4 & 21.4 & 6.6 & 0.039 & 35.1 \\
5 & 35.1 & 10.8 & 0.049 & 44.1 \\
6 & 43.2 & 13.2 & 0.007 & 6.3 \\
7 & 46.0 & 14.1 & 0.008 & 7.2 \\
8 & 54.1 & 16.6 & 0.008 & 7.2 \\
9 & 54.9 & 16.8 & 0.009 & 8.1 \\
10 & 66.9 & 20.5 & 0.013 & 11.7 \\
11 & 72.7 & 22.3 & 0.008 & 7.2 \\
\hline \hline
\end{tabular}


approach the theoretical maximum. The theoretical maximum is determined by operating a reversible cycle between the cold liquid and hot liquid for LNG at $109 \mathrm{~K}$ and water at $300 \mathrm{~K}$. If this were a Carnot cycle, the efficiency would be $\left(T_{h}-T_{c}\right) / T_{h}=64 \%$.

The pressure of this size of explosion would diminish as $1 / r^{2}$ from the cone, and the 44 atmospheres pressure rise at $1 \mathrm{~h}$ becomes less than one atmosphere at a distance of $6 \mathrm{~m}$-the size of the containment vessel (Table AIII.4).

Other experiments using materials more directly relevant are from Sandia National Laboratory (Buxton and Benedick, 1979, 1980; Buxton, Benedick, and Corradini, 1980; Mitchell et al., 1981; Berman et al., 1983). They report induction (delay) times of $15-300 \mathrm{~ms}$ between initiation and explosion in their experiments and conversion of thermal to mechanical energy of up to $1.6 \%$.

\section{REFERENCES}

AEC, 1950, "Summary Report of Reactor Safeguards Committee," U.S. Atomic Energy Commission, WASH-3, March 31.

AEC, 1957, "Theoretical Possibilities and Consequences of Major Accidents in Large Nuclear Power Plants," U.S. Atomic Energy Commission, WASH-740.

AEC, 1962, "Calculation of Distance Factors for Power and Test Reactor Sites," U.S. Atomic Energy Commission, TID14844.

Albrecht, H., and H. Wild, 1981, "Investigation of Fission Product Release by Annealing and Melting LWR Fuel Pins in Air and Steam," Topical Meeting on Reactor Safety Aspects of Fuel Behavior, Sun Valley, Idaho, August.

Allemann, R.T., 1984a, "Status of Validation of the ICEDF Computer Code," BMI-2104, ORNL/TM-8842.

Allemann, R.T., 1984b, "Status of Validation of the SPARC Computer Code," BMI-2104, ORNL/TM-8842.

Allen, A. D., T. W. Davis, and C. J. Hochanadel, 1947, "Formation of Nitric Acid in Irradiated Moist Air," Report, MonC-390.

ANL, 1966, Argonne National Laboratory, Chemical Engineering Division Semiannual Report, ANL-7329.

ANS, 1984, Report of the Special Committee on Source Terms, American Nuclear Society.

Bair, W.J., 1981, "Establishing Risk Estimates for Individual Organs;" Proceedings of the Seventeenth Annual Meeting of the National Council on Radiation Protection and Measurements; "Critical Issues in Setting Radiation Dose Limits," pp. 119-132; Washington, D.C.

Baker, L., and C. Just, 1962, "Studies of Metal-Water Reactions at High Temperatures III. Experimental and Theoretical Studies of the Zirconium-Water Reaction," Argonne National Laboratory, ANL-6548.

Bankoff, S., and O. Jones, 1977, Symposium on Thermal and Hydraulic Aspects of Nuclear Reactor Safety, eds., Atlanta, Georgia.

Battist, L., J. Buchanan, F. Congel, C. Nelson, M. Nelson, H. Peterson, and M. Rasenstein, 1979; "Population Dose and Health Impact of the Accident at the Three Mile Island Nuclear Station," Ad Hoc Dose Assessment Group Preliminary Report, May, 10.

Bergeron, K., K. Murata, P. Rexroth, J. Tills, and D.C. Williams, 1984, "Applications of the CONTAIN 1.0 Computer Code to the Analysis of Containment Loading under Severe Accident Conditions," in Transactions of the 12th Water Reactor Safety Research Information Meeting, October 22-26, Gaithersburg, Maryland.

Berman, M., et al., 1983, "Core Melt/Coolant Interactions: Modelling," Sandia National Laboratories, SAND 83-1852C.

Bittel, J.T., L.H. Sjodahl, and J.F. White, 1969, "Steam Oxidation Kinetics and Oxygen Diffusion in $\mathrm{UO}_{2}$ at High Temperatures," J. Am. Ceram. Soc. 52, 446.

Blejwas, T.L., 1984, "Containment Integrity Program," Sandia National Laboratories, presentation to APS Study Group, March.

Board, S.J., R.W. Hall, and G.E. Brown, 1974, "The Role of Spontaneous Nucleation in Thermal Explosions, Freon/water Experiments," Report RD/BIN 3007 Central Electricity Generative Board, U.K.

Bond, V.P., 1981, "The Conceptual Basis for Evaluating Risk from Low-Level Radiation Exposure;" Proceedings of the Seventeenth Annual Meeting of the National Council on Radiation Protection and Measurements; "Critical Issues in Setting Radiation Dose Limits," pp. 25-65; Washington, D.C., April 8-9.

Bunz, H., and W. Schock, 1984, "Comparison of Aerosol Behavior Measured During DEMONA Experiments to NAUA Code Predictions," in Specialists Meeting on Nuclear Aerosols in Reactor Safety, Karlsruhe, Federal Republic of Germany, September 4-6.

Bunz, H., M. Koyro, and W. Schock, 1982, “A Code for Calculating Aerosol Behavior in LWR Core Melt Accidents, Code Description and User's Manual," Presented at EPRI, Palo Alto, CA.

Burgess, D.S., J. Biordi, and J. Murphy, 1982, "Hazards of Spillage of LNG on Water," PMSRC Rep. No. 4177, U.S. Bureau of Mines.

Butland, A. J., 1983, "Peer Review of the BCL Report, Radionuclide Release Under Specific LWR Accident Conditions," Vols. IV, V, VI, Washington, D.C., p. 206, October 12. Butland, A.J., 1983, in Peer Review of the BCL Report, p. 205. Butland, A.T.D., I.H. Dunbar, P.F. Fuller, A.N. Hall, J.P. Haller, D.J. Hill, N.A. Johns, P.M. Keeping, J.N. Lillington, A.J. Lyons, K.A. Moore, J. Morgan, W.H.L. Porter, S. Ramsdale, G.J. Roberts, P.N. Smith, H. Starkie, B.D. Turland, D.A. Williams, and R.L.D. Young, 1984, Report on Phase I of the PWR severe accident containment study, U.K. Atomic Energy Authority Report A.E.E.W.-R1842, December.

Buxton, L.D., and W.B. Benedick, 1979, "Steam Explosion Efficiency Studies," Sandia National Laboratory, Nuclear Regulatory Commission SAND79-1399; NUREG CR/0947.

Buxton, L.D., W.B. Benedick, and M.L. Corradini, 1980, "Steam Explosion Efficiency Studies," Part II, Sandia National Laboratory, Nuclear Regulatory Commission, SAND 801324, NUREG/CR-1746.

Camp, A.L., et al., 1983, "Light Water Reactor Hydrogen Manual," Nuclear Regulatory Commission, NUREG/CR2726.

Camp, W.J., et al., 1984, Presentation to this APS Study Group, Sandia National Laboratory, March 22.

Cathcart, J.V., 1976, "Quarterly Progress Report on the Zirconium Metal-Water Oxidation Kinetics Program Sponsored by the NRC Division of Reactor Safety Research for OctoberDecember," Oak Ridge National Laboratory, ORNL/NUREG/TM-87.

Cederwall, R.T., D.L. Ermak, H.C. Goldwire, R.P. Koopman, J.W. McClure, T.G. McRae, D.L. Morgan, H.C. Rodean, and 
J.W. Shinn, 1981, Burro Series $40 \mathrm{~m}^{3}$ LNG spill experiments, University of California, UCRL-86704.

Clarke, R.H., 1974, "An Analysis of the 1957 Windscale Accident Using the Weerie Code," Annals of Nuclear Science and Engineering 1, 73 .

Cobble, J., 1984, "Solubility of Inorganic Compounds in HighPressure Steam." Chapter 8 in ASME Handbook of Water Technology for Thermal Power Systems, P. Cohen, Ed.

Conrad, R.A., D.E. Paglia, P.R. Larsen, et al., 1980, "Review of Medical Findings in a Marshallese Population Twenty-Six Years after Accidental Exposure to Radioactive Fallout," Upton, New York, Brookhaven National Laboratory, BNL 51261. Corradini, M.L., 1981, "Phenomenological modelling of the triggering phase of small scale steam explosion experiments," Nucl. Sci. Eng. 78, 154.

Crick, M.J., and G.S. Linsley, 1982, “An Assessment of the Radiological Impact of the Windscale Reactor Fire, October 1957," National Radiological Protection Board Report, NRPB-R135, United Kingdom.

Croff, A.G., 1983, "ORIGEN-2: A Versatile Computer Code for Calculating the Nuclide Compositions and Characteristics of Nuclear Materials," Nuclear Technology (in press).

Cronkite, E.P., 1981, "The Effects of Dose, Dose Rate and Depth Dose on Radiation Mortality;" Proceedings of a Symposium Sponsored by the National Council on Radiation Protection and Measurements; "The Control of Exposure of the Public to Ionizing Radiation in the Event of Accident or Attack," pp. 21-27, Reston, VA, April 27-29.

Cronkite, E.P., and V.P. Bond, 1958 "Acute Radiation Syndrome in Man," U.S. Armed Forces Medical Journal 9, $313-324$

Cubicotti, D., 1981, “A Model for Release of Fission Gases and Volatile Fission Products from Irradiated $\mathrm{UO}_{2}$ in Steam Enviroment," Nucl. Tech. 53, 5.

Cunnane, J., 1984, ANS Meeting, Snowbird, Utah.

Cybulskis, P., 1984, "Ice Condenser PWR Standard Problem," Battelle Memorial Institute, presentation at NRC/IDCOR Meeting, May 15-17.

Deem and Bierniarz, 1984, Presentation to this APS Study Group, Sandia National Laboratory, Albuquerque, New Mexico, March 23.

Denny, V.E., 1983, "The Coremelt Code," Science Appl. Inc., Palo Alto, CA, SAI-361-83-PA.

D’Ottavio, T., and S.L. Goren, 1983, "Aerosol Capture in Granular Beds in the Impaction Dominated Regime," Aerosol Sci. Tech. 2, 91-108.

Elrick, R. M., and R. A. Sallach, 1983, "Fission Product Chemistry in the Primary System," International Meeting on LightWater Reactor Severe Accident Evaluation, Cambridge, MA, August 28-September 1.

Enger, T., and D.E. Hartman, 1979, "LNG Spillage on Water," Tech Progress Report 1-72, Shell Pipeline Corp., "Rapid Phase transformation during LNG Spillage on Water," Paper 2, Sess. VI, LNG 3, Washington, D.C.

EPA, 1975, "Manual of Protective Actions Guides and Protective Actions for Nuclear Incidents," EPA-520/1-75-001.

EPRI, 1983, "Estimation of Fission Product and Core-Material Characteristics," Technical Reports 11.1, 11.4, and 11.5 for IDCOR.

Fauske, H.K., 1973, "On the Mechanism of Uranium Dioxide Sodium Interactions," Nuclear Science and Engineering 51, 95. Finlayson, F.C., and E.P. Radford, 1982, Basis for Selection of Emergency Planning Zones for the Shoreham Nuclear Power Plant-Finlayson and Associates.
Freeman-Kelly, R., and R. Jung, 1982, “A User's Guide for MERGE," Battelle Columbus Laboratories Report.

Friedlander, S.K., and C.S. Wang, 1966, J. Colloid Interface Sci. 22, 126.

Friedlander, S.K., 1977, Smọke, Dust and Haze-Fundamentals of Aerosol Behavior, John Wiley and Sons, New York.

Friedlander, S.K., 1982, Aerosol Sci. Tech. 1, 3.

Fuchs, N.A., 1964, The Mechanics of Aerosols, Pergamon Press, New York.

Fuchs, N.A., and A.G. Sutugin, 1971, High-Dispersed Aerosols in Topics in Current Aerosol Research, Pergamon Press, New York, Volume 2.

General Electric Company, 1962, "Additional Analysis of the SL-1 Emissions," Final Report of Progress, July-October, Report IDO-19313.

Gieseke, J.A., 1983, in "Peer Review of the BCL Report, Radionuclide Release Under Specific LWR Accident Conditions," Washington, D.C., p. 719.

Gieseke, J.A., P. Cybulskis, R.J. Denning, M.R. Kuhlman, H. Chan, and K.W. Lee, 1984, "Radionuclide Release Under Specific LWR Conditions-Volumes I to VI," U.S. Nuclear Regulatory Commission, Battelle Columbus Laboratories, BMI-2104 (sometimes called the BCL Report).

Ginsberg, T.; et al., 1984, "Consensus Summary on Direct Heating," a report by CLWG subcommittee on Direct Heating (unpublished).

Greene, G.A., 1983, "Status of Validation of the CORCON Computer Code," in Kress, T., ORNL/TM-8842.

Greimann, L.G., et al., 1982, "Reliability Analysis of Steel Containment Strength," Nuclear Regulatory Commission, Ames Laboratory, NUREG/CR-2442.

Haller, J.P., N.A. Johns, and A.T.D. Butland, 1984, "The effect of hydrogen on primary system retentions in PWR severe accidents," U.K. Atomic Energy Authority Report A.E.E.W.M2112.

Henry, R.E., J.D. Gabor, I.D. Winsch, E.A. Spleha, D.J. Quinn, E.G. Encleson, J.J. Herberger, and G.T. Goldfun, 1974, "Large Scale Vapor Explosions," Proceedings Fast Reactor Safety Meeting Argonne IU Conference 740 401, p. 2, p. 922.

Henry, R.E., H. Hohmann, and H. Koltwowski, 1979, "The Effect of Pressure on Nuclear $\mathrm{H}_{2} \mathrm{O}$ Explosions," CSNI Special Meet. fuel.

Hidy, G.M., and D.K. Lilly, 1965, J. Colloidal Sci. 20, 867.

Hidy, G.M., and J.R. Brock, 1970, The Dynamics of Aerocolloidal Systems, Pergamon Press, New York.

Hidy, G.M., 1984, Aerosols: An Industrial and Environmental Science, Academic Press, New York.

Higgins, H.M., 1955, "A Study of the Reactions of Metals and Water," AECD-3664 (Newjet-General, California)

Hilliard, R.K., 1983, "Results and code predictions for ABCOVE code validation-Test AB5," Hanford Engineering Laboratory Report, HEDL-TMI-83-16.

Hinds, W.C., 1982, Aerosol Technology-Properties, Behavior, and Measurement of Airborne Particles, John Wiley and Sons, New York.

Hofmayer, C.H., 1984a, "A Summary of German and French Programs on Containment Performance," Brookhaven National Laboratory, presentation at the NRC Containment Review Meeting.

Hofmayer, C.H., 1984b, "Overview of Activities of Containment Working Group," Brookhaven National Laboratory, Presentation to APS Study Group (March).

Hosemann, L.P., et al., 1983, "Radioactive Source Term for 
Light Water Reactors," Kernforschungszentrum Karlsruhe, Draft.

Hoseman, J.P., and D. Haschke, 1984, "The DEMONA Aerosol Removal Experiments," Kernforschungszentrum Karlsruhe, Karlsruhe, Germany, Draft Report.

IDCOR, 1983, "Key Phenomenological Models for Assessing Explosive Steam Generation Rates," Technical Report 14, 1 A.

IDCOR, 1984, "Nuclear Power Plant Response to Severe Accients," Industry Degraded Core Rulemaking (IDCOR) Program, Final Technical Summary.

International Commission on Radiological Protection, 1977, Recommendations of the International Commission on Radiological Protection, Annals of the ICRP Vol. 1, No. 3, ICRP Publication 26, Pergamon Press, New York.

International Commission on Radiological Protection, 1979, Problems Involved in Developing an Index of Harm. Annals of the ICRP Vol. 1, No. 4, ICRP Publication 27, Pergamon Press, New York.

Jaycor, 1983, "Tech Report 16.1A, Review of the MAAP PWR and BWR Codes," San Diego, CA.

Johns, N.A., A.T.D. Butland, and D.A. Williams, 1984, "The heating effect of released fission products on primary system retentions in PWR severe accidents," U.K. Atomic Energy Authority Report A.E.E.W.-M2113.

Jordan, H., J.A. Gieseke, and P. Baybutt, 1979, “TRAP-MELT User's Manual," Nuclear Regulatory Commission, NUREG/CR-0632, BMI-2017, R3,4.

Kant, H. C., Letter to Commissioner Joseph Hendrie, September 12, 1980.

Kanzleiter, T.F., 1984, “Thermal-Hydraulic Behavior of a Containment Atmosphere Measured in the DEMONA Aerosol Experiments," in Specialists Meeting on Nuclear Aerosols in Reactor Safety, Karlsruhe, Federal Republic of Germany, September 4-6.

Karahalios, P., and R. Gardner, 1984, Private Communication, Stone and Webster Engineering Corporation, Boston, MA.

Keenan, J.H., F.G. Keyes, P.G. Hill, and J.G. Moore, 1978, Steam Tables, John Wiley \& Sons, Inc., New York.

Kelly, J. L., A. B. Reynolds, and M. E. McGown, 1984, “Temperature Dependence of Fission Product Release Rates," Nuclear Science and Engineering 88, 184.

Kemeny, J.G., et al., 1979, "Report of the President's Commission on the Accident at Three Mile Island," October 30.

Kenton, M. A., 1984, "Sequoyah Nuclear Plant, IDCOR Task 23.1, Integrated Accident Analysis," presentation at NRC/IDCOR Meeting.

Kolaczkowski, A.M., 1983, "Interim Report on Accident Sequence Likelihood Reassessment (Accident Sequence Evaluation Program, ASEP)," Sandia National Laboratories.

Koopman, R.P., R.T. Cederwall, D.L. Ermale, H.C. Goldwire, J.W. Mclure, T.G. Mc Rae, D.L. Morgan, H.C. Rodeau, and J.H. Shim, 1981, "Description and Analysis of BURRO Series $40 \mathrm{~m}^{3}$ LNG Spill Experiments," UCRL-53186.

Kress, T.S., 1984, "Review of the Status of Validation of the computer codes used in the NRC accident source term reassessment study BMI-2104," Oak Ridge National Laboratory, ORNL/TM-8842.

Lemma, A.W., 1980, "Explosions of Molten Aluminum and Water in Light Metals," E. Mc Minn, Ed., p. 817, 190th AIME Annual Meeting.

Lemmon, A.W., 1957, "Studies Relating to the Reaction Between Zirconium and Water at High Temperatures," BMI2254, Battelle Memorial Institute, Columbus, $\mathrm{OH}$.

Lewis, H.W., et al., 1975, Report to the APS by the Study
Group on Light-Water Reactor Safety, Reviews of Modern Physics 47 (Supplement No.1).

Lewis, H.W., R.J. Budnitz, H.J.C. Kouts, W.B. Loewenstein, W.D. Rowe, F. von Hippel, and F. Zachariasen, 1978, Risk Assessment Review Group, "Risk Assessment Review Group Report to the U.S. Nuclear Regulatory Commission," NUREG/CR-0400.

Linacre, J. K., and W. R. Marsh, 1981, "The Radiation Chemistry of Heterogeneous and Homogeneous Nitrogen and Water System," Harwell, AERE-R10027 (report originally written but not published in 1958).

Lipinski, R.J., et al., 1984, "Uncertainty in Radionuclide Release Under Specific LWR Accident Conditions," Volume II, Analyses, Sandia National Laboratories, SAND 84-0410/2 (Draft).

Liu, B.Y.H., and J.K. Agarwal, 1974, "Experimental Observation of Aerosol Deposition in Turbulent Flow," Aerosol Sci. 5, $145-155$.

Loewe, W.E., and E. Mendelsohn, 1981, "Revised Dose Estimates at Hiroshima," Health Phys. 41, 663.

Long, G., 1957, "Explosions of Molten Aluminum in Water-Cause and Prevention," Met. Prog. 71(5) 107.

Lorenz, R. A., 1983, "Fission Product Release From Irradiated LWR Fuel," Presentation To The APS Study Group. Oak Ridge National Laboratory, December 2.

Lorenz, R.A., 1984, "Review of the Status of Validation of The Computer Codes Used in the NRC Accident Source Term Reassessment Study," Chapter VII of ORNL/TM-8842.

Lorenz, R.A., 1983, "Status and Validation of the CORSOR Computer Code," BMI-2104, ORNL/TM-8842.

Lorenz, R.A., E.C. Beahm, and R.P. Wichner, "Review of Tellurium Release Rates from LWR Fuel Elements Under Accident Conditions," Proc. International Meeting on LWR in Severe Accident Evaluations, Vol. I, August 28-September 1, 1983, Cambridge, MA, TS-4.4.

Loutit, J.F., W.G. Marlay, and R.S. Russel, 1960, Appendix H to "The hazard to man of nuclear and allied radiations," 2nd report to the Medical Research Council, London, HMSO Cmnd 1225.

Loyalka, S.K., 1983, "Mechanics of Aerosols in Nuclear Reactor Safety: A Review," Prog. in Nuclear Energy 12, 1-56.

Marble, W.J., et al., 1983, Preliminary Report on the Fission Product Scrubbing Program, General Electric Report NEDO30017.

McAdams, W.C., 1954, Heat Transmission, McGraw-Hill, New York, 3rd ed., pp. 172-180.

McCardell, McDonald, Nolezmy, Osetek and Kuan, 1983, "Severe Fuel Damage Test 1-1 Quick Look Report," Fin No. A6305.

Mitchell, D., M. Corradini, and W. Tarbell, 1981, "Intermediate Scale Steam Explosion Phenomena: Experiments and Analysis," Sandia National Laboratories, SAND81-0124, NUREG/CR-2145.

Morewitz, H. A., 1982, "Leakage of Aerosols from Containment Buildings," Health Physics 42, 195.

Muhlestein, et al., 1984, Hanford Engineering Laboratory Rept. HEPL-SA-3055.

Muir, J.F., R.K. Cole, and M.L. Corradini, 1984, "An Improved Model for Molten-Core/Concrete Interactions," U.S. Nuclear Regulatory Commission, NUREG/CR-2142, SAND 80-2415, R3.

Murfin, W.B., 1977, “A Preliminary Model for Core Concrete Interactions," Sandia Nat. Lab. Report SAND 77-0370.

NAS, 1972, "The Effects on Populations of Exposure to Low 
Levels of Ionizing Radiation," Report of the Advisory Committee on the Biological Effects of Ionizing Radiations (BEIR-I), National Academy of Sciences/National Research Council.

NAS, 1980, "The Effects on Populations of Exposure to Low Levels of Ionizing Radiation," Committee on the Biological Effects of Ionizing Radiations (BEIR III), National Academy of Sciences/National Research Council.

NCRP, 1959, "Maximum Permissible Body Burdens and Maximum Permissible Concentrations of Radionuclides in Air and in Water for Occupational Exposure" (National Bureau of Standards Handbook 69), National Council on Radiation Protection and Measurements, Washington, NCRP 22.

Nelson, L., and P. Duda, 1981, "Steam Explosion Experiments with Single Drops of Iron Oxide Melted with a $\mathrm{CO}_{2}$ Laser," Sandia National Laboratories, SAND/81-1346, NUREG/CR-2295.

Nelson, L.S., and W.B. Benedick, 1983, "Interactions Between Aerosols and the Combustion of Hydrogen-Air Mixtures," Status Report for the Sandia Hydrogen Programs, June-July.

NRC, 1975, Reactor Safety Study (RSS), Study Director N.C. Rasmussen, WASH-1400, Nuclear Regulatory Commission.

NRC, 1976a, Final Environmental Statement, Nuclear Regulatory Commission, NUREG-0112, Final Supplement.

NRC, 1976b, Safety Evaluation Report, Nuclear Regulatory Commission, NUREG-0107, Supplements 1 and 2.

NRC, 1978a, "Planning Basis for the Development of State and Local Government Radiological Emergency Response Plans in Support of Light Water Nuclear Power Plants," Nuclear Regulatory Commission and U.S. Environmental Protection Agency, NUREG-0396, EPA 520/1-78-016.

NRC, 1978b, "Plan for Research to Improve the Safety of Light-Water Nuclear Power Plants," U.S. Nuclear Regulatory Commission, NUREG-0438.

NRC, 1981a, "Technical Bases for Estimating Fission Product Behavior During LWR Accidents," Nuclear Regulatory Commission, NUREG 0772.

NRC, 1981b, Nuclear Regulatory Commission Report, NUREG/CR2299.

NRC, 1983a, "Nuclear Power Plant Severe Accident Program," Nuclear Regulatory Commission, NUREG 0900.

NRC, 1983b, "PRA Procedures Guide-A Guide to the Performance of Probabilistic Risk Assessments for Nuclear Power Plants," Nuclear Regulatory Commission, NUREG/CR-2300.

NRC, 1984a, Containment Performance Working Group, Containment Leak Rate Estimates, Fourth Draft, Nuclear Regulatory Commission.

NRC, 1984b, "Review and Evaluation of the Nuclear Regulatory Commission Safety Research Programs for Fiscal Year 1985." U. S. Nuclear Regulatory Commission, NUREG1039.

NRC, 1984c, Long-Range Research Plan, FY85-FY89. Nuclear Regulatory Commission, NUREG-1080.

OECD, 1979, "Nuclear Aerosols in Reactor Safety," A State of the Art Report by a Group of Experts of the Nuclear Energy Agency (NEA) Committee on the Safety of Nuclear Installations, NEA, Organization for Economic Cooperation and Development.

Ohlberg, 1984, EPRI Journal, p. 61.

Okrent, David, 1981, Nuclear Reactor Safety: On the History of the Regulatory Process, University of Wisconsin Press.

Osetek, D. J., A. W. Cronenberg, R. R. Hobbins, and K. Vinjamuri, 1984, "Fission Product Behavior during the First Two PBF Severe Fuel Damage Tests," in ANS Topical Meeting on
Fission Product Behavior and Source Term Research, July 15-19.

Owczarski, P.C., 1984, Presentation to this APS Committee, Cambridge, MA, January 17.

Pasadeg, W.F., R.M. Blond, and M.W. Jankowski, 1981, "R'egulatory Impact of Nuclear Reactor Accident Source Term Assumptions," U.S. Nuclear Regulatory Commission, NUREG-0771.

Pasquill, F., 1962, "Atmospheric Diffusion," London, Van Nostrand.

Peehs, N., A. Skokan, and M. Rechmann, 1979, "The Behavior of Concrete in Contact with Molten Corium in the Case of a Hypothetical Core Meltdown Accident," Nuclear Technology 46, 2.

Powers, D.A., et al., 1978, "Exploratory Studies of Molten Core Material/Concrete Interactions," Sandia Nat. Lab.

Powers, D.A., 1977, "Sustained Molten Steel/Concrete Interactions Tests," Proc. Post-Accident Heat Removal Information Exchange, November 4, Argonne National Laboratory, ANL78-10, p. 433.

Powers, D.A., 1978, "Sustained Molten Steel/Concrete Interactions Tests-A Preliminary Report on the Feasibility of Experimental Techniques," Sandia National Laboratories, SAND77-1423.

Powers, D.A., 1985, private communication.

Powers, D.A., and J.E. Brockman, 1983, "Status of Vanesa Validation," in Kress, 1984.

Pruppacher, H.R., and J.D. Klett, 1978, Microphysics of Clouds and Precipitation, D. Reidel, Boston.

Reid, Robert C., 1983, "Rapid Phase Transitions from Liquid to Vapor," Adv. Chem. Eng. 12, 105.

Reimann, M., and W.B. Murfin, 1981, "The wechSL Code: A Computer Code for the Interaction of a Core Melt With Concrete," Kernforschungzentrum Karlsruhe Report, KFK 2890.

Ritchie, L.T., J. Johnson, and R. Blond, 1983, Calculation of Reactor Accident Consequences-CRAC2, Version 2, NUREG/CR-2326.

Ritzman, R.L., 1984, in "Peer Review of the BCL Report, Radionuclide Release Under Specific LWR Accident Conditions," Vols. IV, V, VI, Washington, D.C., p. 309, October 12.

Ritzman, R.L., 1982, "Fission Product Release During Core Heatings in Severe Reactor Accidents," Electric Power Research Institute (to be published), excerpted from Reference 5, pp. 4-32.

Rivard, J.B., V.L. Behr, R.G. Easterling, J.M. Griesmeyer, F.E. Haskin, S.W. Harch, A.M. Kolaczkowski, R.J. Lipinski, M.P. Sherman, A.R. Taig, and A.J. Wickett, "Identification of severe accident uncertainties," U.S. Nuclear Regulatory Commission NUREG/CR-3440; SAND83-1689.

Rogers, T., and C.C. Gamertsfelder, 1971, Proceedings for Environmental Effects of Nuclear Power Stations, Vienna: International Atomic Energy Agency.

Rossi, H.H., 1980, "Critique of BEIR III" (Separate Statement), Appendix to NAS (1980), p. 316.

Sallach, R.A., G.J. Greehdt, and A. R. Taig, 1983, "Chemical Interactions of Tellurium Vapors with Reactor Materials," Nuclear Regulatory Commission, NUREG/CR-2921.

Saffnian, P., and J. Turner, 1956, J. Fluid Mech. 1, 16.

Schultz, D.M., et al., 1984, Test Plan for Concrete Containment Structural Element Tests, Phase 2, Construction Technology Laboratories.

Schultz, R.R., C.D. Fletcher, and T.R. Charlton, 1984, "Station Blackout in U.S. Light-Water Nuclear Reactors," Nucl. Safety $25,501$. 
Seghal, R., 1984, Presentation to this APS Study Group, Sandia National Laboratory, Albuquerque, New Mexico, March 23.

Seinfield, J.H., 1980, Dynamics of Aerosols in Dynamics and Modeling of Reactive Systems, Academic Press, New York.

Shapiro, Z.M., and T.R. Moffett, 1957, Hydrogen Flammability Data and Application to PWR Loss-of-Coolant Accident, WAPD-SC-545, Bettis Plant.

Slade, D.H., 1968, "Meteorology and Atomic Energy," U.S. Atomic Energy Commission.

Snyder, A.M., 1982, A Current Perspective on the Risk Significance of Steam Explosions, Vortrag Jehrestagung Kerntechnik, Mannheim.

Starr, C., 1980, Letter to NRC Chairman J. Hendrie, September 2 (with enclosures).

Stratton, W.R., 1984, "The History of Reactor Accident Experience and Postulated Accident Assumptions: The Impact of TMI-2," unpublished paper.

Stratton, W. R., A. P. Malinauskaus, and D. O. Campbell, 1980, letter to NRC Chairman Ahearne, August 14.

Sullivan, J.H., 1959, J. Chem. Phys. 30, 1292.

Sullivan, J.H., 1962, J. Chem. Phys. 36, 1925.

Sutton, O.G., 1932, "A Theory of Eddy Diffusion in the Atmosphere," Proc. R. Soc. A. 135, 143.

Taig, A.R., 1981, Advanced Reactor Safety Research Safety Research Quarterly Report Oct-Dec, Sandia National Laboratories, Vol. 20, SAND81-1529, NUREG/CR-2238, Albuquerque, NM.

Thompson, T.J., and J.G. Beckerley, 1964, eds., The Technology of Nuclear Reactor Safety (M.I.T Press, Cambridge, Mass.), Vol. 1, p. 653.

Turner, J., 1975, “Handbook of Atmospheric Dispersion Esti- mates," Report AP26 reprinted and updated yearly, U.S. Environmental Protection Agency.

UEC, 1983, "Containment Capability of Indian Point Power Plant Units Nos. 2 and 3 for Internal Pressure Load (revised)," United Engineers \& Constructors.

Urbanic, V.F., and T.R. Heidrick, 1978, "High-Temperature Oxidation of Zircalloy-2 and Zircalloy-4 in Steam," J. Nucl. Mater. 75, 251.

Vinjamuri, K., D.W. Akers, and R.R. Hobbins, 1984, "TMI-2 Leadscrew Radiation Deposition and Characterization," paper presented at the ANS Topical Meeting on Fission Product Behavior and Source Term Research, Snowbird, Utah, June 1.

Von Reisemann, W.A., and C.V. Subramanian, 1984, "Containment Integrity Programs," Sandia National Laboratories presentation to the ACRS.

Waldmann, L., and K.H. Schmitt, 1967, in Aerosol Science, edited by C.N. Davies (Academic, New York).

Weinstein, M.B., 1980, "Primary Containment Leakage Integrity: Availability and Review of Failure Experience," Nuclear Safety 21 , No. 5 .

Wilson, R., S.D. Colome, J.D. Spengler, and D.G. Wilson, 1980, Health Effects of Fossil Fuel Burning, Ballinger Publishing Company, Cambridge, MA.

Winegartner, et al., 1983, Nuclear Regulatory Commission Report, NUREG/CR-3248.

Wooten, R.O., and P. Cybulskis, 1983, "MARCH-2 (Meltdown Accident Response Characteristics) Code Description and User's Manual," Battelle Columbus Laboratory, Draft.

Wright, R.W., and G.H. Humberstone, 1966, Dispersal and Pressure Generation by Water Impact on Molten Aluminum, Trans. Am. Nuclear Society 9, 305. 


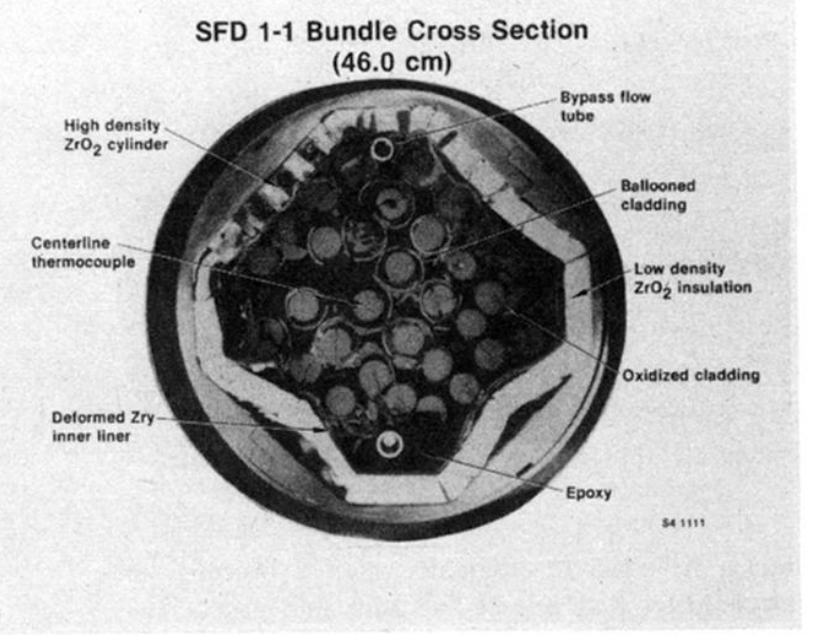

FIG. III.A.10. Photograph of a cross section at $46 \mathrm{~cm}$ of damaged fuel bundle in PBF Test-SFD 1-1. (Courtesy of EG\&G.) 


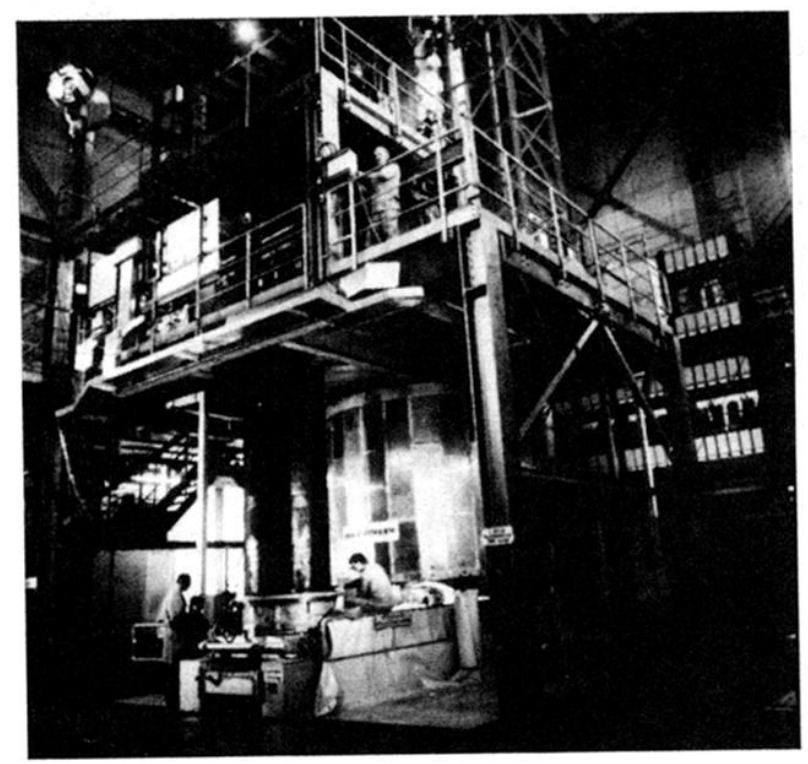

FIG. IV.A.9. BETA facility: Preparation of crucible. (Courtesy of KfK.) 